Programação estocástica e otimização robusta no
planejamento da produção de empresas moveleiras

Douglas José Alem Junior 

Data de Depósito:

Assinatura:

\title{
Programação estocástica e otimização robusta no planejamento da produção de empresas moveleiras
}

\author{
Douglas José Alem Junior
}

Orientador: Prof. Dr. Reinaldo Morabito

Tese apresentada ao Instituto de Ciências Matemáticas e de Computação - ICMC-USP, como parte dos requisitos para obtenção do título de Doutor em Ciências - Ciências de Computação e Matemática Computacional. EXEMPLAR DE DEFESA. 

À Minha Amada Mãe... 
"EU SOU a chama violeta, que atua em mim e reluz EU SOU a chama violeta, só me submeto a luz EU SOU a chama violeta, cósmico poder, farol EU SOU a chama violeta, radiante como o sol EU SOU a luz de Deus a toda hora brilhando EU SOU o poder de Deus que a todos vai libertando"

Autor Desconhecido. 


\section{Agradecimentos}

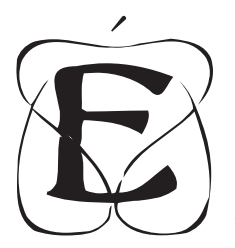

preciso estar muito inspirado para fazer um texto de agradecimento em qualquer ocasião, mas em se tratando de uma tese de doutorado, ainda temos a responsabilidade de não omitir aqueles que sempre estiveram conosco nessa jornada, e que jornada! E, também, a TODOS que propiciaram essa estadia maravilhosa aqui, a luz do Universo e DEUS.

Antes de mais nada, gostaria de agradecer ao apoio financeiro da Fundação de Amparo à Pesquisa do Estado de São Paulo - FAPESP - entre março de 2007 até março de 2009, que foi o período de vigência da minha bolsa de doutorado. Iniciativas como a da FAPESP, CAPES, CNPq e outros órgãos de fomento são muito importantes porque permitem que a pesquisa científica seja uma realidade no Brasil. E, quem sabe um dia, nosso País esteja entre aqueles que mais aplicam as suas pesquisas em prol dos nossos problemas, seja na preservação das nossas riquezas naturais e na construção de uma sociedade ecológica e sustentável, quanto na minimização das tragédias e desastres que nos assolam, ano após ano. Ainda, agradeço o apoio institucional da USP e, mais particularmente, do ICMC, da infraestrutura e dos funcionários que sempre estiveram presentes.

Para muitos, o agradecimento aos pais é somente retórico, mas eu gostaria muito que meus pais soubessem o quanto eu sou grato por tê-los, o quanto eu os amo e eu sei que, sem a força e estímulo que eles me proporcionaram, talvez a minha vida e as minhas escolhas tivessem sido muito diferentes. Além de mãe, eu ainda tive uma mestra, com quem dialoguei, descordei, concordei, chorei, sorri, ri, gargalhei, cresci, amadureci, mudei, enfim... Uma mãe, professora e mestra, que com todo o seu amor puro e devotado, auxiliou-me a trilhar o caminho que eu havia escolhido para a minha vida. Certamente, não há palavras que descrevam meu amor e gratidão, mas, humildemente, eu peço que aceite essas frases emocionadas como forma de agradecimento. Sabemos que as coisas não findam por aqui, não é mesmo? Mas a saudade desse período alegre vai permanecer pela eternidade...

Para ser bem justo, eu precisaria agradecer a todos os meus mestres, desde a infância, mas isso poderia tomar muito tempo e espaço; por essa razão, prefiro dizer um "muito obrigado" a aqueles que realmente fizeram diferença na minha vida escolar.

A graduação foi, sem dúvida, o período de grandes decisões. Alguns mestres muito importantes surgiram no meu caminho e ajudaram-me a construir o início da minha vida acadêmica. Primeiro, o professor Paulo Caetano do Departamento de Matemática 
da UFSCar de São Carlos - foi o primeiro a depositar esperanças no meu sonho. Em seguida, a professora Selma, também do Departamento de Matemática da UFSCar de São Carlos, que com disciplina e muito trabalho, ajudou-me a entender qual era o meu sonho. E o professor Benê, do Departamento de Estatística da UFSCar de São Carlos, ajudou-me a acreditar que o meu sonho, além de possível, era bonito e tinha tudo para dar certo! Esses mestres são muito especiais na minha vida e eu espero tê-los sempre com muito carinho e admiração.

Durante o mestrado, eu tive a certeza de que eu estava no caminho certo, embora algumas intempéries tenham surgido e colocado em questão muitas certezas e crenças que eu mantinha. Mas, muitas pessoas ajudaram-me a superar essas dificuldades, entre as quais, o professor Marcos e as professoras Franklina e Maristela, todos do ICMC-USP. Agradeço a esses três mestres pelos ensinamentos, pela dedicação e, principalmente, pela paciência... Afinal, "Educar é semear com sabedoria e colher com paciência" (Augusto Cury).

A transição do mestrado para o doutorado foi, talvez, o período mais crítico das minhas escolhas e eu as coloquei em xeque muitas vezes. Mas, como as coisas sempre acontecem da melhor maneira possível, tive a felicidade do professor Reinaldo Morabito orientar essa Tese e meus estudos durante esses quatro anos. Eu o respeito muito como orientador e como pessoa, admiro a maneira como lida com o trabalho e com os seus alunos, e espero ter aprendido coisas valiosas para a minha vida. Agradeço pela paciência, dedicação, amizade e estímulo durante esse período e eu tenho certeza de que ainda trabalharemos bastante juntos.

Durante o doutorado eu tive outras provações e pessoas que me acolheram com muito carinho. Dessas provações, as mais marcantes foram as minhas "quase viagens". Quase fui a Cingapura estudar com o professor Melvyn, quase fui a Boston estudar com a professora Pachamanova, quase fui a Santiago passar uma temporada com o professor Ordonèz. Todas as "quase viagens" deixaram-me um pouco frustrado, mas também fiquei mais confiante e forte. E, permeando as minhas viagens, tive que fazer uma difícil escolha: assumir ou não o cargo de Professor Assistente na UFSCar de Sorocaba. Muitas conversas depois com várias pessoas queridas deixaram-me um pouco mais confiante para assumir este cargo. Por vezes arrependido da escolha, hoje tenho certeza de que fiz uma escolha de vida e não momentânea. Agradeço aos que me receberiam nos seus países e agradeço também por não ter cedido! Gostaria de agradecer ao campus de Sorocaba pelo afastamento e aos professores da Engenharia de Produção pelo apoio durante o período em que estive ausente, principalmente às professoras Eli Toso e Juliana Veiga. Ainda, agradeço a todas as turmas de probabilidade, programação da produção e tópicos em pesquisa operacional que, inevitavelmente, dividiram o professor com o seu doutorado.

Gostaria de agradecer a todos os meus amigos queridos do LOT (laboratório de otimização do ICMC-USP). Eu me lembro, como se fosse hoje, da primeira vez que conheci o pessoal do LOT, de todos as nossas festas no 1007, das fofocas entre 1007 e 1011, dos encontros e desencontros, dos dias felizes e infelizes, dos projetos aprovados e reprovados, dos congressos, dos cafés deliciosos, enfim, eu me lembro de tudo. Por favor, os que não forem mencionados não se sintam menos amados, mas eu quero muito deixar registrado o nome de algumas pessoas dessa tempo mágico: Adriana Cherri (sempre disposta a fuzzyficar e muito amiga), Aline (a pior de todas!), Carlitcha (sempre disposta a escutar e 
trabalhar), Claudinha (muito querida, lembra dos nossos estudos noturnos?), Kelly Poldi (risonha e de cabelos longos), Lana (poxa, sempre disposta a conversar, aconselhar e estudar), Márcio (sempre bem humorado e disposto), Mariá (a mais produtiva!) e Tamara (principalmente, pela companhia prazerosa). Deise, agradeço pelos conselhos e por me ouvir quando a apreensão apertou o meu peito. Aos meus amigos muito especiais, Pedro e Victor: agradeço todos os dias pela amizade irrestrita, pelos momentos descontraídos, pelos estudos, pelas conversas e pelo carinho. Pedro: meu amigo muito querido... Sempre tão prático nas emoções, você foi responsável por me trazer de volta à realidade muitas vezes, principalmente, nas minhas inúmeras crises e quando o exagero emocional tomava conta de mim. Aprendi muito com a nossa convivência, até amadureci com os nossos desentendimentos. Cultivarei com muito carinho a nossa amizade para sempre. Victor: sempre me lembro com muito carinho dos nossos momentos juntos, inclusive dos seus dias de mau-humor. Mas, certamente, os dias de bom humor e a sua companhia zelosa e leal compensaram os dias cinzentos. As nossas conversas tolas e as nossas crises existenciais na Casa do Café, ao sabor de uma lasanha e brindando mais um dia de trabalho, são lembranças eternas de uma época maravilhosa em minha vida, assim como é a nossa amizade.

Finalmente e não menos importante, gostaria de agradecer minha irmã e minha tia, meus amigos de coração, meus amigos de infância, meus amigos velhos, meus amigos novos, meus amigos de longe e de perto, os que já não são e os que serão. Ainda, quero agradecer ao Diego por estar sempre ao meu lado, nos dias de bom humor e nos dias azedos, nos dias chuvosos e ensolarados e por sempre acreditar em mim. E que continue assim... 


\section{Resumo}

O planejamento da produção em indústrias moveleiras de pequeno porte é comumente constituído por decisões referentes ao volume de produção e à política de estoque, com o objetivo de minimizar o desperdício de material, os atrasos e as horas-extras utilizadas ao longo do horizonte de planejamento. Administrar tais decisões de uma maneira tratável e eficiente é, em geral, um desafio, especialmente considerando a natureza incerta dos dados. Nessa tese, são desenvolvidos modelos de otimização para apoiar tais decisões no contexto do problema combinado de dimensionamento de lotes e corte de estoque sob incertezas que surge em indústrias moveleiras. Para lidar com as incertezas dos dados, são investigadas duas metodologias: programação estocástica e otimização robusta. Dessa maneira, são propostos modelos de programação estocástica de dois estágios com recurso, assim como modelos estocásticos robustos que incorporam aversão ao risco. A motivação em também desenvolver modelos baseados em otimização robusta é considerar casos práticos em que não há uma descrição probabilística explícita dos dados de entrada, assim como evitar trabalhar com numerosos cenários, o que pode tornar o modelo estocástico computacionalmente intratável. Os experimentos numéricos baseados em exemplares reais de uma empresa moveleira de pequeno porte mostram que as soluções obtidas pelos modelos de programação estocástica fornecem planos de produção robustos e que o (a) decisor (a) pode designar suas preferências em relação ao risco aos modelos, assim como controlar o tradeoff entre o custo total esperado e a robustez da solução. Em relação aos resultados dos modelos de otimização robusta, são obtidos alguns insights entre os chamados budgets de incerteza, as taxas de atendimento da demanda e os valores ótimos. Além disso, evidências numéricas indicam que budgets de incerteza menos conservadores resultam em níveis de serviço razoáveis com baixos custos globais, enquanto a abordagem de pior caso gera, relativamente, boas taxas de atendimento da demanda, mas com custos globais elevados.

Palavras-chave: Problema combinado de dimensionamento de lotes e corte de estoque, programação estocástica, otimização robusta, indústria moveleira. 


\section{Abstract}

Production planning procedures in small-size furniture companies commonly consist of decisions with respect to production level and inventory policy, while attempting to minimize trim-loss, backlogging and overtime usage throughout the planning horizon. Managing these decisions in a tractable and efficient way is often a challenge, especially when the uncertainty of data is taken into account. In this thesis, we develop optimization models to support these decisions in the context of the combined lot-sizing and cutting-stock problem that arises in furniture companies. To deal with data uncertainty, we investigate two methodologies: stochastic programming and robust optimization. In the former case, we propose two-stage stochastic programming models with recourse, as well as robust stochastic models to incorporate risk-aversion. In the latter case, our motivation to investigate robust optimization models is the lack of an explicit probabilistic description of the input data. Furthermore, we want to avoid dealing with a large number of scenarios, which typically lead to computationally intractable stochastic programming models. Numerical experiments based on real data from a small-size furniture plant show that the solutions of the stochastic programming models provide robust production plans so that the decision-maker can assign his or her risk preferences to the model and control the tradeoff between the expected total cost and solution robustness. Regarding the results from the robust optimization models, we provide some insights into the relationship among budgets of uncertainty, fill rates and optimal values. Moreover, numerical evidence indicate that less conservative budgets of uncertainty result in reasonable service levels with cheaper global costs, while worst case deterministic approaches lead to relatively good fill rates, but with prohibitive global costs.

Keywords: Combined lot-sizing and cutting-stock problem, stochastic programming, robust optimization, furniture industry. 


\section{Índice}

Lista de Figuras $\quad$ xiii

Lista de Tabelas $\quad$ xvii

1 Introdução 1

1.1 Motivação . . . . . . . . . . . . . . . . . . . 5

1.2 Objetivos . . . . . . . . . . . . . . . . . . . . 7

1.3 Metodologia . . . . . . . . . . . . . . . . . 8

1.4 Organização . . . . . . . . . . . . . . . . . . 8

2 Planejamento da Produção em Empresas Moveleiras 11

2.1 Um Modelo Geral de Dimensionamento de Lotes e Corte de Estoque . . . . 12

2.2 O Pólo Moveleiro e a Empresa Visitada . . . . . . . . . . . . . . . . . . . 16

2.2.1 Processo Produtivo na Indústria de Móveis . . . . . . . . . . . . . . 16

2.3 Modelo Matemático . . . . . . . . . . . . . . . . . . . . . . . . . . . . . . . 19

2.4 Heurísticas Relax-and-Fix . . . . . . . . . . . . . . . . 22

2.5 Resultados Computacionais . . . . . . . . . . . . . . . 25

2.5.1 Dados de Entrada . . . . . . . . . . . . . . . 26

2.5.2 Exemplares Práticos . . . . . . . . . . . . . . . 27

2.5.3 Resultados com Exemplares Gerados Aleatoriamente . . . . . . . . 29

2.6 Considerações Finais . . . . . . . . . . . . . . . . . . . . . . . . . 34

2.7 Pesquisas Futuras . . . . . . . . . . . . . . . . . . . . 36

2.7.1 Métodos de Solução para o Problema Combinado . . . . . . . . . . 36

2.7.2 Heurística de Decomposição . . . . . . . . . . . . . . . . . . 37

2.7.3 Heurísticas de Arredondamento . . . . . . . . . . . . . . . . . . . 38

2.7.4 Metaheurísticas para o Problema Combinado . . . . . . . . . . . . . 39

3 Modelos de Programação Estocástica para o Problema Combinado 41

3.1 Preliminares em Programação Estocástica . . . . . . . . . . . . . . . . . . 42

3.1.1 Programação Estocástica de Dois Estágios com Recurso . . . . . . . . 42

3.1 .2 Introdução à Programação Estocástica Robusta . . . . . . . . . . . . . 44 
3.1.3 Modelos com Recurso Restrito . . . . . . . . . . . . . . . . . . . 47

3.1.4 O Valor da Informação Perfeita e da Solução Estocástica . . . . . . 48

3.2 Planejamento da Produção via Programação Estocástica . . . . . . . . . . 50

3.2 .1 Formulação Matemática . . . . . . . . . . . . . . . . . . . . . 52

3.2 .2 Formulação com Restrições de Não-Antecipação . . . . . . . . . . . 56

3.2.3 Determinação das Medidas EVPI e VSS . . . . . . . . . . . . . 57

3.2.4 Modelos Estocásticos e Aversão ao Risco . . . . . . . . . . . . . . . 59

3.3 Experimentos Computacionais . . . . . . . . . . . . . . . . . 62

3.3 .1 Teste A . . . . . . . . . . . . . . . . 63

3.3 .2 Teste B . . . . . . . . . . . . . . . . . . 79

3.4 Sumário e Considerações Finais . . . . . . . . . . . . . . . . . . . . . 83

3.5 Pesquisas Futuras . . . . . . . . . . . . . . . . . . . . . . . . 84

3.5.1 Modelos de Programação Estocástica com Probabilidades Incertas . 84

3.5.2 Decomposição de Benders para o Problema Estocástico . . . . . . . 85

4 Modelos de Otimização Robusta para o Problema Combinado 105

4.1 Preliminares em Otimização Robusta . . . . . . . . . . . . . . . . 106

4.2 Modelos de Otimização Robusta . . . . . . . . . . . . . . . . . . . . . 110

4.2 .1 Incerteza nos Custos . . . . . . . . . . . . . . . . . . . . . 110

4.2.2 Incerteza nas Demandas . . . . . . . . . . . . . . . . . . . . . . 112

4.2.3 Incerteza nos Custos e Demandas . . . . . . . . . . . . . . . . . . . 115

4.3 Resultados Computacionais . . . . . . . . . . . . . . . . . . 117

4.3 .1 Incerteza nos Custos . . . . . . . . . . . . . . . . . . . . 118

4.3 .2 Incerteza nas Demandas . . . . . . . . . . . . . . . . . . . . 125

4.3.3 Incerteza nos custos e demandas . . . . . . . . . . . . . . . . . . 136

4.4 Modelos de Otimização Robusta versus Modelos Estocásticos Robustos . 137

4.5 Considerações Finais . . . . . . . . . . . . . . . . . . . . . . . . . . . 140

4.6 Pesquisas Futuras . . . . . . . . . . . . . . . . . . . . . . . 145

4.6.1 Formulações Alternativas para o Modelo Nominal . . . . . . . . . . 145

4.6 .2 Restrições Agregadas . . . . . . . . . . . . . . . . . . . . . . . . . 146

4.6.3 Adversarial Approach . . . . . . . . . . . . . . . . . . . . . . 147

4.6.4 Controle das Variáveis de Decisão . . . . . . . . . . . . . . . . . . . 147

4.6.5 Metodologia AARC . . . . . . . . . . . . . . . . 148

5 Sumário e Contribuições $\quad 149$

$\begin{array}{ll}\text { A Dados da Fábrica X } & 157\end{array}$

B Perfis de Desempenho 167 
C Tabelas Adicionais dos Resultados Computacionais

Referências Bibliográficas 


\section{Lista de Figuras}

1.1 Exemplo ilustrativo da estrutura de um guarda-roupa. . . . . . . . . . . . 2

2.1 Processo produtivo simplificado numa indústria moveleira de pequeno porte. 18

2.2 Exemplo de padrão de corte guilhotinado em 3-estágios. Fonte: Biehl (2008). 19

2.3 Exemplo de padrão de corte tabuleiro. Fonte: Mosquera (2007). . . . . . . 19

2.4 Decomposição por período. . . . . . . . . . . . . . . . . . 24

2.5 Heurística Relax-and-Fix progressiva no tempo. . . . . . . . . . . . 25

2.6 Perfil de desempenho das três estratégias de solução em relação ao gap de otimalidade. . . . . . . . . . . . . . . . . . . . 34

2.7 Perfil de desempenho das três estratégias de solução em relação ao tempo de execução dos algoritmos. . . . . . . . . . . . . . . . . . . . . . . . 34

3.1 Esquema do paradigma da formulação estocástica de dois e três estágios aplicada ao problema combinado de dimensionamento de lotes e corte de estoque, considerando demandas e tempos de preparação estocásticos. As variáveis de decisão de primeiro estágio são relacionadas à produção $X$, frequência de padrões de corte $Y$ e preparações de máquina $Z$. As decisões de segundo estágio são representadas pelo estoque $I^{+}$, atraso $I^{-}$e horas-

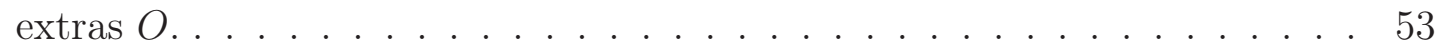

3.2 Árvore de cenários utilizada no Teste A. . . . . . . . . . . . . . . . 65

3.3 Diferença entre as soluções dos problemas Min-Max e RP, em termos de volume de estoque (acima e esquerda); custo de backlogging (cima e direita); demanda perdida e nível de serviço (baixo e esquerda); e horas-extras (baixo direita). . . . . . . . . . . . . . . . . . . . . 73

3.4 Tradeoff entre custo total esperado e robustez de acordo com o aumento do fator de risco $\lambda$, considerando as situações moderada (cima e esquerda), otimista (baixo e esquerda), equiprovável (cima e direita) e pessimista (baixo e direita). . . . . . . . . . . . . . . . . . . . . 77

3.5 Comportamento das decisões de segundo estágio de acordo com o aumento do fator de risco $\lambda$ em todas as situações. . . . . . . . . . . . . . . . . . 78 
3.6 Curva de tradeoff entre aumento do custo total esperado e redução do desvio esperado (primeiro gráfico). Comportamento do volume de estoque, horas-extras e nível de serviço de acordo com a redução do desvio esperado (três gráficos restantes). . . . . . . . . . . . . . . . . . 79

3.7 Desempenho relativo do custo total esperado, volume de estoque, horasextras e nível de serviço, considerando as diferenças entre as soluções dos problemas $M R$ e $R R$. . . . . . . . . . . . . . . . . . 91

3.8 Curvas de tradeoff entre aumento do custo total esperado e redução do risco para $S=20, \cdots, 300$, considerando um exemplar estocástico robusto de recurso restrito.

3.9 Exemplo de redução progressiva do desvio $\Delta_{s}$ de 0 até $100 \%$, considerando um exemplar estocástico robusto de recurso restrito com 20 cenários. . . . 93

3.10 Comportamento da solução ótima do problema com recurso restrito (custo total, volume de produção e estoque) de acordo com o aumento do número de cenários (de 20 até 300), considerando três níveis de redução do desvio esperado: 0,50 e 100\% . . . . . . . . . . . . . . . 94

3.11 Comportamento da solução ótima do problema com recurso restrito (atraso total, nível de serviço e horas-extras) de acordo com o aumento do número de cenários (de 20 até 300), considerando três níveis de redução do desvio esperado: zero, 50 e 100\% . . . . . . . . . . . . . . . 95

3.12 a) Acima: tempos de resolução dos problemas robustos para todos os cenários e níveis de redução. b) Abaixo: tempos computacionais médios dos problemas robustos, respectivos desvios-padrão e curva ajustada. . . . . . . 96

4.1 Aumento (em \%) no valor ótimo do modelo robusto com custos incertos e limitante probabilístico de violação da meta do decisor como função de $\Gamma^{c}$. 121

4.2 Aumento (em \%) no valor ótimo do modelo robusto com custos incertos e limitante probabilístico de violação da meta do decisor como função de $\Gamma^{h+} .121$

4.3 Aumento (em \%) no valor ótimo do modelo robusto com custos incertos e limitante probabilístico de violação da meta do decisor como função de $\Gamma^{s}$. 122

4.4 Aumento (em \%) no valor ótimo do modelo robusto com custos incertos e limitante probabilístico de violação da meta do decisor como função de $\Gamma^{w}$. 122

4.5 Tradeoff entre o custo total e $\Gamma^{\circ}$. . . . . . . . . . . . . . . . 123

4.6 Aumento (em \%) no valor ótimo da função objetivo do problema com demanda incerta $C L C d$, considerando a) $\Gamma_{i t}=0,5+0,1 t$ e $\Gamma_{i t}=1$ para todos os níveis de variabilidade; b) $\Gamma_{i t}=0,5+0,5 t$ e $\Gamma_{i t}=t$ para $\gamma=5 \mathrm{e}$ $10 \%$; c) $\Gamma_{i t}=0,5+0,5 t$ e $\Gamma_{i t}=t$ para $\gamma=20$ e $30 \%$.

4.7 Nível de serviço obtido pelo problema robusto com demanda incerta $C L C d$, considerando vários níveis de variabilidade e budgets de incerteza. . . . . . 130 
4.8 Níveis de estoque obtidos pelo problema $C L C d$ com demanda incerta, considerando vários níveis de variabilidade e budgets de incerteza. . . . . . . . 131

4.9 Níveis de atraso obtidos pelo problema $C L C d$ com demanda incerta, considerando vários níveis de variabilidade e budgets de incerteza. . . . . . . . 132

4.10 Probabilidade de violação das restrições de balanço de estoque. . . . . . . . . 133

4.11 Nível de produção acumulado ao longo do horizonte de planejamento do problema robusto com demanda incerta $C L C d$, considerando vários níveis de variabilidade e budgets de incerteza, além dos valores nominal, máximo e mínimo.

4.12 Quantidade de placas utilizadas ao longo do horizonte de planejamento do problema robusto com demanda incerta $C L C d$, considerando vários níveis de variabilidade e budgets de incerteza, além dos valores nominal, máximo e mínimo.

4.13 Quantidade de preparações de máquina necessárias ao longo do horizonte de planejamento do problema robusto com demanda incerta $C L C d$, considerando vários níveis de variabilidade e budgets de incerteza, além dos valores nominal, máximo e mínimo. . . . . . . . . . . . . . . . . . . 135

4.14 Horas-extras incorridas ao longo do horizonte de planejamento do problema robusto com demanda incerta $C L C d$, considerando vários níveis de variabilidade e budgets de incerteza, além dos valores nominal, máximo e mínimo.136

4.15 Aumento no valor ótimo da função objetivo e robustez do modelo MédiaRisco, considerando o fator de risco $(\lambda)$ entre 0 e $90 . . . . . .141$

4.16 Aumento no valor ótimo e robustez do modelo de otimização robusta $C L C d$, considerando os budgets de incerteza $\Gamma_{i t}^{d}=g t$, com $g=0,01$ até 1 . . . . . . 142

4.17 Nível de serviço do modelo MR1 de acordo com o aumento da robustez. . . 143

4.18 Nível de serviço do modelo de otimização robusta $C L C d$ de acordo com o aumento da robustez. . . . . . . . . . . . . . . . . . . . . 143

4.19 Tempo de execução computacional do modelo Média-Risco de acordo com o aumento da robustez. . . . . . . . . . . . . . . . . . . . . . 144

4.20 Tempo de execução computacional do modelo de otimização robusta $C L C d$ de acordo com o aumento da robustez. . . . . . . . . . . . . . . . . . . 145 


\section{Lista de Tabelas}

1.1 Detalhamento das peças do exemplo. . . . . . . . . . . . . . . . . . . 1

2.1 Notação matemática do modelo matemático $C L C 1 . \ldots . . . .12$

2.2 Notação matemática adicional do modelo CLC2. . . . . . . . . . . . . . . 20

2.3 Comparação entre os modelos $C L C 1$ e $C L C 2$ em termos de número de restrições, número de variáveis contínuas e número de variáveis binárias. . . 22

2.4 Classes de exemplos. . . . . . . . . . . . . . . . . . . . . 30

2.5 Valores médios das soluções geradas pelas três estratégias nas 6 classes de exemplos: custo total, variação $(\%)$, produção $(X)$, estoque $\left(I^{+}\right)$, atraso $\left(I^{-}\right)$, placas $(Y)$, preparação $(Z)$, número de padrões de corte diferentes utilizados $(\# j)$ e hora-extra $(O)$. . . . . . . . . . . . . 32

2.6 Valores extremos dos perfis de desempenho correspondentes aos gaps de otimalidade (esquerda) e aos tempos de execução (direita) . . . . . . . . . . 35

2.7 Médias dos gaps de otimalidade e dos tempos de execução em cada uma das 6 classes de exemplos testadas, de acordo com os três métodos. As quatro linhas finais ainda indicam a média geral, desvio-padrão, valor máximo e mínimo obtidos a partir dos 60 exemplares. As Tabelas C.1 e C.2 do Apêndice $\mathrm{C}$ exibem os resultados completos dos 60 exemplares. . . . . . . . 35

3.1 Notação matemática adicional dos modelos estocásticos. . . . . . . . . . . 54

3.2 Comparação entre os modelos CLC2, CLC2r, Min-Max, $M R$ e $R R$ em termos de número de restrições, número de variáveis contínuas e número de variáveis binárias. . . . . . . . . . . . . . . . . . 62

3.3 Resultados de um exemplar real do modelo estocástico CLC2r na situação moderada, na qual as probabilidades das demandas e tempos de preparação nos cenários Baixo, Médio e Alto são 25, 50 e 25\%, respectivamente. . . . . 90

3.4 Resultados de um exemplar real do modelo estocástico CLC2r na situação equiprovável, na qual as probabilidades das variáveis aleatórias nos cenários Baixo, Médio e Alto são 1/3, 1/3 e 1/3, respectivamente. . . . . . . . . . . 97 
3.5 Resultados de um exemplar real do modelo estocástico CLC2r na situação otimista, na qual as probabilidades das demandas nos cenários Baixo, Médio e Alto são 60, 30 e 10\%, respectivamente, e as probabilidades dos tempos de preparação nos mesmos cenários são 50, 40 e 10\% . . . . . . . . 98

3.6 Resultados de um exemplar real do modelo estocástico $C L C 2 r$ na situação pessimista, na qual as probabilidades das demandas nos cenários Baixo, Médio e Alto são 10, 30 e 60\%, respectivamente, e as probabilidades dos tempos de preparação nos mesmos cenários são 10, 40 e 50\% . . . . . . . . . 99

3.7 Resultados dos problemas wait-and-see e valor esperado de informação perfeita (EVPI) de um exemplar real do modelo CLC2r. . . . . . . . . . . . 100

3.8 Valores acumulados das variáveis de erro $\tilde{I}_{i t s}$, resultados obtidos pelos problemas $E V, E E V$, e valor da solução estocástica $(V S S)$. . . . . . . . . . . 101

3.9 Resultados do problema Min-Max. . . . . . . . . . . . . . . . . 102

3.10 Efeito do número de cenários na solução ótima do problema estocástico (redução zero). . . . . . . . . . . . . . . . . . . 103

3.11 Efeito do número de cenários na solução ótima do problema robusto (redução 50\%) . . . . . . . . . . . . . . . . . . . . 104

3.12 Efeito do número de cenários na solução ótima do problema totalmente robusto (redução 100\%) . . . . . . . . . . . . . . . . . 104

4.1 Comparação entre os modelos $C L C 1, C L C c, C L C d$ e $C L C r$ em termos de número de restrições, número de variáveis contínuas e número de variáveis binárias. . . . . . . . . . . . . . . . . . . . 117

4.2 Demandas nominais $d_{i t}$ e tempos de produção $v_{i}$ (em minutos) do armário de 5 portas (a5p), da cômoda (cmd) e do criado-mudo (crd) . . . . . . . 118

4.3 Análise dos valores de $\Gamma$ (colunas 3, 5, 7 e 9) das soluções robustas e dos correspondentes aumentos $\Delta$ (em porcentagem) no valor da função objetivo (colunas 4, 6, 8 e 10) para $\gamma=5,10,20$ and 30\%, em cada conjunto de coeficientes (primeira coluna). A coluna $|J|$ mostra o número total de coeficientes sujeitos à incerteza. . . . . . . . . . . . . . . . . . . 120

4.4 Valores de $\Gamma$ necessários para assegurar uma probabilidade menor do que $\alpha \%$ de violação da meta do decisor e as correspondentes quantidades de coeficientes que estão protegidos da aleatoriedade $(\beta \%)$. . . . . . . . . . . 123

4.5 Aumentos nos valores ótimos do problema nominal no caso em que todos os custos são considerados simultaneamente. A segunda linha da tabela mostra os budgets de incerteza que devem ser adotados para garantir menos de 1, 5 e $10 \%$ de violação da meta do decisor. 
4.6 Aumento médio, máximo e mínimo nos valores ótimos dos problemas nominais de acordo com a simulação realizada com 1.000 exemplares. A primeira linha da tabela ilustra os níveis de variabilidade e a segunda linha indica a probabilidade máxima de violação da meta do decisor. . . . . . . . . . . . . 125

4.7 Cenários para os budgets de incerteza. A primeira linha da tabela mostra a equação dos budgets de incerteza como função linear do período do horizonte de planejamento; a segunda linha ilustra o budget acumulado ao final do período de planejamento. . . . . . . . . . . . . . . . . 12

4.8 Resultados do modelo robusto $C L C d$ a partir de 40.000 simulações, nas quais foram testadas variações do problema padrão $(P 2-P 4)$ para diferentes budgets de incerteza $\Gamma$ e níveis de variabilidade $\gamma$. As colunas $\rho$ e $\mathcal{B}$ ilustram o custo relativo de utilizar a estratégia $W C$ em detrimento à abordagem $R O$ e o nível de serviço em cada caso, respectivamente. A última coluna mostra o nível de serviço obtido pela estratégia de pior caso $W C \ldots \ldots \ldots \ldots \ldots \ldots \ldots \ldots$

4.9 Número de variáveis de decisão e restrições de um exemplar dos modelos CLCd e MR1. . . . . . . . . . . . . . . . . . . . . . . . . . . . . . . . . 14

A.1 Detalhamento dos padrões de corte utilizados: espessura, tempo de processamento e custo unitário.

A.2 Detalhamento das 49 peças utilizadas na composição dos 3 produtos considerados: armário de 5 portas, cômoda e criado-mudo. As peças são caracterizadas pelo comprimento $C$, largura $(L)$ e espessura $(E)$.

A.3 Demandas nominais $\left(d_{i t}\right)$ e estoques máximos permitidos $\left(I_{i t}^{\max }\right)$ do exemplar 1 da Seção 2.5.2 do Capítulo 2. . . . . . . . . . . . . . . . . . . . . . . 159

A.4 Demandas nominais $\left(d_{i t}\right)$ e estoques máximos permitidos $\left(I_{i t}^{\max }\right)$ utilizadas nos exemplares 2, 3 e 4 da Seção 2.5.2 do Capítulo 2. . . . . . . . . . . . . 159

A.5 Padrões de corte mais frequentes disponibilizados pela Fábrica X (1-15). 160

A.6 Padrões de corte mais frequentes disponibilizados pela Fábrica X (16-30). . 161

A.7 Padrões de corte mais frequentes disponibilizados pela Fábrica X (30-42) . . 162

A.8 Padrões de corte mais frequentes disponibilizados pela Fábrica X (43-56). . 163

A.9 Padrões de corte mais frequentes disponibilizados pela Fábrica X (57-70). . 164

A.10 Padrões de corte mais frequentes disponibilizados pela Fábrica X (70-81). . 165

C.1 Custo total, gap de otimalidade e tempo de execução das estratégias MIP, RFP e RFR relativos aos exemplares 1 - 30. . . . . . . . . . . . . . . . . 170

C.2 Custo total, gap de otimalidade e tempo de execução das estratégias MIP, RFP e RFR relativos aos exemplares $31-60 . . . . . . . .171$ 


\section{Capítulo 1}

\section{Introdução}

processo produtivo de móveis residenciais em empresas de pequeno porte consiste, basicamente, no corte de placas de algum tipo de matéria-prima, como madeira, compensado, MDF (medium density fiberboard), entre outras, de modo que sejam geradas as peças necessárias para a montagem de cada tipo de móvel. Por exemplo, considere o exemplo ilustrativo da Figura 1.1. Para montar o guarda-roupa, é necessário obter os nove tipos de peças (A-I), as quais podem diferir pelas espessuras $(E)$ e dimensões (comprimento $C$ e largura $L$ ), como mostrado na Tabela 1.1. Note que as peças A e B possuem as mesmas dimensões, mas as espessuras são diferentes. Além disso, as quantidades (em unidades) de cada tipo de peça são bem variadas e dependem do produto a ser produzido.

\begin{tabular}{cccccc}
\hline Peça & Descrição & $E(\mathrm{~mm})$ & $L(\mathrm{~mm})$ & $C(\mathrm{~mm})$ & Quantidade \\
\hline A & Tampo da base & 6 & 565 & 2500 & 3 \\
B & Lateral da base & 25 & 565 & 2500 & 4 \\
C & Lateral de gaveta & 12 & 560 & 560 & 10 \\
D & Divisória do camiseiro & 9 & 510 & 2000 & 5 \\
E & Lateral & 3 & 530 & 1062 & 12 \\
F & Porta camiseiro & 12 & 510 & 2500 & 3 \\
G & Travessa da base & 15 & 60 & 490 & 26 \\
H & Fundo maleiro & 15 & 490 & 2250 & 3 \\
I & Fundo camiseiro & 20 & 490 & 1875 & 3 \\
\hline
\end{tabular}

Tabela 1.1: Detalhamento das peças do exemplo.

Entretanto, antes de se iniciar o processo produtivo, o setor responsável pelo planejamento da produção deve tomar algumas decisões referentes às políticas de produção, estocagem e distribuição de móveis ao longo do horizonte de planejamento (em geral, 


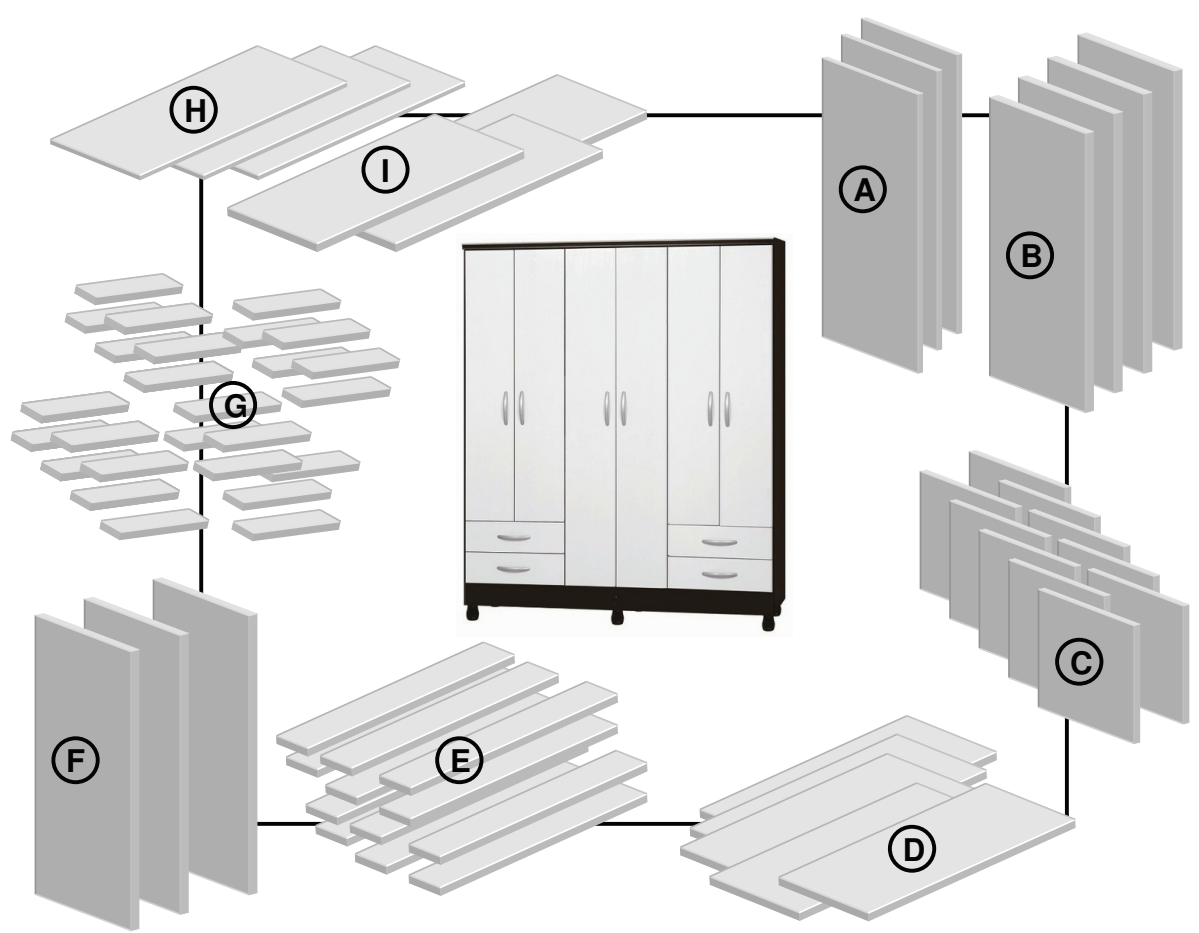

Figura 1.1: Exemplo ilustrativo da estrutura de um guarda-roupa.

composto de vários períodos de dias ou semanas). Inicialmente, conhecidas as demandas dos produtos finais (guarda-roupas, camas, cômodas, criados-mudos, mesas, etc.), deve-se decidir os tipos e quantidades de móveis que serão produzidos em cada período, com base na capacidade disponível (máquinas, equipamentos e mão-de-obra), no nível atual de estoque e nas datas de entrega. Como consequência das decisões sobre os lotes de produção dos produtos, têm-se os lotes de produção das peças que os compõem (os quais são facilmente calculados a partir da estrutura de cada produto). Nesse momento, é preciso determinar como as placas devem ser cortadas para gerarem os lotes de peças, o que corresponde a resolver um problema de corte de estoque bidimensional para obter os padrões de corte bidimensionais (maneiras específicas de cortar as placas para produzir os itens demandados), ou as frequências de utilização de padrões de corte selecionados $a$ priori.

Essa é uma prática comum de empresas moveleiras de pequeno porte, em que as decisões sobre o corte das peças são tomadas a partir das informações dos lotes de produção de uma maneira independente. Ou seja, a solução do problema de dimensionamento de lotes (PDL) é utilizada como dado de entrada do problema de corte de estoque (PCE) sem haver troca de informações entre ambos os problemas. Essa visão simplificada de planejar a produção pode resultar em algumas dificuldades, como: $(i)$ a geração de padrões de corte com baixa produtividade de peças, o que aumenta o desperdício de material, e 
(ii) o número elevado de preparações das máquinas seccionadoras, que consome capacidade de produção. Como consequência de $(i)$ e $(i i)$, o custo total de produção pode se tornar desnecessariamente alto, comprometendo a própria sobrevivência da empresa no mercado. Essa situação é ainda mais grave quando o custo das placas representa uma parte considerável do custo do produto final.

Por outro lado, quando o dimensionamento de lotes e o corte de estoque são resolvidos conjuntamente, há uma tendência em se antecipar a produção de lotes de peças de períodos futuros, na tentativa de produzir padrões de corte com menos desperdício (uma vez que, em geral, é mais fácil determinar boas combinações de peças na placa quando o sortimento de peças é maior) e/ou reduzir o número de preparações da máquina seccionadora ao longo do horizonte de planejamento. Todavia, conforme mais lotes são antecipados, aumenta-se o custo de estoque e uma tendência oposta de postergar a produção pode ser observada. Na prática, antecipar a produção e incorrer em custos de estocagem pode ser uma estratégia mais interessante do que postergar a produção e correr o risco de atrasar o atendimento da demanda, uma vez que os atrasos nas entregas dos produtos comprometem o nível de serviço da empresa.

Nesse contexto, define-se uma extensão do clássico problema de dimensionamento de lotes que envolve um estágio fundamental de corte de peças como o problema combinado de dimensionamento de lotes e corte de estoque. A principal motivação em combinar os dois problemas é permitir que as decisões relacionadas ao dimensionamento de lotes e ao processo de corte de estoque possam ser determinadas conjuntamente e, com isso, melhorar alguma medida de desempenho do sistema.

Embora não se tenham muitos trabalhos na literatura que abordem a integração de problemas de planejamento da produção, existe uma crescente motivação para o estudo desse tema. No trabalho de Drexl e Kimms (1997), os autores ressaltam que os problemas de dimensionamento de lotes e programação da produção interagem com outras atividades de uma indústria, como o planejamento da distribuição, o problema de corte e empacotamento e a programação de projetos. Os autores concluem ainda que a coordenação desses problemas pode diminuir os altos custos de transação. Thomas e Griffin (1996) enfatizam que existe uma tendência em tratar problemas de planejamento e programação da produção de forma integrada e Pochet e Wolsey (2006) aludem à integração de modelos de planejamento da produção para melhorar a produtividade das operações em um sistema de produção. Mais recentemente, Jans e Degraeve (2008) defendem que a integração do dimensionamento de lotes dentro de modelos mais gerais de planejamento da produção é uma interessante área para pesquisas futuras. Além disso, os autores discutem que os modelos integrados poderiam levar em consideração a coordenação entre várias plantas e atividades como o arranjo de cargo na distribuição dos produtos. 
Tese de Doutorado

A literatura específica sobre os problemas combinados de dimensionamento de lotes e corte de estoque é bastante escassa se comparada às literaturas de ambos os problemas estudados separadamente. Gramani e França (2006), Ghidini et al. (2007), dos Santos (2008) e Gramani et al. (2009) estudaram o problema combinado com aplicações à indústria moveleira, desenvolveram formulações matemáticas para o problema e métodos de solução para resolvê-lo. Mesmo com as dificuldades computacionais devido à complexidade do problema, os trabalhos acima apresentados obtiveram resultados numéricos promissores que mostraram a importância de se combinar as decisões do dimensionamento de lotes e do corte de estoque.

No trabalho de Poltroniere et al. (2008), os autores propuseram um modelo de dimensionamento de lotes e corte de estoque para a produção de bobinas de papel. Para isso, os autores consideraram um processo de produção de bobinas-mestre de vários tamanhos que devem ser cortadas em bobinas intermediárias menores. Parte dessas bobinas intermediárias é destinada a atender uma carteira de pedidos específica e o restante é cortado para produzir diferentes tipos de produtos finais, como modelo carta, A4, resmas, entre outros. A disponibilidade de bobinas-mestre no problema de corte é uma variável de decisão. Portanto, as decisões de planejamento consistem em escolher quais bobinasmestre (definidas pelas suas características, como comprimento e gramatura) e em quais quantidades (tamanhos dos lotes de produção) devem ser produzidas em cada período, de forma a atender a carteira de pedidos, evitar atrasos e estoque, e minimizar a perda de material durante o processo de corte.

Respício e Captivo (2002) apresentaram um modelo de programação inteira que integrou o PCE ao problema de planejamento de capacidade num sistema de produção multi-produto. O objetivo das autoras foi encontrar um plano de produção para determinar a quantidade de produtos a serem produzidos em cada período do horizonte de planejamento, de modo a atender a demanda e minimizar os custos de estoque e a quantidade de bobinas utilizadas. Apesar da formulação matemática detectar a influência do processo de corte na produção das bobinas, não é possível antecipar a produção dos produtos, pois as variáveis de decisão associadas aos estoques estão presentes apenas para o primeiro período do horizonte de planejamento. Menon e Schrage (2002) e Correia et al. (2004) também estudaram um problema de planejamento da produção e otimização do corte de bobinas. Como é comum na área de corte e empacotamento, os dois trabalhos resolveram o problema integrado de forma sucessiva, isto é, primeiro resolvem o PDL e depois o PCE, ou vice-versa.

Já os trabalhos de Nonas e Thorstenson (2000) e Nonas e Thorstenson (2008) investigaram uma formulação matemática para o problema integrado de corte de estoque e dimensionamento de lotes para uma companhia da Noruega produtora de um tipo espe- 
cial de caminhão. Como a empresa manufatura a maior parte das peças dos caminhões, grandes placas de aço têm que ser cortadas em diferentes formas e tamanhos. O problema integrado proposto pelos autores tem o objetivo principal de minimizar os custos de perda de material do processo de corte de estoque, custos de preparação e estoques, enquanto atende a demanda e respeita a capacidade máxima de produção.

\subsection{Motivação}

Na prática industrial, o planejamento da produção é utilizado para gerar políticas de produção, estoque, distribuição e vendas, com base nas informações de mercado e nos pedidos dos clientes, e ainda respeitando todas as restrições relevantes. Em geral, assume-se o conhecimento completo sobre tais informações para simplificar a modelagem do problema. Entretanto, na realidade, muitas informações futuras e dados importantes para o planejamento da produção estão sujeitos às incertezas por várias razões, dentre as quais se destacam (Ben-Tal e Nemirovski, 2000; Beyer e Sendhoff, 2007):

(i) Alguns dados (demandas futuras, custos, retornos, etc.) podem não existir no momento em que os problemas são resolvidos, fazendo com que seja necessário utilizar métodos de previsão, que estão sujeitos a erros.

(ii) Alguns dados não podem ser medidos exatamente, como parâmetros físicos e técnicos que são conhecidos apenas dentro de um intervalo de confiança ou dado um certo grau de acurácia, como tempos de processamento e de preparação.

Para corroborar com a hipótese $(i)$, toma-se o exemplo de uma empresa moveleira de pequeno porte típica do setor, que foi estudada neste trabalho. A empresa não possui um histórico organizado dos pedidos dos clientes e nem das ordens de produção efetivadas. Desta maneira, utilizar métodos de previsão para estimar as demandas futuras, em geral, não é possível. Na prática, o planejamento da produção baseia-se num "pot-pourri" de informações referentes a pedidos de clientes, vendas e nível de estoque para estimar as demandas e gerar o planejamento para um horizonte de planejamento de quatro semanas, que é reavaliado ao final de cada semana. O estoque tem um papel fundamental nesse processo, pois ele é usado para atender pedidos urgentes e/ou ordens que surgem ao longo do horizonte de produção e que não conseguem ser encaixadas com os demais pedidos (ou mesmo pela falta de capacidade da empresa em produzi-los). Essas estratégias, em geral, geram problemas de atrasos na entrega dos produtos, assim como uma dificuldade grande em gerir pedidos não previstos, especialmente quando esses pedidos vêm de clientes especiais (em geral, grandes atacadistas do setor moveleiro). Além disso, produzir para 
Tese de Doutorado

estocar como estratégia contra a flutuação da demanda pode gerar um estoque custoso e indesejável de produtos que podem não ter mais procura, acarretando custos significativos de oportunidade, re-trabalho, entre outros.

Considerando a hipótese ( $i i)$, considera-se o exemplo da mesma empresa moveleira de pequeno porte em que a rotatividade dos funcionários é relativamente alta. Como o tempo de execução de várias operações (inclusive a operação de corte de peças) depende muito da habilidade do funcionário - principalmente em operações menos mecanizadas - então, é de se esperar que exista uma flutuação no tempo total de alguns estágios do processo produtivo. Dependendo da magnitude dessa flutuação, é possível que o planejamento da produção, baseado num tempo de produção médio ou otimista, gere uma ordem de produção que certamente não poderá ser cumprida em um determinado período com a capacidade regular. Nesse caso, a empresa pode ter que contratar turnos extras de produção, ou ter que retardar a ordem de produção e incorrer em eventuais atrasos na entrega dos pedidos.

Analisando as questões anteriores, a presente tese propõe estudar problemas combinados de dimensionamento de lotes e corte de estoque típicos de empresas moveleiras brasileiras inseridas num ambiente incerto. Do ponto de vista teórico, o tema dessa tese envolve desafios por adotar dois métodos de otimização sob incertezas - a programação estocástica e a otimização robusta - como arcabouços teóricos para lidar com o problema combinado sob incertezas. Embora os dois métodos sejam utilizados em contextos similares, têm filosofias muito distintas. Do ponto de vista prático, uma contribuição desse estudo é discutir vários resultados que podem auxiliar o tomador de decisões a lidar com as incertezas no seu dia a dia, tornando as suas estratégias de produção mais competitivas no mercado.

Além da programação estocástica e da otimização robusta, existem outras metodologias já consolidadas na literatura de pesquisa operacional, com promissores resultados teóricos e algoritmos. Nesse ponto, vale destacar os trabalhos pioneiros de Dantzig (1955), Bellman (1957) e Charnes e Cooper (1959). Em Dantzig (2004), o autor comenta que a programação linear sob incertezas é um campo de estudo em crescimento. Dentre as várias metodologias existentes para lidar com problemas de otimização sob incertezas, destacam-se:

- Análise de sensibilidade: é um estudo de pós-otimalidade para determinar o impacto que as perturbações causam no problema nominal. Mulvey et al. (1995) considera esses estudos reativos, uma vez que não são concebidos para sugerir ações frente a uma situação de variação dos dados.

- Programação estocástica: Em programação estocástica, assume-se que a distri- 
buição de probabilidade dos parâmetros incertos (estocásticos) é conhecida ou pode ser estimada. O objetivo é determinar alguma política factível para todos (ou quase todos) possíveis valores para os dados de entrada, de forma a minimizar alguma função que depende das variáveis aleatórias. Uma importante restrição dessa metodologia é a suposição de que a distribuição de probabilidade dos dados é conhecida e não depende da decisão tomada. Vale destacar que existem várias formulações possíveis dentro da programação estocástica, como modelos de dois estágios com recurso, modelos multiestágios, modelos com restrições probabilísticas (chance constraints) e modelos estocásticos robustos.

- Programação dinâmica: Essa metodologia também modela os parâmetros incertos como variáveis aleatórias e requer o conhecimento sobre as suas distribuições de probabilidade. A vantagem dessa metodologia é a facilidade com que é implementada. Uma desvantagem da programação dinâmica é a sua aplicação em problemas de grande porte, uma vez que tal técnica sofre do conhecido problema da dimensionalidade (Bellman, 1957).

- Programação Fuzzy: A principal diferença entre a programação estocástica e a programação fuzzy é a maneira como a incerteza é modelada. Na programação fuzzy, os parâmetros aleatórios são considerados números fuzzy e as restrições são tratadas como conjuntos fuzzy. Assim, funções de pertinência são definidas para indicar o grau de satisfação com que as variáveis pertencem aos conjuntos fuzzy (Zimmermann, 1976; Bellman e Zadeh, 1970).

- Otimização robusta: A otimização robusta preocupa-se em desenvolver modelos e métodos para que as soluções sejam factíveis para quaisquer realizações das variáveis aleatórias dentro de um conjunto convexo dado a priori e violações das restrições não são toleradas. Essa metodologia, assim como a programação estocástica, é denominada proativa. Uma diferença bastante evidenciada entre essa metodologia e a programação estocástica é que a primeira não necessita do conhecimento da distribuição de probabilidade do parâmetro incerto, enquanto a segunda precisa.

\subsection{Objetivos}

Os objetivos desta tese são: $(i)$ estudar e propor formulações matemáticas e métodos de solução para o problema combinado de dimensionamento de lotes e corte de estoque no contexto da indústria moveleira sob o enfoque da programação estocástica clássica, da programação estocástica robusta e da otimização robusta; (ii) analisar e discutir os resultados computacionais de exemplares reais e de uma vasta gama de exemplares simulados, 
de modo a obter insights úteis na prática da tomada de decisões e na teoria para estender para outras situações e/ou problemas.

\subsection{Metodologia}

A presente tese utiliza a metodologia de Pesquisa Axiomática Quantitativa Normativa. A pesquisa é denominada axiomática quantitativa porque é primariamente orientada a modelos de problemas idealizados e é normativa porque é baseada em modelos que prescrevem uma decisão para o problema - modelos de programação estocástica e otimização robusta, por exemplo (Morabito e Pureza, 2010; Bertrand e Fransoo, 2002).

\subsection{Organização}

A tese está organizada da seguinte maneira.

O Capítulo 2 apresenta duas formulações matemáticas para o problema combinado de dimensionamento de lotes e corte de estoque, sendo a primeira formulação CLC1 mais geral e baseada em trabalhos anteriores da literatura, a segunda, CLC2, proposta meste trabalho e baseada nas observações de uma planta moveleira de pequeno porte típica do setor. Para analisar o desempenho do modelo CLC2, são geradas e resolvidas algumas classes de exemplares, variando-se parâmetros como a quantidade de produtos, períodos, presença de custo de preparação, entre outros. Devido à dificuldade de resolução de alguns exemplares, são propostas heurísticas baseadas em programação matemática, na tentativa de determinar limitantes superiores razoáveis num tempo computacional aceitável na prática. Finalmente, a qualidade das heurísticas é avaliada com base na resolução direta pelo algoritmo branch-and-cut padrão do CPLEX 11.0.

No Capítulo 3, são desenvolvidos modelos de programação estocástica e programação estocástica robusta para o problema combinado de dimensionamento de lotes e corte de estoque, com demandas e tempos de preparação estocásticos. O modelo estocástico de dois estágios define uma matriz de recurso relativamente completa, fazendo com que seja sempre possível determinar um conjunto de variáveis de segundo estágio para quaisquer realizações das variáveis aleatórias. Os modelos estocásticos robustos consideram parcelas explícitas de aversão ao risco e restrições de recurso que visam estabilizar as decisões de segundo estágio. Ainda, é mostrado que ambos os modelos são equivalentes. Os testes computacionais dos modelos estocásticos permitem acessar o valor esperado de informação perfeita $(E V P I)$ e o valor da solução estocástica ( VSS ), para avaliar o impacto de utilizar os modelos estocásticos em detrimento a abordagens mais simples de valor esperado ou de 
aquisição de informação perfeita. Os testes com os modelos estocásticos robustos ilustram o desempenho dos problemas à medida que a solução vai progressivamente se tornando robusta, muitas vezes às custas de deteriorações significativas nos valores ótimos das funções objetivos.

O Capítulo 4 propõe modelos de otimização robusta para o problema combinado de dimensionamento de lotes e corte de estoque na situação em que custos e demandas não são valores conhecidos com certeza. Diferentemente dos modelos baseados em programação estocástica (estocástica robusta), os modelos de otimização robusta consideram que os parâmetros incertos são variáveis aleatórias limitadas num suporte estabelecido $a$ priori e otimizam o problema numa perspectiva de pior caso intervalar. Nesse capítulo, são desenvolvidos três modelos robustos: o primeiro considera apenas os custos incertos; o segundo apresenta a formulação robusta equivalente para lidar com as demandas incertas e, finalmente, o terceiro combina custos e demandas incertas num mesmo problema de otimização cuja formulação conservadora não permite o tradeoff entre robustez e desempenho fora do intervalo [0,1]. Os resultados obtidos confirmam alguns insights já relacionados em trabalhos recentes da literatura e ainda indicam que, em geral, não é preciso sacrificar muito a solução ótima para se obter uma solução robusta quando apenas os custos variam. Comprovou-se também a importância de determinar budgets de incertezas representativos, de modo a evitar soluções muito conservadoras. Ainda, uma série de simulações foi realizada para investigar o desempenho dos modelos robustos em diferentes situações.

No Capítulo 5, faz-se uma revisão dos principais resultados obtidos nos capítulos anteriores, enfatizando a contribuição científica em cada um deles.

O Apêndice A apresenta alguns dados referentes ao processo produtivo da empresa moveleira típica visitada, como padrões de corte e estruturas dos produtos. O Apêndice B descreve brevemente a técnica de análise dos prefis de desempenho, que foi utilizada em algumas análises do Capítulo 2. Finalmente, no Apêndice C, são exibidas algumas tabelas completas dos resultados computacionais dos capítulos anteriores. 


\section{Capítulo 2}

\section{Planejamento da Produção em Empresas Moveleiras}

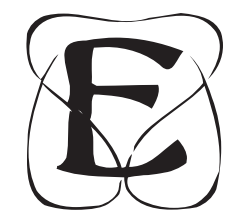

sse capítulo tem como o objetivo principal apresentar duas formulações matemáticas para o problema combinado de dimensionamento de lotes e corte de estoque em empresas moveleiras. A primeira formulação é uma extensão direta do modelo apresentado no trabalho de Gramani et al. (2009), enquanto a segunda é baseada em um estudo de caso numa empresa moveleira de pequeno porte típica do setor, situada no pólo moveleiro de Votuporanga, ao noroeste do estado de São Paulo. De acordo com os testes computacionais preliminares, exemplares práticos do modelo $C L C 1$ são resolvidos na otimalidade num tempo computacional razoável, considerando um conjunto finito de padrões de corte dado a priori. Por outro lado, o modelo $C L C 2$ apresenta dificuldades de resolução, principalmente em exemplares com mais produtos e/ou períodos, com custos de preparação e capacidades apertadas. Por essa razão, foram desenvolvidas estratégias simples de resolução do modelo $C L C 2$ com a motivação de se obter bons limitantes superiores num tempo computacional aceitável. O presente Capítulo está organizado da maneira descrita a seguir. Na Seção 2.1, é apresentado o modelo CLC1. Na Seção 2.2, são apresentados os principais aspectos do processo de produção da empresa moveleira visitada e o modelo $C L C 2$ é desenvolvido. A Seção 2.4 apresenta dois tipos de heurística relax-and-fix como alternativa de resolução do modelo CLC2. Na Seção 2.5, são exibidos os resultados computacionais para algumas classes de exemplos do modelo CLC2. Finalmente, as considerações finais são realizadas na Seção 2.6 e possíveis pesquisas futuras deste capítulo são discutidas na Seção 2.7. 


\subsection{Um Modelo Geral de Dimensionamento de Lotes e Corte de Estoque}

Nessa seção, é apresentada uma simples extensão da formulação matemática do problema combinado de dimensionamento de lotes e corte de estoque $C L C$ apresentado no trabalho de Gramani et al. (2009). Diferentemente da formulação matemática original, no modelo estendido é permitido atraso na produção (inclusive no último período do horizonte de planejamento) e utilização de hora-extra, os quais são penalizados na função objetivo com os respectivos custos.

Sejam os conjuntos $\mathcal{I}$ de produtos (guarda-roupas, cômodas, criados-mudo, camas, etc.) e $\mathcal{P}$ das peças que compõem os produtos que devem ser produzidas de acordo com um conjunto $\mathcal{J}$ de padrões de corte, de modo a atender a demanda ao longo de um conjunto $\mathcal{T}$ de períodos do horizonte de planejamento. Esses conjuntos são indexados por $i, p, j$, e $t$, respectivamente. A Tabela 2.1 lista a notação usada na formulação matemática do problema.

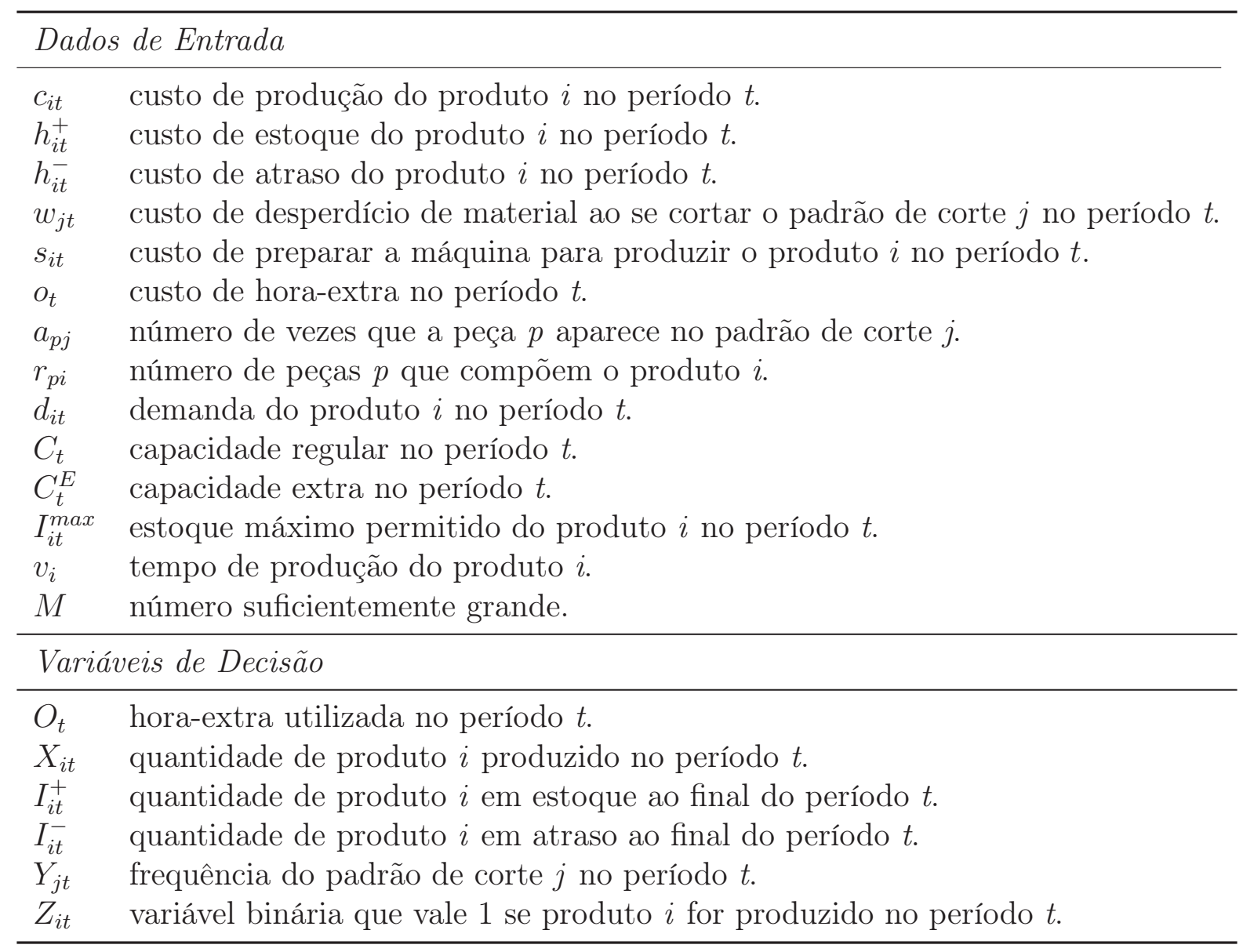

Tabela 2.1: Notação matemática do modelo matemático $C L C 1$.

O modelo matemático inteiro-misto a seguir objetiva determinar um plano de pro- 
dução de móveis a um custo mínimo, a partir do processamento de padrões de corte pré-selecionados, de modo a atender a demanda e satisfazer as restrições do processo produtivo. A seguir, a primeira formulação matemática do problema combinado de dimensionamento de lotes e corte de estoque $C L C 1$ é detalhada.

a) A função objetivo (2.1) consiste em minimizar o custo total de produção, estoque, atraso, preparação, perda de material e hora-extra. O primeiro termo em (2.1) é o custo total incorrido na produção, estoque, atraso e preparação. O segundo termo representa o custo de desperdício de material. O último termo é o custo devido à utilização de hora-extras.

Minimizar $\psi=\sum_{i \in \mathcal{I}} \sum_{t \in \mathcal{T}}\left(c_{i t} X_{i t}+h_{i t}^{+} I_{i t}^{+}+h_{i t}^{-} I_{i t}^{-}+s_{i t} Z_{i t}\right)+\sum_{j \in \mathcal{J}} \sum_{t \in \mathcal{T}} w_{j t} Y_{j t}+\sum_{t \in \mathcal{T}} o_{t} O_{t}$.

b) As restrições de balanceamento de estoque (2.2) fazem o balanço de toda a produção de móveis. Sem perda de generalidade, assume-se que os níveis de estoque e atraso no início do horizonte de planejamento são nulos., i.e., $I_{i 0}^{+}=I_{i 0}^{-}=0, i \in \mathcal{I}$. É possível ainda proibir o atraso no último período do horizonte de planejamento, impondo-se que $I_{i T}^{-}=0$.

$$
X_{i t}+I_{i, t-1}^{+}+I_{i t}^{-}=d_{i t}+I_{i t}^{+}+I_{i, t-1}^{-}, i \in \mathcal{I}, t \in \mathcal{T}
$$

c) As restrições de balanceamento de peças (2.3) forçam o balanço de peças necessárias para montar os produtos. Note que essas restrições de acoplamento são as únicas que integram ambas as decisões relacionadas ao dimensionamento de lotes $X_{i t}$ e ao corte de estoque $Y_{j t}$.

$$
\sum_{j \in \mathcal{J}} a_{p j} Y_{j t} \geq \sum_{i \in \mathcal{I}} r_{p i} X_{i t}, p \in \mathcal{P}, t \in \mathcal{T}
$$

d) As restrições de estoque (2.4) limitam o máximo estoque de móveis permitido e o mínimo estoque de móveis requerido. Nesse caso, o mínimo estoque é zero, mas quantidades positivas podem ser consideradas, dependendo da política da empresa (por exemplo, estoque de segurança).

$$
0 \leq I_{i t}^{+} \leq I_{i t}^{\max }, i \in \mathcal{I}, t \in \mathcal{T}
$$


e) As restrições de capacidade (2.5) indicam que o tempo total de produção dos móveis deve ser inferior à soma das capacidades regular e extra. Pode-se também adotar outra unidade de capacidade de produção, como a área total cortada em metros quadrados, por exemplo.

$$
\sum_{i \in \mathcal{I}} v_{i} X_{i t} \leq C_{t}+O_{t}, t \in \mathcal{T}
$$

f) As restrições de hora-extra (2.6) limitam a utilização da hora-extra em cada período. Pode-se considerar a capacidade extra como uma fração da capacidade regular, i.e., $C_{t}^{E}=f \cdot C_{t}, \operatorname{com} f \in[0,1]$.

$$
0 \leq O_{t} \leq C_{t}^{E}, t \in \mathcal{T}
$$

g) As restrições de preparação (2.7) indicam que pode haver produção do produto $i$ no período $t$ somente se a linha de produção estiver preparada, i.e., se a variável de preparação $Z_{i t}$ for 1 .

$$
X_{i t} \leq M Z_{i t}, i \in \mathcal{I}, t \in \mathcal{T} \text {. }
$$

h) O conjunto de restrições (2.8), (2.9), (2.10) e (2.11) refere-se ao domínio das variáveis de decisão.

$$
\begin{gathered}
X_{i t} \geq 0, i \in \mathcal{I}, t \in \mathcal{T} \\
I_{i t}^{-} \geq 0, i \in \mathcal{I}, t \in \mathcal{T} \\
Y_{j t} \geq 0, j \in \mathcal{J}, t \in \mathcal{T} \\
Z_{i t} \in\{0,1\}, i \in \mathcal{I}, t \in \mathcal{T} .
\end{gathered}
$$

Nesse trabalho, as variáveis relacionados aos padrões de corte, $Y_{j t}$, são considerados números não-negativos reais, mas é possível impor restrições de integralidade sobre as 
mesmas para se obter apenas quantidades inteiras. Vários trabalhos da literatura excluem a restrição de integralidade sobre tais variáveis na tentativa de obter um modelo de otimização mais tratável computacionalmente, como em Nonas e Thorstenson (2008) e Gramani et al. (2009).

Se a condição $I_{i T}^{-}=0, \forall i \in \mathcal{I}$ não for imposta, pode-se mostrar que o modelo $C L C 1$ é factível para qualquer exemplar, propriedade especialmente importante para assegurar a factibilidade dos modelos de otimização robusta.

Proposição 2.1 (Propriedade de factibilidade) Dado um exemplar do modelo CLC1 sempre existe uma solução factivel $\left(X^{\star}, I^{+\star}, I^{-\star}, Y^{\star}, Z^{\star}, O^{\star}\right)$.

Proof.: Considere a solução de produção nula $X_{i t}=0, I_{i t}^{+}=0, I_{i t}^{-}=\sum_{\tau=1}^{t} d_{i \tau}, Z_{i t}=0$, $Y_{j t}=0$ e $O_{t}=0$, para todo $i \in \mathcal{I}, j \in \mathcal{J}, t \in \mathcal{T}$. Para mostrar que tal solução é factível para $C L C$, é suficiente averiguar que as restrições (2.2)-(2.11) são trivialmente satisfeitas, com exceção das restrições de balanceamento de estoque. Tais restrições são satisfeitas porque há possibilidade de atrasar a produção dos produtos, inclusive no último período do horizonte de planejamento:

$$
\begin{aligned}
& I_{i 1}^{-}=d_{i 1}=I_{i 0}^{-}+d_{i 1}, i \in \mathcal{I}, \\
& I_{i 2}^{-}=d_{i 1}+d_{i 2}=I_{i 1}^{-}+d_{i 2}, i \in \mathcal{I}, \\
& I_{i 3}^{-}=d_{i 1}+d_{i 2}+d_{i 3}=I_{i 2}^{-}+d_{i 3}, i \in \mathcal{I}, \\
& \vdots \\
& I_{i T}^{-}=I_{i, T-1}^{-}+d_{i T}=\sum_{t \in \mathcal{T}} d_{i t}, i \in \mathcal{I} .
\end{aligned}
$$

Isso completa a prova.

Note que o modelo $C L C 1$ sem as variáveis de horas-extras e backlogging pode ser visto como o clássico problema de dimensionamento de lotes com restrição de capacidade (CLSP), que foi provado ser NP-difícil (Bitran e Yanasse, 1982). Considerando, adicionalmente, backlogging e a possibilidade de horas-extras, o número de variáveis aumenta, o que aumenta também a complexidade do problema. Portanto, conjectura-se que o modelo CLC1 seja, pelo menos, NP-difícil (Karimi et al., 2006).

A seguir, é discutido um outro modelo matemático para o problema combinado, motivado pelas observações em uma empresa moveleira típica do setor. 


\subsection{O Pólo Moveleiro e a Empresa Visitada}

O pólo moveleiro de Votuporanga é o segundo maior pólo moveleiro do Brasil, formado por $90 \%$ de micro e pequenas empresas, as quais produzem, essencialmente, móveis residenciais. Para confeccionar os móveis, são utilizadas, principalmente, chapas de madeira. A madeira pode ser ainda classificada como madeira maciça, painel de compensado, painel de aglomerado e painel de MDF (medium density fiberboard), que é produzido a partir de fibras de madeira aglutinadas com resinas sintéticas e possui consistência similar à da madeira. O MDF é a principal matéria-prima utilizada pela empresa de móveis visitada.

Os móveis de madeira produzidos pelo pólo moveleiro podem ser classificados em dois tipos básicos: retilíneos (lisos, com formas retas e simples) e torneados (possuem detalhes de acabamento mais sofisticados, com formas retas e curvilíneas). Convém ressaltar que a empresa moveleira visitada produz, principalmente, móveis retilíneos, como camas de solteiro e casal, cômodas, criados e guarda-roupas de 3, 4 e 5 portas. Esses móveis podem ser de várias cores diferentes, como mogno, marfim, cerejeira, tabaco, maple, entre muitas outras.

Como a empresa visitada é uma empresa de móveis de pequeno porte típica do setor, o seu processo de produção é similar ao processo de produção de outras plantas moveleiras de pequeno porte. Assim, infere-se que o modelo matemático aqui desenvolvido representa "indústrias moveleiras" de pequeno porte em geral, ou pode representar após pequenas modificações no modelo. Entretanto, alguns detalhes do processo de produção não foram considerados para fins de modelagem e algumas suposições foram adotadas. Outros detalhes do pólo moveleiro de Votuporanga e da empresa visitada podem ser vistos em Cavali (2004), Figueiredo (2006), Mosquera (2007) e dos Santos (2008). A partir de agora, a empresa visitada é designada como Fábrica X.

\subsubsection{Processo Produtivo na Indústria de Móveis}

O processo de produção de uma empresa moveleira de pequeno porte é composto, em geral, pelos estágios descritos a seguir.

- Setor de corte primário: este setor, em geral, é composto por poucos funcionários que operam uma máquina seccionadora, na qual os objetos são cortados nos itens que irão compor o móvel. As máquinas seccionadoras mais sofisticadas podem cortar uma quantidade de placas bem maior por unidade de tempo, além de produzirem também cortes mais trabalhados.

- Setor de corte secundário: é composto por um conjunto de serras menores, 
que são utilizadas para o processo de aparo das sobras, corte de itens que foram processados de forma agrupada, e ainda são usadas para cortar itens menores. Neste setor, também são feitos os vincos nas peças que são encaixadas em outras na montagem de um determinado móvel. Esse setor pode também ser usado para processar pedidos inesperados ao longo do horizonte de planejamento, de forma a não comprometer a produção da máquina seccionadora principal, por exemplo.

- Setor de furação: este setor é composto por furadeiras (manuais e automáticas), sendo que a maior carga de serviços é realizada pelas máquinas automáticas. Neste setor, são feitos os furos nos itens para o encaixe das peças e montagem do móvel. A maior parte das furadeiras utilizadas pode ser operada apenas por uma pessoa, e tem capacidade para furar peças com um tamanho limite de espessura e largura. Além disso, é comum furadeiras que só podem furar uma peça por vez.

- Setor de montagem: este setor é formado por diversas máquinas, como lixadora e prensa. Nele, as peças são montadas e preparadas para a pintura. É o setor que agrega o maior número de funcionários.

- Setor de pintura: é formado por um conjunto de máquinas que operam interligadas. O conjunto é operado por um número relativamente baixo de funcionários, em geral. O papel deles no processo de produção é preparar o conjunto, efetuando a limpeza das máquinas, a carga das tintas e o monitoramento do processo de pintura das peças do móvel.

- Setor de estocagem: é composto por máquinas que empacotam as peças e permitem que os kit's (formados por todas as peças que compõem um determinado móvel e seus respectivos acessórios, como pregos, parafusos, entre outros) sejam armazenados e empilhados no estoque, até a data de entrega.

A Figura 2.1 ilustra o processo produtivo de uma planta moveleira de pequeno porte.

$\mathrm{Na}$ indústria de móveis, a maneira específica de se cortar as placas é denominada padrão de corte bidimensional, pois apenas duas dimensões são relevantes para o processo de corte. Há vários fatores que concorrem na elaboração de um padrão de corte, como a facilidade de processamento do padrão e a tecnologia da empresa. No pólo moveleiro considerado, são utilizados padrões de corte guilhotinados e padrões de corte tabuleiros devido às restrições da máquina seccionadora que, quando acionada, corta a placa de uma extremidade a outra.

Definição 2.1 Um corte é dito guilhotinado ortogonal, ou simplesmente guilhotinado, quando é feito paralelamente a um dos lados do objeto retangular e o divide em dois novos 


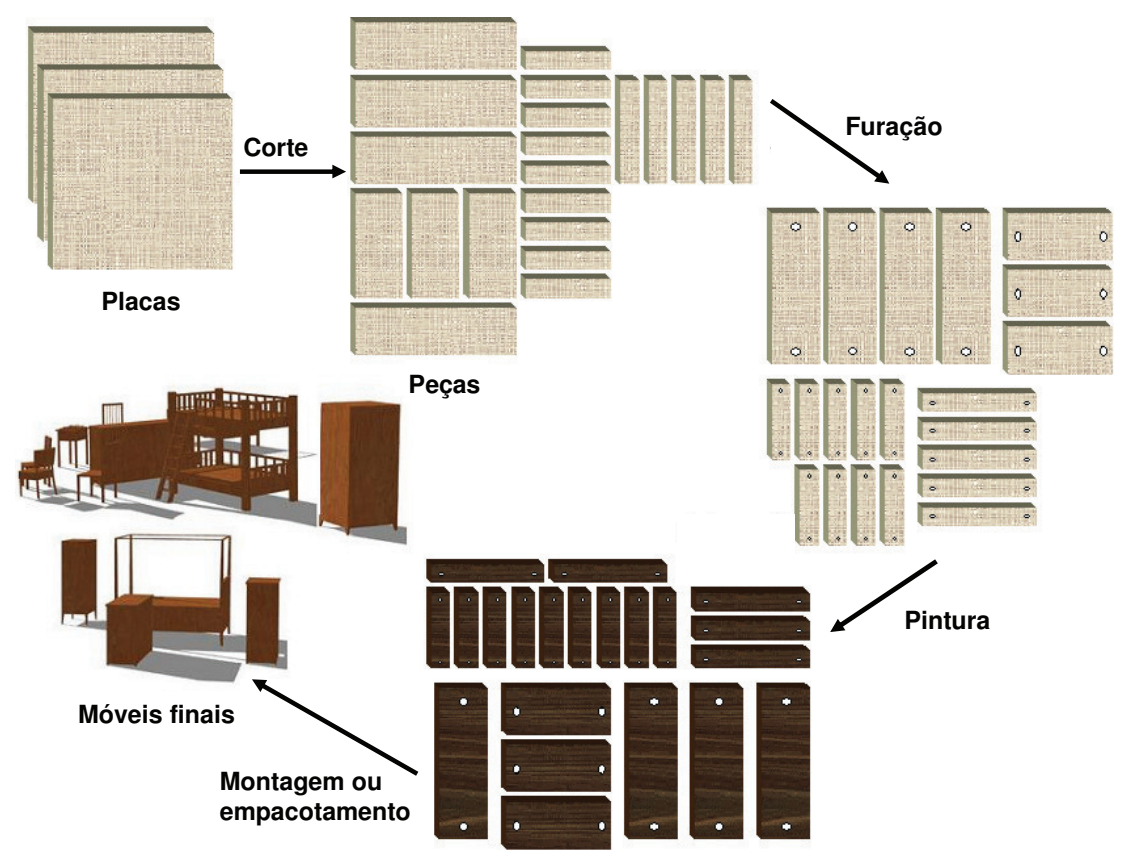

Figura 2.1: Processo produtivo simplificado numa indústria moveleira de pequeno porte.

retângulos. Um padrão de corte composto apenas por cortes guilhotinados é chamado de padrão de corte guilhotinado.

Os padrões de corte guilhotinados podem ser classificados de acordo com o número de estágios de corte para o obtenção dos itens que nele aparecem. O número de estágios de um padrão de corte é determinado pela quantidade de vezes que o objeto deve ser rotacionado de $90^{\circ}$ para que todos os itens sejam cortados. A Figura 2.2 ilustra um padrão de corte guilhotinado em 3-estágios, sendo que os cortes 1, 2 e 3 são feitos no primeiro estágio, seguidos dos cortes 4, 5 e 6 no segundo estágio e, por fim, os cortes 7 e 8 no terceiro estágio.

Definição 2.2 Um caso particular de padrão de corte 2-estágios é o chamado padrão de corte guilhotinado 1-grupo ou padrão de corte tabuleiro, em que os cortes do segundo estágio são realizados simultaneamente nas faixas resultantes do primeiro estágio (Gilmore e Gomory, 1965). Quando um padrão de corte é formado pela combinação de padrões de corte tabuleiros, este é chamado de padrão de corte guilhotinado n-grupo (Gilmore e Gomory, 1965; Yanasse e Morabito, 2006) ou padrão de corte tabuleiro composto (Figueiredo, 2006; Yanasse e Morabito, 2008). 

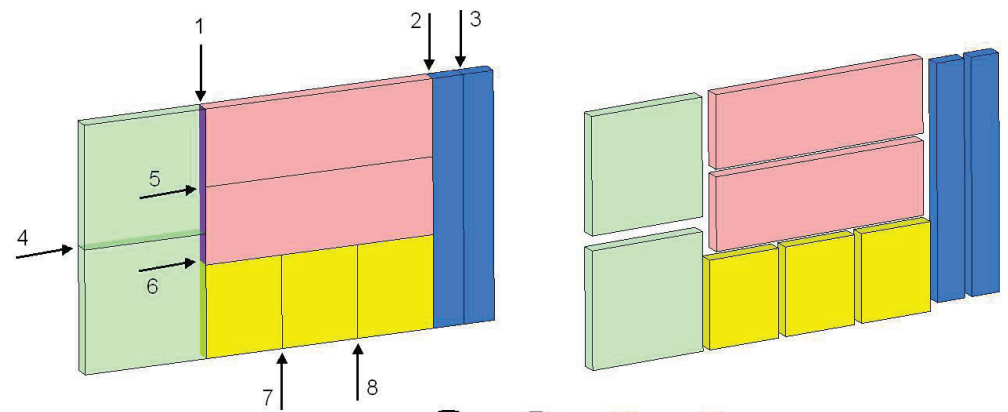

Figura 2.2: Exemplo de padrão de corte guilhotinado em 3-estágios. Fonte: Biehl (2008).

A Figura 2.3 mostra um exemplo de padrão de corte tabuleiro e um exemplo de padrão de corte tabuleiro composto. O leitor interessado em estudos sobre problemas de corte em indústrias moveleiras e correlatos pode consultar Yanasse et al. (1991), Carnieri et al. (1994), Morabito e Arenales (2000), Rangel e Figueiredo (2008), entre outros.

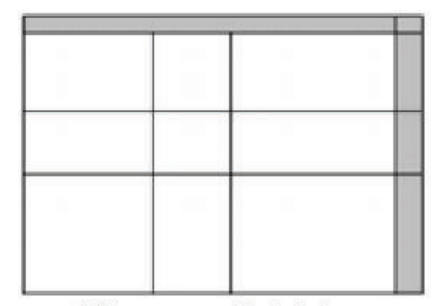

1-Grupo ou Tabuleiro

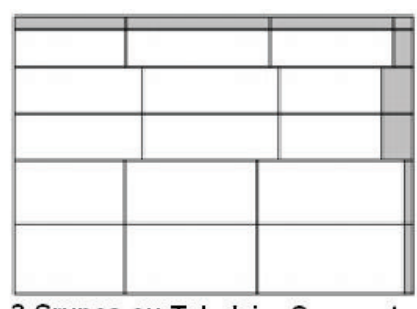

3-Grupos ou Tabuleiro Composto

Figura 2.3: Exemplo de padrão de corte tabuleiro. Fonte: Mosquera (2007).

\subsection{Modelo Matemático}

Antes de iniciar a descrição do modelo, convém salientar algumas suposições para fins de modelagem matemática:

1. Sem perda de generalidade, apenas os processos de corte e furação foram considerados no modelo, por constituírem os processos gargalos do sistema produtivo.

2. O modelo matemático admite que os dois estágios do processo produtivo (corte e furação) ocorrem dentro de cada período $t$. As capacidades desses dois processos são definidas considerando que todas as peças cortadas no período $t$ são furadas em seguida no mesmo período. Portanto, não há estoques intermediários de peças cortadas e não furadas do período $t$ para o período $t+1$.

3. Não há restrições sobre as quantidades de placas de MDF disponíveis para serem cortadas ou sobre as outras matérias-primas necessárias para montar o móvel. 
As suposições descritas anteriormente podem ser desconsideradas e o modelo matemático pode ser facilmente estendido para levar em consideração outros estágios de produção, assim como admitir custos e tempos de preparação relevantes para outros estágios. O modelo também pode ser facilmente estendido para incorporar restrições sobre as matérias-primas e considerar estoques intermediários entre os estágios de corte e furação. Considere, adicionalmente, a notação matemática apresentada na Tabela 2.2 do segundo modelo matemático $C L C 2$.

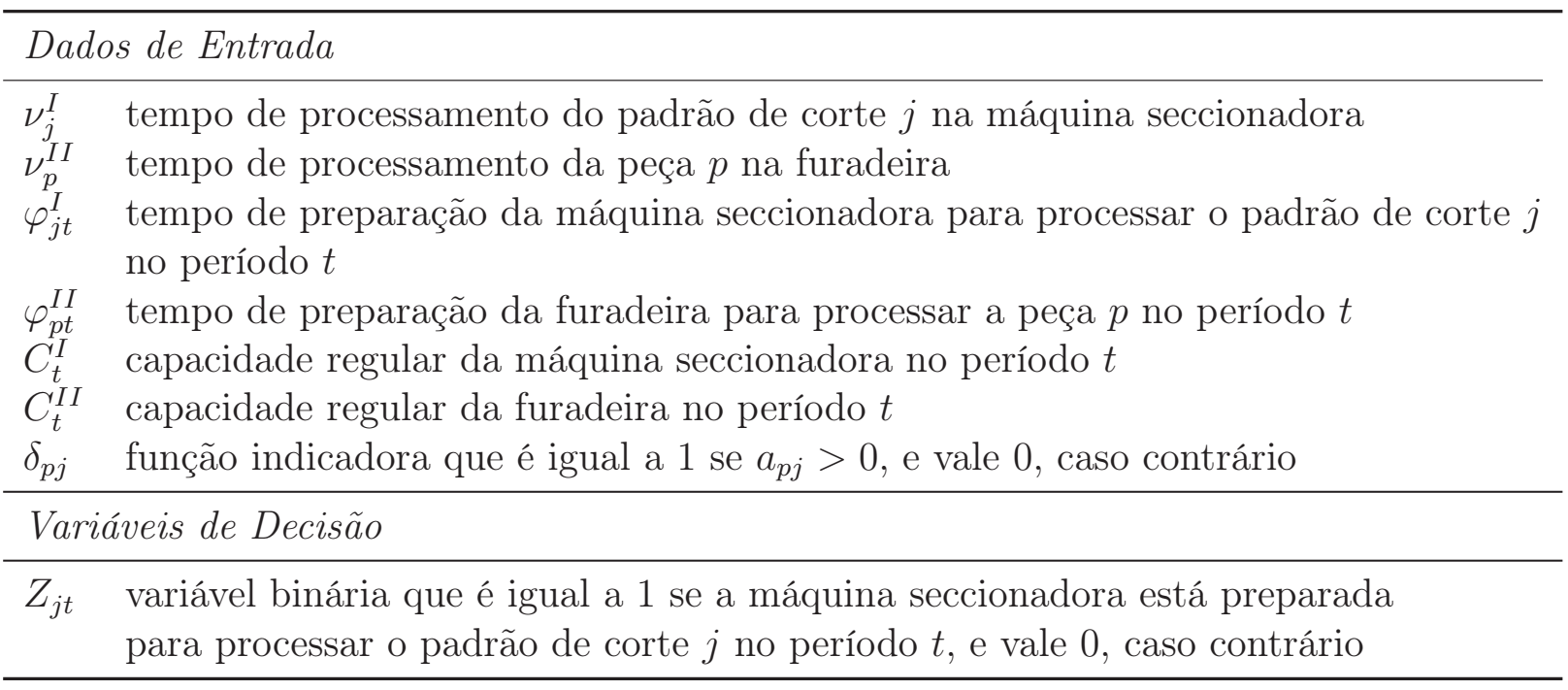

Tabela 2.2: Notação matemática adicional do modelo $C L C 2$.

a) A função objetivo (2.13) consiste em minimizar o custo total de produção, estoque, atraso, perda de material e hora-extra. Note que a função objetivo do modelo $C L C 2$ é similar à do modelo $C L C 1$, mas não são considerados os custos de preparação. As preparações das máquinas seccionadora e furadeira são penalizadas apenas nas restrições de capacidade.

$$
\text { Minimizar } \psi=\sum_{i \in \mathcal{I}} \sum_{t \in \mathcal{T}}\left(c_{i t} X_{i t}+h_{i t}^{+} I_{i t}^{+}+h_{i t}^{-} I_{i t}^{-}\right)+\sum_{j \in \mathcal{J}} \sum_{t \in \mathcal{T}} w_{j t} Y_{j t}+\sum_{t \in \mathcal{T}} o_{t} O_{t} .
$$

b) Restrições de balanceamento de estoque (2.2).

c) Restrições de balanceamento de peças (2.3).

d) Restrições de estoque (2.4).

e) Diferentemente da restrição de capacidade do modelo anterior (2.5) que considera o tempo total de produção dos móveis, as restrições (2.14) e (2.15) contemplam o 
tempo de preparação e processamento das operações de corte e de furação, respectivamente, as quais são os estágios gargalos da empresa visitada.

$$
\begin{gathered}
\sum_{j \in \mathcal{J}}\left(\nu_{j}^{I} Y_{j t}+\varphi_{j t}^{I} Z_{j t}\right) \leq C_{t}^{I}+O_{t}, t \in \mathcal{T} \\
\sum_{p \in \mathcal{P}} \sum_{j \in \mathcal{J}}\left(\nu_{p}^{I I} a_{p j} Y_{j t}+\varphi_{p t}^{I I} \delta_{p j} Z_{j t}\right) \leq C_{t}^{I I}+O_{t}, t \in \mathcal{T} .
\end{gathered}
$$

Para a diminuir o número de variáveis binárias desse modelo, escolheu-se utilizar a mesma variável de preparação $Z_{j t}$ para ambos os estágios de corte e furação, como pode ser visto nas restrições (2.14) e (2.15). As preparações de ambas as máquinas (seccionadora e furadeira) estão relacionadas pela função indicadora $\delta_{p j}$. Se $Z_{j t}=0$, então nenhuma peça é obtida pelo processamento do padrão de corte $j$ no período $t$ e, consequentemente, a furadeira não precisa ser preparada, o que reduz a expressão $\varphi_{p t}^{I I} \delta_{p j} Z_{j t}$ a zero. Por outro lado, quando $Z_{j t}=1$, é preciso analisar se o padrão de corte $j$ origina peças do tipo $p$ ou não. No primeiro caso, como $\delta_{p j}=1$, o termo referente ao tempo de preparação é ativado: considerando que $Z_{j t}=1$ e $\delta_{p j}=1$, a expressão $\varphi_{p t}^{I I} \delta_{p j} Z_{j t}$ é reduzida ao tempo de preparação $\varphi_{p t}^{I I}>0$. No segundo caso, $\delta_{p j}=0$ e a expressão referente ao tempo de preparação é desativada.

f) Restrições de hora-extra (2.6).

g) As restrições de preparação (2.16) indicam se a máquina seccionadora está preparada para processar o $j$-ésimo padrão de corte no período $t$. Se estiver, limita-se o número de padrões de corte a $Q$ unidades.

$$
Y_{j t} \leq M Z_{j t}, j \in \mathcal{J}, t \in \mathcal{T}
$$

h) Restrições de domínio das variáveis de decisão (2.8), (2.9), (2.10) e (2.17):

$$
Z_{j t} \in\{0,1\}, j \in \mathcal{J}, t \in \mathcal{T}
$$

Assim como no modelo anterior, pode-se mostrar que se a condição $I_{i T}^{-}=0, \forall i \in \mathcal{I}$ não for imposta, então todo exemplar do modelo $C L C 2$ é factível. A prova é similar à prova anterior da Seção 2.1. Além disso, conjectura-se que o modelo CLC2 também seja 
NP-difícil, uma vez que, além da restrição de capacidade similar ao clássico CLSP, há tempos de preparação que também consomem capacidade (Bitran e Yanasse, 1982; Maes et al., 1991).

A Tabela 2.3 compara os modelos $C L C 1$ e $C L C 2$ em termos dos números de variáveis e restrições. Considere $|\mathcal{I}|=I,|\mathcal{T}|=T,|\mathcal{J}|=J$ e $|\mathcal{P}|=P$. Em geral, o número de padrões de corte $J$ é muito grande e, por essa razão, $I<<J$. Sendo assim, espera-se que o modelo $C L C 2$ seja mais difícil de ser resolvido do que o modelo $C L C 1$, especialmente devido ao maior número de variáveis binárias do segundo.

\begin{tabular}{llll}
\hline \multirow{2}{*}{ Modelo } & Restrições & \multicolumn{2}{c}{ Variáveis de Decisão } \\
\cline { 2 - 4 } Contínuas & Binárias \\
\hline CLC1 & $2 I T+P T+T$ & $3 I T+J T+T$ & $I T$ \\
& $I T+P T+2 T+J T$ & $3 I T+J T+T$ & $J T$ \\
\hline
\end{tabular}

Tabela 2.3: Comparação entre os modelos $C L C 1$ e CLC2 em termos de número de restrições, número de variáveis contínuas e número de variáveis binárias.

\subsection{Heurísticas Relax-and-Fix}

$\mathrm{Na}$ seção anterior, foram formulados dois modelos matemáticos para o problema combinado de dimensionamento de lotes e corte de estoque. Experimentos computacionais preliminares mostraram que, embora o modelo CLC1 seja NP-difícil, exemplares reais do primeiro modelo são resolvidos na otimalidade num tempo computacional razoável na prática, considerando o conjunto de padrões de corte fornecidos pela empresa moveleira estudada. ${ }^{1}$ Entretanto, o modelo CLC2 não é resolvido com tanta facilidade utilizando pacotes de otimização sofisticados (considerando o mesmo conjunto de padrões de corte), o que motivou a investigação de algumas estratégias alternativas de solução. Convém ressaltar que a empresa estudada mantém um conjunto de padrões de corte para possível uso na máquina seccionadora, que satisfazem diversas restrições envolvidas neste equipamento, mas é possível também gerar outros padrões de corte factíveis para o equipamento, inclusive integrando as decisões de dimensionamento de lotes ao problema de geração de padrões (Ghidini et al., 2007; Ghidini, 2007; Gramani et al., 2009). Nesse caso, entretanto, ambos os problemas $C L C 1$ e $C L C 2$ seriam mais difíceis de serem resolvidos.

Assim, nessa seção, são propostas heurísticas do tipo relax-and-fix (RF) como al-

\footnotetext{
${ }^{1}$ No Capítulo 4, são apresentados estudos computacionais do modelo nominal (determinístico) e de algumas versões robustas desse modelo, mostrando que, de fato, é possível resolver exemplares práticos na otimalidade. Para os casos em que os padrões de corte não são dados de entrada do problema, Gramani et al. (2009) utilizam uma heurística baseada em relaxação lagrangiana e geração de colunas para resolvê-lo.
} 
ternativa de resolução de exemplares do modelo $C L C$ 2. A principal motivação em adotar esse método é a facilidade como é implementado em muitos pacotes de otimização e a esperança de gerar bons limitantes superiores para o valor da solução ótima em um tempo relativamente baixo. Além dessas estratégias, outras heurísticas baseadas em programação matemáticas podem ser investigadas, conforme se discute ao final do capítulo, na Seção 2.7 .

De forma geral, heurísticas Relax-and-Fix decompõem problemas grandes em vários problemas menores, particionando o conjunto de variáveis inteiras em $n$ subconjuntos disjuntos $S_{i}, i=1, \cdots, n$. A cada iteração, somente as variáveis inteiras em $S_{i}$ (consideradas mais "importantes") são definidas como inteiras, enquanto as variáveis inteiras dos outros subconjuntos (menos "importantes") são relaxadas e definidas como contínuas. O subproblema resultante é então resolvido. Posteriormente, as variáveis inteiras do submodelo são fixadas nos seus valores atuais e o processo é repetido para todos os subconjuntos restantes. Se o último subproblema não possuir solução factível, então a heurística falha; caso contrário, o procedimento fornece uma solução relax-and-fix. Note que essa heurística gera problemas inteiros-mistos menores porque a quantidade de variáveis inteiras diminui com o procedimento de fixação. De uma maneira bastante simplificada, os passos de uma heurística RF são:

Passo 1. Relaxe a condição de integralidade das variáveis menos importantes.

Passo 2. Resolva o problema inteiro-misto resultante e fixe as variáveis inteiras mais importantes no seu valor atual.

Passo 3. Resolva novamente o problema inteiro-misto resultante com as variáveis fixadas. Se todas as variáveis forem inteiras, pare. Senão, volte ao passo 1.

Os subconjuntos disjuntos podem ser baseados na decomposição do horizonte de planejamento (ou decomposição por período), máquina, produto, estágio de produção, entre outros. Por exemplo, Ferreira et al. (2009) exploraram diversas estratégias de partição do conjunto de variáveis binárias para resolver um problema integrado de dimensionamento de lotes e programação da produção numa empresa produtora de bebidas.

No presente trabalho, foram estudadas heurísticas relax-and-fix baseadas na decomposição do horizonte de planejamento ou decomposição por período - baseadas no trabalho de Absi (2005) - cuja técnica permite manter a integralidade das variáveis de preparação $\left(Z_{j t}\right)$ de um período fixo do horizonte de planejamento, enquanto as variáveis de preparação de outros períodos são relaxadas. Sendo assim, a cada iteração do método RF, o horizonte de planejamento é decomposto em três partes: horizonte congelado, formado pelas variáveis já fixadas de iterações anteriores; horizonte de decisão, seção do horizonte de planejamento na qual as variáveis de decisão mantém a sua condição de in- 
tegralidade; e horizonte aproximado, no qual as variáveis de decisão têm a sua condição de integralidade relaxada. A Figura 2.4 ilustra essa decomposição.

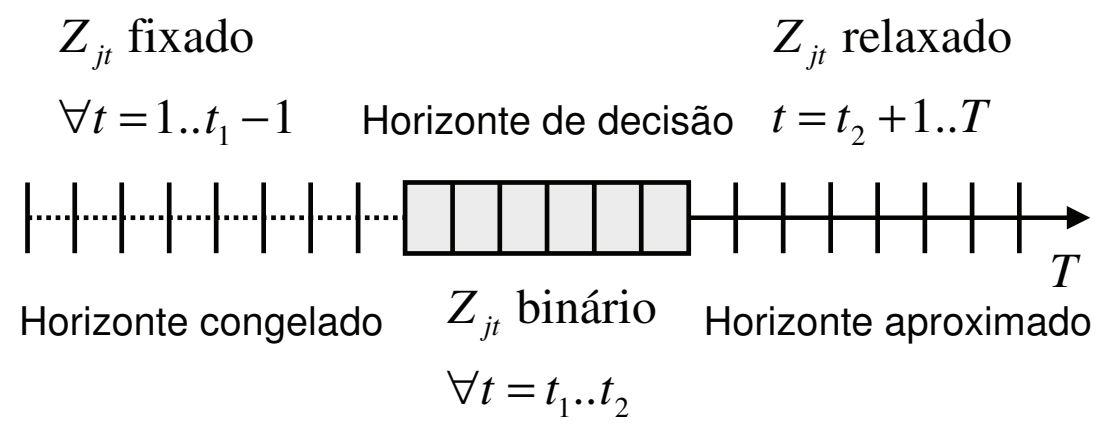

Figura 2.4: Decomposição por período.

Além do tipo de particionamento das variáveis de decisão, é importante definir outros parâmetros relacionados à heurística $\mathrm{RF}$, a saber:

i. $\ell_{k}$ : tamanho do horizonte de decisão na iteração $k$ do algoritmo, sendo $\ell_{k}>0$.

ii. $\ell_{k}^{\prime}$ : quantidade de períodos sobrepostos (overlapping) entre o horizonte de decisão da iteração $k-1$ e $k$, sendo $\ell_{k}^{\prime}<\ell_{k}$.

iii. $O p t_{k}$ : gap de otimalidade mínimo exigido na iteração $k$ do algoritmo.

iv. Time $_{k}$ : tempo de execução limite da iteração $k$ do algoritmo.

Note que os dois primeiros parâmetros estão relacionados à decomposição do horizonte de planejamento e os dois últimos são utilizados como critério de parada do algoritmo branch-and-cut $(B \& C)$.

O princípio da heurística RF proposta é simples. Na iteração inicial, determina-se $\ell_{1}$, restringe-se a condição de integralidade das variáveis binárias $Z_{j t}$ para todo $j \in \mathcal{J}$ e para uma intervalo do índice $t$, como, por exemplo, $t=1, \cdots, t_{1}^{2}$ (de modo que $t_{1}^{2}-1=\ell_{1}$. Nesse caso, $t_{1}^{2}$ refere-se ao segundo instante de tempo da primeira iteração), relaxa-se a integralidade das variáveis para os outros valores de $t$ e resolve-se o problema resultante pelo algoritmo B\&B até que algum critério de parada seja verificado. A partir da iteração seguinte, além de todos os passos anteriores, é necessário ainda escolher $\ell_{k}^{\prime}$. Na última iteração, se o subproblema for factível, todas as variáveis $Z_{j t}$ serão binárias e, portanto, também factíveis para o problema original. Nesse caso, a heurística RF é progressiva no tempo, pois tem início no primeiro período do horizonte de planejamento e termina no último, como ilustra a Figura 2.5. 
Caso o funcionamento da heurística RF fosse de trás para a frente, na iteração 1 , o ponto de início seria $t_{1}^{1}=T$ (i.e., o primeiro instante da primeira iteração) e o ponto de término da iteração $K$ seria $t_{K}^{2}=1$, e a heurística $R F$ seria chamada regressiva no tempo. Nesse trabalho, ambas as heurísticas progressiva e regressiva foram implementadas e testadas.

A inclusão de períodos sobrepostos $\left(\ell_{k+1}^{\prime}>0\right)$ é uma tentativa de tornar o método menos míope, pois parte da decisão feita na iteração $k$ pode ser reavaliada na iteração $k+1$, e melhores planos de produção podem ser obtidos. Nesse caso, por exemplo, é possível que a reavaliação da decisão permita antecipar a produção de uma demanda futura, evitando que a mesma seja postergada para os últimos períodos e, ocasionalmente, perdida por falta de capacidade. Se $\ell_{k}=\ell$ e $\ell_{k}^{\prime}=\ell^{\prime}$ para todo $k$, então o número de iterações da heurística RF será $K=\left[(T-\ell) /\left(\ell-\ell^{\prime}\right)\right]+1$. No pior caso, o número de iterações é dado pelo número de períodos do horizonte de planejamento, $T$.

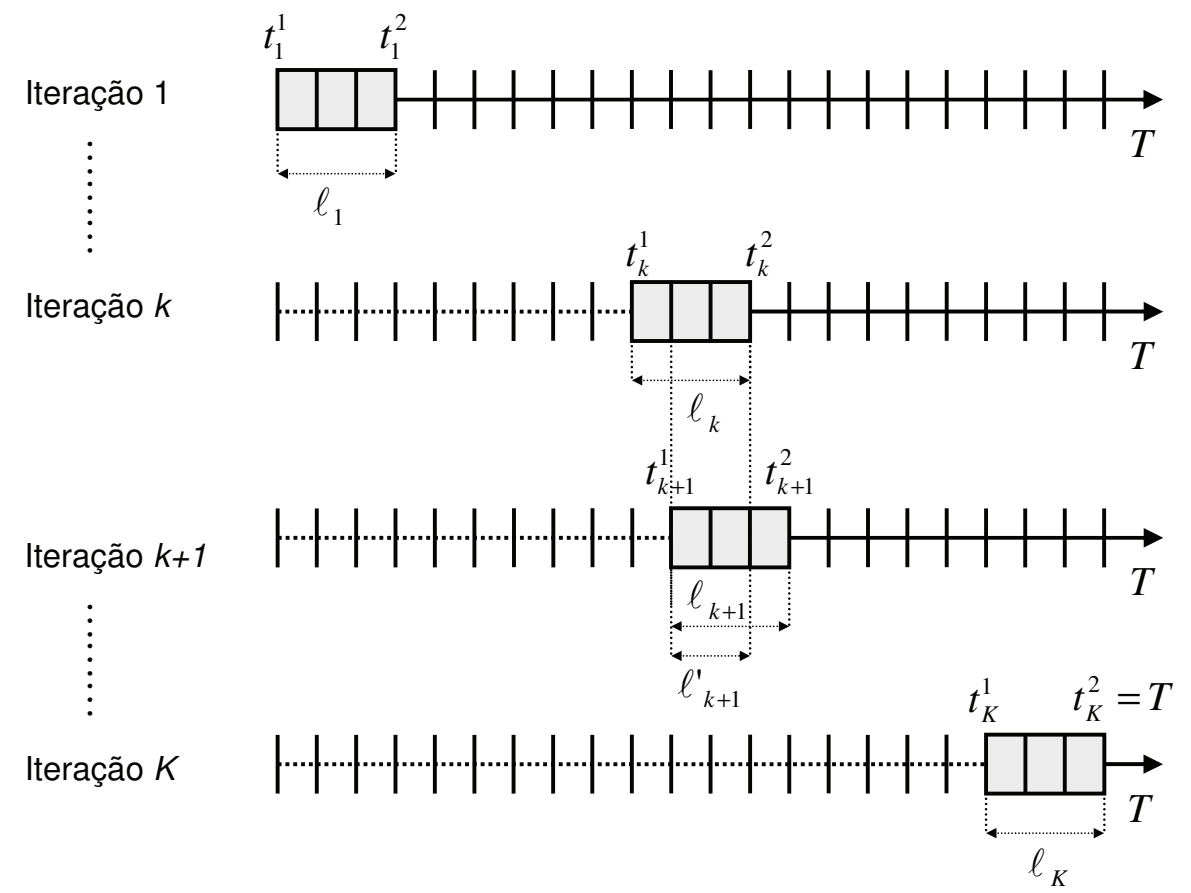

Figura 2.5: Heurística Relax-and-Fix progressiva no tempo.

\subsection{Resultados Computacionais}

Nessa seção, são apresentados os resultados computacionais referentes às estratégias de solução da seção anterior. Os modelos e algoritmos foram codificados no Sistema de 
Tese de Doutorado

Modelagem Algébrica GAMS (McCarl et al., 2010) e resolvido pelo software ILOG-Cplex 11.0 (ILOG, 2008), usando-se os valores default para todos os parâmetros do CPLEX. Os experimentos foram executados num notebook Core 2 Duo 4, 4.0 GB de memória RAM, 2.0 $\mathrm{GHz}$, sob a plataforma Windows VISTA. Antes de iniciar com os métodos propriamente ditos, são apresentados os dados extraídos da Fábrica X, que foram utilizados para testar os modelos e ainda serviram de base para gerar outros exemplares.

\subsubsection{Dados de Entrada}

Dados coletados. Os dados coletados na Fábrica X consistem de 3 famílias de produtos: guarda-roupas de 5 portas (a5p), cômodas (cmd) e criados-mudos (crd), os quais são produzidos a partir do corte de placas de MDF que são adquiridas dos varejistas em duas dimensões 2.75 x $1.83 \mathrm{~m}$ e 2.75 x $1.85 \mathrm{~m}$ e em 6 espessuras distintas: 3, 9, 12, 15, 20 e 25 mm. Os produtos são formados por um total de 49 peças retangulares. Os detalhes das peças (comprimento, largura e espessura) e as necessidades dessas peças em cada produto são mostrados na Tabela A.2. As Tabelas A.5-A.10 mostram os 81 padrões de corte disponibilizados pela Fábrica X, os quais são frequentemente utilizados em seu processo produtivo. Outros detalhes relativos aos padrões de corte são ilustrados na Tabela A.1. Convém ressaltar que cada padrão de corte está associado a um tipo de placa diferente (dimensão e espessura). As quantidades máximas que podem ser estocadas $\left(I_{i t}^{\max }\right)$ de cada produto, em função de limitações de espaço na área de estocagem da Fábrica X, e também de restrições mercadológicas, são mostradas na Tabela A.3. Os custos de produção, venda e aquisição das placas também foram disponibilizados; entretanto, apenas os custos de aquisição das placas são explicitados nessa tese para proteger os interesses da Fábrica X (veja Tabela A.1).

Dados estimados com base nas visitas realizadas na Fábrica $X$. Os tempos de corte da placa $j\left(v_{j}\right)$ encontram-se na Tabela A.1 e os tempos de furação da peça $p$ foram considerados 2,5 s. Os tempos de preparação de ambos os estágios foram considerados 600 e $900 \mathrm{~s}$, respectivamente. As capacidades nominais de máquinas e equipamentos foram estimadas com base em uma jornada de trabalho de 8,8h/dia, enquanto as capacidades extras, 4,4h/dia. Nesse trabalho, considerou-se um horizonte de planejamento dividido em períodos semanais de 5 dias de jornada de trabalho. As demandas nominais dos produtos ao longo do horizonte de planejamento $\left(d_{i t}\right)$ foram geradas segundo uma distribuição uniforme (inteira) entre 1 e 200. Um exemplar dessa demanda é ilustrado na Tabela A.3. Convém ressaltar que as estimativas da demanda foram baseadas em duas carteiras de pedidos da Fábrica X, referentes a períodos de alta e de baixa demanda. Os custos de estocagem, perda de material, hora-extra e preparação foram estimados com base em informações fornecidas pelo gerente de produção da Fábrica X e considerados em unidades 
monetárias (u.m.). Do custo de produção fornecido, subtraiu-se o custo das placas para não contabilizá-lo duas vezes, obtendo-se o parâmetro $c_{i t}$. O custo de estoque $\left(h_{i t}^{+}\right)$foi considerado $5 \%$ do custo de produção total (custo original com o custo das placas). O custo de atraso $\left(h_{i t}^{-}\right)$foi considerado como o próprio preço de venda (venda perdida), ou seja, como uma grande penalização. O custo de preparação do modelo (quando adotado) foi considerado, arbitrariamente, igual a 100 u.m. O custo de desperdício de material foi considerado como o próprio valor de aquisição da placa. Finalmente, o custo de horasextras $\left(o_{t}\right)$ foi calculado com base no gasto com horas-extras dos funcionários, admitindose que tais horas são $150 \%$ mais caras do que as horas regulares. Todos os custos foram considerados não-estacionários, adotando-se uma taxa de $1 \%$ ao mês.

Outras três famílias de produtos foram criadas para testar exemplares um pouco maiores. Para isso, foram geradas matrizes binárias com densidades 60, 40 e 30\%. Em seguida, para todas as posições não-nulas, os parâmetros $r_{p i}(\forall p \in \mathcal{P})$ foram gerados aleatoriamente segundo uma distribuição uniforme inteira nos intervalos $[1,10]$, [1,4] e [1,3], de maneira que os produtos 4 (a5p-1), 5 (cmd-1) e 6 (crd-1) fossem semelhantes aos móveis reais a5p, cmd e crd, respectivamente. Por simplicidade, foram consideradas as mesmas peças $p$ para ser possível utilizar os mesmos padrões de corte fornecidos pela Fábrica X. Todos os parâmetros relacionados aos novos produtos (custos diversos e limites de estoque) foram gerados por uma distribuição uniforme (contínua ou inteira, dependendo do caso) utilizando os dados dos produtos reais similares.

\subsubsection{Exemplares Práticos}

Nessa subseção, são detalhadas as soluções de quatro exemplares do modelo CLC2 advindos da Fábrica X. O primeiro exemplar é constituído por 3 produtos e 8 períodos; o segundo exemplar é composto por 6 produtos e 16 períodos; o terceiro exemplar também tem 6 produtos e 16 períodos, mas o custo de preparação é igual a 100 u.m. Finalmente, o quarto exemplar consiste de 6 produtos, 16 períodos, custo de preparação igual a 100 u.m. e capacidades $30 \%$ menores. As demandas e estoques máximos permitidos encontram-se nas Tabelas A.3 e A.4

Exemplar 1. Após 3,67 segundos de execução no CPLEX 11.0, foi alcançada e provada a solução ótima do primeiro exemplar. O custo total obtido foi 189952 u.m., sendo que os custos de produção, estocagem e quantidade de placas representam 53,9, 0,01 e 46,1\% do custo total esperado, respectivamente. Praticamente, não houve antecipação na produção dos produtos: estocou-se somente 5 unidades do produto 3 entre os períodos 1 e 2 . Não houve atraso na produção e não foram utilizadas horas-extras. Totalizou-se a produção de 2941 produtos com o corte de 6739 placas, de acordo com 47 padrões de corte distintos 
Tese de Doutorado

(dentre 81 disponíveis) e 366 preparações de máquinas. O padrão de corte 43 (menor custo de desperdício) foi o mais utilizado: cerca de 282 vezes.

Exemplar 2. Após o limite de tempo imposto de 4200 segundos de execução, foi alcançada uma solução subótima do segundo exemplar, com um gap de otimalidade (em relação ao melhor limitante inferior encontrado) igual a $0,11 \%$. O custo total obtido foi 813816 u.m., sendo que os custos de produção, estocagem, quantidade de placas e horas-extras representam 48,5, 0,02, 48,8 e 2,7\% do custo total esperado, respectivamente. Houve antecipação na produção de apenas 30 produtos (dentre os produtos 1, 2, 3 e 6). Não houve atraso na produção, mas foram utilizadas quase 103 horas, além da capacidade nominal. Totalizou-se a produção de 10074 produtos com o corte de 31583 placas, de acordo com 67 padrões de corte distintos e 729 preparações de máquinas. O padrão de corte 43 foi, novamente, o mais utilizado: cerca de 344 vezes.

Exemplar 3. Esse exemplar foi executado até o limite de tempo de 4200 segundos e obteve-se uma solução subótima com um gap de otimalidade igual a 1,25\%, que pode ser considerado relativamente pequeno. O custo total obtido foi 8828675 u.m., sendo que os custos de produção, estocagem, quantidade de placas, preparação e horas-extras representam 44,7, 0,18, 45,2, 7,3 e 2,62\% do custo total esperado, respectivamente. Houve antecipação na produção de 409 produtos. Não houve atraso na produção, mas foram utilizadas quase 107 horas, além da capacidade nominal. Totalizou-se a produção de 10074 produtos com o corte de 31758 placas, de acordo com 67 padrões de corte distintos e 646 preparações de máquinas. O padrão de corte 43 foi utilizado na mesma frequência: cerca de 344 vezes.

Exemplar 4. Executando esse exemplar até o limite de 4200 segundos, obteve-se uma solução factível com um gap igual a $61,2 \%$, ou seja, razoavelmente grande. O custo total obtido foi 3459608 u.m., sendo que os custos de produção, estocagem, atraso, quantidade de placas, preparação e horas-extras representam 11, 0,88, 73, 12, 1,5 e 1,4\% do custo total esperado, respectivamente. Houve antecipação na produção de 3465 produtos. Houve atraso na produção de mais de 6200 produtos (mais de 50\% de toda a demanda), e ainda foram utilizadas 231 horas-extras, o que representa 100\% de utilização das mesmas. Totalizou-se a produção de 9818 produtos com o corte de 34516 placas, de acordo com 72 padrões de corte distintos e 490 preparações de máquinas. O padrão de corte 43 foi utilizado na mesma frequência: cerca de 344 vezes. Resolvendo-se esse exemplar por mais 10200 segundos (quase 3 horas), o custo diminuiu 8,25\%, obtendo-se o gap 57,4\%, ainda razoavelmente grande. Em relação à solução, as maiores diferenças foram observadas nos volumes de estoque e no número de atrasos, que diminuiram 29 e 20\%, respectivamente, enquanto o número de preparações aumentou $8 \%$. 
Os resultados desses exemplares mostram que, como esperado, o aumento na quantidade de períodos e produtos torna o problema mais difícil de ser resolvido, assim como a adição de custos de preparação e a redução das capacidades. Note que dobrando-se o número de produtos e períodos no exemplar 2, não foi possível provar a otimalidade da solução em 4200 segundos, diferentemente do exemplar 1, que levou poucos segundos para ser resolvido. Pela resolução do exemplar 3, a inclusão de custos de preparação tornou o problema ainda mais difícil de ser resolvido: o gap passou de 0,11\% para 1,25\%. Quando os custos de preparação são considerados, a solução teve um comportamento esperado: o número de preparações reduziu cerca de $13 \%$ e mais horas-extras foram necessárias. Combinando o aumento de produtos e períodos, custos de preparação e redução das capacidades, o problema resultante torna-se bem mais difícil de ser resolvido. Em 4 horas de execução, obteve-se uma solução factível com um gap elevado. Porém, a solução parece ser plausível: como a capacidade foi reduzida em 30\%, tentou-se aproveitar mais as capacidades dos períodos (inclusive a capacidade extra) com a maior antecipação de produção, ao mesmpo tempo em que grande parte da demanda sofreu atrasos.

Na próxima subseção, são estudadas 6 classes de exemplares para analisar melhor o comportamento do modelo CLC2 em diferentes situações, assim como testar a eficiência do algoritmo branch-and-cut do CPLEX 11.0 e das heurísticas relax-and-fix para tais exemplares.

\subsubsection{Resultados com Exemplares Gerados Aleatoriamente}

Nessa subseção, são estudados outros exemplares baseados nos dados da Fábrica X, os quais foram gerados aleatoriamente, conforme descrito na Seção 2.5.1. Além disso, em todos os exemplares foram mantidos os mesmos custos e tempos de processamento, ao passo que os tempos de preparação foram gerados aleatoriamente entre 70 e $130 \%$ do valor médio estimado (600 e 900 segundos para a seccionadora e a furadeira, respectivamente). Os objetivos de resolver outros exemplares de problemas são, basicamente, dois: (i) analisar o desempenho e comportamento de exemplares modificados; e (ii) testar a eficiência das três estratégias de obtenção de limitantes superiores, branch-and-cut do CPLEX 11.0 (designada de estratégia MIP), heurística relax-and-fix progressiva (RFP) e heurística relax-and-fix regressiva (RFR) no tempo.

Assim, foram geradas 6 classes de exemplos com 10 exemplares cada. As características de cada classe são exemplificadas pela quantidade de produtos, períodos, custo de preparação e se as capacidades são normais ou apertadas, como apresentado na Tabela 2.4. Por exemplo, a primeira classe 3/8/0/N é composta de exemplares com 3 produtos, 8 períodos, custo de preparação nulo e capacidade normal (N). Já a sexta classe 6/16/100/A70, 
Tese de Doutorado

apresenta exemplares com 6 produtos, 16 períodos, custos de preparação de 100 u.m. e capacidades apertadas ( $70 \%$ da capacidade original). Todos os exemplares foram resolvidos pelas três estratégias, considerando-se os parâmetros default do CPLEX 11.0. O tempo limite de execução foi considerado 4200 segundos por problema inteiro-misto.

\begin{tabular}{ccl}
\hline Classe de Exemplos & Exemplares & Característica \\
\hline 1 & $1-10$ & $3 / 8 / 0 / \mathrm{N}$ \\
2 & $11-20$ & $6 / 8 / 0 / \mathrm{N}$ \\
3 & $21-30$ & $3 / 16 / 0 / \mathrm{N}$ \\
4 & $31-40$ & $6 / 16 / 0 / \mathrm{N}$ \\
5 & $41-50$ & $6 / 16 / 100 / \mathrm{N}$ \\
6 & $51-60$ & $6 / 16 / 100 / \mathrm{A} 70$ \\
\hline
\end{tabular}

Tabela 2.4: Classes de exemplos.

Parâmetros das heuristicas relax-and-fix. As heurísticas relax-and-fix propostas têm vários parâmetros que podem concorrer para o seu sucesso e/ou fracasso (número de períodos justapostos, tempo de cada iteração, entre outros), de modo que uma análise muito abrangente poderia levar um tempo impraticável para ser realizada. Por essa razão, foram realizadas análises empíricas iniciais (nessas análises, foram gerados e testados 120 exemplares de acordo com os dados descritos, em que se variou o número de produtos de $3-6$, o número de períodos de $8-16$, os custos de preparação $0-100$, e a capacidade normal e $70 \%$ da normal) para escolher tais parâmetros. Os resultados mais promissores (em termos dos valores da função objetivo e tempos de execução) foram obtidos com os seguintes parâmetros: $\ell_{k}=3, \ell_{k}^{\prime}=2$, Opt $_{k}=1 \%$, e Time $_{k}=300$ ou $700 \mathrm{~s}$, para os exemplares com 16 ou 8 períodos, respectivamente, para toda iteração $k$. Observou-se que permitir o gap de $1 \%$ nos dois métodos diminui sensivelmente o tempo total de iteração, especialmente na estratégia progressiva, enquanto a função objetivo é apenas marginalmente afetada.

Comportamento das soluções. A Tabela 2.5 ilustra as soluções médias geradas pelas três estratégias nas 6 classes de exemplos, em relação ao (a) custo total ótimo; (b) a variação (\%) do custo das heurísticas RFP e RFR em relação ao custo fornecido pela estratégia MIP; (c) o volume de produção; (d) o nível de estoque; (e) o nível de atraso; (f) a quantidade de placas utilizadas; (g) o número de preparações; (h) o número de padrões de corte distintos usados; e (i) as horas-extras usadas. Os custos totais e os níveis de produção, estoque, atraso, hora-extra, quantidade de placas e preparação tiveram um comportamento esperado em todas as classes. O aumento no volume de produção e a quantidade de placas cortadas acompanharam o aumento na quantidade de produtos e períodos. Níveis mais elevados de estoque foram observados nas classes com mais incentivo de estocar, seja pelo aumento na quantidade de produtos e períodos, quanto 
pela consideração de custos de preparação ou mesmo devido à redução de capacidade, fatores que ocasionam um melhor aproveitamento da capacidade de cada período a fim de evitar atrasos futuros. Praticamente, só houve atraso na produção dos exemplares pertencentes à classe 6 , devido à redução de capacidade. Nesses casos, foram utilizadas mais horas-extras do que nas outras classes, chegando a quase $85 \%$ de utilização. Com a adição de custos de preparação, o número de preparações diminuiu cerca de $15 \%$ (compare as classes 4 e 5, por exemplo). Acredita-se que a variedade de padrões de corte utilizados aumenta com a quantidade de produtos (peças), conforme indicado pela comparação entre as classes 1 e 2 . Observe que as variações positivas dos custos indicam que as estratégias relax-and-fix resultam em custos totais melhores do que os obtidos pelo método MIP; isso ocorre especialmente nos exemplares mais difíceis da classe 6. Entretanto, nas outras classes, as variações são baixas, e não chegam a $1 \%$.

Analisando-se a execução do algoritmo branch-and-cut do CPLEX 11.0, notou-se que, em geral, gaps relativamente justos são atingidos em poucos segundos na maioria dos exemplares, mas o certificado de otimalidade pode demorar minutos ou mesmo horas, dependendo do exemplar. Ainda, é possível inferir pela Tabela 2.7 que o aumento na quantidade de produtos ou de períodos torna o problema mais difícil de ser resolvido, como era de se esperar. Entretanto, a adição de custos de preparação parece ter um impacto maior no nível de dificuldade: compare os tempos de execução e os gaps de otimalidade das classes 4 e 5. A redução da capacidade também tem influência na dificuldade do problema, principalmente considerando uma capacidade já relativamente apertada (na situação com mais produtos).

Desempenho das estratégias de solução. Para avaliar o desempenho das estratégias de solução, utilizou-se a técnica chamada perfis de desempenho, proposta em Dolan e Moré (2002) (veja Apêndice B para mais detalhes). Nesse trabalho, o perfil de desempenho de um método de solução é definido como a função de distribuição acumulada para uma dada medida de desempenho ou métrica. Foram avaliados e comparados o desempenho dos métodos de solução MIP, RFP e RFR, baseando-se em 60 problemas teses gerados aleatoriamente. Foram consideradas duas métricas, o gap de otimalidade e o tempo de execução do algoritmo. Os gap's de otimalidade foram calculados com base no melhor limitante inferior obtido pela estratégia default do CPLEX 11.0. Note que, embora o critério de parada tenha sido limitado a 4200 segundos de execução ou gap de otimalidade $0,01 \%$, é possível avaliar os métodos mais rápidos dada um certo de gap de otimalidade e os métodos que geram limitantes superiores melhores para um certo tempo de execução.

Para auxiliar na análise dos perfis de desempenho das Figuras 2.6 e 2.7, os valores extremos das curvas para $\tau=0$ e $\tau \rightarrow r_{M}$ são exibidos na Tabela 2.6. As Figuras 2.6 e 
Tese de Doutorado

\begin{tabular}{ccccccccccc}
\hline Classe & Método & Custo & Variação (\%) & $X$ & $I^{+}$ & $I^{-}$ & $Y$ & $Z$ & $\# j$ & $O$ \\
\hline \multirow{2}{*}{1} & MIP & 174378 & - & 2333 & 40,22 & 0 & 6199 & 365,0 & 47,50 & 904,8 \\
& RFP & 174377 & 0,0006 & 2333 & 45,40 & 0 & 6199 & 364,8 & 47,70 & 505,3 \\
& RFR & 174351 & 0,0155 & 2333 & 43,70 & 0 & 6198 & 365,0 & 47,70 & 480,3 \\
\hline \multirow{2}{*}{2} & MIP & 348614 & - & 4866 & 228,5 & 0 & 13579 & 362,7 & 66,30 & 101465 \\
& RFP & 349926 & $-0,3765$ & 4866 & 281,4 & 0 & 13656 & 366,3 & 67,90 & 107146 \\
& RFR & 349831 & $-0,3492$ & 4866 & 241,9 & 0 & 13660 & 370,3 & 67,30 & 110540 \\
\hline \multirow{3}{*}{3} & MIP & 335884 & - & 4683 & 93,13 & 0 & 11796 & 733,1 & 47,90 & 368,6 \\
& RFP & 335844 & 0,0120 & 4683 & 97,14 & 0 & 11793 & 733,6 & 47,90 & 312,2 \\
& RFR & 335844 & 0,0120 & 4683 & 97,14 & 0 & 11793 & 733,7 & 47,90 & 312,2 \\
\hline \multirow{2}{*}{4} & MIP & 693190 & - & 9488 & 537,5 & 0 & 26879 & 729,6 & 70,30 & 185036 \\
& RFP & 698491 & $-0,7648$ & 9488 & 550,3 & 0 & 27015 & 747,3 & 72,80 & 228502 \\
& RFR & 696153 & $-0,4276$ & 9488 & 432,4 & 0 & 26874 & 760,8 & 72,60 & 246603 \\
\hline \multirow{2}{*}{5} & MIP & 758507 & - & 9488 & 759,1 & $<1$ & 27078 & 621,3 & 66,70 & 183553 \\
& RFP & 765587 & $-0,9334$ & 9488 & 953,9 & 0 & 27180 & 630,2 & 72,30 & 236400 \\
& RFR & 763684 & $-0,6825$ & 9488 & 792,9 & $<1$ & 27100 & 637,1 & 71,90 & 228583 \\
\hline \multirow{2}{*}{6} & MIP & 1222931 & - & 9466 & 2351 & 1169 & 27830 & 604,8 & 71,00 & 734636 \\
& RFP & 1190837 & 2,624 & 9469 & 2051 & 782,0 & 27558 & 629,3 & 71,70 & 763677 \\
& RFR & 1203687 & 1,574 & 9470 & 2127 & 826,4 & 27541 & 628,1 & 70,70 & 761734 \\
\hline
\end{tabular}

Tabela 2.5: Valores médios das soluções geradas pelas três estratégias nas 6 classes de exemplos: custo total, variação $(\%)$, produção $(X)$, estoque $\left(I^{+}\right)$, atraso $\left(I^{-}\right)$, placas $(Y)$, preparação $(Z)$, número de padrões de corte diferentes utilizados $(\# j)$ e hora-extra $(O)$.

2.7 foram construídas usando-se a escala $\log _{2}$ para fornecer uma representação mais compacta dos dados disponíveis (se uma escala linear fosse usada, seria necessário incluir os intervalos $\left[1,2^{2,21}\right]$ e $\left[1,2^{9,13}\right]$, para os perfis do gap e tempo de execução, respectivamente).

Na Figura 2.6, tem-se o gráfico dos perfis de desempenho dos métodos MIP, RFP e RFR considerando o gap de otimalidade como medida de desempenho. O método MIP possui o melhor desempenho geral (a sua curva encontra-se acima das curvas restantes para todo fator $\tau$ ), além de obter o menor gap em $80 \%$ da instâncias $(\tau=0)$. É também o mais estável dentre os três métodos: quando não obteve o melhor gap em um dado exemplar, o gap obtido nunca foi maior do que quase duas vezes $\left(2^{0,831} \approx 1,78\right)$ o melhor gap obtido pelos outros métodos para o mesmo exemplar (nesse caso, observe que a curva MIP atinge a ordenada 1 no ponto 0,831). Já os métodos RFP e RFR apresentaram desempenho inferior, obtendo melhor gap em 36,7\% e 26,7\% dos exemplares, respectivamente. O RFP teve desempenho geral levemente superior ao do RFR, sendo também o mais estável, pois a função de probabilidade assume o valor 1 para um valor de $\tau$ menor (1,83 contra 2,21).

Os perfis de desempenho considerando o tempo de execução são exibidos na Figura 2.7. Pode-se observar que o desempenho relativo dos métodos é bastante discrepante. O método RFP possui o melhor desempenho geral e é também o mais estável dentre os 
demais métodos, pois ele resolve $66,7 \%$ das instâncias com o melhor tempo de execução e quando não tem o melhor tempo em uma dada instância, o tempo obtido não é pior do que $12\left(2^{3,56}\right)$ vezes o melhor tempo atingido pelos outros métodos. O método MIP teve o melhor tempo em 33,3\% das intâncias, enquanto o método RFR resolveu todas as instâncias com o pior tempo computacional em relação aos demais (note que dentro do fator $\tau$ considerado pelo melhor tempo de todas os exemplares, o método RFR não conseguiu resolver nenhum exemplar). Entretanto, o MIP foi o menos estável, utilizando pouco mais de $500\left(2^{9,13}\right)$ vezes o tempo do melhor método em um dos exemplares, pelo menos. Já o RFR precisou de 113 (2 $\left.2^{6,83}\right)$ vezes o tempo do melhor método em pelo menos um dos exemplares.

Da análise anterior, é possível descartar o método RFR, uma vez que ele é totalmente dominado pelo MIP em relação ao gap e é totalmente dominado pelo RFP com respeito ao tempo de execução. Assim, a próxima análise vai se concentrar na comparação apenas entre MIP e RFP.

Embora o método MIP tenha o melhor gap em $80 \%$ dos exemplares, em média, o gap de otimalidade do método RFP é ligeiramente menor (assim como o desvio-padrão), como ilustra a Tabela 2.7. Isso acontece porque em alguns exemplares que o método MIP "perde", o valor do gap é muito pior do que o gap do RFP. De fato, a análise da Tabela C mostra que o exemplar 52 pode ser o responsável por esse fenômeno, uma vez que a diferença entre os gaps MIP e RFP é, nesse caso, 38,5 (em \%). A partir da Tabela C e dos perfis de desempenho, é possível ainda obter outras informações importantes. Em relação ao gap: nos 40 exemplares em que o gap do MIP é estritamente menor do que o gap do RFP (6,13 contra 6,81\%), o tempo médio de execução é 1796 e 38,00 segundos, nas estratégias MIP e RFP, respectivamente. Em relação ao tempo: nos 40 exemplares (não necessariamente iguais aos 40 exemplares já mencionados) em que o RFP ganha em tempo de execução (72,64 versus 2110 segundos), os gaps são 9,46 e 9,14\%, nos métodos MIP e RFP, respectivamente.

Isso mostra que, em 40 exemplares, o RFP tem desempenho superior em relação ao tempo e a média dos gaps ainda é menor. Todos esses reultados sugerem que, considerando os 60 exemplares propostos e resolvidos nesse capítulo, o método RFP tem potencial de desempenhar-se melhor do que o MIP. Entretanto, recomendações mais conclusivas sobre as estratégias de solução propostas devem ser baseadas numa experimentação computacional mais exaustiva. 


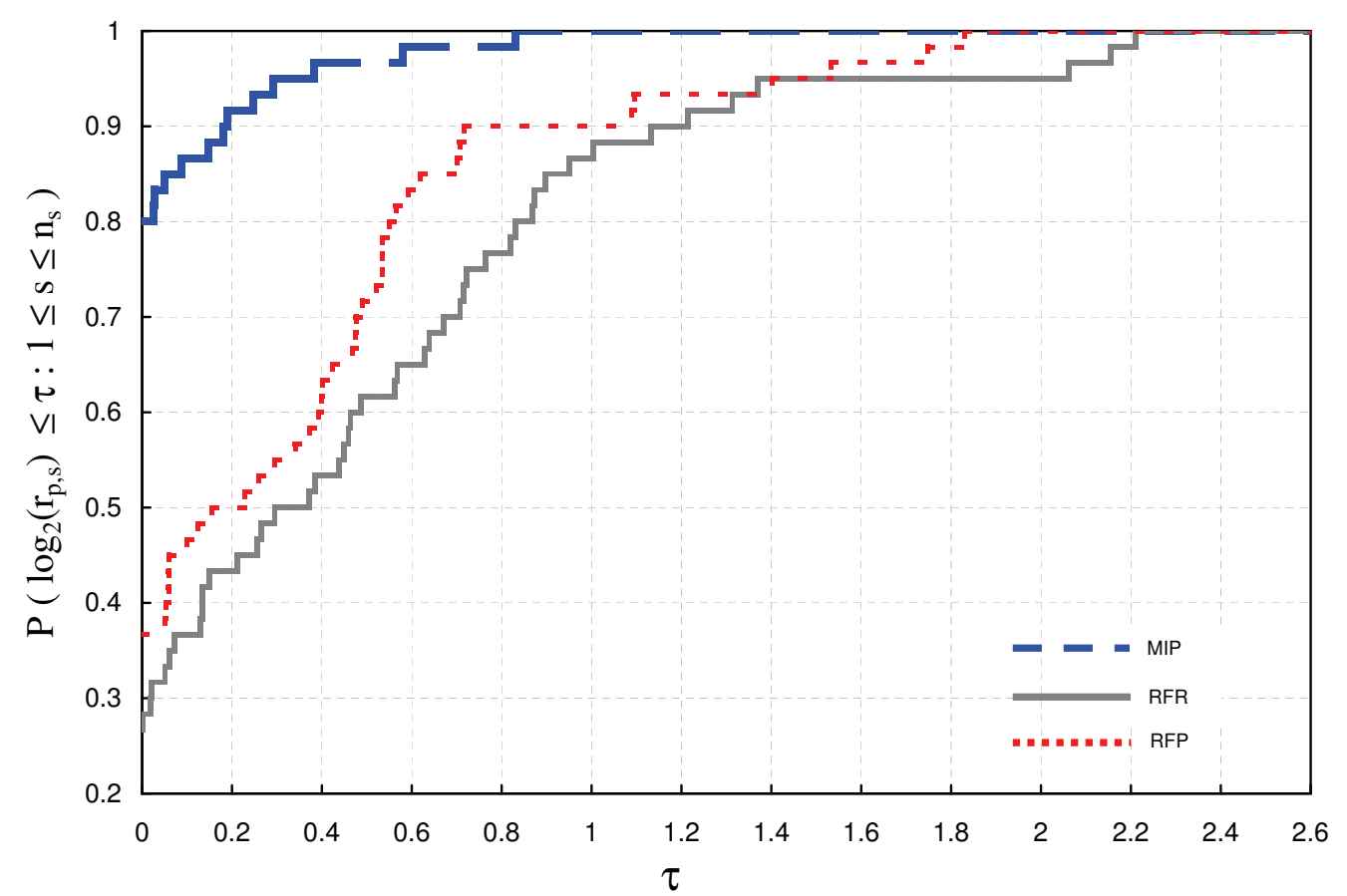

Figura 2.6: Perfil de desempenho das três estratégias de solução em relação ao gap de otimalidade.

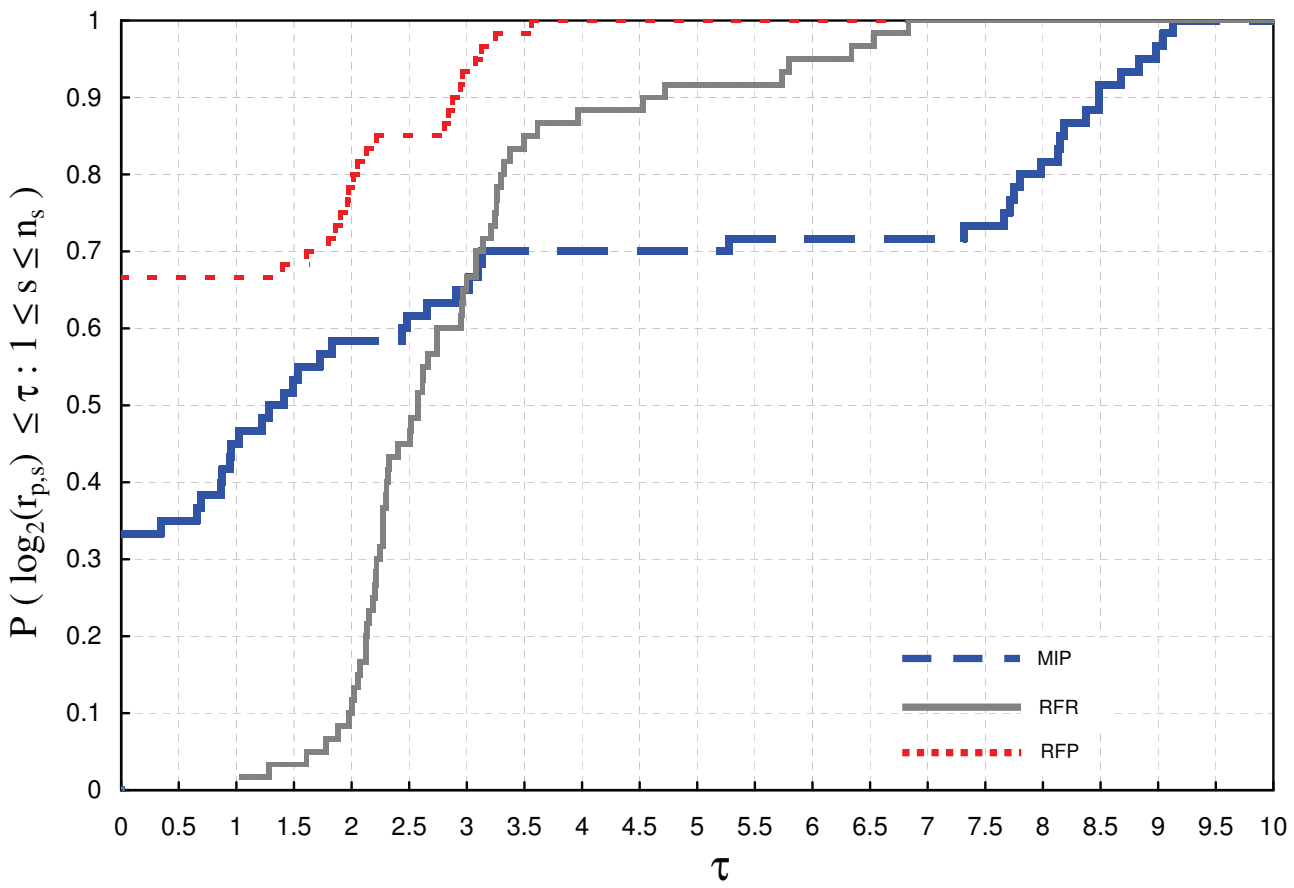

Figura 2.7: Perfil de desempenho das três estratégias de solução em relação ao tempo de execução dos algoritmos.

\subsection{Considerações Finais}

Nesse capítulo, foram propostos dois modelos matemáticos para um problema combinado de dimensionamento de lotes e corte de estoque no contexto de empresas moveleiras de 


\begin{tabular}{cccccc}
\hline Método & $\tau=0$ & $\tau \rightarrow r_{M}$ & Método & $\tau=0$ & $\tau \rightarrow r_{M}$ \\
\hline MIP & 0,800 & 0,831 & MIP & 0,333 & 9,13 \\
RFP & 0,367 & 1,83 & RFP & 0,667 & 3,56 \\
RFR & 0,267 & 2,21 & RFR & 0 & 6,83 \\
\hline
\end{tabular}

Tabela 2.6: Valores extremos dos perfis de desempenho correspondentes aos gaps de otimalidade (esquerda) e aos tempos de execução (direita).

\begin{tabular}{ccccccc}
\hline & \multicolumn{2}{c}{ MIP } & \multicolumn{2}{c}{ RFP } & \multicolumn{2}{c}{ RFR } \\
\cline { 2 - 7 } Classes & Gap & Tempo (s) & Gap & Tempo (s) & Gap & Tempo (s) \\
\hline 1 & 0,2579 & 0,3430 & 0,2578 & 1,247 & 0,2445 & 0,2445 \\
2 & 0,7306 & 5,202 & 1,102 & 2,375 & 1,078 & 11,78 \\
3 & 0,2667 & 0,2667 & 0,2563 & 4,210 & 0,2563 & 4,948 \\
4 & 0,5801 & 37,35 & 1,3565 & 7,204 & 1,020 & 31,92 \\
5 & 1,916 & 4200 & 2,8658 & 11,73 & 2,619 & 86,97 \\
6 & 34,62 & 4200 & 31,2197 & 269,2 & 32,28 & 1547 \\
\hline \hline Média & 6,395 & 1407 & 6,176 & 49,33 & 6,250 & 280,7 \\
Desvio & 27,89 & 1991 & 25,89 & 221,3 & 26,96 & 668,6 \\
Máximo & 185,5 & 4200 & 188,0 & 1272 & 193,2 & 3099 \\
Mínimo & 0 & 0,3000 & 0 & 1,130 & 0 & 1,440 \\
\hline
\end{tabular}

Tabela 2.7: Médias dos gaps de otimalidade e dos tempos de execução em cada uma das 6 classes de exemplos testadas, de acordo com os três métodos. As quatro linhas finais ainda indicam a média geral, desvio-padrão, valor máximo e mínimo obtidos a partir dos 60 exemplares. As Tabelas C.1 e C.2 do Apêndice C exibem os resultados completos dos 60 exemplares.

pequeno porte: um modelo geral $(C L C 1)$ e um específico (CLC2). O modelo geral é baseado em trabalhos já conhecidos da literatura, enquanto o modelo específico, é fundamentado em visitas técnicas realizadas numa empresa produtora de móveis residenciais no interior do estado de São Paulo. O modelo específico apresenta de forma explícita as restrições de capacidade dos estágios de produção gargalos - as seções de corte das placas de MDF e de furação das peças - e ainda apresenta uma restrição de preparação dependente dos estágios intermediários de produção, diferentemente do modelo geral cuja restrição de preparação não é baseado em estágios de produção.

De acordo com os testes computacionais preliminares, exemplares práticos do modelo $C L C 1$ são resolvidos na otimalidade num tempo computacional razoável, considerando o conjunto de padrões de corte fornecidos pela empresa. Já o modelo $C L C \mathscr{2}$, apresenta dificuldades de resolução, principalmente em exemplares com mais produtos e/ou períodos e com capacidades apertadas, como mostram os experimentos computacionais realizados nesse capítulo. Por essa razão, foram desenvolvidas estratégias simples de solução com a motivação de se obter bons limitantes superiores num tempo computacional aceitável. 
Tese de Doutorado

Para essa finalidade, foram propostas duas versões de heurísticas relax-and-fix, uma progressiva (RFP) e outra regressiva (RFR) no tempo, as quais foram comparadas em termos de gap de otimalidade e tempo de execução ao método branch-and cut do CPLEX 11.0, o qual foi nomeado MIP. Concluiu-se que a heurística relax-and-fix progressiva tem um desempenho melhor do que o método MIP em termos de gap e tempo de execução, mas alguns exemplares ainda obtiveram gaps elevados, o que motiva o aprimoramento das heurísticas desenvolvidas nesse capítulo, assim como a investigação de outros métodos de solução mais efetivos. Algumas questões em aberto que devem ser melhor estudadas oportunamente encontram-se descritas na próxima seção.

\subsection{Pesquisas Futuras}

\subsubsection{Métodos de Solução para o Problema Combinado}

Nesse capítulo, observou-se que pode ser computacionalmente custoso determinar uma solução boa (com gap de otimalidade apertado) para alguns exemplares do modelo CLC2 (veja os resultados dos exemplares 51 - 60 na Tabela C.1). Por outro lado, embora as heurísticas relax-and-fix também falhem na obtenção de soluções razoáveis em alguns exemplares, elas produzem limitantes superiores rapidamente, o que motiva o desenvolvimento de heurísticas mais elaboradas, como as heurísticas double-fix-and-relax (Absi, 2005; Absi e Kedad-Sidhoum, 2007). Diferentemente das heurísticas relax-and-fix tradicionais, as heurísticas double-fix-and-relax partem de uma estimativa para o plano de produção de todo o horizonte de planejamento, que é obtida pela resolução da relaxação linear do problema original (considerando que apenas as variáveis de preparação são binárias no problema original e as outras variáveis são contínuas). O plano de produção relaxado é capaz de capturar a interação entre o primeiro e o último período do horizonte de planejamento, o que pode aumentar a qualidade das soluções obtidas.

Além das heurísticas relax-and-fix, também foram investigadas outras duas estratégias de solução para o problema combinado $C L C$ 2: a primeira é baseada na decomposição do problema combinado e a segunda é baseada no arredondamento das variáveis de preparação. Resultados preliminares indicaram que ambas as estratégias não foram capazes de gerar limitantes superiores competitivos com aqueles gerados pelas heurísticas relaxand-fix e, por essa razão, tais resultados não foram detalhados no presente capítulo. A seguir, esses métodos são brevemente apresentados para possíveis investigações futuras. 


\subsubsection{Heurística de Decomposição}

Uma heurística de decomposição bem simples pode basear-se na resolução dos problemas de dimensionamento de lotes e corte de estoque de maneira independente. No primeiro estágio da heurística, determina-se o dimensionamento de lotes de produção ao longo do horizonte de planejamento. No segundo estágio, as decisões referentes ao processo de corte são realizadas com base nas decisões do primeiro estágio. A Heurística de Decomposição (HD) em estágios de decisão para o modelo CLC2 pode funcionar da seguinte maneira:

Passo 1. Resolva o seguinte Problema de Dimensionamento de Lotes (PDL):

$$
\begin{array}{ll}
\text { Minimizar } & \sum_{i \in \mathcal{I}} \sum_{t \in \mathcal{T}}\left(c_{i t} X_{i t}+h_{i t}^{+} I_{i t}^{+}+h_{i t}^{-} I_{i t}^{-}\right) \\
\text {Sujeito a: } & X_{i t}+I_{i, t-1}^{+}+I_{i t}^{-}=d_{i t}+I_{i t}^{+}+I_{i, t-1}^{-}, i \in \mathcal{I}, t \in \mathcal{T} \\
& 0 \leq I_{i t}^{+} \leq I_{i t}^{\max }, i \in \mathcal{I}, t \in \mathcal{T} \\
& X_{i t}, I_{i t}^{-} \geq 0
\end{array}
$$

Passo 2. Resolva o seguinte Problema de Corte de Estoque (PCE):

$$
\begin{aligned}
\text { Minimizar } & \sum_{j \in \mathcal{J}} \sum_{t \in \mathcal{T}} w_{j t} Y_{j t}+\sum_{t \in \mathcal{T}} o_{t} O_{t} \\
\text { Sujeito a: } & \sum_{j \in \mathcal{J}} a_{p j} Y_{j t} \geq \sum_{i \in \mathcal{I}} r_{p i} X_{i t}^{\star}, p \in \mathcal{P}, t \in \mathcal{T}, i \in \mathcal{I}, t \in \mathcal{T} \\
& \sum_{j \in \mathcal{J}}\left(\nu_{j}^{I} Y_{j t}+\varphi_{j t}^{I} Z_{j t}\right) \leq C_{t}^{I}+O_{t}, t \in \mathcal{T} \\
& \sum_{p \in \mathcal{P}} \sum_{j \in \mathcal{J}}\left(\nu_{p}^{I I} a_{p j} Y_{j t}+\varphi_{p t}^{I I} \delta_{p j} Z_{j t}\right) \leq C_{t}^{I I}+O_{t}, t \in \mathcal{T} \\
& Y_{j t} \leq M Z_{j t}, j \in \mathcal{J}, t \in \mathcal{T} \\
& 0 \leq O_{t} \leq C_{t}^{E}, t \in \mathcal{T} \\
& Y_{j t} \geq 0, Z_{j t} \in\{0,1\}, j \in \mathcal{J}, t \in \mathcal{T}
\end{aligned}
$$

em que $X_{i t}^{\star}$ é a solução ótima do PDL no passo 1.

Se o PCE tiver solução factível, então a HD encontrou uma solução factível para o problema combinado original; caso contrário, a heurística falhou. Resultados computacionais preliminares mostraram que essa heurística foi bastante rápida; porém, em muitos casos a heurística falhou na obtenção de uma solução factível. Esse resultado era esperado, uma vez que o PDL inicial não possui nenhuma restrição que o impeça de produzir em demasia em algum período do horizonte de planejamento e, consequentemente, gerar uma solução infactível para o segundo passo. Baseando-se nesses resultados preliminares, pretende-se, futuramente, melhorar essa heurística, impondo-se restrições para forçar a antecipação de itens no passo 1, limitar a quantidade produzida por período, ou utilizar 
Tese de Doutorado

uma heurística simples de factibilização num passo 3. Tais estratégias devem ser propostas e testadas oportunamente.

Note que se a variável de preparação do problema de corte de estoque (PCE) for relaxada, resta um problema de otimização linear para ser resolvido. Então, esse problema pode ser reescrito de tal forma que o parâmetro $a_{p j}$ torne-se uma variável de decisão para um problema de geração de padrões de corte, como proposto no trabalho de Ghidini (2007). O subproblema resultante é um problema de múltiplas mochilas que pode ser resolvido por branch-and-bound ou programação dinâmica (Gilmore e Gomory, 1961, 1963). A limitação desse procedimento básico é que ele apenas gera limitantes inferiores para o PCE, que já é um subproblema do problema CLC2 original.

\subsubsection{Heurísticas de Arredondamento}

Essas heurísticas partem da solução da relaxação linear do MIP original e as variáveis de decisão fracionárias são arredondadas de maneira subsequente. Maes et al. (1991) propuseram vários procedimentos de arredondamento para resolver o problema de dimensionamento de lotes multi-nível com restrições de capacidade e sem tempos de preparação, baseados na própria estrutura do problema. Em geral, os passos de uma heurística de arredondamento são:

Passo 1. Resolva a relaxação linear do modelo.

Passo 2. Selecione um conjunto de variáveis não-inteiras e arredonde-as para cima ou para baixo, de acordo com algum critério.

Passo 3. Resolva novamente o modelo relaxado com as variáveis arredondadas fixadas. Se todas as variáveis forem inteiras, pare. Senão, volte ao passo 2.

Se as variáveis de interesse forem binárias, o arredondamento pode consistir simplesmente na fixação das variáveis fracionárias em 1 (passo 2), de acordo com alguma tolerância estabelecida a priori. Buschkühl et al. (2010) enfatiza que em alguns problemas de dimensionamento de lotes com restrição de capacidade, as estratégias de arredondamento frequentemente resultam em soluções infactíveis, principalmente quando o horizonte de planejamento é composto por poucos períodos.

Para o problema combinado $C L C$ 2, foram testadas três heurísticas de arredondamento: a primeira versão (RoundAll) é baseada no arredondamento das variáveis de preparação sem nenhum critério adicional, i.e., no segundo passo, todas as variáveis fracionárias são fixadas em 1. No terceiro passo, resolve-se o modelo original (inteiro-misto) com a esperança de alguma variável nula (não fixada) ser escolhida e melhorar a solu- 
ção. A segunda versão (RoundSuce) arredonda as variáveis maiores do que uma tolerância (tol). Baseado na estrutura do problema, a tolerância inicia-se em 0,01 e diminui gradativamente até 0,001 (em intervalos de 0,001), fazendo com que a cada iteração, apenas as maiores variáveis sejam fixadas em 1. Ao final desse processo, todas as variáveis são inteiras (fim da heurística) ou estritamente menores do que 0,001. Nesse último caso, a condição de integralidade das mesmas é reinstalada e o modelo inteiro-misto resultante é resolvido para se obter uma solução factível. Na versão 3 (RoundPerda), a partir da solução da relaxação linear, as variáveis de preparação são arredondadas de acordo com a ordem crescente da perda do seu respectivo padrão de corte. A versão 4 (RoundFreqPerda) utiliza um procedimento análogo, mas o arredondamento é realizado em todos os padrões cuja perda percentual esteja em um determinado patamar.

Resultados computacionais preliminares mostraram que a heurística RoundSuce teve um desempenho superior às outras heurísticas em todos os problemas testados. Também, como era de se esperar, nenhuma heurística falhou na obtenção de uma solução factível. As três outras heurísticas têm um comportamento muito parecido, não sendo possível concluir se alguma domina as demais. As heurísticas de arredondamento propostas geraram soluções com gaps mais elevados do que aqueles fornecidos pelas heurísticas relax-and-fix. Entretanto, devido a rapidez na obtenção de limitantes superiores, pretende-se, oportunamente, testar outras estratégias de arredondamento, assim como utilizar as soluções de arredondamento como soluções iniciais do algoritmo branch-and-cut e de heurísticas relax-and-fix.

\subsubsection{Metaheurísticas para o Problema Combinado}

Além das heurísticas baseadas em programação matemática, estratégias alternativas de solução podem ser desenvolvidas utilizando-se metaheurísticas, como Simulated Annealing, Busca Tabu, Algoritmos Genéticos, Algoritmos Meméticos, Colônia de Formigas, entre outras. Na literatura referente aos problemas de dimensionamento de lotes, há um interesse crescente no desenvolvimento de métodos de solução baseados em metaheurísticas, devido à complexidade computacional desses problemas, como pode ser visto nos trabalhos de revisão de Jans e Degraeve (2007) e Buschkühl et al. (2010). Em particular, os algoritmos genéticos têm sido aplicados com sucesso em problemas complexos de dimensionamento e sequenciamento de lotes (Toledo et al., 2009; Santos et al., 2010), o que motiva pesquisas futuras. 


\section{Capítulo 3}

\section{Modelos de Programação Estocástica para o Problema Combinado}

"If only deterministic models are used in engineering applications then inadequate simplified conclusions are made". (Pavel Popela)

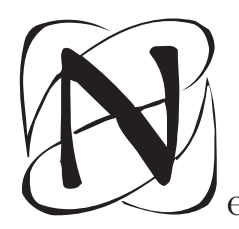

esse capítulo, são desenvolvidos modelos de programação estocástica para o problema combinado de dimensionamento de lotes e corte de estoque típico de empresas moveleiras de pequeno porte. Como os modelos $C L C 1$ e $C L C 2$ apresentam similaridades, optou-se por aplicar tal metodologia apenas no CLC2 pela motivação do estudo de caso. A aplicação desta metodologia no $C L C 1$ é análoga, e acredita-se que a apresentação de ambos os modelos estenderia em demasia o trabalho sem, necessariamente, trazer contribuições adicionais importantes em termos dos objetivos desta tese. Além da tradicional abordagem de programação estocástica de dois estágios com recurso, são propostos modelos de programação estocástica de dois estágios robusto para o problema combinado, de acordo com a definição de robustez de Mulvey et al. (1995), e modelos com restrição de recurso. Para analisar o desempenho dos modelos, são resolvidos alguns exemplares baseados na Fábrica X. O capítulo está organizado da seguinte maneira. Na Seção 3.1, são apresentados alguns conceitos importantes sobre programação estocástica e programação estocástica robusta. Na Seção 3.2, são desenvolvidos os modelos matemáticos para o problema combinado com parâmetros estocásticos. As experiências computacionais e as análises dos modelos são realizadas na Seção 3.3. Finalmente, as considerações finais do capítulo são discutidas na Seção 3.4 e os possíveis encaminhamentos de pesquisas futuras deste capítulo, na Seção 3.5. 


\subsection{Preliminares em Programação Estocástica}

Nessa seção, são apresentados alguns conceitos básicos de programação estocástica e programação estocástica robusta que são usados para formular os modelos matemáticos ao longo desse capítulo. O leitor interessado em se aprofundar nesses conceitos pode consultar Birge e Louveaux (1997), Kall e Wallace (1994), Shapiro et al. (2009), entre outros.

\subsubsection{Programação Estocástica de Dois Estágios com Recurso}

Na programação estocástica de dois estágios com recurso, tem-se um conjunto de variáveis de decisão de primeiro estágio que devem ser determinadas antes da realização das variáveis aleatórias. Por esse motivo, é comum atribuir a essas variáveis a denominação de decisões "aqui-e-agora" (here-and-now). Após a realização das variáveis aleatórias, determinam-se as variáveis de decisão de segundo estágio, que são ações corretivas tomadas para adaptar ou finalizar as decisões feitas no primeiro estágio, de acordo com a observação dos valores das variáveis aleatórias. As variáveis de segundo estágio também são comumente chamadas de decisões "espere-e-veja" (wait-and-see) ou decisões de recurso (recourse decisions). O objetivo de um modelo de programação estocástica de dois estágios é identificar uma solução de primeiro estágio que seja bem equilibrada, diante de todas as possíveis realizações das variáveis aleatórias.

Em várias aplicações, é comum representar as variáveis aleatórias em algum espaço de probabilidade $(\Omega, \mathcal{F}, \Pi$ ), em que $\Omega$ é o conjunto de possíveis estados da natureza (sendo que a realização genérica da variável aleatória $\xi$ é denotada por $\omega$ ) equipado com uma $\sigma$-álgebra de eventos $\mathcal{F}$ e com uma medida de probabilidade $\Pi$. O modelo geral linear de dois estágios com recurso (ou, simplesmente, problema recurso $R P$ ) pode ser escrito da seguinte maneira:

$$
\begin{array}{ll}
\text { Minimizar } & c^{T} x+\mathbb{E}\left[\min q(\omega)^{T} y(\omega)\right] \\
\text { Sujeito a: } & A x=b \\
& T(\omega) x+W(\omega) y(\omega)=h(\omega) \\
& x, y(\omega) \geq 0
\end{array}
$$

No modelo (3.1), c, $A$ e $b$ são parâmetros determinísticos e definem a parte determinística do vetor de custos, da matriz tecnológica e do termo independente ou right-hand side (rhs), respectivamente. Para cada possível realização $\omega, q(\omega), T(\omega), W(\omega)$ e $h(\omega)$ definem (nessa ordem) os parâmetros estocásticos referentes ao custo, à matriz tecnológica, à matriz de recurso e ao rhs. Além disso, $x$ é a variável de decisão de primeiro estágio e $y(\omega)$ define a variável de decisão de segundo estágio, como função da reali- 
zação $\omega$. Colocando todos parâmetros estocásticos juntos, obtém-se o vetor aleatório $\xi(\omega) \stackrel{\text { def }}{=}(q(\omega), T(\omega), W(\omega), h(\omega))$. O valor esperado de (3.1) é tomado em relação à distribuição de probabilidade de $\xi(\omega)$, que é supostamente conhecida com expectância finita.

O modelo (3.1) pode ainda ser escrito como o seguinte modelo determinístico equivalente:

$$
\begin{array}{ll}
\text { Minimizar } & c^{T} x+\mathcal{Q}(x) \\
\text { Sujeito a: } & A x=b \\
& x \geq 0,
\end{array}
$$

sendo que $\mathcal{Q}(x)=\mathbb{E}[Q(x, \xi(\omega))]$ e o valor ótimo do problema de segundo estágio é representado da seguinte forma:

$$
Q(x, \xi(\omega))=\min _{y(\omega)}\left\{q(\omega)^{T} y(\omega) \mid T(\omega) x+W(\omega) y(\omega)=h(\omega), y(\omega) \geq 0\right\}
$$

A representação (3.2)-(3.3) ilustra a sequência de eventos no problema recurso. Primeiramente, são determinadas as decisões de primeiro estágio na presença de incertezas. No segundo estágio, as realizações $\omega$ tornam-se conhecidas e as ações corretivas $y(\omega)$ podem ser tomadas para remediar as decisões de primeiro estágio. As decisões de primeiro estágio são escolhidas, entretanto, levando-se em consideração seus efeitos futuros, os quais são medidos pela função de recurso $\mathcal{Q}(x)$.

Nessa tese, admite-se que os parâmetros aleatórios têm uma distribuição de probabilidade discreta com um número finito $S$ de possíveis realizações $\xi_{s}=\left(q_{s}, T_{s}, W_{s}, h_{s}\right)$, com suporte finito $\Omega=\left\{\xi_{1}, \xi_{2}, \cdots, \xi_{S}\right\}$. Tais realizações são denominadas cenários e têm uma probabilidade de ocorrência representativa da chance do evento materializar-se, dada por $\operatorname{Pr}\left\{\xi=\xi_{s}\right\}=\pi_{s}$, de tal maneira que $\pi_{s}>0$ e $\sum_{s \in \Omega} \pi_{s}=1$. Na abordagem por cenários, $\mathbb{E}[Q(x, \xi(\omega))]=\sum_{s=1}^{S} \pi_{s} Q\left(x, \xi_{s}\right)$, em que

$$
Q\left(x, \xi_{s}\right)=\min _{y_{s}}\left\{q_{s}^{T} y_{s} \mid T_{s} x+W_{s} y_{s}=h_{s}, y_{s} \geq 0\right\}
$$

Assim, o problema estocástico (3.2) -(3.3) pode ser escrito na sua forma equivalente determinística, que resulta, em geral, num problema de otimização de grande porte:

$$
\begin{array}{ll}
\text { Minimizar } & c^{T} x+\sum_{s \in \Omega} \pi_{s} q_{s}^{T} y_{s} \\
\text { Sujeito a: } & A x=b \\
& T_{s} x+W_{s} y_{s}=h_{s}, s \in \Omega \\
& x, y_{s} \geq 0, s \in \Omega .
\end{array}
$$


Os problemas com recurso podem ser classificados em algumas categorias, dependendo do tipo de matriz de recurso que possuem. Então, um problema de programação estocástica com recurso é dito possuir: recurso fixo, se a matriz $W$ do problema recurso for determinística; recurso completo, se o problema de segundo estágio for factível para qualquer valor das variáveis de primeiro estágio; recurso relativamente completo, se o problema de segundo estágio for factível para qualquer valor das variáveis de primeiro estágio que satisfazem as restrições de primeiro estágio; recurso simples, se a matriz recurso $W$ puder ser expressa como [I, - I], em que I é a matriz identidade. Recurso simples é um caso especial de recurso completo, que por sua vez é um caso especial de recurso completo relativo.

\subsubsection{Introdução à Programação Estocástica Robusta}

Uma alternativa à utilização da programação estocástica tradicional é uma abordagem aparentemente introduzida no trabalho de Mulvey et al. (1995), que foi denominada pelos autores de otimização robusta - denominada nessa tese de programação estocástica robusta - para evitar confusão com otimização robusta segundo Ben-Tal e Nemirovski (2000) e estudada no próximo capítulo. A programação estocástica robusta é baseada na integração entre a programação por metas e a abordagem por cenários. A motivação dessa metodologia é gerar uma série de soluções que sejam progressivamente menos sensíveis aos diferentes cenários do problema. Para definir o problema de programação estocástica robusta, é preciso introduzir a noção de robustez, definida em Mulvey et al. (1995):

Definição 3.1 A solução ótima de um modelo de programação estocástica é robusta em relação à otimalidade se ela permanece "perto" da solução ótima para qualquer realização do cenário $s \in \Omega$. A isso, dá-se o nome de solução robusta.

Definição 3.2 A solução ótima de um modelo de programação estocástica é robusta em relação à factibilidade se ela for "quase" factível para qualquer realização do cenário $s \in \Omega$. A isso, dá-se o nome de modelo robusto.

O significado matemático de "perto" e "quase" pode ser quantificado pela escolha apropriada das normas.

Dada a improbabilidade da solução de um determinado problema de programação estocástica permanecer factível e ótima para todo $s \in \Omega$, Mulvey et al. (1995) desenvolveram uma metodologia para permitir o controle do tradeoff entre a robustez da solução e a robustez do modelo, a partir da introdução de variáveis auxiliares e pesos que pos- 
suem uma conotação multiobjetivo. A formulação geral de um problema de programação estocástica robusta é apresentada a seguir.

$$
\begin{array}{ll}
\text { Minimizar } & c^{T} x+\sum_{s \in \Omega} \pi_{s} q_{s}^{T} y_{s}+\lambda \sigma\left(y_{1}, y_{2}, \cdots, y_{S}\right)+\gamma \rho\left(z_{1}, z_{2}, \cdots, z_{S}\right) \\
\text { Sujeito a: } & A x=b \\
& T x+W_{s} y_{s}+z_{s}=h_{s}, s \in \Omega \\
& x, y_{s} \geq 0, z_{s} \text { livre, } s \in \Omega .
\end{array}
$$

As variáveis de decisão irrestritas em sinal $z_{s}$ medem a infactibilidade das restrições estocásticas e são penalizadas na função objetivo pela função $\rho(\cdot)$. A função $\sigma(\cdot)$ representa a medida de variabilidade do custo de segundo estágio. Ambos $\gamma$ e $\lambda$ são pesos multiobjetivos usados para refletir as preferências do decisor em relação à robustez do modelo e à robustez da solução, respectivamente. É comum designar o termo risco às parcelas referentes a $\gamma$ e $\lambda$, o que confere à formulação (3.6) o nome de modelo Média-Risco $(M R)$.

Aos coeficientes $\lambda$ e $\gamma$ das funções $\rho(\cdot)$ e $\sigma(\cdot)$ são designados valores numéricos definidos pelo decisor. Por exemplo, se $\gamma=0$, permite-se obter soluções altamente infactíveis a um custo baixo; por outro lado, se $\gamma$ é suficientemente grande, é possível obter soluções "quase" factíveis para todos os cenários, mas o custo total esperado pode deteriorar-se em demasia.

O parâmetro $\lambda$ fornece a importância relativa entre a expectância e a variabilidade do custo. Se $\lambda=0$, o objetivo é minimizar a expectância, ignorando a variabilidade dos custos. Esse caso é preferível por decisores mais tolerantes/neutros ao risco. Se o decisor é averso ao risco, deve-se atribuir $\lambda>0$, de modo que seja tão importante minimizar o custo esperado quanto a sua variabilidade (isso ocorre para $\lambda=1$ ). Também, pode ser mais importante minimizar a variabilidade do que o custo esperado de segundo estágio $(\lambda>1)$.

Nos problemas de programação estocástica robusta, é importante elaborar funções apropriadas para a medida de variabilidade $\sigma(\cdot)$ e de penalidade $\rho(\cdot)$. Há vários trabalhos que mencionam o modelo clássico de média-variância de Markowitz (Markowitz, 1959) afim de balancear expectância e variabilidade: Mulvey et al. (1995), Yu e Li (2000), Leung e Wu (2004), Leung et al. (2007) e Khor et al. (2008). Considerando, a partir desse ponto, $\zeta_{s}=c^{T} x+q_{s}^{T} y_{s}$, a função $\sigma(\cdot)$ pode ser escrita como a variância $\mathbb{E}\left[\left(\zeta_{s}-\mathbb{E}\left(\zeta_{s}\right)\right)^{2}\right]$ :

$$
\sigma\left(y_{1}, y_{2}, \cdots, y_{S}\right)=\sum_{s \in \Omega} \pi_{s}\left(\zeta_{s}-\sum_{s^{\prime} \in \Omega} \pi_{s^{\prime}} \zeta_{s^{\prime}}\right)^{2}
$$


Uma desvantagem prática da função (3.7) é a intratabilidade computacional do problema de otimização resultante, que é um problema de programação quadrática não linear convexo, que poderia ainda conter variáveis de decisão inteiras ou binárias (o que resultaria em um problema de programação quadrática não linear inteiro/binário convexo). Para evitar formulações não lineares, Konno e Yamazaki (1991) propuseram uma função alternativa $\sigma(\cdot)$ baseada no desvio médio-absoluto (MAD). De acordo com a formulação MAD, a função $\sigma(\cdot)$ é dada por:

$$
\sigma\left(y_{1}, y_{2}, \cdots, y_{S}\right)=\sum_{s \in \Omega} \pi_{s}\left|\zeta-\sum_{s^{\prime} \in \Omega} \pi_{s^{\prime}} \zeta_{s^{\prime}}\right| .
$$

A função não linear (3.8) pode ser linearizada pela imposição da restrição $\zeta_{s}-$ $\sum_{s^{\prime} \in \Omega} \pi_{s^{\prime}} \zeta_{s^{\prime}}=\Delta_{s}^{+}-\Delta_{s}^{-}$, minimizando $\lambda \sum_{s \in \Omega} \pi_{s}\left(\Delta_{s}^{+}+\Delta_{s}^{-}\right)$na função objetivo do modelo. Note que não é preciso impor a condição de complementariedade $\Delta_{s}^{+} \times \Delta_{s}^{-}=0 \mathrm{em}$ problemas lineares e contínuos, uma vez que os próprios métodos de solução asseguram que apenas uma variável é positiva para $\lambda>0$. Outra opção de linearização é apresentada no trabalho de Yu e Li (2000), em que os autores utilizam apenas um conjunto de variáveis auxiliares, de acordo com o Teorema a seguir.

Teorema 3.1 O problema de programaçãa por metas $\min _{x}\{Z=|f(x)-g|: x \in F\}$ pode ser linearizado da seguinte maneira: $\min _{x, \theta}\left\{Z^{\prime}=f(x)-g+2 \theta: g-f(x) \leq \theta, \theta \geq 0, x \in F\right\}$, em que $F$ é um conjunto factível $e|\cdot|$ denota o valor absoluto.

Prova: A prova desse teorema deve verificar os casos em que $f(x)-g \geq 0$ e $f(x)-g<0$. No primeiro caso, note que a restrição $g-f(x) \leq \theta$ é redundante, pois $\theta \geq 0$. Assim, na solução ótima, $\theta=0$, o que resulta em $Z^{\prime}=Z$. No segundo caso, a solução ótima força $\theta=g-f(x)$, implicando em $Z^{\prime}=f(x)-g+2(g-f(x))=g-f(x)=Z$.

Utilizando o Teorema 3.1, tem-se que a medida de variabilidade (3.8) pode ser linearizada impondo-se a restrição $\zeta_{s}-\sum_{s^{\prime} \in \Omega} \pi_{s^{\prime}} \zeta_{s^{\prime}}-\Delta_{s} \geq 0$, e minimizando a expressão $\lambda \sum_{s \in \Omega} \pi_{s}\left[\left(\zeta_{s}-\sum_{s^{\prime} \in \Omega} \pi_{s^{\prime}} \zeta_{s^{\prime}}\right)+2 \Delta_{s}\right]$. Nesse caso, tem-se $\Delta_{s}$ menos variáveis, em comparação com a linearização anterior.

As funções (3.7) e (3.8) são aplicáveis quando os desvios positivo e negativo dos custos são igualmente indesejáveis. Se apenas os desvios positivos são indesejáveis, é possível adotar a seguinte medida de variabilidade.

$$
\sigma\left(y_{1}, y_{2}, \cdots, y_{S}\right)=\sum_{s \in \Omega} \pi_{s} \Delta_{s}
$$


em que $\Delta_{s}=\max \left\{0,\left(\zeta_{s}-\sum_{s^{\prime} \in \Omega} \pi_{s^{\prime}} \zeta_{s^{\prime}}\right)\right\}$, que pode ser linearizada pela imposição de que $\Delta_{s} \geq \zeta_{s}-\sum_{s^{\prime} \in \Omega} \pi_{s^{\prime}} \zeta_{s^{\prime}}$. O rhs da expressão (3.9) é denominado média parcial superior (upper partial mean ou UPM), de acordo com Ahmed e Sahinidis (1998).

Basedo na idéia de UPM, Zanjani et al. (2009) propuseram a variância parcial superior (upper partial variance ou UPV), em que o rhs de (3.9) é substituído por $\lambda \sum_{s \in \Omega} \pi_{s} \Delta_{s}^{2}$. Takriti e Ahmed (2004) desenvolveram a medida de variabilidade com $\Delta_{s}=\max \left\{0,\left(\zeta_{s}-R^{*}\right)\right\}$, sendo que $R^{*}$ representa a meta do custo de segundo estágio. Zanjani et al. (2009) estenderam essas funções para os chamados momentos parciais superiores de ordem 2 (upper partial moment of order 2 ou UPM-2), em que $\sigma\left(y_{1}, y_{2}, \cdots, y_{S}\right)=$ $\sum_{s \in \Omega} \pi_{s} \Delta_{s}^{2}, \operatorname{com} \Delta_{s}=\max \left\{0,\left(\zeta_{s}-R^{*}\right)\right\}$.

Para as funções de penalidade, pode-se utilizar $\rho\left(z_{1}, z_{2}, \cdots, z_{S}\right)=\sum_{s \in \Omega} \pi_{s} z_{s}^{T} z_{s}$, que é uma penalidade quadrática aplicável, por exemplo, quando ambas as violações positivas e negativas das restrições são indesejáveis. Se apenas os desvios positivos são indesejáveis, pode-se adotar $\rho\left(z_{1}, z_{2}, \cdots, z_{S}\right)=\sum_{s \in \Omega} \pi_{s} \max \left\{0, z_{s}\right\}$, que também pode ser linearizada. Para mais detalhes em medidas de risco e funções de penalidade, assim como assuntos correlatos, o leitor pode consultar, por exemplo, Dupacová (2008); Fabozzi et al. (2010) e Shapiro et al. (2009).

A programação estocástica robusta no sentido de Mulvey et al. (1995) tem sido utilizada em muitas aplicações, como expansão de capacidade (Laguna, 1998), planejamento agregado (Leung e Wu, 2004) e (Aghezzaf et al., 2010), revenue menagement (Lai e Ng, 2005; Lai et al., 2007), planejamento da produção em múltiplas plantas (Leung et al., 2007), programação de frota de ônibus (Yan e Tang, 2009), produção de toras de madeira (Zanjani et al., 2009), cadeia de suprimentos num contexto de manufatura ágil (Pan e Nagi, 2010), fornecimento de gás natural (Aouam et al., 2010), processamento de sinal (Ukkusuri et al., 2010), planejamento e programação da produção e processos em indústrias químicas e refinarias de petróleo (Suh et al., 2001; Jia e Ierapetritou, 2004; Khor et al., 2008; Li e Ierapetritou, 2008), dentre outras aplicações.

\subsubsection{Modelos com Recurso Restrito}

As metodologias referidas como programação estocástica robusta são especialmente importantes quando há a necessidade de controlar a robustez da solução e do modelo. Em muitas aplicações, entretanto, seria suficiente garantir uma estabilidade das variáveis de decisão de segundo estágio, para que as decisões não tivessem que ser re-implementadas a cada novo cenário materializado. Foi nesse contexto que Vladimirou e Zenios (1997) desenvolveram a metodologia denominada programação estocástica com recurso restrito. 
Os modelos robustos propostos em Mulvey et al. (1995) empregam a noção de otimização multiobjetivo para otimizar (indiretamente) o conflitante critério de robustez e custo, enquanto os modelos com restrição de recurso incorporam condições de robustez diretamente pela satisfação das restrições. Além disso, Mulvey et al. (1995) consideram a robustez da solução e do modelo, enquanto o foco de Vladimirou e Zenios (1997) é apenas controlar a variabilidade das decisões de segundo estágio, dado um conjunto de cenários.

O modelo geral de dois estágios com recurso restrito é obtido pela introdução de uma restrição que limita a variabilidade das decisões de segundo estágio. Tal restrição pode ser formulada, por exemplo, usando os valores médios calculados com base nas variáveis de segundo estágio. O modelo estocástico com restrição de recurso pode ser escrito da seguinte maneira:

$$
\begin{array}{lll}
\min & c^{T} x+\sum_{s \in \Omega} \pi_{s} q_{s}^{T} y_{s} & \\
\text { s.a. } & A x=b & \\
& T_{s} x+W_{s} y_{s}=h_{s} & \\
& \sum_{s \in \Omega} \pi_{s}\left\|y_{s}-\sum_{s^{\prime} \in \Omega} \pi_{s^{\prime}} y_{s^{\prime}}\right\| \leq \epsilon \\
& x, y_{s} \geq 0 & \\
& &
\end{array}
$$

em que $\| \cdot||$ denota a norma euclidiana e $\epsilon$ é uma tolerância estabelecida a priori. Note que esse modelo estocástico difere do modelo (3.5) apenas pela terceira restrição, que limita a variabilidade das decisões de segundo estágio. Reduzindo parametricamente a tolerância $\epsilon$, é possível observar o balanço entre o custo esperado e a variância das decisões de segundo estágio. O modelo (3.10) apresenta uma restrição não linear que impede a aplicação direta de métodos de decomposição e ainda dificulta a sua resolução exata pelos pacotes de otimização comerciais. No trabalho de Ahmed e Sahinidis (1998), os autores mostram que também é possível restringir os custos de segundo estágio em vez de limitar apenas as variáveis. Mais detalhes dessas diferenças são discutidos na Seção 3.2. Diferentemente da metodologia proposta em Mulvey et al. (1995), a estratégia de recurso restrito tem sido pouco utilizada, conforme Beraldi et al. (2003), Triki e Violi (2007).

\subsubsection{O Valor da Informação Perfeita e da Solução Estocástica}

Muitos modelos matemáticos são afetados pela aleatoriedade das variáveis, mas isso não implica que se deve, necessariamente, introduzi-la nos modelos. Tradicionalmente, a importância em considerar a aleatoriedade e/ou utilizar estratégias aproximadas é medida pelo Valor Esperado de Informação Perfeita (EVPI) e Valor da Solução Estocástica 
$(V S S)$.

O EVPI é obtido pela diferença entre o valor do problema estocástico $(R P)$ e o valor esperado das soluções wait-and-see $(W S)$, i.e., $E V P I=R P-W S$. Na literatura de programação estocástica, é usual designar $R P$ como o valor do problema recurso, enquanto $W S$ representa a expectância $W S=\sum_{s} \pi_{s} W S_{s}^{\star}$, em que $W S_{s}^{\star}$ é o valor do problema waitand-see de cada cenário $s \in \Omega$, i.e., é o valor ótimo do problema (3.5) para cada cada $s \in \Omega$ fixado ${ }^{1}$. Note que $W_{s}^{\star}$ é resolvido supondo-se informação perfeita sobre as variáveis aleatórias.

Segundo Birge e Louveaux (1997), o EVPI mede o quanto o decisor estaria disposto a pagar em troca de informação perfeita e precisa sobre o futuro. Para Kall e Wallace (1994), o EVPI representa quanto se esperaria ganhar se fosse possível determinar de antemão o valor das variáveis aleatórias. Para esses mesmos autores, o EVPI é importante porque mostra se é importante considerar a aleatoriedade do problema ou não. Não necessariamente, valores elevados para essa medida indicam a necessidade de resolver o problema estocástico. Por outro lado, quando o EVPI é baixo, tem-se a indicação de que não é tão importante considerar a aleatoriedade do problema e, portanto, aproximações podem funcionar bem.

O VSS pode ser considerado como o custo de ignorar a aleatoriedade dos parâmetros na escolha de uma decisão (Birge e Louveaux, 1997). Seu cálculo supõe que, em vez de resolver o problema estocástico (3.5), o decisor prefira resolver o problema do valor esperado $(E V)$, que consiste em substituir todas as variáveis aleatórias do problema pelos seus respectivos valores esperados.

Uma pergunta que advém da possibilidade de usar a solução do problema $E V$ é quão boa ou ruim é ela em comparação à solução $R P$. Para responder a esta pergunta, define-se o resultado esperado de usar a solução do problema $E V$, ou apenas $E E V$. O EEV é obtido fixando-se as variáveis de primeiro estágio encontradas pelo problema $E V$ no problema estocástico. O resultado exprime como as variáveis de decisão de segundo estágio são escolhidas otimamente em função das variáveis de primeiro estágio do problema $E V$. Finalmente, define-se o valor da solução estocástica como a diferença entre $R P$ e $E E V$, i.e., $V S S=E E V-R P$.

Pode-se também definir o problema $E V$ em função do cenário mais provável, ou de pior caso, e o problema $E E V$ é obtido de forma análoga. Em todas as situações, determinar VSS auxilia na comparação entre o problema estocástico e estratégias determinísticas

\footnotetext{
${ }^{1} \mathrm{O}$ problema (3.5) para cada cenário $s \in \Omega$ fixado pode ser visto como o próprio problema determinístico. Por isso é comum dizer que na determinação da medida EVPI são resolvidos $S$ problemas determinísticos. Entretanto, não é errado dizer que o problema (3.5) refere-se a um problema estocástico com apenas um único cenário (Lai et al., 2007).
} 
Tese de Doutorado

aproximadas. Quanto maior for o valor de VSS, maior é o ganho em considerar o problema estocástico em detrimento à estratégia aproximada adotada. Similarmente, se o valor for muito baixo (menor do que uma tolerância definida pelo decisor), o ganho em resolver o problema estocástico em vez do problema $E V$ é desprezível e, portanto, pode-se utilizar a estratégia aproximada de valor esperado.

\subsection{Planejamento da Produção via Programação Esto- cástica}

Em geral, o planejamento da produção de muitas empresas é realizado exclusivamente com dados supostamente conhecidos e determinísticos. Em empresas moveleiras típicas do setor, a realidade não é diferente. O gerente de produção utiliza informações sobre as carteiras de pedidos dos clientes, quantidade de produtos estocados e sua experiência para decidir os tamanhos dos lotes de produção semanais. Caso ocorra a chegada de novos pedidos ou algum imprevisto (quebra de algum equipamento, ausência de funcionários, etc.), a decisão é reavaliada num espaço de tempo menor. Em geral, a quantidade de produtos a serem produzidos $X(i)$ é obtida pela equação $X(i)=I(i)-D(i)$, em que $I(i)$ é a quantidade de produto $i$ atualmente em estoque e $D(i)$ é a sua demanda. Embora $I(i)$ possa ser facilmente determinado (uma simples verificação no estoque, por exemplo), a quantidade $D(i)$ é baseada numa expectativa de venda que nem sempre ocorre.

Nesse processo, como já comentado na Seção 1.1, o estoque tem um papel importante, mas ele acaba mascarando uma situação de incerteza inerente do processo de planejamento. Como o estoque é usado para atender pedidos urgentes e/ou ordens que surgem ao longo do horizonte de produção, e que não conseguem ser encaixadas com os demais pedidos (ou mesmo pela falta de capacidade da empresa em produzi-los), os lotes de produção são planejados levando-se em considerações altos níveis de estoque da maioria dos produtos. Essas estratégias geram problemas de atrasos na entrega de produtos considerados menos importantes (que não possuem um estoque de segurança, por exemplo), assim como uma grande dificuldade em gerir pedidos de outros produtos não previstos, especialmente quando esses pedidos vêm de clientes especiais (em geral, grandes atacadistas do setor moveleiro). Além disso, produzir para estocar como estratégia contra a flutuação da demanda, além dos custos de estoque em si, pode gerar um estoque indesejável de produtos que não têm mais procura, acarretando custos adicionais significativos de oportunidade, re-trabalho, entre outros.

Assim como a demanda é inerentemente estocástica, tempos de processamento e preparação que dependem da habilidade dos funcionários também o são. Tipicamente, 
o planejamento da produção leva em consideração tempos médios ou situações de pior caso que podem gerar planos obsoletos e/ou muito conservadores. Por um lado, utilizar somente valores médios e ignorar a variação do tempo de muitas atividades pode superestimar capacidades de máquinas e funcionários - acarretando em atrasos na linha de produção ou mesmo gerando planos infactíveis na prática. Por outro lado, adotar planos mais conservadores para mitigar a ação das incertezas pode subestimar a capacidade de produção, ocasionando uma contratação desnecessária de turnos e/ou funcionários extras. Ainda, os custos, que dependem do comportamento da economia, também podem ser difíceis de serem estimados ao longo do horizonte de planejamento e, por essa razão, têm caráter estocástico.

Uma análise inicial pode evidenciar a necessidade de considerar todos os parâmetros incertos: tempos de produção, preparação, demandas e custos diversos. Porém, nesse capítulo, foram feitas algumas simplificações. Primeiramente, os tempos de produção da máquina seccionadora e da furadeira são considerados fixos e conhecidos. Essa suposição é plausível, considerando que a maior carga de trabalho recai sobre as máquinas automáticas, cujos tempos de corte e furação são pré-estabelecidos pelo programador da máquina. Além disso, os custos foram considerados fixos e conhecidos ao longo do horizonte de planejamento. Tal suposição foi adotada para simplificar a análise dos modelos estocásticos e robustos, considerando que a modelagem por programação estocástica dos custos na função objetivo não adiciona nenhuma contribuição significativa a esse capítulo, contrariamente à modelagem por otimização robusta dos custos, presente no próximo capítulo. Finalmente, convém ressaltar que essas suposições podem ser ignoradas e os modelos desenvolvidos aqui podem ser estendidos para incorporar outras fontes de incertezas.

Por outro lado, até mesmo a preparação das máquinas automáticas deve ser feita manualmente. Na seccionadora, por exemplo, o ajuste inicial das placas que serão cortadas, a rotação das placas para serem cortadas segundo cortes guilhotinados e a troca das serras desgastadas são exemplos de operações executadas manualmente pelas funcionários. No estágio de furação, é necessário instalar diferentes brocas para furar peças com espessuras distintas e verificar a profundidade dos furos para evitar o rompimento das peças, tarefas as quais também são realizadas manualmente pelos funcionários da empresa. Além disso, todas essas atividades descritas dependem bastante da habilidade e da experiência do funcionário, motivo pelo qual as preparações são consideradas variáveis aleatórias independentes com alguma distribuição discreta conhecida. Finalmente, as demandas são também consideradas variáveis aleatórias independentes com alguma distribuição discreta conhecida, devido à dificuldade em estimar os pedidos que surgem ao longo do horizonte de planejamento e à ausência de dados históricos para fazer previsões confiáveis. 


\subsubsection{Formulação Matemática}

Considerando os tempos de preparação e as demandas como variáveis aleatórias com realizações discretas segundo distribuições de probabilidades conhecidas, é importante decidir sobre os estágios do modelo de programação estocástica. De acordo com o paradigma dos modelos de dois estágios, as decisões são executadas antes e depois da realização das variáveis aleatórias. Assim, define-se as decisões anteriores à realização das variáveis aleatórias como here-and-now, em contrapartida das decisões feitas após o conhecimento das variáveis aleatórias, designadas de wait-and-see.

Considerando o problema combinado de dimensionamento de lotes e corte de estoque proposto nesse trabalho, considera-se razoável que os níveis de produção em cada período do horizonte de planejamento sejam decididos antes da realização das variáveis aleatórias. Consequentemente, a frequência de utilização dos padrões de corte e a programação das preparações também. Então, tem-se que $X_{i t}, Y_{j t}$ e $Z_{j t}$ são as decisões de primeiro estágio do problema. Após o conhecimento das variáveis aleatórias, é possível adaptar a solução obtida pelas ações de segundo estágio de estocar ou atrasar a produção e utilizar horasextras, adotando $I_{i t}^{+}, I_{i t}^{-}$e $O_{t}$ como decisões de segundo estágio. Convém ressaltar que outras escolhas associadas aos estágios das variáveis de decisão poderiam ser interessantes em contextos diferentes.

A Figura 3.1 esquematiza o modelo de dois estágios adotado nesse trabalho e ilustra como seria um modelo de três estágios. No modelo de dois estágios, o decisor é forçado a determinar as variáveis de primeiro estágio para todo o horizonte de planejamento, antes mesmo de conhecer qualquer realização das variáveis aleatórias. Esse paradigma de modelagem apresenta as limitações óbvias, uma vez que, não necessariamente, o nível de produção do período $t$ depende da demanda real dos períodos $t+1 \mathrm{em}$ diante. Assim, no modelo de dois estágios, só existe um momento de realização das variáveis aleatórias, a partir do qual as variáveis de segundo estágio estão bem definidas. No modelo de três estágios, entretanto, existem dois momentos de realização das variáveis aleatórias, o que permite a escolha de parte das decisões de primeiro estágio que não dependem do segundo momento de realização das variáveis aleatórias.

Modelos multiestágios podem ser particularmente interessantes para representar situações em que as variáveis aleatórias ocorrem ao longo de um horizonte, e não em um momento apenas, pois em cada estágio (que pode coincidir com o período) as decisões são tomadas apenas com as informações existentes até aquele momento, e não é preciso antecipar ações futuras antes que novas variáveis aleatórias tornem-se conhecidas.

Nessa tese, preferiu-se desenvolver modelos de dois estágios por duas razões principais. Primeiro, os modelos multiestágios são muito mais difíceis de serem resolvidos do 
que os modelos de dois estágios, principalmente, em se tratando de modelos com variáveis discretas. Em segundo lugar, mesmo os modelos multiestágios sendo mais precisos e permitindo soluções superiores, a real melhoria na qualidade da solução pode ser desprezível e não justificar esforços computacionais extras para resolvê-los (Huang, 2005). Na literatura, são poucos os trabalhos que comparam modelos de dois e mais estágios para analisar se, de fato, as formulações multiestagiadas são superiores em termos de qualidade de solução. No trabalho de Riis e Andersen (2004), por exemplo, os autores desenvolveram formulações de dois e multiestágios para um problema de expansão de capacidade multiperíodo com demanda estocástica. Como o ganho em resolver o problema com vários estágios foi pequeno, os autores sugerem que a formulação de dois estágios deve ser utilizada em detrimento à multiestagiada, se o tempo computacional for um fator crítico.

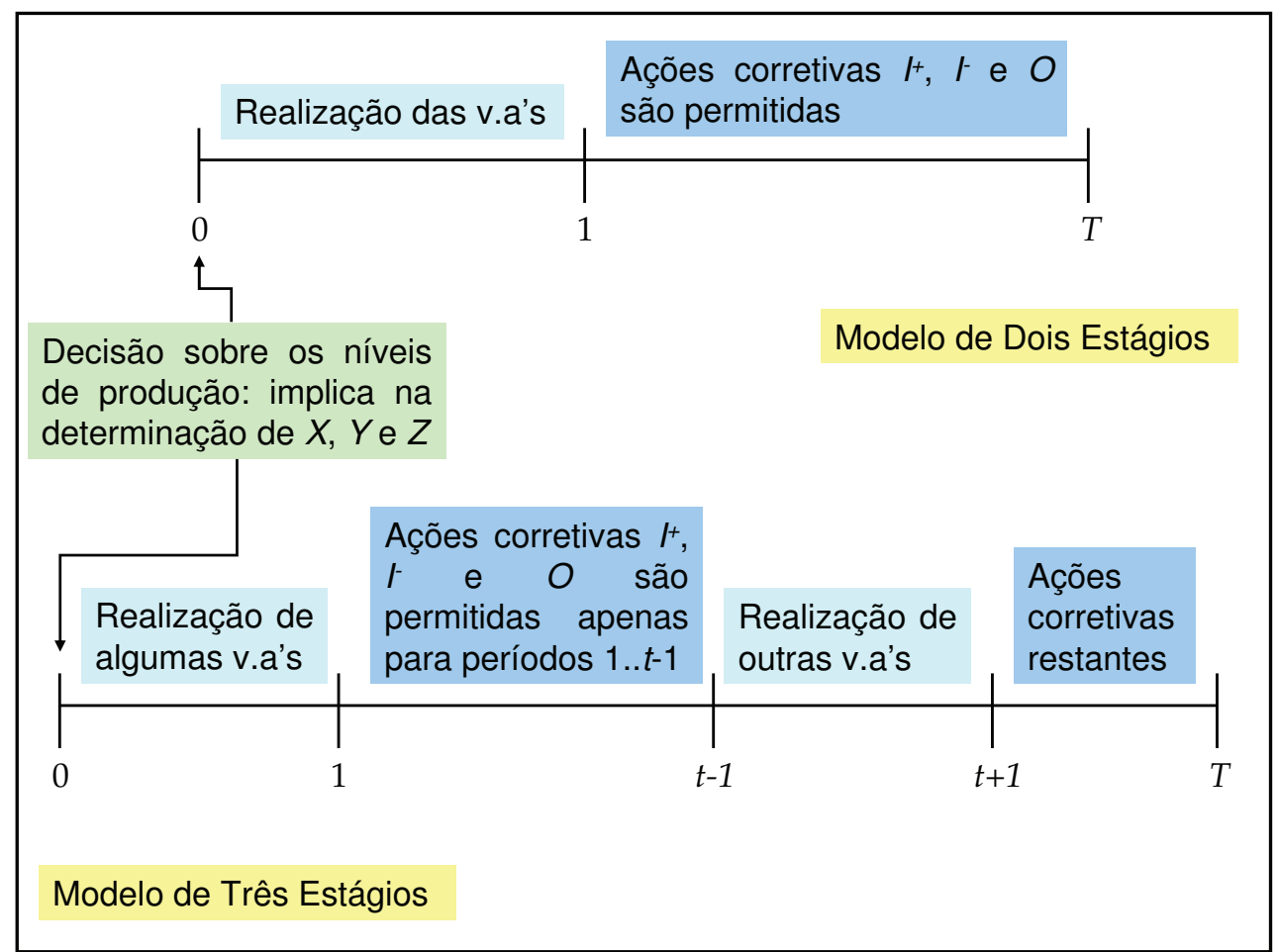

Figura 3.1: Esquema do paradigma da formulação estocástica de dois e três estágios aplicada ao problema combinado de dimensionamento de lotes e corte de estoque, considerando demandas e tempos de preparação estocásticos. As variáveis de decisão de primeiro estágio são relacionadas à produção $X$, frequência de padrões de corte $Y$ e preparações de máquina $Z$. As decisões de segundo estágio são representadas pelo estoque $I^{+}$, atraso $I^{-}$e horas-extras $O$.

Para formular os modelos estocásticos desse capítulo, considere a notação matemática adicional exibida na Tabela 3.1 e defina $X=\left\{X_{i t}, \forall i, t\right\}, Y=\left\{Y_{j t}, \forall j, t\right\}$ e $Z=\left\{Z_{j t}, \forall j, t\right\}$. 
Dados de Entrada Dependentes dos Cenários

$d_{i t s} \quad$ demanda do produto $i$ no período $t$ no cenário $s$

$\varphi_{j t s}^{I}$ tempo de preparação da seccionadora para cortar o padrão $j$ no período $t$ no cenário $s$

$\varphi_{\text {pts }}^{I I}$ tempo de preparação da furadeira para furar a peça $p$ no período $t$ no cenário $s$

$\pi_{s} \quad$ probabilidade de ocorrência do cenário $s$

Variáveis de Decisão de Primeiro Estágio

$X_{i t}$ quantidade de produto $i$ produzido no período $t$

$Y_{j t}$ frequência do padrão de corte $j$ no período $t$

$Z_{j t} \quad$ variável binária que é igual a 1 se a máquina seccionadora está preparada para processar o padrão de corte $j$ no período $t$, e vale 0 , caso contrário

Variáveis de Decisão de Segundo Estágio

$I_{i t s}^{+} \quad$ quantidade de produto $i$ em estoque ao final do período $t$ no cenário $s$

$I_{i t s}^{-} \quad$ quantidade de produto $i$ em atraso ao final do período $t$ no cenário $s$

$O_{t s} \quad$ hora-extra utilizada no período $t$ no cenário $s$

Tabela 3.1: Notação matemática adicional dos modelos estocásticos.

Então, o modelo de dois estágios com recurso pode ser escrito da seguinte forma:

$$
\begin{array}{ll}
\text { Minimizar } & \sum_{i \in \mathcal{I}} \sum_{t \in \mathcal{T}} c_{i t} X_{i t}+\sum_{j \in \mathcal{J}} \sum_{t \in \mathcal{T}} w_{j t} Y_{j t}+\sum_{s \in \Omega} \pi_{s} Q\left(X, Y, Z, \xi_{s}\right) \\
\text { Sujeito a: } & \text { restrições }(2.3),(2.8),(2.10),(2.16) \mathrm{e}(2.17)
\end{array}
$$

em que $Q\left(X, Y, Z, \xi_{s}\right)$ é o valor ótimo do problema de segundo estágio (3.12) para cada $s \in \Omega:$

$$
\begin{array}{ll}
Q\left(X, Y, Z, \xi_{s}\right) & =\text { Minimizar } \sum_{i \in \mathcal{I}} \sum_{t \in \mathcal{T}}\left(h_{i t}^{+} I_{i t s}^{+}+h_{i t}^{-} I_{i t s}^{-}\right)+\sum_{t \in \mathcal{T}} o_{t} O_{t s} \\
\text { Sujeito a: } & X_{i t}+I_{i, t-1, s}^{+}-I_{i t s}^{+}+I_{i t s}^{-}-I_{i, t-1, s}^{-}=d_{i t s}, i \in \mathcal{I}, t \in \mathcal{T}, s \in \Omega \\
& 0 \leq I_{i t s}^{+} \leq I_{i t}^{\max }, i \in \mathcal{I}, t \in \mathcal{T}, s \in \Omega \\
& \sum_{j \in \mathcal{J}}\left(\nu_{j}^{I} Y_{j t}+\varphi_{j t s}^{I} Z_{j t}\right) \leq C_{t}^{I}+O_{t s}, t \in \mathcal{T}, s \in \Omega \\
& \sum_{p \in \mathcal{P}} \sum_{j \in \mathcal{J}}\left(\nu_{p}^{I I} a_{p j} Y_{j t}+\varphi_{p t s}^{I I} \delta_{p j} Z_{j t}\right) \leq C_{t}^{I I}+O_{t s}, t \in \mathcal{T}, s \in \Omega \\
& 0 \leq O_{t s} \leq C_{t}^{E}, t \in \mathcal{T}, s \in \Omega \\
& I_{i t s}^{-} \geq 0, i \in \mathcal{I}, t \in \mathcal{T}, s \in \Omega .
\end{array}
$$

O problema (3.11) representa as variáveis de decisão de primeiro estágio, em que o objetivo é minimizar a soma dos custos fixos de produção e matéria-prima, e os custos 
variáveis de segundo estágio, enquanto o problema (3.12) está associado às variáveis de decisão de segundo estágio. A função $Q(\cdot)$ representa o custo aleatório de segundo estágio para cada cenário s para um dado nível de produção, configuração de padrão de corte e preparação de máquinas, também chamado de recurso aleatório. As restrições (3.12) são similares às suas versões determinísticas, mas devem ser satisfeitas para todo cenário $s \in \Omega$.

O recurso de segundo estágio também pode estar explicitamente descrito na função objetivo, combinando ambos os estágios, assim como apresentado no modelo (3.13) - (3.22). Essa formulação é denominada $C L C 2 r$.

$$
\begin{aligned}
\text { Minimizar } & \sum_{t \in \mathcal{T}}\left\{\sum_{i \in \mathcal{I}} c_{i t} X_{i t}+\sum_{j \in \mathcal{J}} w_{j t} Y_{j t}\right\}+\sum_{t \in \mathcal{T}} \sum_{s \in \Omega} \pi_{s}\left\{\sum_{i \in \mathcal{I}}\left(h_{i t}^{+} I_{i t s}^{+}+h_{i t}^{-} I_{i t s}^{-}\right)+o_{t} O_{t s}\right\} \\
\text { Sujeito a: } & X_{i t}+I_{i, t-1, s}^{+}-I_{i t s}^{+}+I_{i t s}^{-}-I_{i, t-1, s}^{-}=d_{i t s}, i \in \mathcal{I}, t \in \mathcal{T}, s \in \Omega \\
& 0 \leq I_{i t s}^{+} \leq I_{i t}^{\max }, i \in \mathcal{I}, t \in \mathcal{T}, s \in \Omega \\
& \sum_{j \in \mathcal{J}}\left(\nu_{j}^{I} Y_{j t}+\varphi_{j t s}^{I} Z_{j t}\right) \leq C_{t}^{I}+O_{t s}, t \in \mathcal{T}, s \in \Omega \\
& \sum_{p \in \mathcal{P}} \sum_{j \in \mathcal{J}}\left(\nu_{p}^{I I} a_{p j} Y_{j t}+\varphi_{p t s}^{I I} \delta_{p j} Z_{j t}\right) \leq C_{t}^{I I}+O_{t s}, t \in \mathcal{T}, s \in \Omega \\
& 0 \leq O_{t s} \leq C_{t}^{E}, t \in \mathcal{T}, s \in \Omega \\
& I_{i t s}^{-} \geq 0, i \in \mathcal{I}, t \in \mathcal{T}, s \in \Omega \\
& \text { Restrição de acoplamento }(2.3) \\
& \text { Restrição de preparação }(2.16) \\
& \text { Domínio das variáveis de primeiro estágio (2.8),(2.10),(2.17). }
\end{aligned}
$$

Observe que o problema de segundo estágio (3.12) é factível para qualquer realização das variáveis aleatórias. Tome, por exemplo, o caso extremo em que $I_{i t s}^{-}=\sum_{\tau=1}^{t} d_{i \tau s}$, com as outras variáveis trivialmente zero. Portanto, o problema (3.11)-(3.12) tem recurso relativamente completo. Nesse caso, tem-se que todo terno $(X, Y, Z)$ pertencente ao conjunto $\mathcal{X}$, definido por:

$$
\begin{array}{r}
\mathcal{X}=\left\{(X, Y, Z) \mid \sum_{j \in \mathcal{J}} a_{p j} Y_{j t} \geq \sum_{i \in \mathcal{I}} r_{p i} X_{i t}, Y_{j t} \leq M Z_{j t}, X_{i t}, Y_{j t} \geq 0, Z_{j t} \in\{0,1\},\right. \\
i \in \mathcal{I}, j \in \mathcal{J}, t \in \mathcal{T}\}
\end{array}
$$


implica que o conjunto factível de segundo estágio é não-vazio para todo $s \in \Omega$. Ou seja, o recurso é relativamente completo se para todo $(X, Y, Z)$ factível, a inequação $Q\left(X, Y, Z, \xi_{s}\right)<+\infty$ é assegurada para todo $s$. Essa última condição já seria suficiente para que o problema tivesse recurso relativamente completo. Ainda, como as variáveis aleatórias têm um suporte finito ( $\Omega$ tem cardinalidade finita), tal condição torna-se necessária e suficiente.

Além disso, qualquer exemplar do modelo $C L C 2 r$ é factível, a não ser que a condição $I_{i T s}^{-}=0, \forall i, s$ seja imposta (prova similar à propriedade de factibilidade 2.1; veja a Seção 2.1 do Capítulo 2).

\subsubsection{Formulação com Restrições de Não-Antecipação}

Note que (3.11)-(3.12) pode ser relaxado pela substituição das variáveis de primeiro estágio por $S$ diferentes realizações $X_{i t s}, Y_{j t s}$ e $Z_{j t s}$ :

Minimizar $\sum_{t \in \mathcal{T}} \sum_{s \in \Omega} \pi_{s}\left\{\sum_{i \in \mathcal{I}}\left(c_{i t} X_{i t s}+h_{i t}^{+} I_{i t s}^{+}+h_{i t}^{-} I_{i t s}^{-}\right)+\sum_{j \in \mathcal{J}} w_{j t} Y_{j t s}+o_{t} O_{t s}\right\}$

Sujeito a: $\quad X_{i t s}+I_{i, t-1, s}^{+}-I_{i t s}^{+}+I_{i t s}^{-}-I_{i, t-1, s}^{-}=d_{i t s}, \forall i \in \mathcal{I}, t \in \mathcal{T}, s \in \Omega$

$\sum_{j \in \mathcal{J}} a_{p j} Y_{j t s} \geq \sum_{i \in \mathcal{I}} r_{p i} X_{i t s}, \forall p \in \mathcal{P}, t \in \mathcal{T}, s \in \Omega$

$0 \leq I_{i t s}^{+} \leq I_{i t}^{\max }, \forall i \in \mathcal{I}, t \in \mathcal{T}, s \in \Omega$

$\sum_{j \in \mathcal{J}}\left(\nu_{j}^{I} Y_{j t s}+\varphi_{j t s}^{I} Z_{j t s}\right) \leq C_{t}^{I}+O_{t s}, t \in \mathcal{T}, s \in \Omega$
$\sum_{p \in \mathcal{P}} \sum_{j \in \mathcal{J}}\left(\nu_{p}^{I I} a_{p j} Y_{j t s}+\varphi_{p t s}^{I I} \delta_{p j} Z_{j t s}\right) \leq C_{t}^{I I}+O_{t s}, t \in \mathcal{T}, s \in \Omega$

$0 \leq O_{t s} \leq C_{t}^{E}, t \in \mathcal{T}, s \in \Omega$

$I_{i t s}^{-} \geq 0, \forall i \in \mathcal{I}, t \in \mathcal{T}, s \in \Omega$

$Y_{j t s} \leq Q Z_{j t s}, j \in \mathcal{J}, t \in \mathcal{T}, s \in \Omega$

$X_{i t s} \geq 0, i \in \mathcal{I}, t \in \mathcal{T}, s \in \Omega$

$Y_{j t s} \geq 0, Z_{j t s} \in\{0,1\}, j \in \mathcal{J}, t \in \mathcal{T}, s \in \Omega$.

Dessa maneira, o problema (3.24) torna-se separável - no sentido de que é possível dividi-lo em $S$ problemas menores, um para cada cenário - o que pode facilitar a sua resolução numérica (note que a resolução do problema decomposto não considera as $S$ realizações da variável binária, por exemplo). Entretanto, (3.24) não é indicado 
para modelar contextos de dois estágios, pois as variáveis de primeiro estágio são agora cenário-dependentes. Para utilizar (3.24) em processos de dois estágios, basta adicionar à formulação apresentada restrições que não permitam a variação das variáveis de primeiro estágio em cada cenário, i.e.,

$$
X_{i t s}=X_{i t s^{\prime}}, Y_{j t s}=Y_{j t s^{\prime}}, Z_{j t s}=Z_{j t s^{\prime}}, i \in \mathcal{I}, j \in \mathcal{J}, t \in \mathcal{T}, 1 \leq s \leq s^{\prime} \leq S
$$

O problema (3.24) em conjunto com as restrições (3.25) é equivalente ao modelo CLC2r. As restrições (3.25) são denominadas restrições de não-antecipação (nonanticipativity constraints) e asseguram que as decisões de primeiro estágio são independentes da realização de segundo estágio das variáveis aleatórias. De maneira similar, tais restrições de não-antecipação são utilizadas para estruturar as informações numa árvore de cenários em problemas de programação estocástica multiestágios.

\subsubsection{Determinação das Medidas EVPI e $V S S$}

O cálculo da medida EVPI implica na resolução de $S$ problemas determinísticos (problemas wait-and-see) do tipo $C L C 2$, nos quais $\varphi_{j t}^{I}=\varphi_{j t s}, \varphi_{p t}^{I I}=\varphi_{p t s}$ e $d_{i t}=d_{i t s}$, para $s=1, \cdots, S$. Como esses problemas são factíveis para qualquer dado de entrada (veja propriedade de factibilidade 2.1 na Seção 2.1 do Capítulo 2), então para todo $s \in \Omega$ existe uma solução factível, de tal forma que a esperança $W S=\sum_{s} \pi_{s} W S_{s}^{\star}$ é bem definida (finita) e, portanto, $0 \leq E V P I \leq+\infty$.

O cálculo do valor da solução estocástica, por sua vez, requer apenas a resolução de dois problemas: $E V$ e $E E V$. Tipicamente, o problema $E V$ é um problema wait-and-see de valor esperado, i.e., $\varphi_{j t}^{I}=\sum_{s} \pi_{s} \varphi_{j t s}, \varphi_{p t}^{I I}=\sum_{s} \pi_{s} \varphi_{p t s}$ e $d_{i t}=\sum_{s} \pi_{s} d_{i t s}$. É possível também que o problema $E V$ seja definido a partir de um cenário de referência qualquer, como o cenário de pior caso ou o mais provável. Qualquer que seja a definição de $E V$, a sua factibilidade é sempre assegurada. Entretanto, o problema $E E V$ não tem garantia de factibilidade, a não ser que algumas condições sejam satisfeitas, como mostra a proposição $(3.1)$.

Proposição 3.1 Considere o problema EEV com as variáveis de primeiro estágio fixadas de acordo com o problema $E V: X_{i t}=X_{i t}^{\star}, Y_{j t}=Y_{j t}^{\star}$ e $Z_{j t}=Z_{j t}^{\star}(i \in \mathcal{I}, j \in \mathcal{J}, t \in \mathcal{T})$. Então,

i) $I_{i t}^{\max }=\sum_{\tau=1}^{t}\left(\bar{X}_{i \tau}^{\star}-d_{i \tau s}\right) e$ 
ii) $C_{t}^{E} \geq \max \left\{\sum_{j \in \mathcal{J}}\left(\nu_{j}^{I} Y_{j t}^{\star}+\varphi_{j t s}^{I} Z_{j t}^{\star}-C_{t}^{I}\right), \sum_{p \in \mathcal{P}} \sum_{j \in \mathcal{J}}\left(\nu_{p}^{I I} a_{p j} Y_{j t}^{\star}+\varphi_{p t s}^{I I} \delta_{p j} Z_{j t}^{\star}-C_{t}^{I I}\right)\right\}$,

são condições suficientes para que o problema EEV seja factivel para qualquer cenário de referência.

Prova. Para que o problema EEV seja factível, basta garantir que as restrições de balanceamento de estoque (3.14) e de capacidades (3.16) e (3.17) sejam satisfeitas para quaisquer variáveis de primeiro estágio fixadas. Primeiramente, suponha que $I_{i t s}^{-}=0, \forall i, t, s$. Sem perda de generalidade, admita que $I_{i 0 s}^{+}=0$. Então,

$$
\begin{aligned}
& I_{i 1 s}^{+}=X_{i 1}^{\star}-d_{i 1 s}, i \in \mathcal{I}, s \in \Omega \\
& I_{i 2 s}^{+}=X_{i 1}^{\star}+X_{i 2}^{\star}-d_{i 1 s}-d_{i 2 s}, i \in \mathcal{I}, s \in \Omega \\
& I_{i 3 s}^{+}=X_{i 1}^{\star}+X_{i 2}^{\star}+X_{i 3}^{\star}-d_{i 1 s}-d_{i 2 s}-d_{i 3 s}, i \in \mathcal{I}, s \in \Omega \\
& \vdots \\
& I_{i t s}^{+}=\sum_{\tau=1}^{t}\left(X_{i t}^{\star}-d_{i \tau s}\right), i \in \mathcal{I}, s \in \Omega \\
& \vdots \\
& I_{i T s}^{+}=\sum_{\tau=1}^{T}\left(X_{i t}^{\star}-d_{i \tau s}\right), i \in \mathcal{I}, s \in \Omega
\end{aligned}
$$

pode ser visto como o excesso máximo de produção gerado em cada período do horizonte de planejamento. Assim, limitando-se o estoque máximo a essa quantidade, garante-se a factibilidade da restrição (3.14). Se $I_{i 0 s}^{+} \geq 0$, então $I_{i t}^{+} \leq I_{i t}^{\max }$ e a condição (i) ainda é válida.

Da condição (ii), tem-se que é possível determinar $O_{t s}$ tal que $O_{t s} \leq C_{t}^{E}(t \in \mathcal{T}, s \in$ $\Omega$ ), de modo que o máximo consumo de capacidade do processo gargalo seja satisfeito para quaisquer $Y_{j t}^{\star}$ e $Z_{j t}^{\star}$ fixados, o que assegura a factibilidade das restrições (3.16) e $(3.17)$.

Da definição do valor da solução estocástica, sabe-se que o problema $E V$ pode ser uma boa aproximação do problema estocástico $C L C 2 r$, se $V S S$ for menor do que uma tolerância pré-estabelecida. Se VSS for elevado, significa que existe um ganho adicional em modelar e resolver o problema estocástico e, por essa razão, justifica-se resolvê-lo. Quando $E E V$ é infactível, tem-se que o problema $E V$ não pode ser utilizado para aproximar o problema estocástico. Nesse caso, representa-se $V S S \rightarrow+\infty$ e o problema estocástico deve ser adotado sem restrições. 


\subsubsection{Modelos Estocásticos e Aversão ao Risco}

O modelo $C L C 2 r$ é neutro em relação ao risco, i.e., a função objetivo otimiza apenas um valor esperado. De acordo com Shapiro et al. (2009), isto é justificado quando se pode invocar a Lei dos Grandes Números ${ }^{2}$ e o interesse é num desempenho do modelo a longo prazo, sem considerar as flutuações de uma realização específica. Todavia, quando se torna importante controlar a variabilidade das realizações, é necessário incorporar uma medida de risco no modelo. Nesse capítulo, é utilizada uma medida de risco do tipo desvio médio-absoluto, já apresentada na Seção 3.1.2. Essa medida de risco é simples de ser incorporada ao modelo, e ainda permite que o decisor controle a robustez do modelo e da solução, a partir da sua atitude em relação ao risco. Além da medida de risco, variáveis de erro são adicionadas ao modelo para controlar as violações das restrições de balanceamento de demanda.

\section{Modelo Min-Max}

Para formular o problema Min-Max, é necessário determinar as soluções wait-and-see $W S_{s}^{\star}$, que são obtidas pela resolução do problema $C L C 2$ r (3.13)-(3.22) para cada cenário $s \in \Omega$. Tais soluções representam o menor custo total de produção se as variáveis aleatórias fossem perfeitamente conhecidas. Em seguida, é preciso minimizar o desvio (arrependimento) máximo da função objetivo entre o custo ideal e o custo de cada cenário, para todo $s \in \Omega$. Seja $\zeta_{s}=\sum_{i, t}\left(c_{i t} X_{i t}+h_{i t}^{+} I_{i t s}^{+}+h_{i t}^{-} I_{i t s}^{-}\right)+\sum_{j, t}\left(w_{j t} Y_{j t}+\sum_{t} o_{t} O_{t s}\right)$ o valor da função objetivo do problema de dois estágios CLC2r. Então, o problema Min-Max pode ser escrito da seguinte maneira:

$$
\begin{array}{ll}
\text { Minimizar } & \Delta \\
\text { Sujeito a: } & \zeta_{s}=\sum_{t \in \mathcal{T}}\left\{\sum_{i \in \mathcal{I}}\left(c_{i t} X_{i t}+h_{i t}^{+} I_{i t s}^{+}+h_{i t}^{-} I_{i t s}^{-}\right)+\sum_{j \in \mathcal{J}} w_{j t} Y_{j t}+o_{t} O_{t s}\right\}, \forall s \\
& \Delta \geq \zeta_{s}-W S_{s}^{\star}, \forall s \\
& \Delta \geq 0 \\
& \text { Restrições }(3.14)-(3.22) .
\end{array}
$$

A função objetivo combinada com as duas primeiras restrições assegura que o desvio (arrependimento) máximo $\Delta$ entre o problema de dois estágios e os valores da função objetivo do problema wait-and-see $\left(W S_{s}^{\star}\right)$ seja minimizado. Note que não é necessário

\footnotetext{
${ }^{2}$ De forma simplificada, se a Lei dos Grandes Números é válida, então, após um número suficientemente grande de repetições de um experimento aleatório, a média dos resultados dos experimentos converge com probabilidade um para o seu valor esperado teórico (Shapiro et al., 2009).
} 
garantir $\zeta_{s} \geq W S_{s}^{\star}$, pois $\Delta \geq 0$ assegura que, de fato, apenas os desvios desfavoráveis são considerados. A formulação (3.27) é especialmente indicada para decisores com aversão ao risco muito conservadores, pois apenas o cenário de pior caso é considerado. O critério Max-Min também é indicado numa situação em que não há uma estimativa razoável das probabilidade dos cenários, pois essa informação não é utilizada pelo modelo.

Por outro lado, o modelo (3.27) pode ser inapropriado se as estimativas das probabilidades estiverem disponíveis e o cenário de pior caso possuir uma probabilidade de ocorrência desprezível. Uma maneira de evitar soluções muito conservadores é utilizar uma versão similar em que se determina o arrependimento esperado. Basta definir $\Delta_{s}$ como o arrependimento do cenário $s$, de modo que $\Delta_{s} \geq \zeta_{s}-W S_{s}^{\star}, \forall s$, com objetivo de minimizar $\sum_{s} \pi_{s} \Delta_{s}$ e $\Delta_{s} \geq 0$. Assim, a contribuição de todos os cenários é considerada e a solução é menos pessimista. Outros trabalhos consideram um nível de confiabilidade para evitar soluções de pior caso muito conservadores, como em Daskin et al. (1997) e Chen et al. (2006).

\section{Modelo Média-Risco $(M R)$}

Similarmente aos modelos baseados no critério Min-Max já apresentados, o modelo MédiaRisco também incorpora a noção de minimizar desvios em relação a algum cenário de referência. Entretanto, o cenário de referência adotado é o próprio valor esperado do problema estocástico, de modo que a formulação matemática torna-se:

$$
\begin{array}{ll}
\text { Minimizar } & \sum_{s \in \Omega} \pi_{s} \zeta_{s}+\lambda \sum_{s \in \Omega} \pi_{s} \Delta_{s} \\
\text { Sujeito a: } & \zeta_{s}^{R}=\sum_{i \in \mathcal{I}} \sum_{t \in \mathcal{T}}\left(h_{i t}^{+} I_{i t s}^{+}+h_{i t}^{-} I_{i t s}^{-}\right)+\sum_{t \in \mathcal{T}} o_{t} O_{t s}, s \in \Omega \\
& \Delta_{s} \geq \zeta_{s}^{R}-\sum_{s^{\prime} \in \Omega} \pi_{s^{\prime}} \zeta_{s^{\prime}}^{R}, s \in \Omega \\
& \Delta_{s} \geq 0, s \in \Omega \\
& \text { Restrições }(3.14)-(3.22) .
\end{array}
$$

Observe que, diferentemente dos modelos anteriores baseados no critério Min-Max, em que os valores das funções objetivos dos problemas wait-and-see são dados de entrada, nesse formulação média-risco, o valor associado a cada cenário e o custo esperado total são calculados implicitamente pela segunda restrição.

O modelo também tem um caráter multicritério com dois objetivos explícitos na função objetivo: a primeira parcela representa o custo total médio ou esperado (soma dos custos de primeiro e segundo estágios) que ignora o custo de variabilidade, enquanto a segunda parcela é exatamente o custo da variabilidade ponderado pelo parâmetro de risco 
$\lambda$. Quanto maior for o desvio $\Delta_{s}$, maior é o risco atribuído à solução para um dado $s$, uma vez que, nesse caso, a solução do cenário $s$ é superior ao custo total esperado. Então, ao se minimizar o desvio, os custos dos diferentes cenários tendem a se aproximar e, com isso, a solução ótima de um cenário $s$ permanece "perto" da solução ótima para qualquer outro cenário $s^{\prime}$, e a solução é dita robusta.

Para $\lambda=0$, a parcela referente ao risco é ignorada e os modelos $C L C 2 r$ e $M R$ são equivalentes. A princípio, não há um valor máximo para $\lambda$. Diz-se, simplesmente, que quanto maior é esse valor, mais o decisor é averso ao risco, no sentido que ele está disposto a sacrificar o custo total esperado em troca de obter soluções mais robustas. Em geral, são resolvidos vários modelos MR para cada valor de $\lambda$ num intervalo definido, para ser possível determinar curvas de tradeoff entre custo total e robustez. Assim, o decisor pode fazer a escolha de $\lambda$ de acordo com a sua atitude em relação ao risco.

\section{Modelo com Recurso Restrito $(R R)$}

Também pode ser interessante restringir $\Delta_{s}$ a uma tolerância pré-estabelecida, $\Delta_{\max }$, e remover o respectivo termo na função objetivo, da seguinte maneira:

$$
\begin{array}{ll}
\text { Minimizar } & \sum_{s \in \Omega} \pi_{s} \zeta_{s} \\
\text { Sujeito a: } \quad & \zeta_{s}^{R}=\sum_{i \in \mathcal{I}} \sum_{t \in \mathcal{T}}\left(h_{i t}^{+} I_{i t s}^{+}+h_{i t}^{-} I_{i t s}^{-}\right)+\sum_{t \in \mathcal{T}} o_{t} O_{t s}, s \in \Omega \\
& \Delta_{s} \geq \zeta_{s}^{R}-\sum_{s^{\prime} \in \Omega} \pi_{s^{\prime}} \zeta_{s^{\prime}}^{R}, s \in \Omega \\
& \sum_{s \in \Omega} \pi_{s} \Delta_{s} \leq \Delta_{\max }, \\
& \Delta_{s} \geq 0, s \in \Omega \\
& \text { Restrições }(3.14)-(3.22) .
\end{array}
$$

A formulação (3.29) é chamada de Modelo com Recurso Restrito $(R R)$ e gera uma série de soluções cada vez menos sensíveis à variação dos cenários quando o parâmetro $\Delta_{\max }$ é decrementado sucessivamente. Observe que as formulações (3.29) e (3.28) têm filosofias semelhantes. De fato, pode-se mostrar que ambas são equivalentes de acordo com a proposição 3.2 (Ahmed e Sahinidis, 1998):

Proposição 3.2 Dada uma tolerância $\Delta_{\max },\left(X^{\star}, I^{+\star}, I^{-\star}, Y^{\star}, Z^{\star}, O^{\star}, \Delta^{\star}\right)$ é solução ótima do modelo (3.29) se e somente se existe $\lambda \geq 0$ tal que $\left(X^{\star}, I^{+\star}, I^{-\star}, Y^{\star}, Z^{\star}, O^{\star}, \Delta^{\star}\right)$ é solução ótima o modelo (3.28).

Prova: Seja a variável $\lambda$ utilizada para dualizar a restrição de desvio máximo do modelo. 
Então, o problema por relaxação Lagrangeana é dado por:

$$
\begin{array}{ll}
\text { Minimizar } & \sum_{s \in \Omega} \pi_{s} \zeta_{s}+\lambda\left(\Delta_{\max }-\sum_{s \in \Omega} \pi_{s} \Delta_{s}\right) \\
\text { Sujeito a: } & \zeta_{s}^{R}=\sum_{i \in \mathcal{I}} \sum_{t \in \mathcal{T}}\left(h_{i t}^{+} I_{i t s}^{+}+h_{i t}^{-} I_{i t s}^{-}\right)+\sum_{t \in \mathcal{T}} o_{t} O_{t s}, s \in \Omega \\
& \Delta_{s} \geq \zeta_{s}^{R}-\sum_{s^{\prime} \in \Omega} \pi_{s^{\prime}} \zeta_{s^{\prime}}^{R}, s \in \Omega \\
& \Delta_{s} \geq 0, s \in \Omega \\
& \text { Restrições }(3.14)-(3.22) .
\end{array}
$$

Como a restrição de desvio máximo é convexa, por dualidade forte tem-se que $\left(X^{\star}, I^{+\star}, I^{-\star}, Y^{\star}, Z^{\star}, O^{\star}, \Delta^{\star}\right)$ é solução ótima de (3.29) se e somente se existe $\lambda \geq 0$ tal que $\left(X^{\star}, I^{+\star}, I^{-\star}, Y^{\star}, Z^{\star}, O^{\star}, \Delta^{\star}\right)$ é solução ótima de (3.30). Claramente, a solução é ótima para (3.30) se e somente se é ótima para (3.28).

Observe, entretanto, que para comprovar empiricamente a igualdade dos valores ótimos de ambos os problemas, é preciso corrigir a função objetivo do problema (3.28), subtraindo o custo de risco $\lambda \sum_{s \in \Omega} \pi_{s} \Delta_{s}$. Após a correção, para um dado desvio $\Delta_{\max }$, os valores ótimos dos problemas (3.28) e (3.29) têm que coincidir.

A Tabela 3.2 mostra o número de restrições e de variáveis contínuas/binárias do modelo determinístico $C L C 2$, do modelo estocástico, e dos modelos estocásticos robustos. Note que, embora o número de variáveis binárias não se altere nas formulações estocásticas (e robustas), o número de restrições e de variáveis contínuas cresce com o número de cenários, o que pode comprometer a resolução de exemplares mais complexos.

\begin{tabular}{llll}
\hline \multirow{2}{*}{ Modelo } & Restrições & \multicolumn{2}{c}{ Variáveis de Decisão } \\
\cline { 2 - 4 } CLC2 & $I T+P T+2 T+J T$ & Contínuas & Binárias \\
\hline$L C 2 r$ & $I T S+P T+2 T S+J T$ & $I T+2 I T S+J T+T S$ & $J T$ \\
Min-Max & $I T S+P T+2 T S+J T+1$ & $I T+2 I T S+J T+T S+S+1$ & $J T$ \\
$M R$ & $I T S+P T+2 T S+J T+S$ & $I T+2 I T S+J T+T S+S$ & $J T$ \\
$R R$ & $I T S+P T+2 T S+J T+S+1$ & $I T+2 I T S+J T+T S+S$ & $J T$ \\
\hline
\end{tabular}

Tabela 3.2: Comparação entre os modelos CLC2, CLC2r, Min-Max, $M R$ e $R R$ em termos de número de restrições, número de variáveis contínuas e número de variáveis binárias.

\subsection{Experimentos Computacionais}

Nessa seção, são apresentados os resultados computacionais referentes aos modelos matemáticos estocásticos e robustos apresentados. Os modelos foram codificados no Sistema de 
Modelagem Algébrica GAMS (McCarl et al., 2010) e resolvidos pelo software ILOG-Cplex 11.0 (ILOG, 2008), usando-se os valores default para todos os parâmetros do CPLEX. Os experimentos foram executados num notebook Core 2 Duo 4, 4.0 GB de memória RAM, 2.0 GHz, sob a plataforma Windows VISTA. Os dados utilizados referem-se a um exemplo real da Fábrica X, os quais estão descritos na Seção 2.5 (Classe 1), considerando-se 3 produtos e 8 períodos do horizonte de planejamento; qualquer exceção será explicitamente descrita. O tempo limite de resolução dos problemas foi considerado 4200s, mas todos foram resolvidos até a prova de otimalidade pelo CPLEX num tempo inferior a este limite. Por essa razão, não foi necessário adaptar e aplicar as heurísticas RFP ou RFR do Capítulo 2 para resolver os exemplares desse capítulo.

Na literatura científica, há diversas maneiras de gerar os cenários associados à realização das variáveis aleatórias (veja o trabalho de Dupacová et al. (2000) para uma revisão dos métodos de geração de cenários). Nesse trabalho, foram adotadas duas formas. A forma ( $i$ ) é ilustrada no Teste A e considera a geração dos cenários de acordo com a combinação dos parâmetros estocásticos (demandas, tempos de preparação da serra e tempos de preparação da furadeira), como no trabalho de Ma et al. (2010). A segunda forma (ii) é mostrada no Teste B e consiste, basicamente, na enumeração de algumas realizações discretas e equiprováveis, como nos trabalhos de Geng et al. (2009) e Pan e Nagi (2010), por exemplo.

\subsubsection{Teste A}

Para construir a árvore de cenários, associa-se cada parâmetro estocástico a três possíveis realizações, que são definidas qualitativamente por variáveis linguísticas. A demanda estocástica pode ser classificada como Baixa, Média ou Alta; e os tempos de preparação estocásticos (da serra e da furadeira) podem ser qualificados em Baixo, Médio ou Alto. A essas variáveis linguísticas foram associados valores numéricos relacionados aos valores nominais. As demandas não-inteiras foram arredondadas para o menor inteiro maior que o valor fracionário. Combinando as realizações dos parâmetros estocásticos, tem-se a árvore de cenários apresentada na Figura 3.2. Como são três parâmetros estocásticos e três possíveis realizações para cada um, $3^{3}$ cenários foram gerados.

As realizações associadas às demandas nos cenários baixos (B), médios (M) e altos (A) seguiram uma distribuição uniforme discreta nos intervalos $\left[0,7 d_{i t} ; 0,95 d_{i t}\right],\left[0,95 d_{i t}\right.$; $\left.1,05 d_{i t}\right]$ e $\left[1,05 d_{i t} ; 1,3 d_{i t}\right]$, respectivamente, em que $d_{i t}$ é o valor nominal da variável aleatória. As realizações associadas aos tempos de preparação foram geradas de maneira análoga, segundo uma distribuição uniforme contínua, nesses casos. As probabilidades associadas aos 27 cenários da árvore ilustrada na Figura 3.2 foram calculadas pela regra 
do produto, supondo independência entre as variáveis aleatórias e considerando as probabilidades de todas as variáveis aleatórias nos cenários B, M e A iguais 25, 50, 25\% (situação moderada), respectivamente. A probabilidade do cenário 1 (Baixa-Baixo-Baixo), por exemplo, foi obtida da seguinte maneira: $\pi_{B}^{I}$ (probabilidade da demanda ser baixa) $\times \pi_{B}^{I I}$ (probabilidade do tempo de preparação da serra ser baixo) $\times \pi_{B}^{I I I}$ (probabilidade do tempo de preparação da furadeira ser baixo) $=\pi_{B}^{I} \pi_{B}^{I I} \pi_{B}^{I I I}=0,25^{3}=0,015625$. 


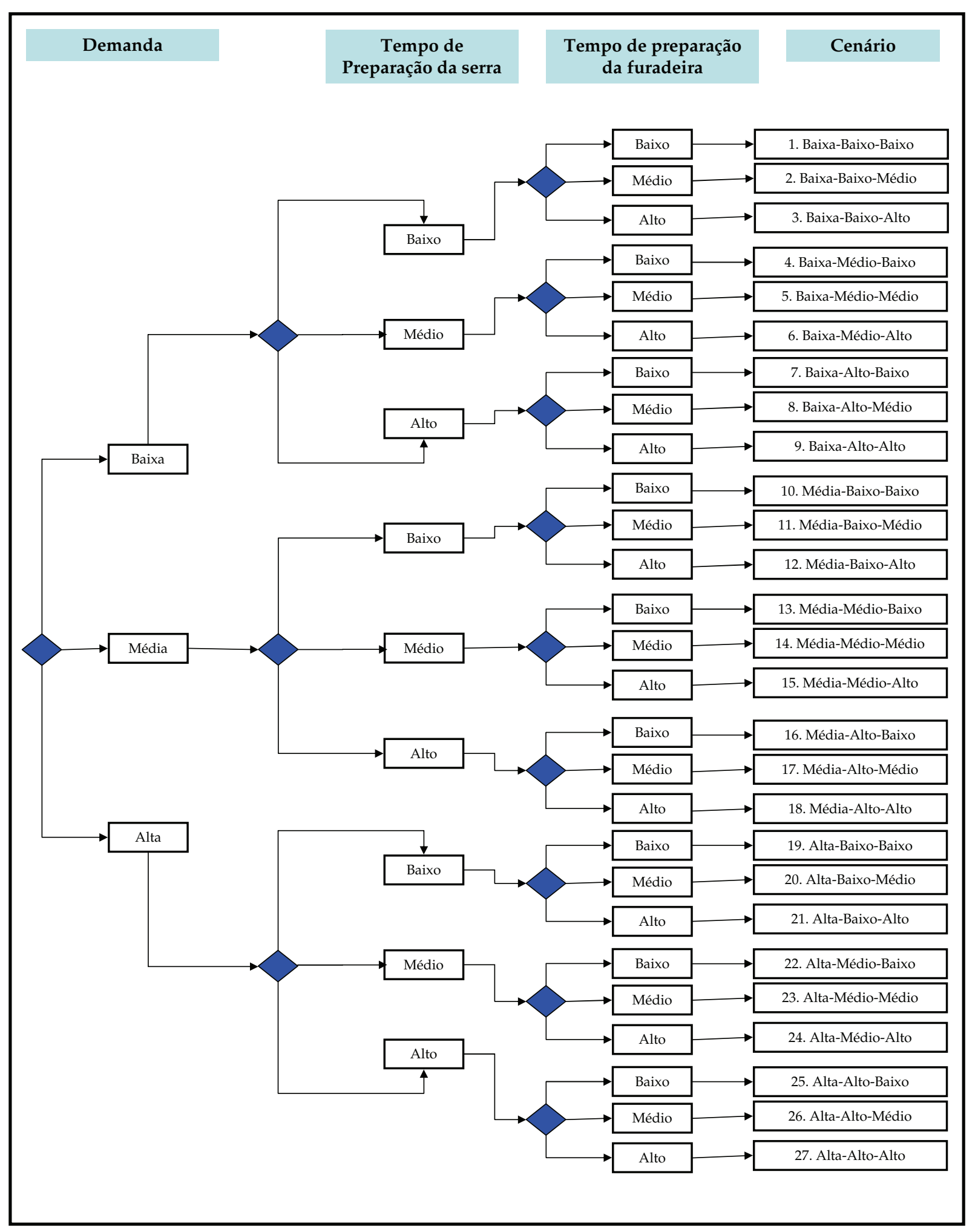

Figura 3.2: Árvore de cenários utilizada no Teste A. 


\section{Resultados do Modelo Estocástico Tradicional}

Em algumas análises, considerou-se o nível de serviço tipo II (ou taxa de atendimento da demanda) para analisar a fração da demanda perdida em cada cenário $s: \mathcal{B}_{s}=1-I_{s}^{-} / D_{s}$, em que $I_{s}^{-}=\sum_{i, t} I_{i t s}^{-}$, com $I_{i t s}^{-}=d_{i t s}-X_{i t s}$, se $d_{i t s}>X_{i t s}$, e $I_{i t s}^{-}=0$, caso contrário. A demanda total foi computada como $D_{s}=\sum_{i, t} d_{i t s}$. Como o interesse foi determinar apenas a fração da demanda não atendida ao final do horizonte de planejamento, analisouse apenas $I_{i T s}^{-}$, em que $T$ é o último período de produção.

A Tabela 3.3 sumariza os resultados obtidos. Os parâmetros de segundo estágio são apresentados para todos os 27 cenários, i.e., as probabilidades $(\pi)$, os custos de estoque (IC), perdas de demanda (BC) e horas-extras (OC), assim como as respectivas variáveis de decisão e os níveis de serviço $\mathcal{B} \%$. Ao final da tabela, tem-se os custos de primeiro estágio: produção (PC), perda de material (TC) e o número de preparações realizadas $(Z)$. O custo total esperado e o tempo de execução do algoritmo branch-and-cut para resolver o exemplar até a otimalidade também são mostrados.

Como era de se esperar, nos cenários 1 - 9 de baixa demanda, os níveis de serviço atingem o máximo valor de $100 \%$, uma vez que toda a demanda é atendida até o final do horizonte de planejamento. Nesses casos, os níveis acumulados de estoque atingem os maiores valores também. Horas-extras são utilizadas principalmente nos cenários nos quais o tempo de preparação da furadeira é alto. Ainda, o tempo de preparação da serra parece não ter muita influência sobre as outras decisões de segundo estágio, como pode ser analisado nos cenários 3, 6 e 9, que representam o pior caso em relação ao tempo de preparação da serra. Nesses cenários, os estoques são igualmente muito elevados, mas não há evidências de que esses cenários consumam mais capacidade do que os cenários 2, 5 e 8, cujo tempo de preparação de serra é moderado. Já nos cenários de demanda média 10 - 18, os estoques têm uma redução média de $67 \%$, assim como os níveis de serviço, que são deteriorados em média 5\%. Além disso, há um aumento na utilização das horas-extras, principalmente nos cenários mais pessimistas para o tempo de preparação da furadeira.

No cenários de demanda alta 19 - 27, os estoques decrescem ainda mais: cerca de $85 \%$ em relação à media estocada nos cenários de demanda média. Como consequência das altas demandas, as perdas de demanda são intensificadas e o nível de serviço têm o pior desempenho - em média, 81,5\%. Nesses cenários, não são observadas variações significativas nos níveis de horas-extras utilizadas. Esses resultados sugerem que a variação da demanda tem maior impacto no problema estocástico e, portanto, os cenários $19-27$ são os mais pessimistas, independentemente dos tempos de preparação.

Com o objetivo de investigar a sensibilidade do modelo $C L C 2 r$ em relação aos va- 
lores das probabilidades, especialmente porque estimativas precisas são difíceis de serem determinadas, três situações diferentes foram testadas. i) Equiprobabilidade: nesse caso, as probabilidades dos cenários (B, M e A) foram consideradas $\frac{1}{3}$, tornando os 27 cenários equiprováveis. ii) Otimista: no caso otimista, a probabilidade de ocorrência das demandas e dos tempos de preparação nos cenários (B, M e A) é (60, 30, 10) e (50, 40, 10)\%, respectivamente. iii) Pessimista: no caso pessimista, a probabilidade de ocorrência das demandas e dos tempos de preparação nos cenários (B, M e A) é (10, 30, 60) e (10, 40, $50) \%$, respectivamente. Os resultados são ilustrados nas Tabelas 3.4, 3.5 e 3.6.

É possível inferir que ambas as variáveis de primeiro e segundo estágios (e seus respectivos custos) praticamente não se modificaram com as diferentes configurações de probabilidade. Porém, o custo total esperado altera-se significativamente: em relação à situação moderada, os custos totais das situações equiprovável, otimista e pessimista são $10 \%$ maior, 30\% menor e 54\% maior, respectivamente. Esse aparente paradoxo entre solução e valor de solução é devido aos custos de segundo estágio, pois a variação das probabilidades ocasiona uma alteração na contribuição de cada cenário no custo total esperado. Por exemplo: o custo do cenário 27 (cenário mais pessimista) nas situações moderada, equiprovável, otimista e pessimista ( $\mathrm{IC}+\mathrm{BC}+\mathrm{OC})$ é igual a 343691, 343691, 348261 e 343658, respectivamente. Porém, a contribuição real desses custos leva em consideração a probabilidade do cenário 27 nas quatro situações, i.e., 1,56, 3,70, 0,100 e 15,0\%, o que resulta nos seguintes custos de segundo estágio do cenário 27: 5361, 12716, 348 e 51549 , respectivamente.

Esses resultados mostram que, estruturalmente, a solução do modelo $C L C 2$ r não é sensível a variações nos valores das probabilidades dos cenários, mas o valor ótimo da função objetivo é sensível. Por essa razão, tanto o valor esperado de informação perfeita $(E V P I)$ quanto o valor da solução estocástica (VSS) tornam-se muito dependentes de uma escolha precisa das probabilidades. Esses resultados são mostrados em detalhes a seguir.

\section{Análise do $E V P I$}

Para calcular o EVPI, foram resolvidos os 27 problemas wait-and-see. Tais soluções são ilustradas na segunda coluna da Tabela $3.7\left(W S_{s}^{\star}\right)$, assim como o valor esperado de utilizar tais soluções, i.e., $W S_{s}^{\star} \times \pi_{s}$. As últimas linhas fornecem a solução final $W S$, as soluções do modelo estocástico CLC2r (RP), o EVPI e o seu respectivo valor relativo $\left(E V P I \%=\frac{R P-W S}{R P} 100 \%\right)$. Todas as configurações propostas para as probabilidade foram analisadas.

Primeiramente, convém ressaltar que as soluções wait-and-see têm um desempenho 
semelhante às soluções $R P$, no sentido de que o custo total dos cenários 1 - 9 é o mais baixo, seguido pelo custo dos cenários $10-18$ e, finalmente, pelo custo total dos últimos cenários 19-27, como era de se esperar. Para resolver todos os problemas até a prova de otimalidade, foram necessários 97 segundos, sendo 3,62 (2,90) a respectiva média (desviopadrão).

Os valores absolutos do EVPI sugerem que as situações mais pessimistas geram os maiores EVPI: EVPI (pessimista $=526712)>E V P I($ equiprovável $=332917)>E V P I$ $($ moderada $=284318)>E V P I($ otimista $=154862)$. Isso ocorre porque, nas situações mais pessimistas, os cenários cujos parâmetros estocásticos possuem os maiores desvios em relação aos valores nominais têm probabilidades mais elevadas. Assim, a aleatoriedade dos cenários mais desfavoráveis ganha mais importância do que a aleatoriedade dos cenários mais favoráveis, o que reflete no EVPI. Além disso, esses resultados também confirmam o efeito que as probabilidades têm sobre o EVPI: a diferença entre o EVPI obtido no cenário otimista e aquele obtido no cenário pessimista representa mais de $240 \%$ do menor valor obtido (154862).

Esses resultados indicam que seria possível poupar uma quantia considerável de dinheiro - em todas as situações - se a informação perfeita sobre os parâmetros estocásticos pudesse ser disponibilizada. Além disso, os valores elevados para o EVPI também sugerem que a aleatoriedade desempenha um papel importante no problema apresentado nesse capítulo.

\section{Análise do $V S S$}

O problema $E V$ foi determinado de acordo com os valores médios $\varphi_{j t}^{I}=\sum_{s} \pi_{s} \varphi_{j t s}, \varphi_{p t}^{I I}=$ $\sum_{s} \pi_{s} \varphi_{p t s}$ e $d_{i t}=\sum_{s} \pi_{s} d_{i t s}$. Fixando as variáveis de primeiro estágio no problema $E E V$, obteve-se uma solução infactível. Portanto, o problema $E V$ não pode ser usado para aproximar o problema estocástico e $V S S \rightarrow+\infty$.

Para investigar a causa da infactibilidade, foram inseridos dois conjuntos de variáveis de erro $\left(\tilde{I}_{i t s}\right.$ e $\left.\tilde{O}_{t s}\right)$ para contabilizar o excesso de estoque e de capacidade, respectivamente, nas restrições de estocagem e horas-extras. Tais variáveis foram adicionadas à função objetivo com pesos suficientemente grandes, i.e., iguais a 10000.

$$
I_{i t s}^{+} \leq I_{i t}^{\max }+\tilde{I}_{i t s}, \forall i, t, s ; O_{t s} \leq C_{t}^{E}+\tilde{O}_{t s}, t \in \mathcal{T}, s \in \Omega
$$

Os valores acumulados das variáveis de erro $\tilde{I}_{i t s}$ em cada situação e cenário encontramse na Tabela 3.8. A linha Infactibilidade (\%) representa a porcentagem média de violação do limite máximo de estoque $I_{i t}^{\max }$. Os últimos dados referem-se aos valores obtidos pelos 
problemas $E V, E E V$ (modificado), RP e o $V S S$. Os resultados mostram que as restrições de capacidade não foram violadas, pois $\tilde{O}_{t s}=0$ para todo $t, s$.

Diferentemente do problema estocástico, que visa balancear produção, estoques e atrasos devido à variação dos níveis de demanda em cada cenário, os problemas $E V$ têm a tendência de produzir o máximo possível da demanda determinística e evitar atrasos. Dessa maneira, quando a demanda determinística é mais elevada, os níveis de produção $X_{i t}^{\star}$ são maiores também, o que ocasiona uma elevação dos níveis de estoque no problema $E E V$. Por essa razão, os maiores níveis de infactibilidade foram atingidos nas situações mais pessimistas.

Observe nas Tabelas 3.3-3.6 que os maiores volumes de estoque são encontrados nos cenários $1-9$, que têm demanda baixa. Nesses cenários, uma vez que $X_{i t}^{\star}$ é elevado e a demanda $d_{i t s}$ é baixa, a diferença entre ambos produz maiores níveis de estoque. Conforme a demanda aumenta nos cenários subsequentes e o montante de produção permanece igual, os níveis de estoque diminuem e o limite máximo $I_{i t}^{\max }$ é respeitado.

Também no caso do VSS, fica clara a influência das probabilidades na determinação desse parâmetro. O VSS variou de 103929 até 318922, uma diferença que representa mais de $206 \%$ do primeiro valor. Embora os valores de VSS sejam aproximados, é possível ter uma ideia do ganho adicional em resolver o problema estocástico $C L C 2 r$, em vez de adotar a solução do problema $E V$. Novamente, nas situações mais pessimistas, modelar e resolver o problema estocástico torna-se mais interessante, pois o VSS tem um valor absoluto maior. Mesmo na situação otimista, o ganho pode chegar a $30 \%$ do valor ótimo do problema estocástico.

\section{Modelos Determinísticos ou Estocásticos?}

As filosofias dos modelos determinísticos e estocásticos são bastantes distintas e, por essa razão, deve-se ter certo cuidado na comparação entre as suas respectivas soluções, para não ignorar as suas diferenças. Primeiro, enquanto o valor ótimo do modelo determinístico corresponde a um único custo mínimo, o valor ótimo do modelo estocástico refere-se a uma composição de custos mínimos, um para cada cenário, ponderados pelas probabilidades desses cenários, e que é comumente denominada de custo mínimo esperado. Além disso, o modelo determinístico gera um único plano de produção (volume de produção, estoque e atrasos, desperdício de material, número de preparações e hora-extra), ao passo que o modelo determinístico de dois estágios gera planos de produção dependentes dos cenários. O fato de uma única decisão do modelo determinístico corresponder a $S$ possíveis decisões no modelo estocástico (variáveis de segundo estágio) faz com que os modelos estocásticos sejam atraentes em muitos contextos, mesmo quando eles não são justificados pelo EVPI 
Tese de Doutorado

e/ou VSS.

Considere o Exemplar 1 resolvido na Seção 2.5.2 do Capítulo 2 e o exemplar resolvido nessa Seção, que se refere ao modelo estocástico $C L C 2 r$, cujo resultado encontra-se na Tabela 3.3. Os dois exemplares têm os mesmos dados de entrada, com exceção das demandas e tempos de preparação, que no caso do modelo CLC2r são representados em 27 cenários. Porém, o problema wait-and-see correspondente ao Cenário 14 do problema estocástico (demanda média, tempo de preparação da serra médio e tempo de preparação da furadeira médio) é similar ao Exemplar 1 do Capítulo 2, em termos da quantidade de dados de entrada e dos seus valores (os dados foram perturbados a partir do cenário médio para compor os 26 cenários restantes). Assim, é possível comparar o cenário 14 de forma mais direta com o Exemplar 1 do modelo $C L C 2$.

A partir da Tabela 3.7, observe que o custo total do problema wait-and-see do cenário 14 é $W S_{14}^{\star}=189572$, ao passo que o custo total do Exemplar 1 do modelo $C L C 2$ é 189952 , conforme Seção 2.5.2 do Capítulo 2 (essa pequena diferença é devido a maneira de gerar os cenários; veja a Seção 3.3.1). Os problemas também têm níveis similares de volume de produção e placas cortadas, praticamente não há estoque, e os atrasos e as horas-extras são nulos. Além do problema wait-and-see referente ao cenário 14, todos os outros 26 problemas podem ser vistos como exemplares da Classe 1 proposta na Seção 2.5.3 do Capítulo 2 e, portanto, são similares ao Exemplar 1 mencionado, assim como o próprio problema $E V$. Dessa forma, espera-se que todos esses problemas tenham uma solução estritamente comparável e um comportamento similar.

Observe também que a solução de primeiro estágio do problema estocástico (Tabela 3.3) é similar à solução do Exemplar 1 em termos de volume de produção, quantidade de placas cortadas e número de preparações. Entretanto, as variáveis de segundo estágio não são comparáveis aos níveis de estoque, atraso e horas-extras do Exemplar 1, devido à presença de múltiplos cenários. Considere, por exemplo, a solução dos cenários $1-9$ em relação à demanda atrasada e confirme que tal solução é idêntica à solução do Exemplar 1. Porém, os volumes de estoque desses cenários são bem altos e diferem da política de estoques do exemplar determinístico, assim como a quantidade de horas-extras utilizadas. Esse comportamento é justamente o que define problemas estocásticos de dois estágios com recurso: a capacidade das soluções ajustarem-se às decisões de primeiro estágio e aos parâmetros estocásticos de cada cenário. Esse fato representa uma vantagem da programação estocástica de dois estágios com recurso sobre a programação determinística convencional.

Para o tomador de decisão, por exemplo, utilizar a solução do problema estocástico pode ser mais prático, porque evita re-implementar todas as decisões para cada novo cenário materializado. Por exemplo, se o cenário 14 ocorrer, serão estocados 954 produtos 
e 142 terão sua produção postergada. Porém, se o cenário 27 (de pior caso) ocorrer, devem ser estocados 128 produtos, 620 serão postergados e 10093 segundos de hora-extra serão necessários, mantendo-se os mesmos níveis de produção, quantidade de placas cortadas e preparações. Entretanto, é preciso analisar se ter mais flexibilidade no momento da decisão pode gerar custos menores ou, ao contrário, pode gerar despesas maiores. Para responder a essa questão, pode-se recorrer a análise do EVPI e do VSS, como foi feito nesse capítulo. Ambos os valores positivos indicaram que a programação estocástica é vantajosa, do ponto de vista financeiro, em relação aos modelos determinísticos wait-andsee e aos problemas $E V$. Finalmente, mesmo nessa circunstância, é o especialista que deve decidir se o planejamento da produção sofre com as incertezas e qual o tipo de solução é mais adequada no seu caso.

\section{Resultados do problema Min-Max}

A Tabela 3.9 mostra a solução do problema Min-Max. O valor ótimo 911766 corresponde à solução de dois cenários: 19 e 21 (mostrados em negrito na tabela). Como essa abordagem ignora as probabilidades dos diferentes cenários e apenas o desvio mais desfavorável é considerado, o valor ótimo é mais conservador do que os valores obtidos pelos problemas estocásticos (RP) nas diferentes situações. O custo desse conservadorismo é bastante significativo: em relação aos cenários moderado, equiprovável, otimista e pessimista, o problema Min-Max é, aproximadamente, 93, 74, 178 e 26\% maior, respectivamente. Em geral, quando o cenário de pior caso é muito pior do que a maioria dos cenários considerados, a abordagem Min-Max pode gerar valores muito pessimistas e, portanto, não ser uma abordagem plausível.

Pelos resultados anteriores, era de se esperar que o cenário de pior caso do problema Min-Max estivesse entre os cenários 19-27, que são os mais pessimistas. O fato do cenário 27 - cenário teórico mais desfavorável - não ter sido o cenário mais pessimista na prática é resultado da geração dos parâmetros estocásticos, pois mesmo os tempos de preparação do cenário 27 sendo maiores do que aqueles do cenário 21 (ou 19), a demanda do cenário 21 (ou 19) pode ser até $25 \%$ maior do que a demanda do cenário 27.

Os cenários de pior caso 19 e 25 também resultaram os maiores custos de atraso (956197 e 961246, respectivamente) e nos piores níveis de serviço (73,5 e 79,3\%, respectivamente), ao passo que atingiram os menores níveis de estoque e horas-extras. A solução do problema Min-Max foi comparada às soluções dos problemas estocásticos tradicionais, considerando a situação equiprovável (as quatro situações apresentam soluções similares). A Figura 3.3 mostra as diferenças entre as soluções de segundo estágio do problema $R P$ e da abordagem Min-Max (as soluções de primeiro estágio praticamente não se alteram). 
Na maioria dos cenários, o problema Min-Max obteve cerca de 50 produtos a mais em estoque, atingindo o pico de 284 produtos no cenário 19 de pior caso da demanda. Ambos os problemas apresentaram custos de atraso idênticos nos cenários $1-18,21,23$ e 25. Nos outros cenários, o problema Min-Max teve um desempenho pior, sendo que no cenário 19, o custo de atraso atingiu sua diferença máxima: 57000. Porém, o nível de serviço foi deteriorado apenas no cenário 19, em torno de $7 \%$ relativo a 284 produtos não produzidos (veja o pico e o vale da terceira curva ilustrada na Figura 3.3). A utilização de horas-extras, por sua vez, foi mais utilizada no problema $R P$, preponderantemente nos cenários cujo tempo de preparação da furadeira é alto.

\section{Resultados dos Modelos Média-Risco e com Restrição de Recurso}

Uma série de soluções foram geradas impondo-se níveis progressivamente maiores de robustez, seja pelo aumento no fator de risco $\lambda$ da formulação (3.28), quanto na redução da tolerância $\Delta_{\max }$ da formulação (3.29). No primeiro caso, considerou-se $\lambda=1, \cdots, 10$, com passo 0,5 em todas as situações (moderada, equiprovável, otimista e pessimista). No segundo caso, adotou-se para a tolerância máxima inicial o valor esperado do desvio quando $\lambda=0$, ou seja, $\Delta_{\max }^{0}=\sum_{s} \pi_{s} \Delta_{s}$. Note que há uma tolerância inicial diferente em cada situação. A tolerância foi então reduzida iterativamente até chegar a zero (entretanto, nesse exemplar, tolerâncias inferiores a $5 \%$ resultaram em solução infactível) com passo 5\%. No total, foram resolvidos 116 modelos (3.28) e 152 modelos (3.29).

Resultados gerais. Em todos os problemas, o custo total esperado aumentou conforme a solução tornou-se mais robusta. Quando $\lambda=0, \Delta$ atingiu o máximo valor, uma vez que os desvios não são penalizados. Nesse caso, o valor ótimo dos problemas coincide com o respectivo problema estocástico tradicional. Aumentando-se progressivamente o fator de risco, $\Delta$ é sensivelmente reduzido às custas de grandes variações dos custos de segundo estágio. As decisões e custos de segundo estágio apresentaram comportamentos específicos para diferentes valores do fator de risco, mas as variáveis de decisão de primeiro estágio praticamente não se alteraram.

Modelo Média-Risco. Os gráficos da Figura 3.4 ilustram os tradeoffs entre o custo total esperado e a robustez da solução de acordo com o fator de risco $\lambda$. A Figura 3.5 ilustra os volumes de estoque, horas-extras utilizadas (em horas) e os níveis de serviço, também de acordo com $\lambda$ para todas as situações consideradas. As soluções exibem algumas interessantes "transições de fases", conforme o fator de risco aumenta.

Na situação moderada, para $0 \leq \lambda \leq 4$, o desvio praticamente não varia (a redução 

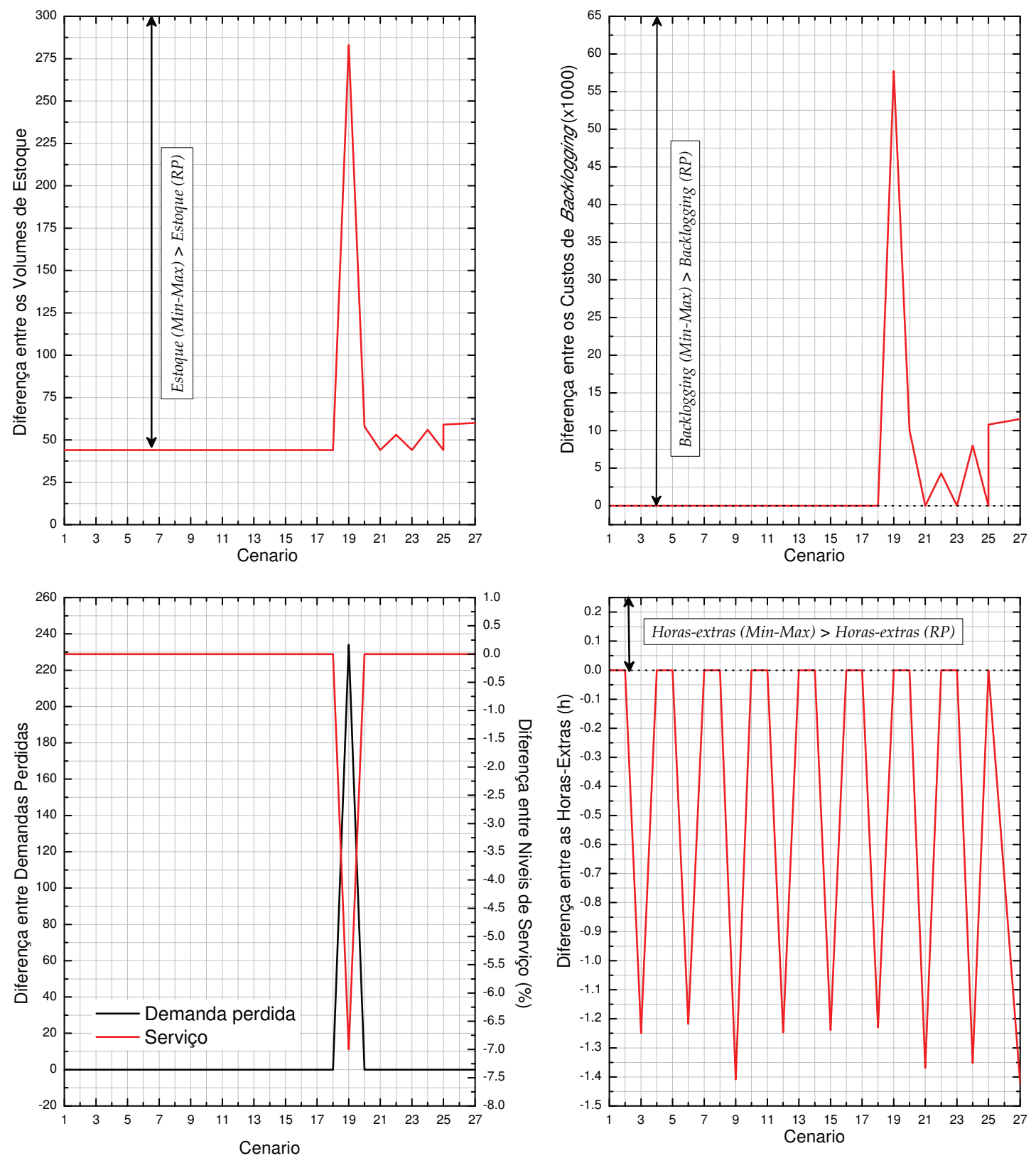

Figura 3.3: Diferença entre as soluções dos problemas Min-Max e $R P$, em termos de volume de estoque (acima e esquerda); custo de backlogging (cima e direita); demanda perdida e nível de serviço (baixo e esquerda); e horas-extras (baixo direita).

é em torno de 0,02\% apenas), o volume de estoque varia entre 1200 e 1263 unidades, é utilizada menos de 1 hora de hora-extra e o nível de serviço permanece em $92 \%$, ao passo que o custo total esperado cresce quase $93 \%$. O intervalo $4,5 \leq \lambda \leq 10$ representa uma nova fase: o custo total cresce menos (observe a visível diminuição do coeficiente 
angular da reta que descreve o crescimento do custo), ao passo que o desvio cai cerca de $70 \%$, passando de $123000 \mathrm{em} \lambda=4$ para $35000 \mathrm{em} \lambda=4,5$. Depois dessa queda, o desvio decresce gradualmente até cerca de $75 \%$ do valor inicial, enquanto o custo total é deteriorado em 148\%. Ainda, a partir de $\lambda=4,5$, o volume de estoque aumenta $50 \%$ e varia em torno de 1800 unidades até $\lambda=9,5$, quando um novo aumento de $15 \%$ é verificado. As horas-extras elevam-se vertiginosamente e mantêm uma tendência de crescimento, que é acentuada em $\lambda=8,5$ e atinge o máximo de 60 horas em $\lambda=10$. O nível de serviço tem uma queda de $5 \%$ no início da nova fase de transição, recupera-se logo em seguida, exibe uma estabilização até $\lambda=9,5$ e cai novamente em $\lambda=10$.

Para investigar a existência de estabilização do desvio (i.e., da robustez da solução), testes adicionais com $\lambda=10, \cdots, 1000$ e passo 10 foram executados. Os resultados mostraram que o desvio decresce gradualmente até 30114 em torno de $\lambda=300$, permanecendo o mesmo até o último valor testado $\lambda=1000$. Assim, não é preciso ser muito conservador na escolha do fator de risco, pois com $\lambda=4,5$, o desvio já decresceu $85 \%$ da sua máxima redução e o custo total foi suficientemente deteriorado.

As situações equiprovável e pessimista apresentaram tendências similares, com duas fases bem distintas nos intervalos $[0,3]-[3,5 ; 10]$ e $[0 ; 1,5]-[2-10]$, respectivamente. Novamente, reduções significativas no desvio, aumentos consideráveis nos volumes de estoque e nas horas-extras utilizadas e níveis de serviço deteriorados são aspectos preponderantes da segunda fase.

A situação otimista apresentou uma transição em três fases, a saber: $[0 ; 2,5]$ $[3,5 ; 5,5]$ e $[6,5 ; 10]$, sendo que a última fase exibe uma tendência clara de estabilização. Diferentemente das outras situações em que a segunda fase é marcada por uma mudança no coeficiente angular da reta do custo esperado, a presente situação não apresenta tal variação, sendo o crescimento homogêneo até $\lambda=10$. O volume de produção variou 14\%, no máximo, sendo as transições de fases muito sutis. As horas-extras foram pouco utilizadas até $\lambda=2,5$, variaram em torno de 5 horas entre [3;6,5], reduziram em cerca de $92 \%$ até $\lambda=9,5$ e atingiram o máximo em $\lambda=10$. O nível de serviço elevou-se até $\lambda=2,5$, decresceu menos de $1 \%$ a partir desse valor e manteve-se em torno de $94 \%$ até $\lambda=10$.

Modelo com Recurso Restrito. A Figura 3.6 ilustra o tradeoff entre custo total esperado, robustez e decisões de segundo estágio. Contrariamente aos resultados anteriores, não foram observadas transições de fases à medida que a solução torna-se mais robusta. Ainda, é possível acessar a robustez máxima em cada situação, sem a necessidade de executar testes adicionais como nos problemas Média-Risco. As reduções máximas obtidas foram 75, 67,5, 70 e 82,5\%, nas situações moderada, equiprovável, otimista e pessimista, com acréscimos nos custos esperados de 85, 65, 135 e 35\%, respectivamente. Entretanto, 
as menores reduções possiveis são estritamente menores do que $2,5 \% 3$ a mais dos valores encontrados, i.e., 76,9, 69,2, 71,8 e 84,6\%. Todos os valores iguais ou maiores do que esses resultaram em soluções infactíveis.

O volume de estoque também aumentou com a robustez da solução em todas as situações até atingir um máximo, a partir do qual teve uma leve diminuição. Como nos testes anteriores, o maior volume de estoque foi obtido na situação otimista, seguida pela equiprovável, moderada e pessimista. As horas-extras utilizadas não tiveram um comportamento muito bem definido. Aparentemente, para uma redução maior do que 2,5\%, a situação pessimista utiliza menos horas-extras do que todas as outras situações, atingindo um máximo de 21 horas, quando o desvio é mínimo. Nas outras situações, as horas-extras também apresentaram picos de crescimento próximos aos desvios mínimos, chegando a 75 horas na situação otimista, quando o desvio reduz 67,5\% do valor inicial. Os níveis de serviço têm um desempenho bastante similar aqueles obtidos nos testes anteriores. Claramente, o nível de serviço da situação otimista domina todos os outros, enquanto o nível de serviço da situação pessimista é dominado pelos demais. Por outro lado, na situação otimista é obtida a maior deterioração dessa medida de desempenho quando o desvio mínimo é atingido - 5,3\%, contra uma média de 3,7\% nas outras situações.

Comparação entre os problemas $M R$ e $R R$. Para investigar a relação entre os problemas $M R$ e $R R$, os problemas $R R$ foram resolvidos considerando-se as tolerâncias $\Delta_{\text {max }}$ como os próprios desvios $\Delta_{\text {max }}=\sum_{s} \pi_{s} \Delta_{s}$ obtidos com $\lambda=1, \cdots, 10$. Para efeito ilustrativo, adotou-se somente a situação moderada. As curvas da Figura 3.7 ilustram as soluções, os desvios e as diferenças entre as soluções de segundo estágio de ambos os problemas. Para $\lambda=0$, os custos $M R$ e $R R$ são iguais, o desvio é máximo e a parcela $\lambda \Delta$ é igual a zero. Conforme mais robustez é imposta à solução, o custo $M R$ e a parcela $\lambda \Delta$ crescem a proporções altas e iguais (observe os coeficientes angulares das respectivas retas), enquanto o custo $M R$ cresce e o desvio decresce, ambos vagarosamente, segundo um comportamento de transição de fases já mencionado. Isso acontece porque até $\lambda=4$ (i.e., até $\Delta_{\max }=123122$ ), o termo $\lambda \Delta$ cresce mais rapidamente do que a parcela de custo esperado que compõe a função objetivo de ambos os problemas. O ponto $\lambda=4$ marca a transição de todas as curvas: como o desvio é consideravelmente reduzido em $\lambda=4,5$ $\left(\Delta_{\max }=35357\right)$ às custas de uma alta deterioração nos valores dos custos $R R$ (cerca de $70 \%$ ), a parcela $\lambda \Delta$ tem uma queda acentuada nesse intervalo e a taxa de crescimento dos custos $M R$ é reduzida. Conforme o desvio estabiliza-se, os custos de segundo estágio são menos sacrificados, fazendo com que os custos $R R$ retomem um crescimento lento. É

\footnotetext{
${ }^{3}$ Independente das reduções máximas obtidas, o próximo passo de todos os problemas foi determinado pela equação $\Delta^{n}=0,995 \times \Delta^{n-1}$, que resultou em solução infactível. Porém, é possível que para todos os fatores no intervalo $(0,995 ; 1]$, a solução seja factível, ou seja, para todos os passos estritamente menores do que 0,995 .
} 
fácil observar que a soma das parcelas $\lambda \Delta$ aos custos $R R$ produzem exatamente os custos $M R$, comprovando a proposição 3.2 da Seção 3.2.4 do presente Capítulo.

Contudo, como pode ser observado nas curvas da Figura 3.7, formulações equivalentes não implicam em soluções idênticas. De fato, até $\lambda=3,5$ (ou $\Delta_{\max }=125278$ ), as soluções dos problemas são idênticas. Porém, à medida que a solução torna-se mais robusta, surgem as diferenças expressas pelas curvas contínuas. Visivelmente, não há nenhuma solução que domine ou seja dominada por outra em nenhum dos quesitos analisados. Porém, se em $\lambda=4,5$ o nível de serviço do problema $M R$ fosse maior ou igual ao nível de serviço do problema $R R$, a solução do último seria dominada, mas apenas em relação a essa medida de desempenho. 

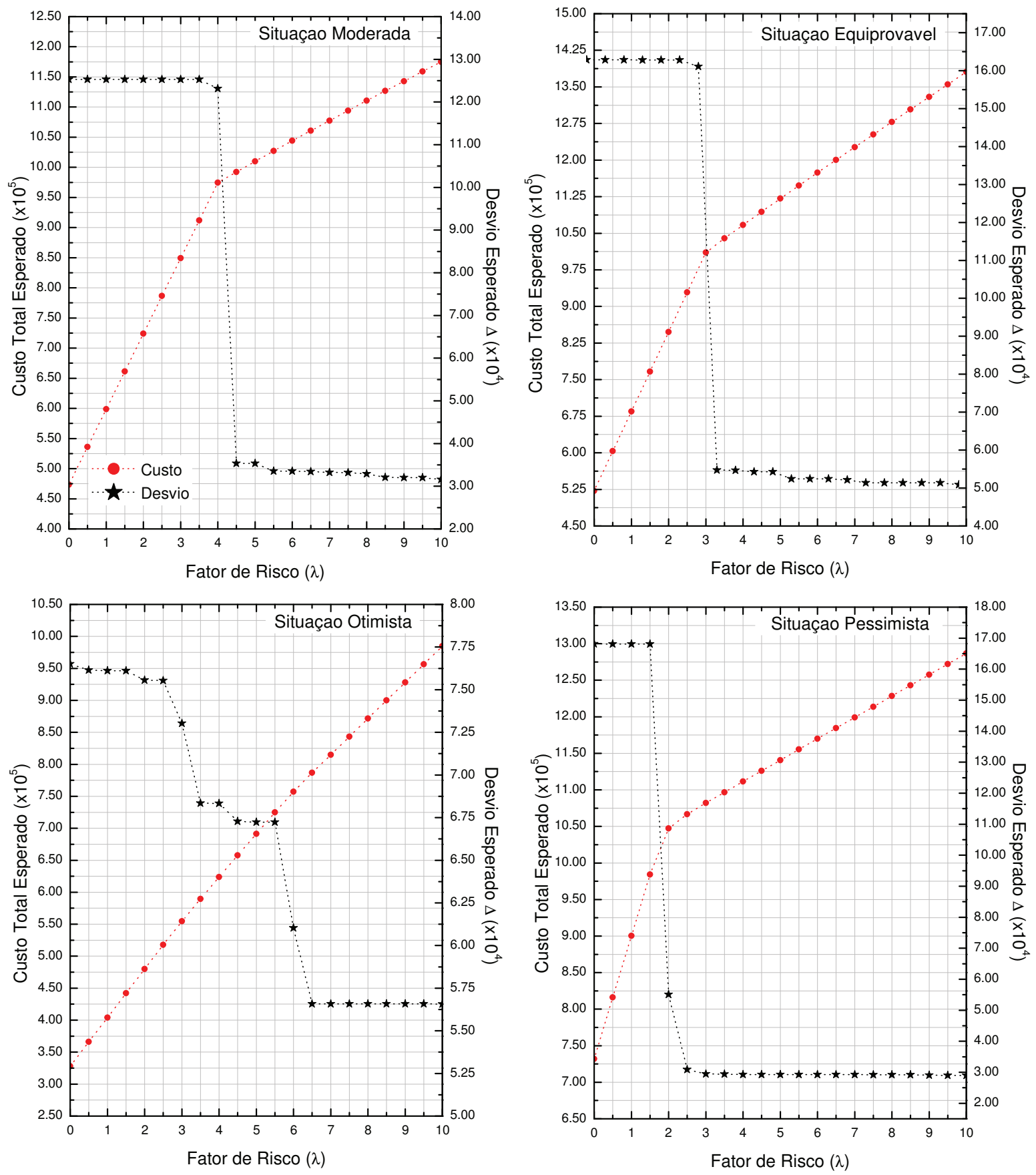

Figura 3.4: Tradeoff entre custo total esperado e robustez de acordo com o aumento do fator de risco $\lambda$, considerando as situações moderada (cima e esquerda), otimista (baixo e esquerda), equiprovável (cima e direita) e pessimista (baixo e direita). 

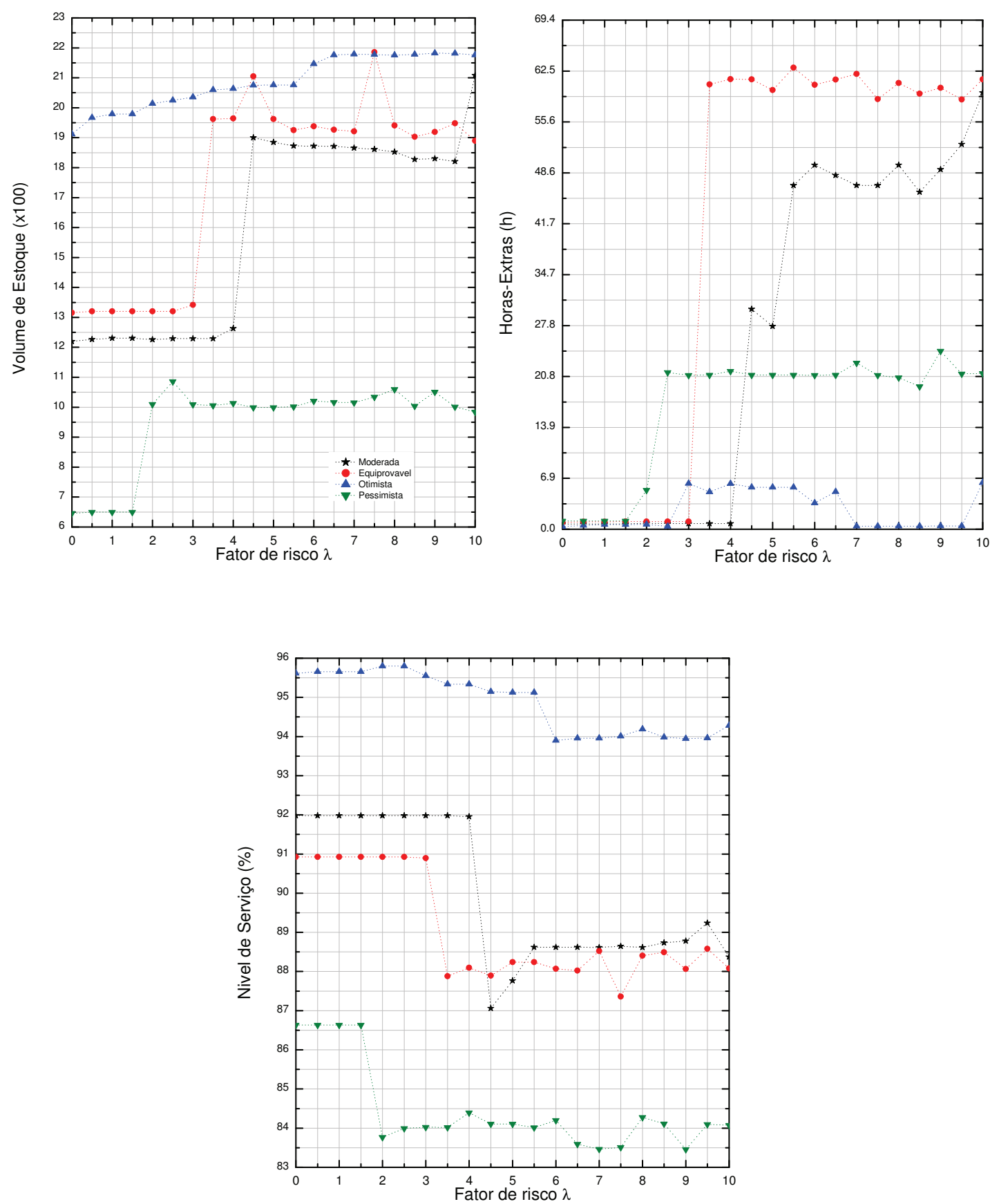

Figura 3.5: Comportamento das decisões de segundo estágio de acordo com o aumento do fator de risco $\lambda$ em todas as situações. 

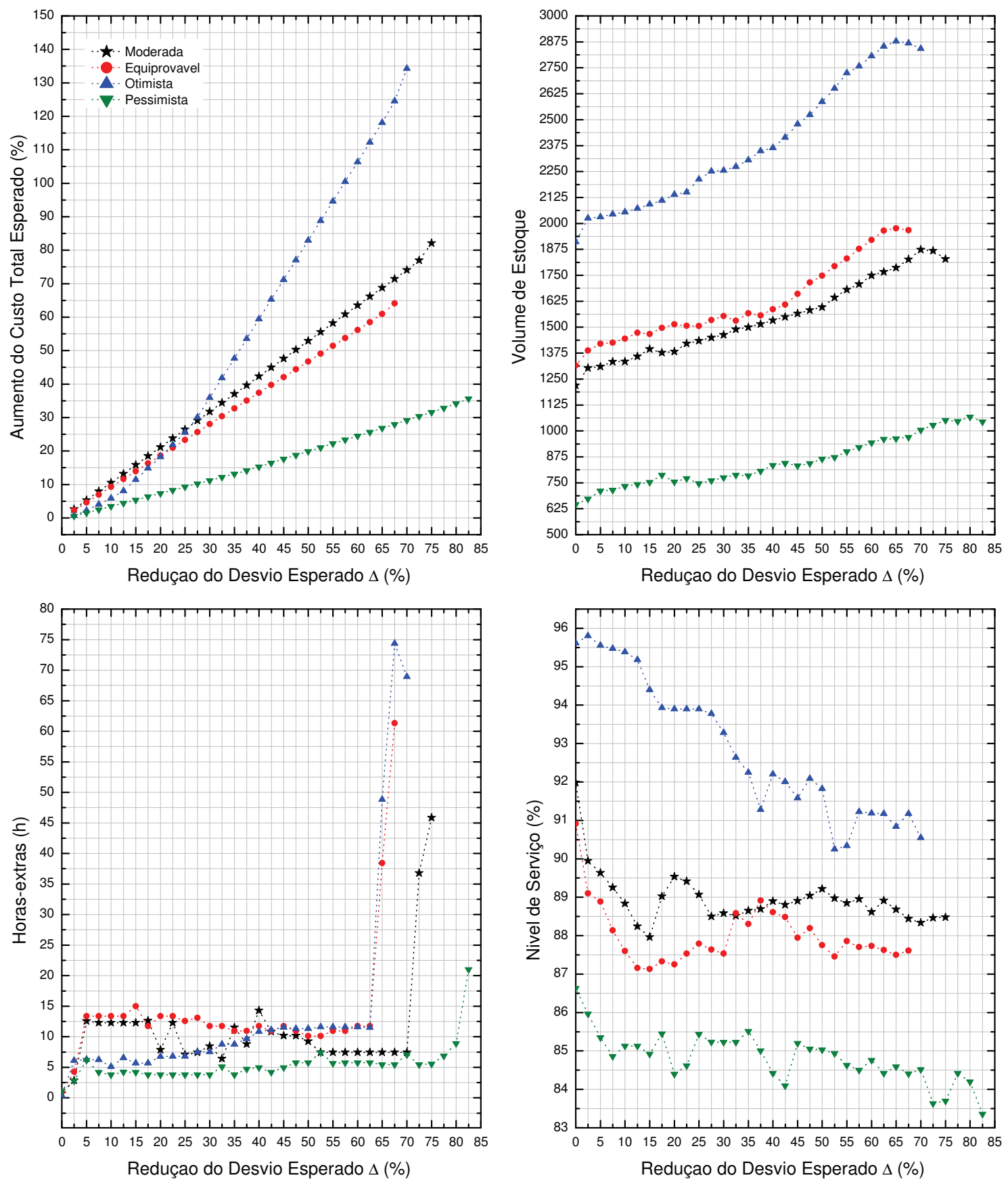

Figura 3.6: Curva de tradeoff entre aumento do custo total esperado e redução do desvio esperado (primeiro gráfico). Comportamento do volume de estoque, horas-extras e nível de serviço de acordo com a redução do desvio esperado (três gráficos restantes).

\subsubsection{Teste B}

Nesse teste, os cenários foram gerados de acordo com o procedimento (ii) descrito anteriormente no início da Seção 3.3, i.e., as demandas e os tempos de preparação esto- 
cásticos foram gerados aleatoriamente conforme uma distribuição uniforme (inteira para a demanda e contínua para os demais parâmetros) entre 70 e 130\% do respectivo valor nominal. O número de cenários $(S=|\Omega|)$ variou entre 20 e 300 com passo 20 (totalizando 15 testes), e admitiu-se que os cenários têm probabilidades iguais de ocorrência em todos os casos. Testes subsequentes utilizaram os cenários de testes anteriores, de modo que, em cada teste, apenas 20 cenários foram gerados. Por exemplo, para $S=40$, os 20 primeiros cenários foram exatamente os 20 cenários do teste anterior $(S=20)$, e assim por diante. A motivação em construir os cenários dessa maneira foi permitir a comparação entre diferentes configurações de cenários. Para cada configuração de cenário, o desvio $(\Delta)$ foi progressivamente reduzido de zero (problema estocástico tradicional) até 100\%. Nessa tese, o problema cujo desvio foi $100 \%$ reduzido é designado problema totalmente robusto.

Análise de robustez. A Figura 3.8 ilustra as curvas de tradeoff entre a robustez do modelo (redução do desvio esperado $\Delta$ ) e o incremento no valor da função objetivo (em \%), considerando $S=20, \cdots, 100$ (gráfico de cima e esquerda); $S=120, \cdots, 200$ (gráfico de cima e direita); e $S=220, \cdots, 300$ (gráfico de baixo). Em vários casos, não é dispendioso assegurar soluções mais robustas: sacrificando o valor ótimo em apenas 1\%, é possível reduzir $\Delta$ em 40,25, 10 e 10\%, para $S=40,60,100$ e 180, respectivamente. Ainda, para todas as configurações de cenário, é preciso sacrificar em torno de $25 \%$ do custo total esperado para alcançar uma redução do desvio de $50 \%$. Forçando ainda mais a robustez da solução, a deterioração no valor da função objetivo eleva-se consideravelmente, principalmente quando $S=120$ - 300. Note, por exemplo, que a taxa de variação do custo total aumenta mais quando a redução está mais próxima de zero: reduzir $\Delta$ em apenas $5 \%$ - de 95 para $100 \%$ - implica em aumentar o custo total em mais de $30 \%$ para $S=220,260,280,300$, e em mais de $40 \%$ para $S=180$ e 240 , o que inviabiliza a adoção desses planos de produção. O melhor compromisso entre robustez e custo foi obtido para $S=20$; nesse caso, o desvio foi totalmente reduzido com apenas $28 \%$ de aumento no valor ótimo. No pior desempenho $(S=180)$, a redução de $100 \%$ ocasionou um aumento drástico de quase $150 \%$ no custo total esperado.

Para ilustrar um exemplo de como o modelo com recurso restrito gera soluções progressivamente mais robustas, a Figura 3.9 exibe os valores do desvio $\Delta_{s}$ de um exemplar com apenas 20 cenários, considerando níveis de redução entre 0 e $100 \%$. Inicialmente, há 5 desvios positivos: $\Delta_{5}, \Delta_{15}, \Delta_{16}, \Delta_{18}$ e $\Delta_{19}$, sendo o máximo desvio $\Delta_{18} \approx 53000$. Os outros 15 cenários apresentam desvios nulos, i.e., o custo esperado é maior do que os custos individuais desses cenários. Quando a redução atinge $35 \%, \Delta_{16}=0$ e o máximo desvio vale $\Delta_{18} \approx 43000$. Prosseguindo com a observação da figura, note que $\Delta_{18}$ é o último desvio positivo quando a redução está em 95\% e vale, aproximadamente, 7500 . Finalmente, todos os desvios anulam-se. Entretanto, isso nem sempre é alcançado, como 
foi mostrado no Teste A.

Efeito da robustez na solução ótima. Para assegurar a robustez da solução, o custo total é elevado como consequência do aumento nos custos individuais proporcionado pelo aumento ou redução nos níveis das variáveis de decisão. O efeito da robustez na solução ótima foi analisado em todos os casos, mas é discutido em detalhes apenas para $S=20,100,200$ e 300 (nos outros casos, a análise é similar). Como já mencionado no Teste $\mathrm{A}$, as variáveis de primeiro estágio não variaram significativamente, porém, observou-se uma suave tendência de redução nos níveis de produção e quantidade de placas utilizadas conforme a solução torna-se mais robusta. Ao passo que os volumes de estoque não tiveram um comportamento definido, os atrasos aumentaram consideravelmente, principalmente quando as reduções aproximaram-se de zero, fazendo com que os respectivos custos fossem responsáveis pela maior parte da deterioração nos valores ótimos. Entretanto, os níveis de serviço não foram muito deteriorados, pois a maior parte da demanda atrasada é produzida até o final do horizonte de planejamento. Em média, 65, 57, 78 e 73\% da demanda total atrasada não é perdida, para $S=20,100,200$ e 300, respectivamente. Foram observados alguns picos na utilização de horas-extras à medida que o desvio aproxima-se de zero, cuja magnitude parece aumentar quando mais cenários são incorporados ao problema.

Efeito do número de cenários na solução ótima. Fixando-se o nível de redução do desvio, é possível analisar o efeito do número de cenários na solução ótima do modelo estocástico robusto. As Tabelas 3.10, 3.11 e 3.12 exibem o desempenho dos problemas estocásticos e robustos quando a redução do desvio é zero, 50 e 100\%, respectivamente, para $S=20, \cdots, 300$. Os valores ótimos elevam-se com o aumento do número de cenários para os três níveis de redução. Para o problema estocástico tradicional, há uma suave tendência na estabilização do valor ótimo entre 170000 e 180000, como ilustra a Figura 3.10. Nos problemas robustos com reduções de 50 e 100\%, os valores ótimos têm um comportamento semelhante ao caso anterior, porém, são cerca de 16 e $95 \%$ mais elevados (em média), apresentam picos maiores e a tendência de estabilização não é bem definida. Analisar a estabilização do valor ótimo em relação ao número de cenários pode ser importante porque permite ao decisor operar com um conjunto bem definido (fixo) de cenários e garantir precisão à solução do problema.

É possível inferir que o comportamento das soluções para 0, 50 e $100 \%$ de redução é bastante similar quando o número de cenários aumenta, ressaltando que, no problema totalmente robusto, algumas tendências de redução e/ou crescimento são amplificadas. Note que a variação (desvio-padrão relativo) do volume de produção, quantidade de placas utilizadas e número de preparações é cerca de $3 \%$ no problema totalmente robusto (veja última linha da Tabela 3.12). Com exceção do número de preparações, que não apresenta 
nenhuma tendência, os volumes de produção e estoque decrescem lentamente quando $S$ aumenta; tal comportamento pode ser confirmado na Figura 3.10 (o comportamento da quantidade de placas utilizadas é muito similar ao comportamento do volume de produção e, por essa razão, seu gráfico foi omitido). As decisões de segundo estágio, por sua vez, tiveram uma variação alta. O volume de estoque variou cerca de $16 \%$ no problema totalmente robusto e o atraso total variou mais de $48 \%$ no problema robusto com redução de 50\%. Entretanto, a variação do nível de serviço foi, no máximo, 8,4\% no problema totalmente robusto, confirmando que grande parte da demanda é produzida até o final do horizonte de planejamento (veja também que o maior pico de atraso em $S=180$ não corresponde ao pior nível de serviço em $S=220$ na Figura 3.11). A utilização de horas-extras ocorreu em picos em apenas em alguns cenários, principalmente no problema totalmente robusto, como pode ser observado na Figura 3.11.

Tempo computacional. A Figura 3.12 exibe os tempos médios de resolução necessários para obter o certificado de otimalidade dos problemas robustos para $S=20, \cdots, 300$ e os respectivos desvios-padrão, considerando todos os níveis de redução do desvio. Como era de se esperar, conforme o número de cenários aumenta, o tempo computacional elevase drasticamente. A variação entre os tempos de resolução para um mesmo $S$ deve-se ao fato de que níveis de redução diferentes requerem esforços computacionais distintos. Para muitos valores de $S$, à medida que a solução torna-se mais robusta, o tempo de resolução eleva-se gradualmente. Um fato curioso, entretanto, ocorre nos problemas totalmente robustos. O tempo de resolução requerido desses problemas é, em geral, muito mais baixo do que para os outros níveis de redução do desvio, incluindo os problemas com redução zero - isso é particularmente visível a partir de $S=220$. Para prever o tempo computacional requerido para resolver exemplares com mais cenários, três curvas foram ajustadas aos pontos da Figura 3.12: uma linear, outra polinomial de ordem 2 e outra exponencial. Os ajustes $R^{2}$ das curvas foram 0,54857, 0,9198 e 0,94054, respectivamente. Utilizando o ajuste exponencial (que explica $94 \%$ da variância nos tempos de solução), estima-se que seriam necessários 20000 s para resolver na otimalidade exemplares de 400 cenários. Testes adicionais com exemplares de 400 cenários mostraram que em $3600 \mathrm{~s}$ nenhuma solução factível foi encontrada para todos os níveis de redução do desvio. 


\subsection{Sumário e Considerações Finais}

Nesse capítulo, foram desenvolvidos e analisados modelos de programação estocástica para o problema combinado de dimensionamento de lotes e corte de estoque na presença de demandas e tempos de preparação estocásticos. Os modelos foram testados em situações que refletem diferentes designações de probabilidades à árvore de cenários construída. Em cada situação, moderada, equiprovável, otimista e pessimista, as probabilidades dos cenários favoráveis e desfavoráveis foram devidamente ajustadas. Os resultados mostraram que as variáveis de decisão de primeiro e segundo estágios não são sensíveis à variação das probabilidades, mas os valores ótimos são e, por esse motivo, deve-se atribuí-las com bastante cautela.

A partir do modelo de dois estágios tradicional, foram determinadas duas medidas importantes, o valor esperado de informação perfeita (EVPI) e o valor da solução estocástica (VSS). Embora o EVPI possa ser calculado facilmente a partir dos problemas wait-and-see, a obtenção do VSS foi prejudicada devido à infactibilidade do problema $E E V$, fato já mostrado na proposição sobre as condições suficientes para assegurar a factibilidades desses problemas. Em seguida, determinou-se uma solução do problema EEV pela adição de dois conjuntos de variáveis de erro, cujo objetivo era assegurar as condições de suficiência propostas. EVPI e VSS variaram entre $47-72 \%$ e $31-60 \%$, respectivamente, indicando que, além do problema ser muito influenciado pelas incertezas, abordagens mais simples de valores médios não são adequadas para aproximar o problema estocástico. A variação dessas medidas de acordo com as situações consideradas corrobora com a sugestão de que um cálculo de probabilidades impreciso e/ou incoerente pode atrapalhar a análise de desempenho dos modelos estocásticos.

Os resultados do modelo Min-Max indicam que essa abordagem pode gerar valores ótimos muito conservadores, uma vez que os modelos baseiam-se numa perspectiva de minimização dos desvios mais desfavoráveis e as probabilidades dos diferentes cenários não é considerada. Entretanto, pode ser uma alternativa plausível para decisores com muita aversão ao risco e em contextos em que há dificuldade na estimação das probabilidades dos cenários.

Os testes com os modelos estocásticos robustos ilustram o desempenho dos problemas à medida que a solução vai progressivamente se tornando robusta, muitas vezes às custas de deteriorações significativas nos valores ótimos das funções objetivos. Dois modelos foram propostos: o modelo Média-Risco e o modelo com restrições de recurso. Embora 
os valores ótimos sejam equivalentes - para um certo fator de risco e redução do desvio esperado - as soluções não são, necessariamente, idênticas. Além disso, é importante frisar que o modelo $M R$ apresenta uma função objetivo que é muito mais deteriorada do que a função objetivo do modelo $R R$, devido à parcela $\lambda \Delta$ presente no primeiro. Por outro lado, atribuir valores para $\lambda$ pode ser mais simples para um especialista interessado no tradeoff entre custo e robustez do que diminuir gradualmente o desvio para atingir a estabilização dos custos de segundo estágio. De qualquer modo, vale a pena ressaltar que ambos os modelos constituem-se numa poderosa ferramenta de análise por fornecer soluções baseadas no compromisso entre custo esperado e estabilização das variáveis recurso. Tais soluções alternativas não são identificadas pelos programas estocásticos tradicionais e são importantes para não ser necessário replanejar para toda possível realização das variáveis aleatórias. Ainda, há várias questões em aberto neste capítulo que devem ser melhor estudadas oportunamente; algumas delas encontram-se descritas na próxima seção.

\subsection{Pesquisas Futuras}

\subsubsection{Modelos de Programação Estocástica com Probabilidades Incertas}

Nesse capítulo, mostrou-se que a variação das probabilidades dos cenários pode afetar o valor ótimo e a solução do modelo estocástico e comprometer a análise de desempenho dos mesmos. Na maioria dos trabalhos científicos de programação estocástica, entretanto, há poucos que propõem metodologias específicas para lidar com modelos cujas probabilidades não são conhecidas com certeza. Uma das formas de lidar com essa questão é utilizar modelos tradicionais de Min-Max com arrependimento. Entretanto, tais modelos podem ser muito conservadores, especialmente quando o cenário de pior caso é muito pior do que a maioria dos cenários considerados. Uma maneira interessante de lidar com esse tema é proposto em Thiele (2008), em que a autora utiliza o arcabouço teórico de otimização robusta para determinar formulações robustas equivalentes de problemas gerais de dois estágios com recurso, na situação em que as próprias probabilidades são definidas como variáveis aleatórias limitadas em conjuntos de incerteza poliédricos, similarmente ao que é desenvolvido no Capítulo 4:

$$
\pi_{s}=\bar{\pi}_{s}+\hat{\pi}_{s} z_{s}, \quad-1 \leq z_{s} \leq 1, s \in \Omega
$$

em que $z_{s}$ é o desvio em relação à probabilidade nominal. Ainda, é preciso assegurar que $\sum_{s \in \Omega} \hat{\pi}_{s} z_{s}=0$, pois a soma total de todas as probabilidades não pode ultrapassar 1 . 
Considerando o conjunto de incertezas poliédrico, a formulação equivalente robusta mantém a tratabilidade do problema original que, em geral, já é um problema de grande porte pela descrição explícita de todos os cenários. Sendo assim, estender a formulação robusta para lidar com as probabilidades incertas no problema combinado apresentado nessa tese pode originar resultados interessantes. Obviamente, é esperado sacrificar a otimalidade do custo total esperado para obter uma solução robusta em relação à variação das probabilidades nos intervalos pré-estabelecidos. Ainda nesse tema de pesquisa, é preciso verificar a estabilidade das decisões de segundo estágio segundo a perspectiva de pior caso. Embora a solução possa ser robusta em relação às probabilidades, a autora não discute questões referentes a restrições de recurso ou incorporação de aversão ao risco nos exemplos apresentados nesse trabalho pioneiro, o que poderia ser um tema bastante interessante de pesquisa futura.

\subsubsection{Decomposição de Benders para o Problema Estocástico}

Uma técnica bastante conhecida e aplicada a problemas difíceis, inclusive a problemas de programação estocástica, é a Decomposição de Benders (Benders, 1962; Geoffrion, 1972). O sucesso da utilização desse método em vários problemas estocásticos de dois ou multi estágios advém do seguinte fato: a decomposição substitui um problema estocástico difícil e de grande porte por um conjunto de problemas menores e mais fáceis. Isso permite que problemas extremamente grandes e intratáveis possam ser resolvidos (Ruszczynski, 2003).

De forma geral, considerando problemas estocásticos de dois estágios com recurso, a Decomposição de Benders resolve, iterativamente, um problema mestre composto das variáveis de primeiro estágio, enquanto estima o valor da função objetivo dos subproblemas, aos quais estão associadas as variáveis de segundo estágio. Se alguma restrição do problema original for infactível, então são adicionados planos de corte de factibilidade ao problema mestre. Se a estimativa do valor da função objetivo dos subproblemas não satisfaz o critério de otimalidade, então são adicionados planos de corte de otimalidade aos subproblemas. Esse processo é repetido até que não seja mais necessário adicionar nenhum tipo de plano de corte ao problema mestre e aos subproblemas.

Assim, seja $\mathbf{X}=\left\{X_{i t}\right\}, \mathbf{Y}=\left\{Y_{j t}\right\}$ e $\mathbf{Z}=\left\{Z_{j t}\right\}$. Considere uma solução tentativa $(\hat{\mathbf{X}}, \hat{\mathbf{Y}}, \hat{\mathbf{Z}})$ associada às variáveis de primeiro estágio: volume de produção $X_{i t}$, frequência de padrões de corte $Y_{j t}$ e preparação de máquinas $Z_{j t}$, respectivamente, do problema (3.13)-(3.22). Essa solução é substituída na formulação original, convertendo as variáveis de primeiro estágio $\{\mathbf{X}, \mathbf{Y}, \mathbf{Z}\}$ em parâmetros $\{\hat{\mathbf{X}}, \hat{\mathbf{Y}}, \hat{\mathbf{Z}}\}$. Como consequência, as restrições compostas somente por essas variáveis podem ser descartadas. O problema resultante torna-se dependente apenas das variáveis de segundo estágio $I_{i t}^{+}, I_{i t}^{-}$e $O_{t s}$, e pode ser 
escrito, para cada cenário $s \in \Omega$, da seguinte maneira:

$$
v^{s}(\hat{\mathbf{X}}, \hat{\mathbf{Y}}, \hat{\mathbf{Z}})=\operatorname{Minimizar} \sum_{i \in \mathcal{I}} \sum_{t \in \mathcal{T}} h_{i t}^{+} I_{i t s}^{+}+\sum_{i \in \mathcal{I}} \sum_{t \in \mathcal{T}} h_{i t}^{-} I_{i t s}^{-}+\sum_{t \in \mathcal{T}} o_{t} O_{t s}
$$

Sujeito a:

$$
\begin{aligned}
& \hat{X}_{i t}+I_{i, t-1, s}^{+}-I_{i t s}^{+}+I_{i t s}^{-}-I_{i, t-1, s}^{-}=d_{i t s}, i \in \mathcal{I}, t \in \mathcal{T} \\
& I_{i t s}^{+} \leq \Lambda_{i t}^{\max }, i \in \mathcal{I}, t \in \mathcal{T} \\
& \sum_{j \in \mathcal{J}}\left(\nu_{j}^{I} \hat{Y}_{j t}+\varphi_{j t s}^{I} \hat{Z}_{j t}\right) \leq C_{t}^{I}+O_{t s}, t \in \mathcal{T} \\
& \sum_{p \in \mathcal{P}} \sum_{j \in \mathcal{J}}\left(\nu_{p}^{I I} a_{p j} \hat{Y}_{j t}+\varphi_{p t s}^{I I} \delta_{p j} \hat{Z}_{j t}\right) \leq C_{t}^{I I}+O_{t s}, t \in \mathcal{T} \\
& 0 \leq O_{t s} \leq C_{t}^{E}, t \in \mathcal{T} \\
& I_{i t s}^{+}, I_{i t s}^{-} \geq 0, i \in \mathcal{I}, t \in \mathcal{T} .
\end{aligned}
$$

Agora, considere as variáveis duais associadas às restrições (3.33)-(3.37): $\alpha_{i t}^{s}, \lambda_{i t}^{s}$, $\beta_{i t}^{s}, \gamma_{t}^{s}, \phi_{t}^{s}$ e $\theta_{t}^{s}$, respectivamente. Então, o dual do problema (3.32)-(3.38), para cada cenário $s \in \Omega$, é dado por:

$$
\begin{aligned}
& v^{s}(\hat{\mathbf{X}}, \hat{\mathbf{Y}}, \hat{\mathbf{Z}})=\operatorname{Maximizar} \sum_{i \in \mathcal{I}} \sum_{t \in \mathcal{T}}\left(d_{i t s}-\hat{X}_{i t}\right) \alpha_{i t}^{s}-\sum_{i \in \mathcal{I}} \sum_{t \in \mathcal{T}} \Lambda_{i t}^{\max } \beta_{i t}^{s}+ \\
& +\sum_{t \in \mathcal{T}}\left(\sum_{j \in \mathcal{J}}\left(\nu_{j}^{I} \hat{Y}_{j t}+\varphi_{j t s}^{I} \hat{Z}_{j t}\right)-C_{t}^{I}\right) \gamma_{t}^{s}+ \\
& +\sum_{t \in \mathcal{T}}\left(\sum_{p \in \mathcal{P}} \sum_{j \in \mathcal{J}}\left(\nu_{p}^{I I} a_{p j} \hat{Y}_{j t}+\varphi_{p t s}^{I I} \delta_{p j} \hat{Z}_{j t}\right)-C_{t}^{I I}\right) \phi_{t}^{s}-\sum_{t \in \mathcal{T}} C_{t}^{E} \theta_{t}^{s}
\end{aligned}
$$

Sujeito a:

$$
\begin{aligned}
& -\alpha_{i t}^{s}+\alpha_{i, t+1}^{s}-\beta_{i t}^{s} \leq h_{i t}^{+}, i \in \mathcal{I}, t \in \mathcal{T}-\{T\} \\
& -\alpha_{i T}^{s}-\beta_{i T}^{s} \leq h_{i T}^{+}, i \in \mathcal{I} . \\
& \alpha_{i t}^{s}-\alpha_{i, t+1}^{s} \leq h_{i t}^{-}, i \in \mathcal{I}, t \in \mathcal{T}-\{T\} . \\
& \alpha_{i T}^{s} \leq h_{i T}^{-}, i \in \mathcal{I} . \\
& \gamma_{t}^{s}+\phi_{t}^{s}-\theta_{t}^{s} \leq o_{t}, t \in \mathcal{T} . \\
& \alpha_{i t}^{s} \text { livre }, \beta_{i t}^{s}, \gamma_{t}^{s}, \phi_{t}^{s}, \theta_{t}^{s} \geq 0, i \in \mathcal{I} t \in \mathcal{T} .
\end{aligned}
$$

Para obter uma solução tentativa, resolve-se o problema mestre relaxado (RMP), 
que é inicialmente definido por:

Minimizar $\sum_{i \in \mathcal{I}} \sum_{t \in \mathcal{T}} c_{i t} X_{i t}+\sum_{j \in \mathcal{J}} \sum_{t \in \mathcal{T}} w_{j t} Y_{j t}+\sum_{j \in \mathcal{J}} \sum_{t \in \mathcal{T}} z_{j t} Z_{j t}+\sum_{s \in \Omega} \pi_{s} z_{s}$

Sujeito a:

$\sum_{i \in \mathcal{I}} r_{p i} X_{i t}-\sum_{j \in \mathcal{J}} a_{p j} Y_{j t} \leq 0, p \in \mathcal{P}, t \in \mathcal{T}$

$Y_{j t}-Q Z_{j t} \leq 0, j \in \mathcal{J}, t \in \mathcal{T}$

$X_{i t} \geq 0, i \in \mathcal{I}, t \in \mathcal{T}$

$Y_{j t} \geq 0, Z_{j t} \in\{0,1\}, j \in \mathcal{J}, t \in \mathcal{T}$

$z_{s} \geq 0, s \in \Omega$.

Dada uma solução ótima $\left(\hat{X}_{i t}, \hat{Y}_{j t}, \hat{Z}_{j t}, z_{s}\right)$ desse problema, resolve-se o subproblema (3.39)-(3.40), para cada $s \in \Omega$, usando $\left(\hat{X}_{i t}, \hat{Y}_{j t}, \hat{Z}_{j t}\right)$. Assim, tem-se duas situações possíveis:

1. O subproblema (3.39)-(3.40) tem uma solução ótima finita $\left(\hat{\alpha}_{i t}^{s}, \hat{\beta}_{i t}^{s}, \hat{\gamma}_{t}^{s}, \hat{\phi}_{t}^{s}, \hat{\theta}_{t}^{s}\right)$ e, portanto, o problema primal associado é factível. Da função objetivo do subproblema, obtém-se um corte de otimalidade:

$$
\begin{aligned}
& \sum_{i \in \mathcal{I}} \sum_{t \in \mathcal{T}}\left(d_{i t s}-X_{i t}\right) \hat{\alpha}_{i t}^{s}-\sum_{i \in \mathcal{I}} \sum_{t \in \mathcal{T}} \Lambda_{i t}^{\max } \hat{\beta}_{i t}^{s}+\sum_{t \in \mathcal{T}}\left(\sum_{j \in \mathcal{J}}\left(\nu_{j}^{I} Y_{j t}+\varphi_{j t s}^{I} Z_{j t}\right)-C_{t}^{I}\right) \hat{\gamma}_{t}^{s}+ \\
& +\sum_{t \in \mathcal{T}}\left(\sum_{p \in \mathcal{P}} \sum_{j \in \mathcal{J}}\left(\nu_{p}^{I I} a_{p j} Y_{j t}+\varphi_{p t s}^{I I} \delta_{p j} Z_{j t}\right)-C_{t}^{I I}\right) \hat{\phi}_{t}^{s}-\sum_{t \in \mathcal{T}} C_{t}^{E} \hat{\theta}_{t}^{s} \leq z_{s},
\end{aligned}
$$

que pode ser reescrito como:

$$
\begin{aligned}
& -z_{s}-\sum_{i \in \mathcal{I}} \sum_{t \in \mathcal{T}} \hat{\alpha}_{i t}^{s} X_{i t}+\sum_{t \in \mathcal{T}} \sum_{j \in \mathcal{J}}\left(\hat{\gamma}_{t}^{s} \nu_{j}^{I}+\hat{\phi}_{t}^{s} \sum_{p \in \mathcal{P}} \nu_{p}^{I I} a_{p j}\right) Y_{j t} \\
& +\sum_{t \in \mathcal{T}} \sum_{j \in \mathcal{J}}\left(\hat{\gamma}_{t}^{s} \varphi_{j t s}^{I}+\hat{\phi}_{t}^{s} \sum_{p \in \mathcal{P}} \varphi_{p t s}^{I I} \delta_{p j}\right) Z_{j t} \\
& \leq-\sum_{i \in \mathcal{I}} \sum_{t \in \mathcal{T}} d_{i t s} \hat{\alpha}_{i t}^{s}+\sum_{i \in \mathcal{I}} \sum_{t \in \mathcal{T}} \Lambda_{i t}^{\max } \hat{\beta}_{i t}^{s}+\sum_{t \in \mathcal{T}} C_{t}^{E} \hat{\theta}_{t}^{s}+\sum_{t \in \mathcal{T}} C_{t}^{I} \hat{\gamma}_{t}^{s}+\sum_{t \in \mathcal{T}} C_{t}^{I I} \hat{\phi}_{t}^{s} .
\end{aligned}
$$

2. O subproblema (3.39)-(3.40) é ilimitado e, portanto, o respectivo problema primal é infactível. Então, pode-se obter um raio extremo $\left(\hat{\alpha}_{i t}^{s}, \hat{\beta}_{i t}^{s}, \hat{\gamma}_{t}^{s}, \hat{\phi}_{t}^{s}, \hat{\theta}_{t}^{s}\right)$, de tal forma que um corte de factibilidade pode ser definido da função objetivo da seguinte maneira: 


$$
\begin{aligned}
& \sum_{i \in \mathcal{I}} \sum_{t \in \mathcal{T}}\left(d_{i t s}-X_{i t}\right) \hat{\alpha}_{i t}^{s}-\sum_{i \in \mathcal{I}} \sum_{t \in \mathcal{T}} \Lambda_{i t}^{\max } \hat{\beta}_{i t}^{s}+\sum_{t \in \mathcal{T}}\left(\sum_{j \in \mathcal{J}}\left(\nu_{j}^{I} Y_{j t}+\varphi_{j t s}^{I} Z_{j t}\right)-C_{t}^{I}\right) \hat{\gamma}_{t}^{s}+ \\
& +\sum_{t \in \mathcal{T}}\left(\sum_{p \in \mathcal{P}} \sum_{j \in \mathcal{J}}\left(\nu_{p}^{I I} a_{p j} Y_{j t}+\varphi_{p t s}^{I I} \delta_{p j} Z_{j t}\right)-C_{t}^{I I}\right) \hat{\phi}_{t}^{s}-\sum_{t \in \mathcal{T}} C_{t}^{E} \hat{\theta}_{t}^{s} \leq 0,
\end{aligned}
$$

que pode ser reescrito como:

$$
\begin{aligned}
& -\sum_{i \in \mathcal{I}} \sum_{t \in \mathcal{T}} \hat{\alpha}_{i t}^{s} X_{i t}+\sum_{t \in \mathcal{T}} \sum_{j \in \mathcal{J}}\left(\hat{\gamma}_{t}^{s} \nu_{j}^{I}+\hat{\phi}_{t}^{s} \sum_{p \in \mathcal{P}} \nu_{p}^{I I} a_{p j}\right) Y_{j t} \\
& +\sum_{t \in \mathcal{T}} \sum_{j \in \mathcal{J}}\left(\hat{\gamma}_{t}^{s} \varphi_{j t s}^{I}+\hat{\phi}_{t}^{s} \sum_{p \in \mathcal{P}} \varphi_{p t s}^{I I} \delta_{p j}\right) Z_{j t} \\
& \leq-\sum_{i \in \mathcal{I}} \sum_{t \in \mathcal{T}} d_{i t s} \hat{\alpha}_{i t}^{s}+\sum_{i \in \mathcal{I}} \sum_{t \in \mathcal{T}} \Lambda_{i t}^{\max } \hat{\beta}_{i t}^{s}+\sum_{t \in \mathcal{T}} C_{t}^{E} \hat{\theta}_{t}^{s}+\sum_{t \in \mathcal{T}} C_{t}^{I} \hat{\gamma}_{t}^{s}+\sum_{t \in \mathcal{T}} C_{t}^{I I} \hat{\phi}_{t}^{s} .
\end{aligned}
$$

Dependendo do valor ótimo dos subproblemas, a solução tentativa atual é ótima para o problema original e, portanto, o procedimento termina. Caso contrário, os cortes gerados pelos subproblemas são adicionados ao RMP e ele é reotimizado. Esse processo é resumido no Algoritimo 1.

Algoritmo 1. Método de planos de corte para a decomposição de Benders.

Input. Problema RMP inicial (3.41) e respectivos subproblemas (3.39)-(3.40).

Passo 1. Resolva o problema RMP atual para obter uma solução tentativa $(\hat{\mathbf{X}}, \hat{\mathbf{Y}}, \hat{\mathbf{Z}})$.

Passo 2. Para todo $s \in \Omega$ faça

(a) Resolva o subproblema (3.39)-(3.40) para o valor de $s$ atual.

(b) Se o subproblema tiver uma solução ótima finita e o seu valor for menor ou igual a $\hat{z}_{s}$, todas as restrições são satisfeitas, e tem-se uma solução ótima para o problema mestre e o algoritmo termina.

(c) Se o subproblema for ilimitado, então se tem um raio extremo $(\hat{\alpha}, \hat{\beta}, \hat{\gamma}, \hat{\phi}, \hat{\theta})$ para definir um corte de factibilidade. Caso contrário, obtém-se um ponto extremo ótimo $(\hat{\alpha}, \hat{\beta}, \hat{\gamma}, \hat{\phi}, \hat{\theta})$ que é usado para definir um corte de otimalidade, se o valor ótimo da solução do subproblema for maior do que $\hat{z}_{s}$.

(d) Determine o corte e insira-o no problema RMP atual. 
Passo 3. Vá ao Passo 1.

Uma implementação inicial do algoritmo 1 foi realizada neste estudo, mas o desempenho computacional não foi satisfatório em comparação à resolução do problema original pelo CPLEX 11.0. De fato, exceto para uma pequena classe de problemas, é improvável que a simples aplicação da decomposição de Benders pura, sem o apoio de outras estratégias, resulte em um desempenho computacional superior. Diversos autores têm proposto técnicas que resultam em um melhor desempenho da decomposição de Benders (Geoffrion e Graves, 1974; Magnanti e Wong, 1981; Penuel et al., 2010; Camargo et al., 2009). Para um survey em decomposição de Benders aplicado em problemas do tipo fixed-charge network design, o leitor pode consultar o trabalho de Costa (2005). Como perspectivas futuras, pretende-se aplicar essas técnicas no contexto do problema aqui tratado, bem como investigar o desenvolvimento de técnicas específicas para este contexto. Além disso, é importante também estender os métodos de resolução dos problemas estocásticos para os problemas robustos do tipo média-risco e de recurso restrito. Em Takriti e Ahmed (2004) e Ahmed (2006), os autores propõem métodos de decomposição e de planos de corte para alguns problemas gerais de média-risco. Tais trabalhos devem ser investigados em pesquisas futuras. 


\begin{tabular}{lcccccccc}
\hline Cenário & $\pi \%$ & $\mathrm{IC}$ & $I^{+}$ & $\mathrm{BC}$ & $I_{T}^{-}$ & $\mathrm{OC}$ & $O$ & $\mathcal{B} \%$ \\
\hline 1. Baixa-Baixo-Baixo & 1,56 & 27258 & 3131 & 0 & 0 & 0 & 0 & 100 \\
2. Baixa-Baixo-Médio & 3,13 & 21678 & 2717 & 0 & 0 & 29 & 493 & 100 \\
3. Baixa-Baixo-Alto & 1,56 & 26717 & 2813 & 0 & 0 & 552 & 9295 & 100 \\
4. Baixa-Médio-Baixo & 3,13 & 26208 & 2925 & 0 & 0 & 0 & 0 & 100 \\
5. Baixa-Médio-Médio & 6,25 & 23714 & 2677 & 0 & 0 & 19 & 316 & 100 \\
6. Baixa-Médio-Alto & 3,13 & 27011 & 2918 & 0 & 0 & 548 & 9223 & 100 \\
7. Baixa-Alto-Baixo & 1,56 & 31255 & 2874 & 0 & 0 & 0 & 0 & 100 \\
8. Baixa-Alto-Médio & 3,13 & 27252 & 3090 & 0 & 0 & 0 & 0 & 100 \\
9. Baixa-Alto-Alto & 1,56 & 28002 & 2705 & 0 & 0 & 528 & 8884 & 100 \\
10. Média-Baixo-Baixo & 3,13 & 6712 & 834 & 165280 & 163 & 0 & 0 & 94,2 \\
11. Média-Baixo-Médio & 6,25 & 6987 & 985 & 233583 & 155 & 31 & 521 & 94,4 \\
12. Média-Baixo-Alto & 3,13 & 7030 & 975 & 159802 & 138 & 608 & 10242 & 95,0 \\
13. Média-Médio-Baixo & 6,25 & 7280 & 957 & 149932 & 160 & 0 & 0 & 94,2 \\
14. Média-Médio-Médio & 12,5 & 6807 & 954 & 169981 & 142 & 0 & 0 & 94,9 \\
15. Média-Médio-Alto & 6,25 & 7139 & 934 & 168725 & 145 & 597 & 10047 & 94,8 \\
16. Média-Alto-Baixo & 3,13 & 7512 & 968 & 115131 & 134 & 0 & 0 & 95,1 \\
17. Média-Alto-Médio & 6,25 & 6521 & 927 & 206286 & 165 & 9 & 155 & 94,1 \\
18. Média-Alto-Alto & 3,13 & 7020 & 896 & 114982 & 138 & 635 & 10692 & 95,0 \\
19. Alta-Baixo-Baixo & 1,56 & 1409 & 206 & 898490 & 641 & 0 & 0 & 80,6 \\
20. Alta-Baixo-Médio & 3,13 & 1090 & 165 & 757576 & 573 & 8 & 141 & 82,3 \\
21. Alta-Baixo-Alto & 1,56 & 414 & 22 & 961246 & 682 & 577 & 9709 & 79,6 \\
22. Alta-Médio-Baixo & 3,13 & 503 & 61 & 795375 & 602 & 0 & 0 & 81,6 \\
23. Alta-Médio-Médio & 6,25 & 1958 & 217 & 652827 & 528 & 2 & 30 & 83,5 \\
24. Alta-Médio-Alto & 3,13 & 1018 & 143 & 885985 & 625 & 517 & 8708 & 81,0 \\
25. Alta-Alto-Baixo & 1,56 & 1138 & 140 & 789059 & 597 & 0 & 0 & 81,7 \\
26. Alta-Alto-Médio & 3,13 & 807 & 120 & 844174 & 586 & 39 & 651 & 82,0 \\
27. Alta-Alto-Alto & 1,56 & 815 & 128 & 894661 & 620 & 600 & 10093 & 81,1 \\
\hline \hline Média & - & 11528 & 1314 & 331967 & 252 & 196 & 3304 & 92,0 \\
\hline
\end{tabular}

${ }^{1}$ Custo: 473384; PC: 95913(2667); TC: 82337(6347); Z: 364; Tempo: $47 \mathrm{s.}$

Tabela 3.3: Resultados de um exemplar real do modelo estocástico $C L C 2 r$ na situação moderada, na qual as probabilidades das demandas e tempos de preparação nos cenários Baixo, Médio e Alto são 25, 50 e 25\%, respectivamente. 
$\Delta\left(\times 10^{4}\right)$
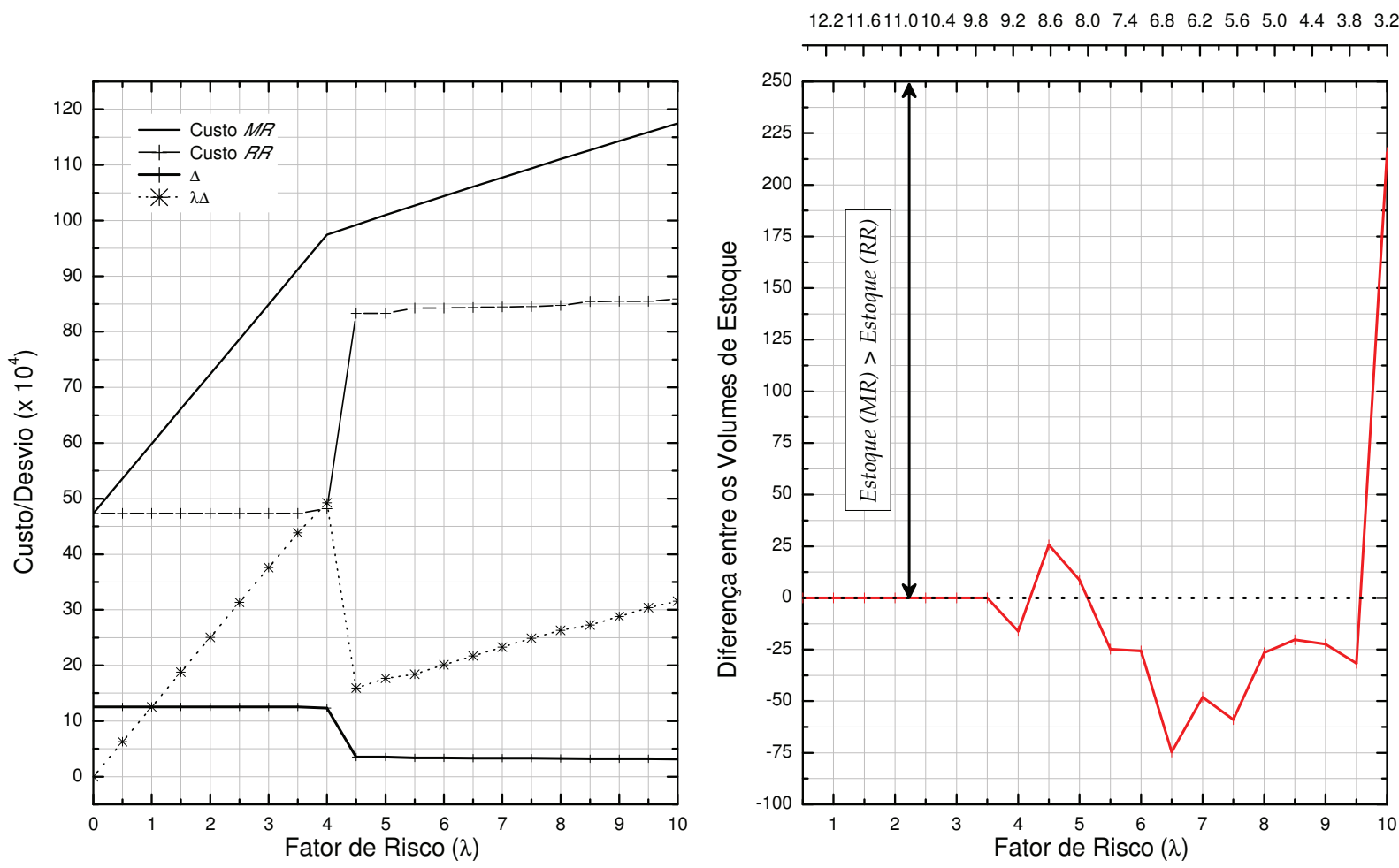

$\Delta\left(\times 10^{4}\right)$

$\Delta\left(\times 10^{4}\right)$
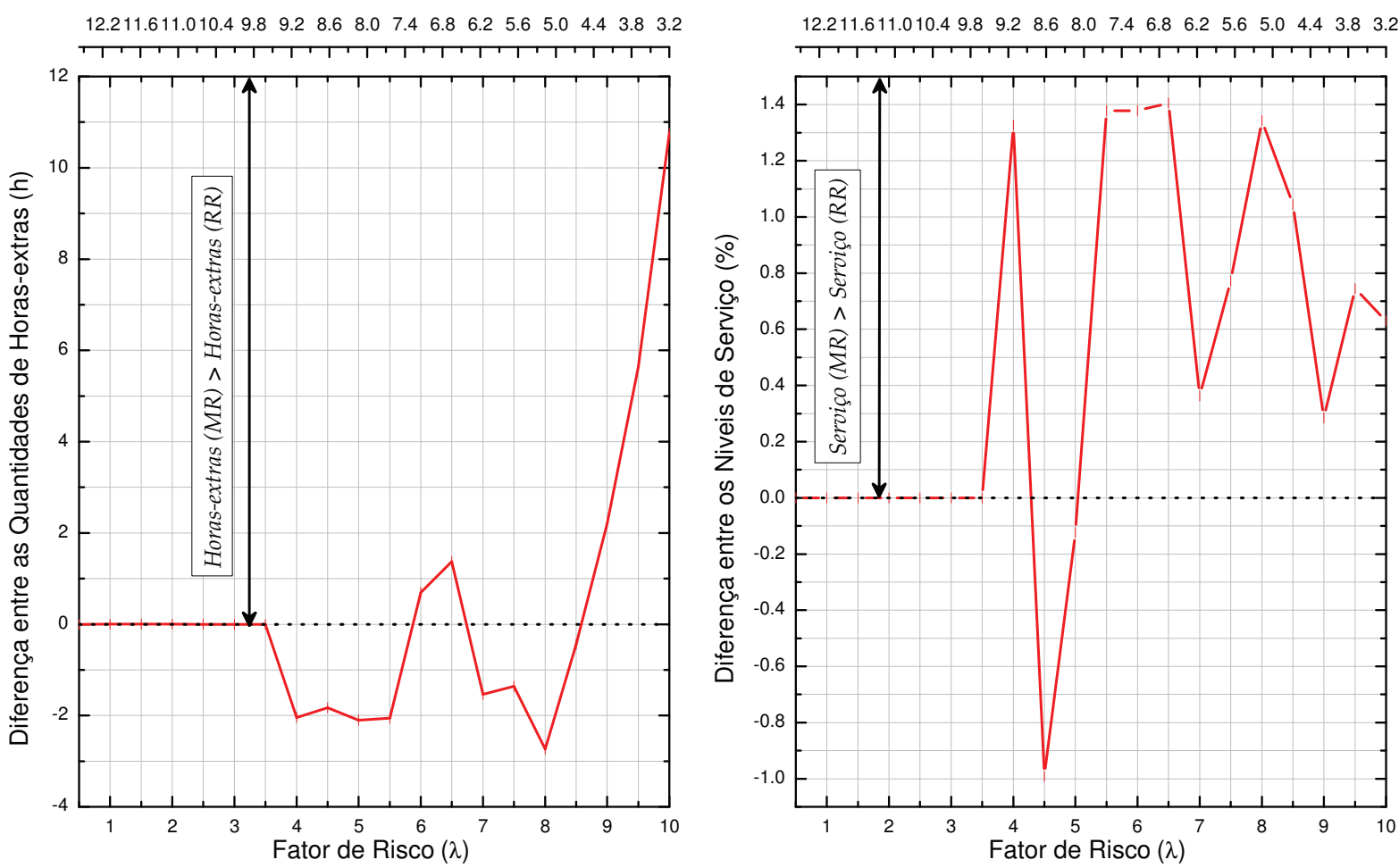

Figura 3.7: Desempenho relativo do custo total esperado, volume de estoque, horas-extras e nível de serviço, considerando as diferenças entre as soluções dos problemas $M R$ e $R R$. 

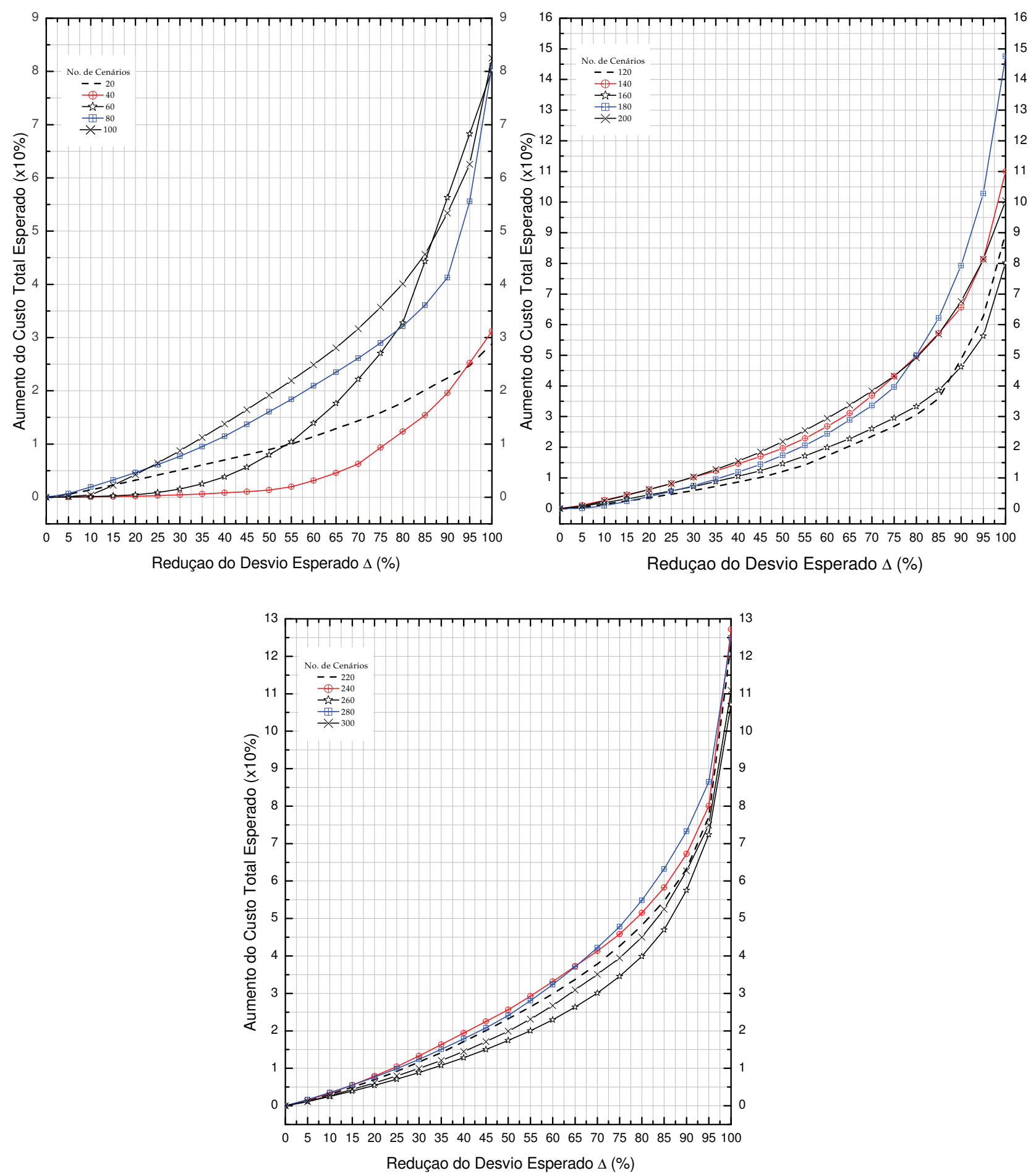

Figura 3.8: Curvas de tradeoff entre aumento do custo total esperado e redução do risco para $S=20, \cdots, 300$, considerando um exemplar estocástico robusto de recurso restrito. 

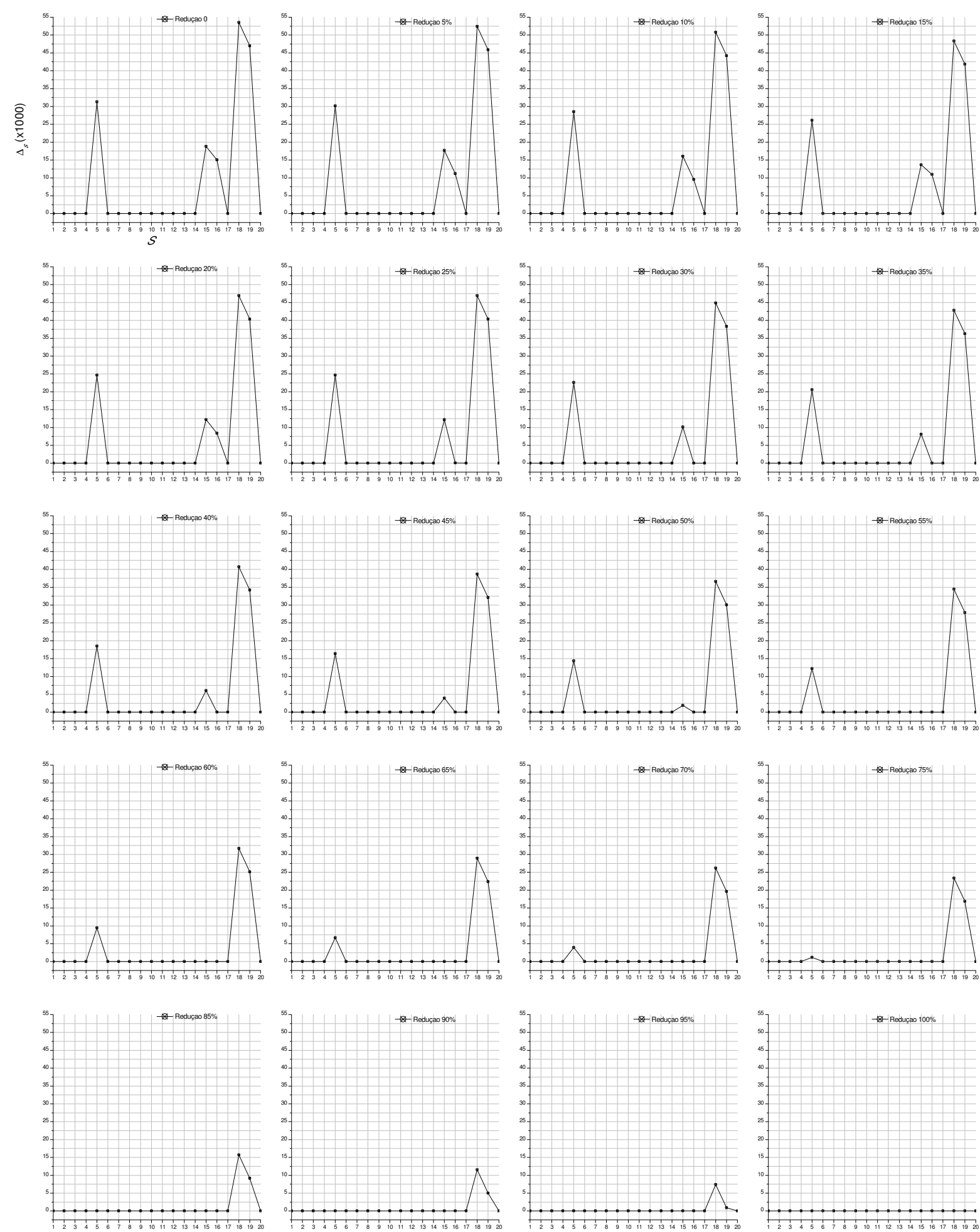

Figura 3.9: Exemplo de redução progressiva do desvio $\Delta_{s}$ de 0 até 100\%, considerando um exemplar estocástico robusto de recurso restrito com 20 cenários. 

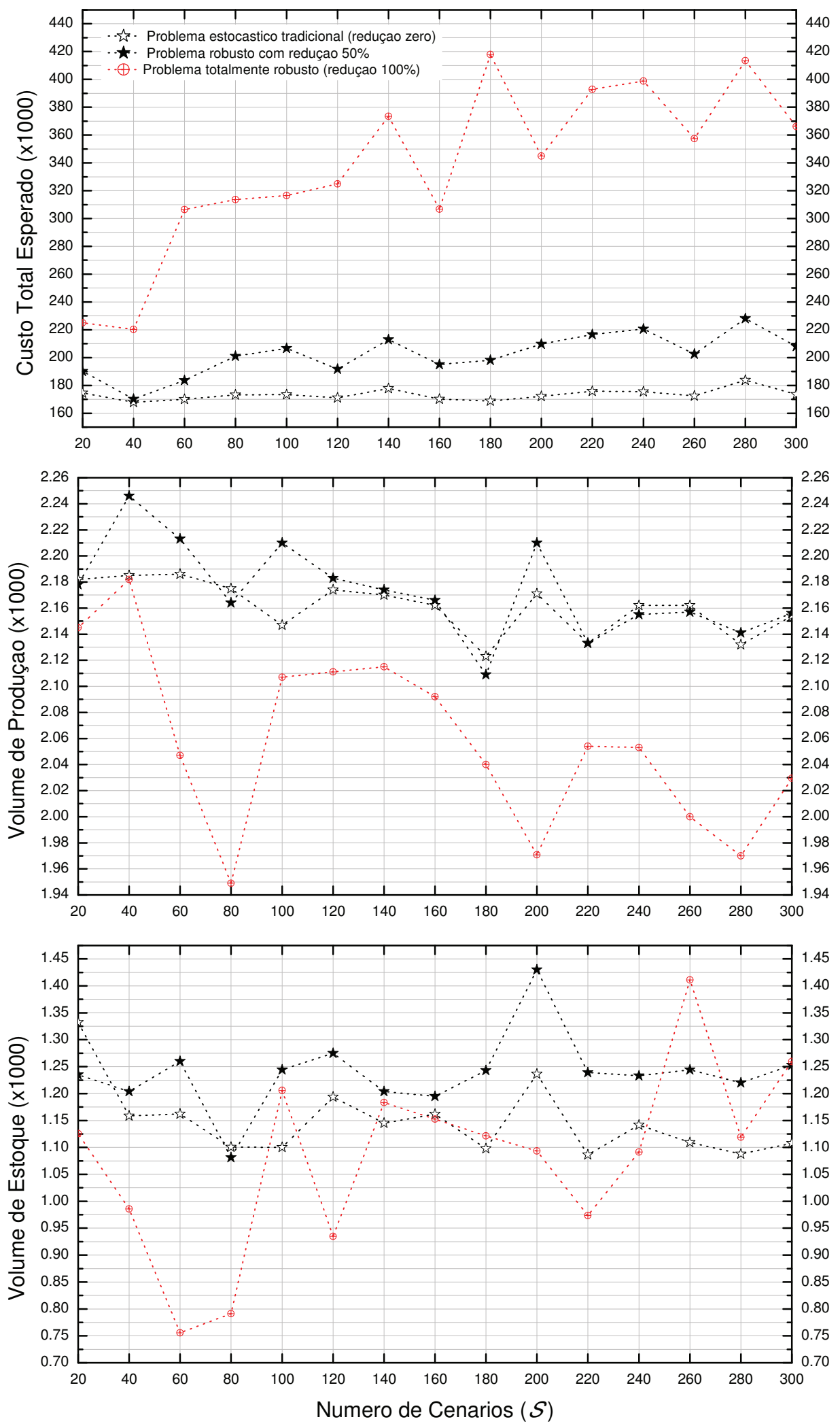

Figura 3.10: Comportamento da solução ótima do problema com recurso restrito (custo total, volume de produção e estoque) de acordo com o aumento do número de cenários (de 20 até 300), considerando três níveis de redução do desvio esperado: 0, 50 e 100\%. 

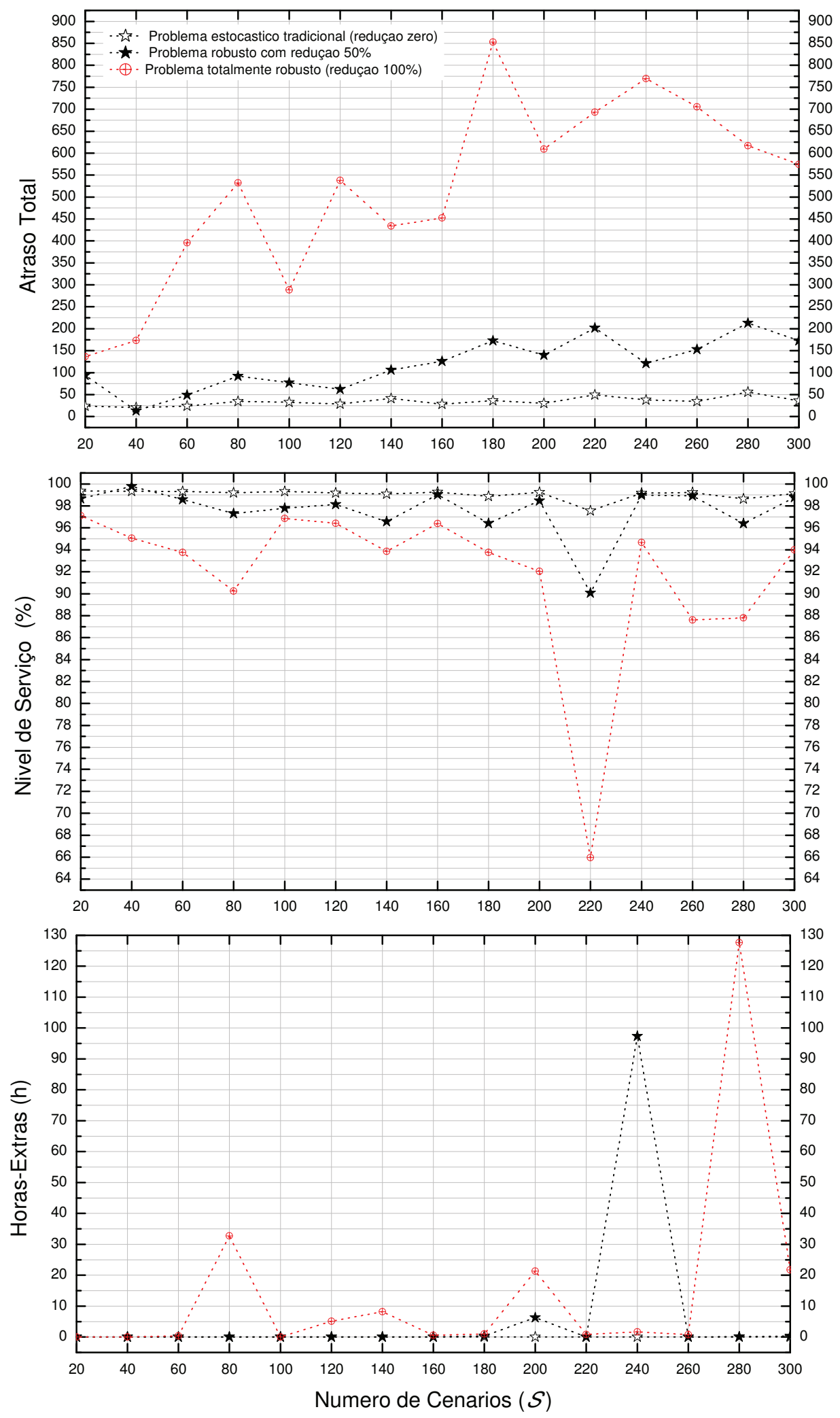

Figura 3.11: Comportamento da solução ótima do problema com recurso restrito (atraso total, nível de serviço e horas-extras) de acordo com o aumento do número de cenários (de 20 até 300), considerando três níveis de redução do desvio esperado: zero, 50 e 100\%. 

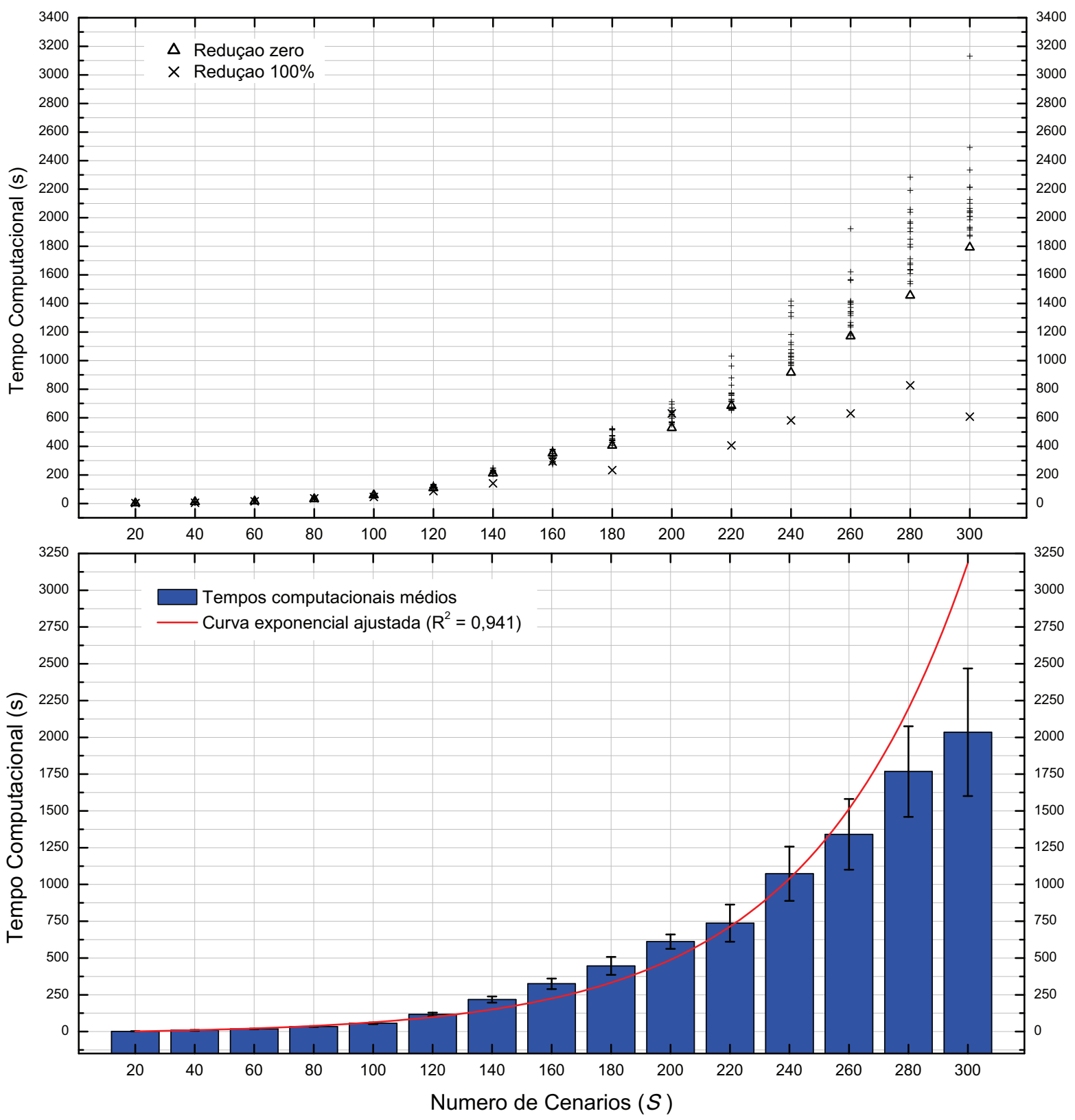

Figura 3.12: a) Acima: tempos de resolução dos problemas robustos para todos os cenários e níveis de redução. b) Abaixo: tempos computacionais médios dos problemas robustos, respectivos desvios-padrão e curva ajustada. 


\begin{tabular}{|c|c|c|c|c|c|c|c|c|}
\hline Cenário & $\pi \%$ & $\mathrm{IC}$ & $I^{+}$ & $\mathrm{BC}$ & $I_{T}^{-}$ & $\mathrm{OC}$ & $O$ & $\mathcal{B} \%$ \\
\hline 1. Baixa-Baixo-Baixo & 3,70 & 27262 & 3132 & 0 & 0 & 0 & 0 & 100 \\
\hline 2. Baixa-Baixo-Médio & 3,70 & 21682 & 2718 & 0 & 0 & 34 & 574 & 100 \\
\hline 3. Baixa-Baixo-Alto & 3,70 & 26720 & 2814 & 0 & 0 & 557 & 9375 & 100 \\
\hline 4. Baixa-Médio-Baixo & 3,70 & 26212 & 2926 & 0 & 0 & 0 & 0 & 100 \\
\hline 5. Baixa-Médio-Médio & 3,70 & 23718 & 2678 & 0 & 0 & 24 & 396 & 100 \\
\hline 6. Baixa-Médio-Alto & 3,70 & 27014 & 2919 & 0 & 0 & 553 & 9303 & 100 \\
\hline 7. Baixa-Alto-Baixo & 3,70 & 31258 & 2875 & 0 & 0 & 0 & 0 & 100 \\
\hline 8. Baixa-Alto-Médio & 3,70 & 27256 & 3091 & 0 & 0 & 0 & 0 & 100 \\
\hline 9. Baixa-Alto-Alto & 3,70 & 28005 & 2706 & 0 & 0 & 532 & 8965 & 100 \\
\hline 10. Média-Baixo-Baixo & 3,70 & 6716 & 835 & 165280 & 163 & 0 & 0 & 94,2 \\
\hline 11. Média-Baixo-Médio & 3,70 & 6990 & 986 & 233583 & 155 & 36 & 601 & 94,4 \\
\hline 12. Média-Baixo-Alto & 3,70 & 7034 & 976 & 159802 & 138 & 613 & 10323 & 95,0 \\
\hline 13. Média-Médio-Baixo & 3,70 & 7283 & 958 & 149932 & 160 & 0 & 0 & 94,2 \\
\hline 14. Média-Médio-Médio & 3,70 & 6810 & 955 & 169981 & 142 & 0 & 0 & 94,9 \\
\hline 15. Média-Médio-Alto & 3,70 & 7142 & 935 & 168725 & 145 & 602 & 10128 & 94,8 \\
\hline 16. Média-Alto-Baixo & 3,70 & 7516 & 969 & 115131 & 134 & 0 & 0 & 95,1 \\
\hline 17. Média-Alto-Médio & 3,70 & 6524 & 928 & 206286 & 165 & 14 & 235 & 94,1 \\
\hline 18. Média-Alto-Alto & 3,70 & 7024 & 897 & 114982 & 138 & 640 & 10772 & 95,0 \\
\hline 19. Alta-Baixo-Baixo & 3,70 & 1412 & 207 & 898490 & 641 & 0 & 0 & 80,6 \\
\hline 20. Alta-Baixo-Médio & 3,70 & 1093 & 166 & 757576 & 573 & 13 & 222 & 82,3 \\
\hline 1. Alta-Baixo-Alto & 3,70 & 417 & 23 & 961246 & 682 & 581 & 9789 & 79,6 \\
\hline 22. Alta-Médio-Baixo & 3,70 & 506 & 62 & 795375 & 602 & 0 & 0 & 81,6 \\
\hline 23. Alta-Médio-Médio & 3,70 & 1962 & 218 & 652827 & 528 & 7 & 110 & 83,5 \\
\hline 24. Alta-Médio-Alto & 3,70 & 1018 & 143 & 885816 & 625 & 522 & 8789 & 81,0 \\
\hline 25. Alta-Alto-Baixo & 3,70 & 1141 & 141 & 789059 & 597 & 0 & 0 & 81,7 \\
\hline 26. Alta-Alto-Médio & 3,70 & 810 & 121 & 844174 & 586 & 43 & 732 & 82,0 \\
\hline 27. Alta-Alto-Alto & 3,70 & 819 & 129 & 894661 & 620 & 604 & 10173 & 81,1 \\
\hline Média & - & 11531 & 1315 & 331960 & 252 & 199 & 0001 & 92,0 \\
\hline
\end{tabular}

${ }^{1}$ Custo: 521941; PC: 95913(2667); TC: 82338(6347); Z: 362; Tempo: 50,4 s.

Tabela 3.4: Resultados de um exemplar real do modelo estocástico $C L C 2 r$ na situação equiprovável, na qual as probabilidades das variáveis aleatórias nos cenários Baixo, Médio e Alto são $1 / 3,1 / 3$ e $1 / 3$, respectivamente. 


\begin{tabular}{|c|c|c|c|c|c|c|c|c|}
\hline Cenário & $\pi \%$ & $\mathrm{IC}$ & $I^{+}$ & $\mathrm{BC}$ & $I_{T}^{-}$ & $\mathrm{OC}$ & $O$ & $\mathcal{B} \%$ \\
\hline 1. Baixa-Baixo- & 15,0 & 26447 & 3007 & 0 & 0 & 0 & 0 & 0 \\
\hline 2. Baixa- & 0 & 0867 & 25 & 0 & 0 & 51 & 863 & 00 \\
\hline 3. Baixa-Baixo-Alto & 3,00 & 25905 & 2689 & 0 & 0 & 620 & 10437 & 100 \\
\hline 4. Baixa-Médio-Baixo & 12,0 & 25397 & 2801 & 0 & 0 & 0 & 0 & 100 \\
\hline 5. Baixa-Médio-Médio & 9,60 & 22903 & 2553 & 0 & 0 & 42 & 709 & 100 \\
\hline 6. Baixa- & & & & 0 & 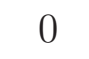 & 616 & 10364 & 100 \\
\hline 7. Baixa- & 3,00 & 30443 & 2750 & 0 & 0 & 0 & 0 & 100 \\
\hline 8. Baixa-Alto-Médio & 2,40 & 26441 & 2966 & 0 & 0 & - & 128 & 100 \\
\hline 9. Baixa- $A$ & 00 & 27190 & 2581 & 0 & 0 & 581 & 9786 & 100 \\
\hline 10. Média- & 50 & 5934 & & 64 & 168 & 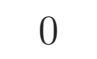 & 0 & 94.0 \\
\hline 11. Méc & & & & & & 51 & & 94,4 \\
\hline 12. Média-Baixo & 1,50 & 6219 & & 2 & 138 & 651 & 10966 & 95,0 \\
\hline 13. Média-Médio- & & & & & & 0 & 0 & 94,2 \\
\hline 14. Méc & 4 & 5995 & & 1 & 1 & 10 & 170 & 94,9 \\
\hline 15. Médi & 1,20 & 6361 & & 1608 & 150 & 648 & 10916 & 94,6 \\
\hline 16. Méd & 1,50 & 6701 & & 1 & 134 & 0 & 0 & 95,1 \\
\hline 17. Médi & 1 & 5 & & 6 & 16 & 26 & 431 & 94,1 \\
\hline 18. Méd & & & & & & 687 & & 94,8 \\
\hline 19. Alta-Baixo-Baixo & 2,50 & 923 & 126 & 909801 & 683 & 0 & 0 & 79,4 \\
\hline 20. Alta-Baixo-Médio & & 582 & & & & 30 & & 81,0 \\
\hline 21. Alta-Ba & 0,500 & 34 & 16 & 5 & 724 & 620 & 10445 & 78,4 \\
\hline 22. Alta-Médio-Baixo & & 343 & 35 & & 644 & 0 & 0 & 80,3 \\
\hline 23. Alta & 1 & 1428 & 135 & 6626 & & 19 & 319 & 82,2 \\
\hline 24. Alta-Méc & 0,400 & 602 & & 900767 & 667 & 562 & 9458 & 79,7 \\
\hline 25. Alta & & & & & 639 & 0 & 0 & 80,4 \\
\hline 26. Alta- & 0,400 & 410 & & 859538 & 628 & 61 & 1023 & 80,7 \\
\hline 27. Alta-Alto-Alto & 0,100 & 432 & 68 & 910292 & 662 & 642 & 10801 & 79,9 \\
\hline Média & & 10862 & 1210 & 337180 & 266 & 218 & 3695 & 91.6 \\
\hline
\end{tabular}

${ }^{1}$ Custo: 327891; PC: 95913(2667); TC: 81505(6283); Z: 365; Tempo: $51.3 \mathrm{s.}$

Tabela 3.5: Resultados de um exemplar real do modelo estocástico $C L C 2 r$ na situação otimista, na qual as probabilidades das demandas nos cenários Baixo, Médio e Alto são 60, 30 e 10\%, respectivamente, e as probabilidades dos tempos de preparação nos mesmos cenários são 50, 40 e 10\%. 


\begin{tabular}{lcccccccc}
\hline Cenário & $\pi \%$ & $\mathrm{IC}$ & $I^{+}$ & $\mathrm{BC}$ & $I_{T}^{-}$ & $\mathrm{OC}$ & $O$ & $\mathcal{B} \%$ \\
\hline 1. Baixa-Baixo-Baixo & 0,100 & 27238 & 3130 & 0 & 0 & 0 & 0 & 100 \\
2. Baixa-Baixo-Médio & 0,400 & 21658 & 2716 & 0 & 0 & 0 & 0 & 100 \\
3. Baixa-Baixo-Alto & 0,500 & 26696 & 2812 & 0 & 0 & 514 & 8649 & 100 \\
4. Baixa-Médio-Baixo & 0,400 & 26188 & 2924 & 0 & 0 & 0 & 0 & 100 \\
5. Baixa-Médio-Médio & 1,60 & 23694 & 2676 & 0 & 0 & 0 & 0 & 100 \\
6. Baixa-Médio-Alto & 2,00 & 26991 & 2917 & 0 & 0 & 499 & 8406 & 100 \\
7. Baixa-Alto-Baixo & 0,500 & 31234 & 2873 & 0 & 0 & 0 & 0 & 100 \\
8. Baixa-Alto-Médio & 2,00 & 27232 & 3089 & 0 & 0 & 0 & 0 & 100 \\
9. Baixa-Alto-Alto & 2,50 & 27981 & 2704 & 0 & 0 & 429 & 7221 & 100 \\
10. Média-Baixo-Baixo & 0,300 & 6692 & 833 & 165280 & 163 & 0 & 0 & 94,2 \\
11. Média-Baixo-Médio & 1,20 & 6967 & 984 & 233583 & 155 & 0 & 0 & 94,4 \\
12. Média-Baixo-Alto & 1,50 & 7010 & 974 & 159802 & 138 & 544 & 9152 & 95,0 \\
13. Média-Médio-Baixo & 1,20 & 7259 & 956 & 149932 & 160 & 0 & 0 & 94,2 \\
14. Média-Médio-Médio & 4,80 & 6786 & 953 & 169981 & 142 & 0 & 0 & 94,9 \\
15. Média-Médio-Alto & 6,00 & 7118 & 933 & 168725 & 145 & 497 & 8362 & 94,8 \\
16. Média-Alto-Baixo & 1,50 & 7492 & 967 & 115131 & 134 & 0 & 0 & 95,1 \\
17. Média-Alto-Médio & 6,00 & 6500 & 926 & 206286 & 165 & 0 & 0 & 94,1 \\
18. Média-Alto-Alto & 7,50 & 7000 & 895 & 114982 & 138 & 553 & 9314 & 95,0 \\
19. Alta-Baixo-Baixo & 0,600 & 1395 & 206 & 898720 & 641 & 0 & 0 & 80,6 \\
20. Alta-Baixo-Médio & 2,40 & 1069 & 164 & 757576 & 573 & 0 & 0 & 82,3 \\
21. Alta-Baixo-Alto & 3,00 & 393 & 21 & 961246 & 682 & 473 & 7962 & 79,6 \\
22. Alta-Médio-Baixo & 2,40 & 509 & 64 & 796300 & 602 & 0 & 0 & 81,6 \\
23. Alta-Médio-Médio & 9,60 & 1938 & 216 & 652827 & 528 & 0 & 0 & 83,5 \\
24. Alta-Médio-Alto & 12,0 & 985 & 138 & 885354 & 625 & 411 & 6919 & 81,0 \\
25. Alta-Alto-Baixo & 3,00 & 1118 & 139 & 789059 & 597 & 0 & 0 & 81,7 \\
26. Alta-Alto-Médio & 12,0 & 786 & 119 & 844174 & 586 & 0 & 0 & 82,0 \\
27. Alta-Alto-Alto & 15,0 & 795 & 127 & 894661 & 620 & 500 & 8416 & 81,1 \\
\hline \hline Média & - & 11508 & 1313 & 331986 & 252 & 164 & 2756 & 92,0 \\
\hline 1. Custo: 732024; PC: $95913(2667) ; \mathrm{TC}:$ & $82399(6350) ; Z: 362 ;$ & Tempo: & 48,0 & $\mathrm{~s}$.
\end{tabular}

Tabela 3.6: Resultados de um exemplar real do modelo estocástico $C L C 2 r$ na situação pessimista, na qual as probabilidades das demandas nos cenários Baixo, Médio e Alto são 10, 30 e 60\%, respectivamente, e as probabilidades dos tempos de preparação nos mesmos cenários são 10, 40 e 50\%. 


\begin{tabular}{lccccc}
\hline & & Moderado & Equiprovável & Otimista & Pessimista \\
\cline { 3 - 6 } Cenário $(s)$ & $W S_{s}^{\star}$ & $W S_{s}^{\star} \pi_{s}$ & $W S_{s}^{\star} \pi_{s}$ & $W S_{s}^{\star} \pi_{s}$ & $W S_{s}^{\star} \pi_{s}$ \\
\hline 1. Baixa-Baixo-Baixo & 154179 & 2409 & 5710 & 23127 & 154 \\
2. Baixa-Baixo-Médio & 160510 & 5016 & 5945 & 19261 & 642 \\
3. Baixa-Baixo-Alto & 157552 & 2462 & 5835 & 4727 & 788 \\
4. Baixa-Médio-Baixo & 156216 & 4882 & 5786 & 18746 & 625 \\
5. Baixa-Médio-Médio & 159450 & 9966 & 5906 & 15307 & 2551 \\
6. Baixa-Médio-Alto & 154596 & 4831 & 5726 & 3710 & 3092 \\
7. Baixa-Alto-Baixo & 149069 & 2329 & 5521 & 4472 & 745 \\
8. Baixa-Alto-Médio & 156533 & 4892 & 5798 & 3757 & 3131 \\
9. Baixa-Alto-Alto & 153206 & 2394 & 5674 & 919 & 3830 \\
10. Média-Baixo-Baixo & 188911 & 5903 & 6997 & 14168 & 567 \\
11. Média-Baixo-Médio & 191505 & 11969 & 7093 & 11490 & 2298 \\
12. Média-Baixo-Alto & 188224 & 5882 & 6971 & 2823 & 2823 \\
13. Média-Médio-Baixo & 188726 & 11795 & 6990 & 11324 & 2265 \\
14. Média-Médio-Médio & 189572 & 23696 & 7021 & 9099 & 9099 \\
15. Média-Médio-Alto & 188970 & 11811 & 6999 & 2268 & 11338 \\
16. Média-Alto-Baixo & 186005 & 5813 & 6889 & 2790 & 2790 \\
17. Média-Alto-Médio & 190531 & 11908 & 7057 & 2286 & 11432 \\
18. Média-Alto-Alto & 186796 & 5837 & 6918 & 560 & 14010 \\
19. Alta-Baixo-Baixo & 225875 & 3529 & 8366 & 5647 & 1355 \\
20. Alta-Baixo-Médio & 219851 & 6870 & 8143 & 4397 & 5276 \\
21. Alta-Baixo-Alto & 228454 & 3570 & 8461 & 1142 & 6854 \\
22. Alta-Médio-Baixo & 221722 & 6929 & 8212 & 4434 & 5321 \\
23. Alta-Médio-Médio & 215990 & 13499 & 8000 & 3456 & 20735 \\
24. Alta-Médio-Alto & 223717 & 6991 & 8286 & 895 & 26846 \\
25. Alta-Alto-Baixo & 222927 & 3483 & 8257 & 1115 & 6688 \\
26. Alta-Alto-Médio & 220944 & 6904 & 8183 & 884 & 26513 \\
27. Alta-Alto-Alto & 223622 & 3494 & 8282 & 224 & 33543 \\
\hline \hline WS & - & 189066 & 189024 & 173029 & 205312 \\
RP & - & 473384 & 521941 & 327891 & 732024 \\
EVPI & 284318 & 332917 & 154862 & 526712 \\
EVPI(\%) & 60,1 & 63,8 & 47,2 & 72,0 \\
\hline
\end{tabular}

Tabela 3.7: Resultados dos problemas wait-and-see e valor esperado de informação perfeita $(E V P I)$ de um exemplar real do modelo $C L C 2 r$. 


\begin{tabular}{lcccc}
\hline & Moderado & Equiprovável & Otimista & Pessimista \\
\hline 1. Baixa-Baixo-Baixo & $39^{1}$ & 43 & 0 & 535 \\
2. Baixa-Baixo-Médio & 50 & 57 & 0 & 431 \\
3. Baixa-Baixo-Alto & 62 & 66 & 0 & 546 \\
4. Baixa-Médio-Baixo & 107 & 17 & 0 & 629 \\
5. Baixa-Médio-Médio & 54 & 62 & 0 & 494 \\
6. Baixa-Médio-Alto & 160 & 174 & 0 & 695 \\
7. Baixa-Alto-Baixo & 199 & 195 & 2 & 614 \\
8. Baixa-Alto-Médio & 87 & 98 & 0 & 643 \\
9. Baixa-Alto-Alto & 108 & 106 & 0 & 485 \\
\hline \hline Média & 96 & 91 & 0,219 & 563 \\
Infactibilidade\% & 2,31 & 2,18 & 0,005 & 13,5 \\
$E V$ & 188987 & 188917 & 172996 & 205305 \\
EEV & 642423 & 837029 & 431820 & 1050946 \\
$R P$ & 473384 & 521941 & 327891 & 732024 \\
$V S S$ & 169039 & 315088 & 103929 & 318922 \\
$V S S \%$ & 35,7 & 60,4 & 31,7 & 43,6 \\
\hline 1 Esses valores representam os níveis acumulados das variáveis de erro $\tilde{I}_{i t}^{+}$ \\
$\quad$ nos cenários 1 - 9.
\end{tabular}

Tabela 3.8: Valores acumulados das variáveis de erro $\tilde{I}_{i t s}$, resultados obtidos pelos problemas $E V, E E V$, e valor da solução estocástica ( $V S S$ ). 


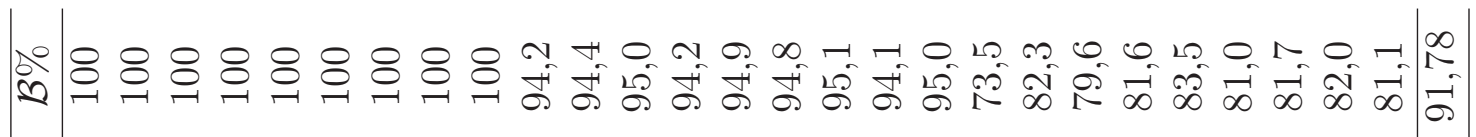

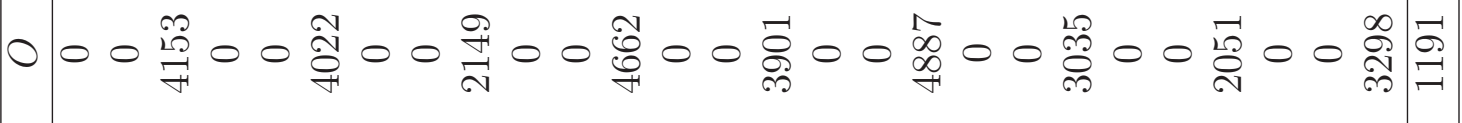

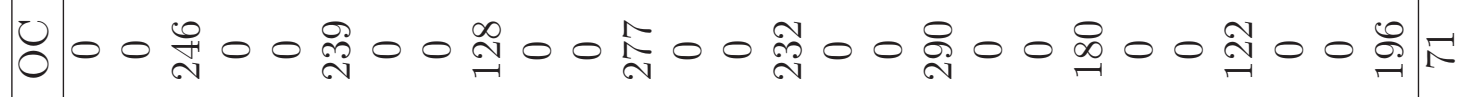

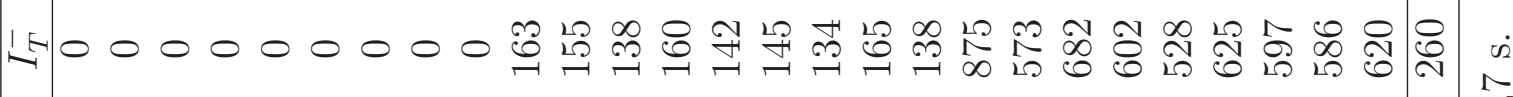

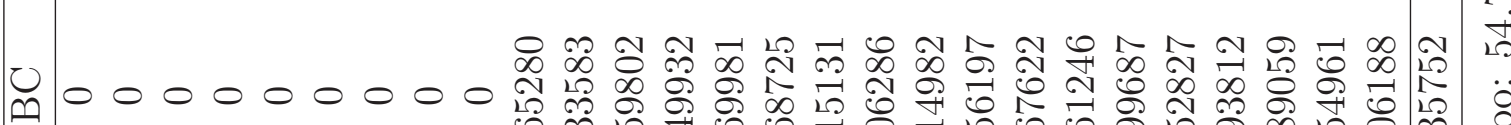

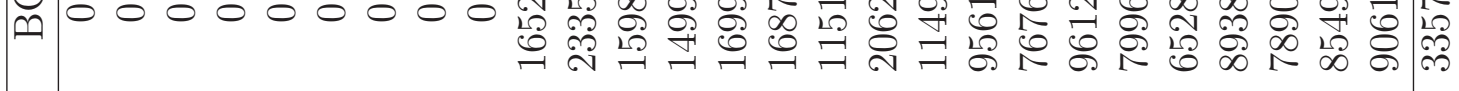

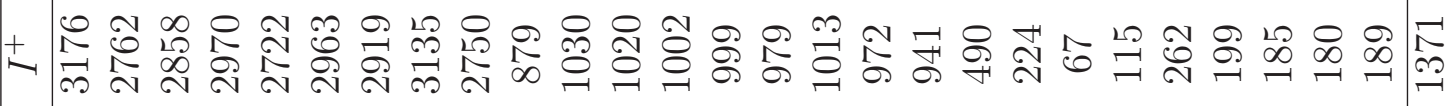

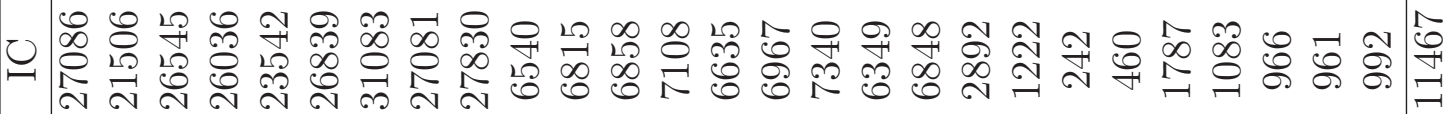

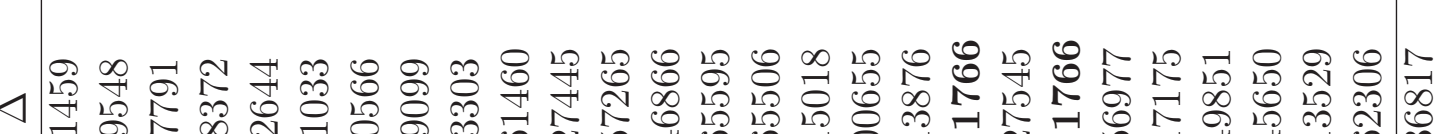

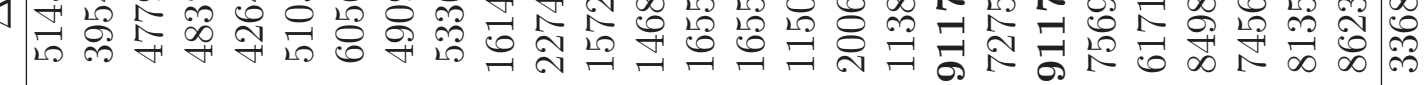

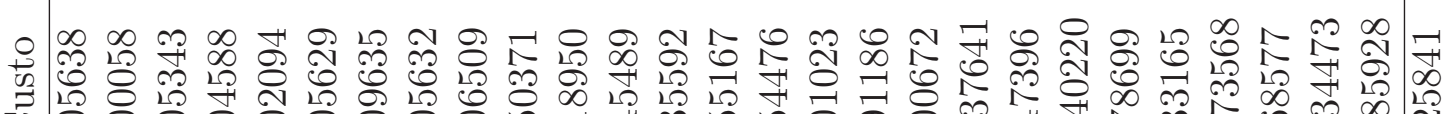

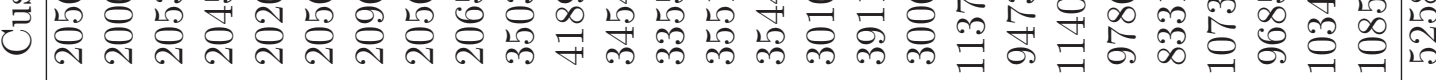

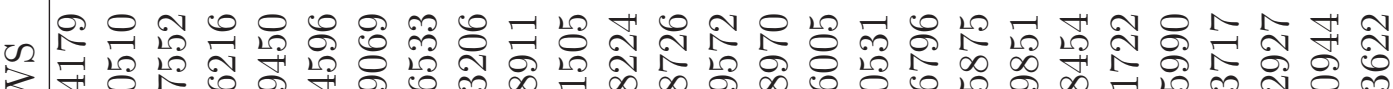

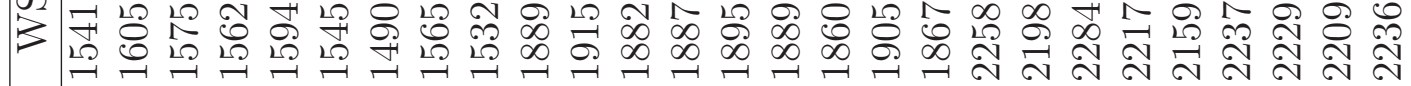

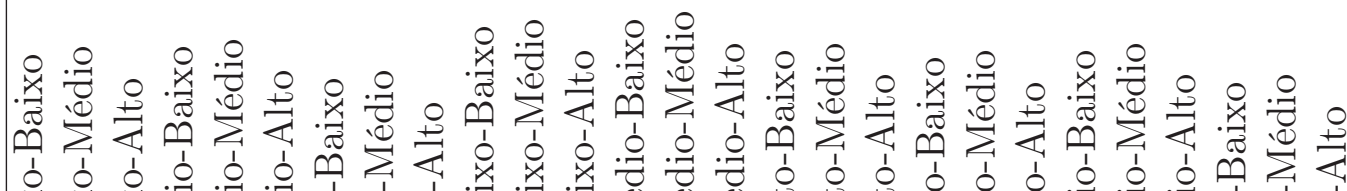

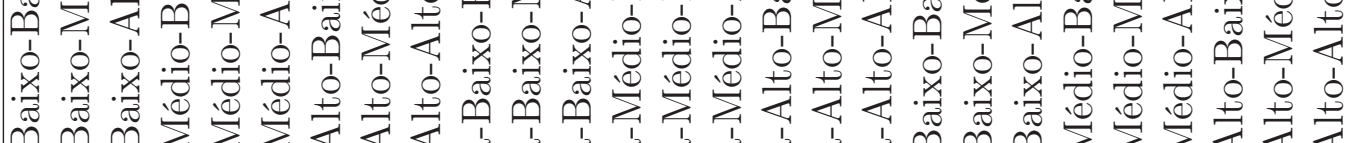

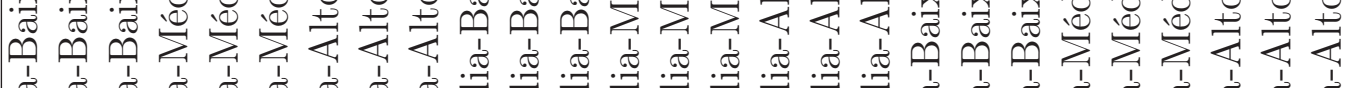

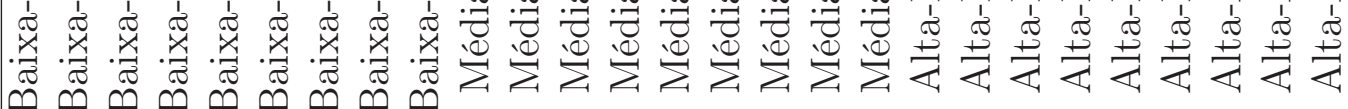

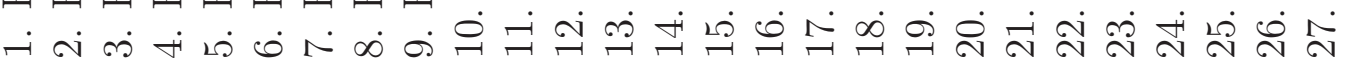




\begin{tabular}{cccccccccc}
\hline$S$ & Custo & $X$ & $I^{+}$ & $I^{-}$ & $Y$ & $Z$ & $O$ & $\Delta$ & $\mathcal{B} \%$ \\
\hline 20 & 174595 & 2182 & 1332 & 24 & 5249 & 366 & 0,000 & 8287 & 99,4 \\
40 & 167888 & 2185 & 1159 & 21 & 5229 & 365 & 0,000 & 5243 & 99,3 \\
60 & 169989 & 2186 & 1162 & 24 & 5198 & 362 & 0,000 & 6974 & 99,3 \\
80 & 173224 & 2175 & 1101 & 34 & 5121 & 361 & 0,000 & 11450 & 99,2 \\
100 & 173410 & 2147 & 1100 & 33 & 5126 & 364 & 0,000 & 12309 & 99,3 \\
120 & 171126 & 2174 & 1194 & 29 & 5130 & 365 & 0,000 & 8187 & 99,2 \\
140 & 177857 & 2170 & 1145 & 41 & 5077 & 366 & 0,000 & 14977 & 99,1 \\
160 & 170237 & 2162 & 1162 & 28 & 5126 & 366 & 1,02 & 8687 & 99,2 \\
180 & 168802 & 2123 & 1098 & 36 & 5045 & 365 & 0,000 & 9074 & 98,9 \\
200 & 172074 & 2171 & 1236 & 30 & 5161 & 365 & 0,000 & 9648 & 99,2 \\
220 & 175866 & 2133 & 1086 & 50 & 5092 & 364 & 0,000 & 12719 & 97,6 \\
240 & 175554 & 2162 & 1141 & 38 & 5107 & 366 & 0,000 & 13053 & 99,2 \\
260 & 172515 & 2162 & 1109 & 34 & 5152 & 365 & 0,000 & 9873 & 99,2 \\
280 & 183820 & 2132 & 1088 & 56 & 4970 & 365 & 0,000 & 18542 & 98,6 \\
300 & 173551 & 2154 & 1108 & 36 & 5126 & 363 & 0,000 & 11262 & 99,1 \\
\hline Média & 173367 & 2161 & 1148 & 34,3 & 5127 & 365 & 0,068 & 10686 & 99,1 \\
DP ${ }^{1}$ & 3978 & 19,8 & 66,5 & 9,43 & 69,5 & 1,51 & 0,263 & 3350 & 0,454 \\
$(\%)^{2}$ & 2,29 & 0,917 & 5,80 & 27,5 & 1,36 & 0,413 & 387 & 31,4 & 0,458 \\
\hline
\end{tabular}

${ }^{1}$ Desvio-padrão;

${ }^{2}$ Desvio-padrão relativo ao valor médio (em \%).

Tabela 3.10: Efeito do número de cenários na solução ótima do problema estocástico (redução zero). 


\begin{tabular}{cccccccccc}
\hline$S$ & Custo & $X$ & $I^{+}$ & $I^{-}$ & $Y$ & $Z$ & $O$ & $\Delta$ & $\mathcal{B} \%$ \\
\hline 20 & 190229 & 2178 & 1235 & 94 & 5232 & 366 & 0,000 & 4143 & 98,7 \\
40 & 170136 & 2246 & 1204 & 13 & 5413 & 366 & 0,000 & 2622 & 99,8 \\
60 & 183550 & 2213 & 1260 & 49 & 5328 & 362 & 0,000 & 3487 & 98,6 \\
80 & 201021 & 2164 & 1081 & 92 & 5098 & 364 & 0,000 & 5725 & 97,3 \\
100 & 206639 & 2210 & 1244 & 77 & 5247 & 365 & 0,000 & 6154 & 97,8 \\
120 & 191754 & 2183 & 1275 & 62 & 5139 & 365 & 0,000 & 4093 & 98,1 \\
140 & 212885 & 2174 & 1204 & 106 & 5083 & 366 & 0,000 & 7488 & 96,6 \\
160 & 195111 & 2166 & 1195 & 126 & 5129 & 364 & 0,000 & 4343 & 99,0 \\
180 & 198147 & 2109 & 1243 & 173 & 5070 & 363 & 1320 & 4537 & 96,4 \\
200 & 209676 & 2210 & 1430 & 140 & 5197 & 368 & 22572 & 4824 & 98,5 \\
220 & 216668 & 2133 & 1239 & 202 & 5092 & 377 & 0,000 & 6359 & 90,1 \\
240 & 220593 & 2155 & 1233 & 121 & 5104 & 366 & 350571 & 6527 & 99,0 \\
260 & 202575 & 2157 & 1244 & 153 & 5150 & 365 & 0,000 & 4937 & 98,9 \\
280 & 228095 & 2141 & 1220 & 213 & 4975 & 380 & 289 & 9271 & 96,4 \\
300 & 208090 & 2156 & 1253 & 173 & 5127 & 363 & 1056 & 5631 & 98,8 \\
\hline Média & 202345 & 2173 & 1237 & 120 & 5159 & 367 & 25054 & 5343 & 97,6 \\
Desvio-padrão & 14973 & 35,4 & 69,8 & 57,2 & 110 & 5,07 & 90237 & 1675 & 2,33 \\
(\%) & 7,40 & 1,63 & 5,64 & 47,9 & 2,13 & 1,38 & 360 & 31,4 & 2,38 \\
\hline
\end{tabular}

Tabela 3.11: Efeito do número de cenários na solução ótima do problema robusto (redução $50 \%)$.

\begin{tabular}{cccccccccc}
\hline$S$ & Custo & $X$ & $I^{+}$ & $I^{-}$ & $Y$ & $Z$ & $O$ & $\Delta$ & $\mathcal{B} \%$ \\
\hline 20 & 224971 & 2145 & 1126 & 136 & 5216 & 367 & 0,000 & 0 & 97,1 \\
40 & 220288 & 2182 & 986 & 173 & 5393 & 363 & 0,000 & 0 & 95,1 \\
60 & 306397 & 2047 & 756 & 396 & 5152 & 361 & 1320 & 0 & 93,8 \\
80 & 313665 & 1949 & 791 & 532 & 4876 & 361 & 117810 & 0 & 90,2 \\
100 & 316446 & 2107 & 1206 & 289 & 5149 & 365 & 0,000 & 0 & 96,9 \\
120 & 324906 & 2111 & 935 & 538 & 5052 & 365 & 18480 & 0 & 96,4 \\
140 & 373497 & 2115 & 1183 & 434 & 5000 & 365 & 29417 & 0 & 93,9 \\
160 & 306692 & 2092 & 1153 & 452 & 5092 & 365 & 1980 & 0 & 96,4 \\
180 & 417945 & 2040 & 1121 & 853 & 4980 & 363 & 3520 & 0 & 93,8 \\
200 & 344874 & 1971 & 1094 & 609 & 4929 & 394 & 76869 & 0 & 92,0 \\
220 & 392916 & 2054 & 973 & 693 & 5039 & 363 & 3100 & 0 & 66,0 \\
240 & 398801 & 2053 & 1091 & 770 & 4993 & 367 & 5940 & 0 & 94,7 \\
260 & 357361 & 2000 & 1411 & 706 & 5016 & 346 & 2742 & 0 & 87,6 \\
280 & 413469 & 1970 & 1119 & 617 & 4799 & 365 & 459643 & 0 & 87,8 \\
300 & 366070 & 2030 & 1260 & 574 & 4988 & 366 & 78144 & 0 & 94,0 \\
\hline Média & 338553 & 2058 & 1080 & 518 & 5045 & 365 & 53264 & 0 & 91,7 \\
Desvio-padrão & 60417 & 67,8 & 171 & 208 & 144 & 9,47 & 118288 & 0 & 7,73 \\
(\%) & 17,8 & 3,30 & 15,8 & 40,2 & 2,85 & 2,59 & 222 & 0 & 8,42 \\
\hline
\end{tabular}

Tabela 3.12: Efeito do número de cenários na solução ótima do problema totalmente robusto (redução 100\%). 


\section{Capítulo 4}

\section{Modelos de Otimização Robusta para o Problema Combinado}

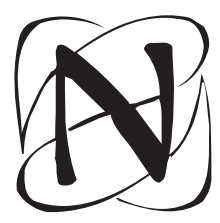

esse capítulo, são desenvolvidas formulações matemáticas baseadas em otimização robusta (Ben-Tal e Nemirovski, 2000) para o modelo geral de dimensionamento de lotes e corte de estoque $C L C 1$. A motivação em aplicar tal técnica no modelo $C L C 1$ é a sua facilidade de resolução em comparação ao modelo $C L C 2$ (veja mais comentários na Seção 2.3 do Capítulo 2), especialmente porque algumas análises próprias da otimização robusta são comprometidas quando não são conferidas às soluções o certificado de otimalidade, o que acontece em alguns exemplares testados do modelo $C L C 2$. Diferentemente do modelo $C L C 2$ analisado no Capítulo 3, que pode possuir quatro fontes de incertezas (custos, tempos de preparação, tempos de produção e demandas), o modelo $C L C 1$ analisado neste capítulo apresenta apenas três delas, pois o tempo de preparação não é contabilizado explicitamente no modelo $C L C 1$, conforme mostrado no Capítulo 2. Supondo-se ainda que o tempo de produção dos produtos é fixo (analogamente à Seção 3.2 do Capítulo 3), restam duas fontes de incerteza - custos e demandas - os quais são considerados variáveis aleatórias independentes e limitadas nas formulações robustas propostas. Assim, são desenvolvidos três modelos de otimização robusta: o primeiro modelo é focado apenas nos custos incertos; o segundo, apenas nas demandas incertas e, finalmente, o terceiro combina custos e demandas. Para testar os modelos, são executados experimentos computacionais cujos dados de entrada são baseados na Fábrica X. A análise dos resultados baseia-se no valor ótimo da função objetivo e no nível de serviço tipo II (taxa de atendimento da demanda). O capítulo está organizado da seguinte maneira. Na Seção 4.1, são apresentadas algumas preliminares em otimização robusta e uma breve revisão da literatura sobre o tema. Na Seção 4.2 são desenvolvidos os três modelos robustos para o 
CLC1. Na Seção 4.3, são explorados os experimentos computacionais e o desempenho dos modelos robustos é analisado sob diversos aspectos. Finalmente, as considerações finais são discutidas na Seção 4.5 e algumas perspectivas de extensões futuras são apresentadas na Seção 4.6.

\subsection{Preliminares em Otimização Robusta}

Nesse capítulo, adotou-se a metodologia de otimização robusta sob o enfoque do Modelo de Dados Incertos U (Ben-Tal e Nemirovski (2000)), descrito da seguinte forma. Dado o problema de otimização $\min _{x \geq 0}\left\{c^{T} x \mid A x \leq b\right\}$, define-se $J_{i}$ como o conjunto de coeficientes da linha $i$ da matriz tecnológica $A$ sujeito à incerteza. Cada elemento de $A$, a saber, $a_{i j}, j \in J_{i}$, é modelado como uma variável aleatória simétrica, independente e limitada, $\tilde{a}_{i j}$, que pertence ao intervalo $\left[a_{i j}-\hat{a}_{i j}, a_{i j}+\hat{a}_{i j}\right]$ centrado no ponto $a_{i j}$. Associado ao dado incerto $\tilde{a}_{i j}$, define-se o seu desvio em relação ao valor nominal como $z_{i j}=\left(\tilde{a}_{i j}-a_{i j}\right) / \hat{a}_{i j}$ que pertence ao intervalo $[-1,1]$.

Embora os primeiros passos em otimização robusta linear tenham sido dados no trabalho pioneiro de Soyster (1973), a expressão otimização robusta foi usada pela primeira vez, aparentemente, no trabalho de Mulvey et al. (1995), para denominar uma nova metodologia de programação estocástica composta da abordagem por cenários e da programação por metas. Na presente tese, como já mencionado, a metodologia de Mulvey e outros é referida por programação estocástica robusta. A formulação robusta de Soyster é expressa da seguinte maneira:

$$
\begin{array}{ll}
\text { Minimizar } & \sum_{j} c_{j} x_{j} \\
\text { Sujeito a: } & \sum_{j} a_{i j} x_{j}+\sum_{j \in J_{i}} \hat{a}_{i j} x_{j} \leq b_{i}, \forall i \\
& x_{j} \geq 0, \forall j .
\end{array}
$$

Como a metodologia de Soyster é equivalente ao problema de otimização no qual todos os parâmetros incertos são fixados nos respectivos valores de pior caso, então os valores ótimos robustos são, em geral, muito piores do que os valores ótimos do problema de otimização original. Para superar o problema do conservadorismo das soluções de Soyster, muitos trabalhos enfocaram formulações robustas alternativas menos conservadoras, como Ben-Tal e Nemirovski (1998, 1999), El-Ghaoui e Lebret (1997) e El-Ghaoui et al. (1998). Particularmente, Ben-Tal e Nemirovski (2000) desenvolveram uma formulação robusta para permitir o tradeoff entre a robustez e o desempenho: 


$$
\begin{array}{ll}
\text { Minimizar } & \sum_{j} c_{j} x_{j} \\
\text { Sujeito a: } & \sum_{j} a_{i j} x_{j}+\gamma\left(\sum_{j \in J_{i}} \hat{a}_{i j} x_{j}+\epsilon_{i} \sqrt{\sum_{j \in J_{i}} \hat{a}_{i j} x_{j}^{2}}\right) \leq b_{i}, \forall i \\
& x_{j} \geq 0, \forall j .
\end{array}
$$

em que $\gamma>0$ é um nível de variabilidade dado ( $\gamma=10 \%$, por exemplo) e $\epsilon_{i}$ é um parâmetro positivo definido pelo decisor, cuja função é controlar o nível de confiabilidade, i.e., a probabilidade máxima de violação da restrição $i$, dada pela expressão $k=\exp \left(-\epsilon_{i}^{2}\right) / 2$ (por exemplo, $k=10^{-6}$ ).

A desvantagem da formulação (4.2) é a sua intratabilidade computacional, especialmente em se tratando de problemas com variáveis discretas. Observando que a formulação (4.1) é muito conservadora e que a formulação (4.2) é não-linear, Bertsimas e Sim (2003, 2004) propuseram uma metodologia de otimização robusta linear baseada em conjuntos de incertezas poliédricos, de forma a evitar ambos os problemas de conservadorismo da solução e da possível intratabilidade da formulação não-linear. Os autores argumentam que é improvável a realização de todas as variáveis aleatórias $\tilde{a}_{i j}$ coincidirem com os respectivos valores de pior caso, como proposto por Soyster (1973). Então, os autores propõem um número máximo de variáveis aleatórias que pode assumir o respectivo valor de pior caso, que é denominado de budget de incerteza e representado pelo parâmetro $\Gamma_{i}$. Impondo-se tal budget, o desvio total das variáveis aleatórias é assim limitado: $\sum_{j \in J_{i}}\left|z_{i j}\right| \leq \Gamma_{i}, \forall i$.

O parâmetro $\Gamma_{i}$ pertence ao intervalo $\left[0,\left|J_{i}\right|\right]$ e é usado para controlar o grau de conservadorismo ou o nível de proteção da solução e ajustar a atitude do decisor em relação ao risco. Por exemplo, $\Gamma_{i}=0$ representa o caso nominal, em que a solução não é nada conservadora e está desprotegida das incertezas que afetam o problema. Nesse caso, diz-se que o decisor é neutro em relação ao risco. Por outro lado, $\Gamma_{i}=\left|J_{i}\right|$ representa o pior caso ou método de Soyster, que fornece proteção máxima à solução, mas é muito conservadora e reflete a atitude de um decisor averso ao risco. Entre esses extremos, o decisor pode escolher o valor do budget de incerteza mais de adequado às suas preferências. Sendo assim, o modelo de otimização robusta pode ser escrito da seguinte maneira (Bertsimas e Sim, 2003): 


$$
\begin{aligned}
\text { Minimizar } & \sum_{j} c_{j} x_{j} \\
\text { Sujeito a: } & \sum_{j} a_{i j} x_{j}+\lambda_{i} \Gamma_{i}+\sum_{j \in J_{i}} \mu_{i j} \leq b_{i}, \forall i \\
& \lambda_{i}+\mu_{i j} \geq \hat{a}_{i j} x_{j}, \forall i, j \in J_{i} \\
& \mu_{i j} \geq 0, \forall i, j \in J_{i} \\
& x_{j} \geq 0, \forall j \\
& \lambda_{i} \geq 0, \forall i,
\end{aligned}
$$

em que $\lambda_{i}$ e $\mu_{i j}$ são as variáveis duais usadas para evitar formulações não-lineares. Se, no máximo, $\left\lfloor\Gamma_{i}\right\rfloor$ coeficientes $\tilde{a}_{i j}$ variarem, então a factibilidade do modelo (4.3) está garantida. Porém, se mais coeficientes variarem, então não há mais garantia de factibilidade do modelo (4.3). Nesse caso, a metodologia de otimização robusta fornece alguns limitantes para determinar a probabilidade de violação do primeiro conjunto de restrição em (4.3). Seja $x_{j}^{\star}$ a solução do modelo de otimização robusta. Então, a probabilidade de violação da $i$-ésima restrição pode ser aproximada por:

$$
\operatorname{Pr}\left(\sum_{j} \tilde{a}_{i j} x_{j}^{\star}>b_{i}\right) \leq 1-\Phi\left(\frac{\Gamma_{i}-1}{\sqrt{\left|J_{i}\right|}}\right)
$$

em que

$$
\Phi(\theta)=\frac{1}{\sqrt{2 \pi}} \int_{-\infty}^{\theta} \exp \left(-\frac{y^{2}}{2}\right) d y
$$

é a função de distribuição acumulada de uma normal padrão.

A partir da expressão (4.4) é possível determinar valores para os budgets de incerteza. Note que se $\operatorname{Pr}\left(\sum_{j} \tilde{a}_{i j} x_{j}^{\star}>b_{i}\right)=\epsilon_{i}$, então a inequação (4.4) pode ser escrita da seguinte forma:

$$
\epsilon_{i}=1-\Phi\left(\frac{\Gamma_{i}-1}{\sqrt{\left|J_{i}\right|}}\right) \Rightarrow \frac{\Gamma_{i}-1}{\sqrt{\left|J_{i}\right|}}=\Phi^{-1}\left(1-\epsilon_{i}\right) \Rightarrow \Gamma_{i}=1+\Phi^{-1}\left(1-\epsilon_{i}\right) \sqrt{\left|J_{i}\right|} .
$$

A extensão da presente abordagem robusta para considerar a incerteza nos coeficientes da função objetivo ou no vetor independente $b_{i}$ é direta. No primeiro caso, o Modelo de Dados Incertos $U$ é um pouco diferente, uma vez que apenas os desvios positivos (mais desfavoráveis) são considerados, i.e., $\tilde{c}_{j} \in\left[c_{j}, c_{j}+\hat{c}_{j}\right]$ para todo $j \in J_{i}$. Na Seção 4.2.1, é detalhada a obtenção da formulação robusta equivalente para o modelo combinado $C L C 1$ 
com custos incertos. No segundo caso, introduz-se uma nova variável $x_{n+1}$ ao modelo, de forma a reescrevê-lo como $A x-b x_{n+1} \geq 0 \operatorname{com} x_{n+1}=1$ para incluir $b$ na matriz A. Nesse caso, entretanto, a metodologia apresentada em Bertsimas e Sim (2003) não é interessante, uma vez que se tem apenas um coeficiente incerto na linha $i$ da matriz $A$. Como consequência, o budget de incerteza varia de 0 (caso nominal) até 1 (pior caso), e a formulação BS perde a sua característica principal de controlar o grau de conservadorismo da solução. Uma maneira de superar essa questão é utilizar desvios acumulados da variável aleatória, como proposto no trabalho de Bertsimas e Thiele (2006), cuja metodologia é mais detalhada na Seção 4.2.2.

O campo de estudo da otimização robusta contém uma vasta coleção de trabalhos teóricos, como, por exemplo: construção dos conjuntos de incerteza (Bertsimas et al., 2004), propriedades das soluções e a tratabilidade computacional de formulações robustas (Bertsimas e Sim, 2006), a conexão entre medidas de risco e conjuntos de incerteza (Chen et al., 2010), restrições de chance robustas (Erdogan e Iyengar, 2006), otimização robusta em problemas de programação estocástica (Chen et al., 2007) e formulações fortes para problemas de otimização robusta discretos (Atamtürk, 2006). Além disso, a metodologia tem sido aplicada com sucesso em diversos contextos, dentre os quais, destacam-se: $(i)$ gestão da cadeia de suprimento (Ben-Tal et al., 2005; Bertsimas e Thiele, 2006) e controle de estoque (Bienstock e Ozbay, 2008); (ii) planejamento agregado de produção em usinas de açúcar e álcool (Paiva, 2009), indústrias de processamento de laranja (Munhoz, 2009; Munhoz e Morabito, 2011) e colheita da uva (Bohle et al., 2009); (iii) planejamento e programação da produção na gestão florestal (Maturana et al., 2007; Palma e Nelson, 2009); (iv) e programação da produção na indústria química (Li e Ierapetritou, 2008); $(v)$ roteamento de veículos (Sungur et al., 2008) e roteamento de aeronaves (Marla e Barnhart, 2009); (vi) fluxo em redes (Ordóñez e Zhao, 2007), redes de sensores (Ye et al., 2008) e gerenciamento de projeto (Adida e Joshi, 2009); (vii) gestão de portfólios e otimização financeira (Bertsimas e Pachamanova, 2008; Chen et al., 2011); (viii) sistemas de abastecimento de água (Chung et al., 2008); ( $i x$ ) análise de envoltória de dados (DEA) (Sadjadi e Omrani, 2008), (x) teoria dos jogos (Aghassi e Bertsimas, 2006), entre outras aplicações. O leitor pode consultar o trabalho de Beyer e Sendhoff (2007) e Bertsimas et al. (2010) para um survey em otimização robusta. 


\subsection{Modelos de Otimização Robusta}

\subsubsection{Incerteza nos Custos}

Considere que os coeficientes da função objetivo (2.1) do modelo CLC1 sejam variáveis aleatórias limitadas com valores nominais $c_{i t}, h_{i t}^{+}, h_{i t}^{-}, s_{i t}, w_{j t}$ e $o_{t}$, e com uma variação máxima expressa com o símbolo chapéu sobre cada valor nominal (i.e., $\hat{c}_{i t}, \hat{h}_{i t}^{+}$, e assim por diante). Os budgets de incerteza são dados por $\Gamma^{c}, \Gamma^{h^{+}}, \Gamma^{h^{-}}, \Gamma^{s}, \Gamma^{w}$ e $\Gamma^{o}$, respectivamente. Nesse trabalho, os budgets foram admitidos valores inteiros, mas o caso que considera valores não-inteiros é direto (Bertsimas e Sim, 2004). O equivalente robusto não-linear da função objetivo com custos incertos pode ser escrito da seguinte maneira:

$$
\begin{aligned}
& \text { Minimizar } \psi+\max _{\Omega^{c}, \Omega^{h+}, \Omega^{h-}, \Omega^{s}, \Omega^{w}, \Omega^{o}}\left\{\sum_{(i, t) \in S^{c}} \hat{c}_{i t} X_{i t}+\sum_{(i, t) \in S^{h+}} \hat{h}_{i t}^{+} I_{i t}^{+}+\sum_{(i, t) \in S^{h-}} \hat{h}_{i t}^{-} I_{i t}^{-}+\right. \\
& \left.\sum_{(i, t) \in S^{s}} \hat{s}_{i t} Z_{i t}+\sum_{(j, t) \in S^{w}} \hat{w}_{j t} Y_{j t}+\sum_{t \in S^{o}} \hat{o}_{t} O_{t}\right\}
\end{aligned}
$$

Sujeito a: restrições $(2.2)-(2.11)$,

em que

- $\Omega^{c}=\left\{S^{c}\left|S^{c} \subseteq J^{c},\right| S^{c} \mid \leq \Gamma^{c}\right\}, \operatorname{com} J^{c}=\left\{(i, t) \mid \hat{c}_{i t}>0\right\}$ e $\Gamma^{c} \in\left[0,\left|J^{c}\right|\right]$;

- $\Omega^{h^{+}}=\left\{S^{h^{+}}\left|S^{h^{+}} \subseteq J^{h^{+}},\right| S^{h^{+}} \mid \leq \Gamma^{h^{+}}\right\}, \operatorname{com} J^{h^{+}}=\left\{(i, t) \mid \hat{h}_{i t}^{+}>0\right\}$ e $\Gamma^{h^{+}} \in\left[0,\left|J^{h^{+}}\right|\right]$;

- $\Omega^{h^{-}}=\left\{S^{h^{-}}\left|S^{h^{-}} \subseteq J^{h^{-}},\right| S^{h^{-}} \mid \leq \Gamma^{h^{-}}\right\}, \operatorname{com} J^{h^{-}}=\left\{(i, t) \mid \hat{h}_{i t}^{-}>0\right\}$ e $\Gamma^{h^{-}} \in\left[0,\left|J^{h^{-}}\right|\right]$;

- $\Omega^{s}=\left\{S^{s}\left|S^{s} \subseteq J^{s},\right| S^{s} \mid \leq \Gamma^{s}\right\}, \operatorname{com} J^{s}=\left\{(i, t) \mid \hat{s}_{i t}>0\right\}$ e $\Gamma^{s} \in\left[0,\left|J^{s}\right|\right]$;

- $\Omega^{w}=\left\{S^{w}\left|S^{w} \subseteq J^{w},\right| S^{w} \mid \leq \Gamma^{w}\right\}, \operatorname{com} J^{w}=\left\{(j, t) \mid \hat{w}_{j t}>0\right\}$ e $\Gamma^{w} \in\left[0,\left|J^{w}\right|\right]$;

- $\Omega^{o}=\left\{S^{o}\left|S^{o} \subseteq J^{o},\right| S^{o} \mid \leq \Gamma^{o}\right\}, \operatorname{com} J^{o}=\left\{t \mid \hat{o}_{t}>0\right\}$ e $\Gamma^{o} \in\left[0,\left|J^{o}\right|\right]$.

Para reescrever (4.6) como uma função linear, considere apenas o custo de produção incerto por simplicidade. Primeiramente, dada a solução do problema de otimização robusta $X_{i t}^{\star}$, define-se a função de proteção do custo de produção como

$$
\beta^{c}\left(X_{i t}^{\star}, \Gamma^{c}\right)=\max _{\left\{S^{c}\left|S^{c} \subseteq J^{c},\right| S^{c} \mid \leq \Gamma^{c}\right\}} \sum_{(i, t) \in S^{c}} \hat{c}_{i t} X_{i t}^{\star}
$$


Agora, a função de proteção $\beta^{c}\left(X_{i t}^{\star}, \Gamma^{c}\right)$ pode ser reescrita como o seguinte problema de otimização:

$$
\begin{array}{ll}
\max & \sum_{(i, t) \in J^{c}} \hat{c}_{i t} X_{i t}^{\star} z_{i t}^{c} \\
\text { s.t: } & \sum_{(i, t) \in J^{c}} z_{i t}^{c} \leq \Gamma^{c} \\
& 0 \leq z_{i t}^{c} \leq 1, \forall(i, t) \in J^{c} .
\end{array}
$$

Note que a solução ótima de (4.8) consiste de $\Gamma_{c}$ variáveis $z_{i t}^{c}$ fixadas em 1 , o que é equivalente a selecionar o subconjunto $\left\{S^{c}\left|S^{c} \subseteq J^{c},\right| S^{c} \mid \leq \Gamma^{c}\right\}$ com o correspondente valor de função objetivo $\sum_{(i, t) \in S^{c}} \hat{c}_{i t} X_{i t}^{\star}$ (Bertsimas e Sim, 2003).

Como a função de proteção (4.7) é equivalente ao problema (4.8), esse último pode ser incorporado à expressão (4.6) a fim de obter uma função linear para $X_{i t}^{\star}$ dado. Entretanto, quando $X_{i t}$ é uma variável de decisão, é necessário obter o dual do problema (4.8) e então adicioná-lo à expressão (4.6), para finalmente obter uma função linear para todo $X_{i t}$. Considere o dual do problema (4.8) como se segue:

$$
\begin{array}{ll}
\min & \sum_{(i, t) \in J^{c}} \mu_{i t}^{c}+\lambda^{c} \Gamma^{c} \\
\text { s.a: } & \mu_{i t}^{c}+\lambda^{c} \geq \hat{c}_{i t} X_{i t}, \forall(i, t) \in J^{c} \\
& \mu_{i t}^{c} \geq 0, \forall(i, t) \in J^{c} \\
& \lambda^{c} \geq 0 .
\end{array}
$$

em que $\lambda^{c}$ e $\mu_{i t}^{c}$ são as variáveis duais associadas à restrições em (4.8). Uma vez que o problema (4.8) é factível e limitado para todo $\Gamma^{c} \in\left[0,\left|J^{c}\right|\right]$, de acordo com a dualidade forte, o problema (4.9) é também factível e limitado. Além disso, os valores das funções objetivos de (4.8) e (4.9) coincidem. Incorporando-se o problema (4.9) à expressão (4.6), obtém-se a função objetivo robusta com custo de produção incerto. Aplicando esses mesmos passos aos outros parâmetros da função objetivo (4.6), obtém-se o equivalente robusto do modelo $C L C$ com custos incertos $(C L C c)$ :

$$
\begin{array}{r}
\operatorname{Minimizar} \tilde{\psi}=\psi+\sum_{(i, t) \in J^{c}} \mu_{i t}^{c}+\lambda^{c} \Gamma^{c}+\sum_{(i, t) \in J^{h^{+}}} \mu_{i t}^{h+}+\lambda^{h^{+}} \Gamma^{h^{+}}+\sum_{(i, t) \in J^{h^{-}}} \mu_{i t}^{h-}+\lambda^{h^{-}} \Gamma^{h^{-}}+ \\
\sum_{(i, t) \in J^{s}} \mu_{i t}^{s}+\lambda^{s} \Gamma^{s}+\sum_{(j, t) \in J^{w}} \mu_{j t}^{w}+\lambda^{w} \Gamma^{w}+\sum_{t \in J^{o}} \mu_{t}^{o}+\lambda^{o} \Gamma^{o}
\end{array}
$$


sujeito a:

$$
\begin{array}{ll}
\text { restrições }(2.2)-(2.11) & \\
\mu_{i t}^{c}+\lambda^{c} \geq \hat{c}_{i t} X_{i t}, & \forall(i, t) \in J^{c} \\
\mu_{i t}^{h+}+\lambda^{h^{+}} \geq \hat{h}_{i t}^{+} I_{i t}^{+}, & \forall(i, t) \in J^{h^{+}} \\
\mu_{i t}^{h-}+\lambda^{h^{-}} \geq \hat{h}_{i t}^{-} I_{i t}^{-}, & \forall(i, t) \in J^{h^{-}} \\
\mu_{i t}^{s}+\lambda^{s} \geq \hat{s}_{i t} Z_{i t}, & \forall(i, t) \in J^{s} \\
\mu_{j t}^{w}+\lambda^{w} \geq \hat{w}_{j t} Y_{j t}, & \forall(j, t) \in J^{w} \\
\mu_{t}^{o}+\lambda^{o} \geq \hat{o}_{t} O_{t}, & \forall t \in J^{o} \\
\mu_{i t}^{c} \geq 0, & \forall(i, t) \in J^{c} \\
\mu_{i t}^{h+} \geq 0, & \forall(i, t) \in J^{h^{+}} \\
\mu_{i t}^{h-} \geq 0, & \forall(i, t) \in J^{h^{-}} \\
\mu_{i t}^{s} \geq 0, & \forall(i, t) \in J^{s} \\
\mu_{j t}^{w} \geq 0, & \forall(j, t) \in J^{w} \\
\mu_{t}^{o} \geq 0, & \forall t \in J^{o} \\
\lambda^{c}, \lambda^{h^{+}}, \lambda^{h^{-}}, \lambda^{s}, \lambda^{w}, \lambda^{o} \geq 0, &
\end{array}
$$

Os passos gerais para determinar os equivalentes robustos podem ser assim resumidos. Formule as funções de proteção $\beta(\cdot)$ para todos os termos $\max (\cdot)$ em $(4.6)$, construa os respectivos problemas de otimização e determine os duais associados aos problemas de otimização, considerando as variáveis duais: $\lambda^{c}, \lambda^{h^{+}}, \lambda^{h^{-}}, \lambda^{s}, \lambda^{w}, \lambda^{o}, \mu_{i t}^{c}, \mu_{i t}^{h^{+}}, \mu_{i t}^{h^{-}}, \mu_{i t}^{s}, \mu_{j t}^{w}$ e $\mu_{t}^{o}$. Por dualidade forte, ambos os problemas primal e dual são factíveis e limitados para todo budget de incerteza, e os seus valores de função objetivo coincidem. Incorporando-se o problema dual em (4.6), obtém-se o equivalente robusto (4.10)-(4.11).

\subsubsection{Incerteza nas Demandas}

Para aplicar a metodologia de otimização robusta ao $C L C 1$ com demanda incerta, reescrevese a restrição (2.2), pois a mesma apresenta uma igualdade, que pode não ser satisfeita para todas as realizações da demanda. Assim, a restrição (2.2) é redefinida como uma restrição de custo de estoque e atraso, da seguinte maneira. Defina o estoque do produto $i$ no período $t$ por $I_{i t}=I_{i t}^{+}-I_{i t}^{-}$. Note que o estoque definido dessa maneira é irrestrito em sinal, podendo representar estoque em mãos ou atraso. Uma vez que $I_{i t}=\sum_{\tau=1}^{t}\left(X_{i \tau}-d_{i \tau}\right)$, e definindo as variáveis não-negativas de custo ou atraso, $H_{i t}$, obtém-se:

$$
H_{i t} \geq h_{i t}^{+} I_{i t}=h_{i t}^{+}\left(\sum_{\tau=1}^{t}\left(X_{i \tau}-d_{i \tau}\right)\right), i \in \mathcal{I}, t \in \mathcal{T}
$$


$\mathrm{e}$

$$
H_{i t} \geq h_{i t}^{-}\left(-I_{i t}\right)=h_{i t}^{-}\left(-\sum_{\tau=1}^{t}\left(X_{i \tau}-d_{i \tau}\right)\right), i \in \mathcal{I}, t \in \mathcal{T} \text {. }
$$

Agora, pode-se aplicar as técnicas de otimização robusta para lidar com a demanda incerta nas restrições reformuladas (4.12) e (4.13). Assim, considere que as demandas acumuladas sejam variáveis aleatórias simétricas e limitadas $\tilde{d}_{i \tau}$ que assumem valores no intervalo $\left[d_{i \tau}-\hat{d}_{i \tau}, d_{i \tau}+\hat{d}_{i \tau}\right]$. O desvio relativo entre as demandas incertas e nominais é determinado por $z_{i t}=\left(\tilde{d}_{i t}-d_{i t}\right) / \hat{d}_{i t}$ que pertence ao intervalo $[-1,1]$. Tomando os budgets de incerteza $\Gamma_{i t}^{d} \in[0, t]$, é possível também escrever $\tilde{d}_{i t}=d_{i t}+\hat{d}_{i t} z_{i t}$. Baseado no trabalho de Bertsimas e Thiele (2006), os budgets de incerteza são caracterizados como se segue:

i) $\Gamma_{i 1}^{d} \leq \Gamma_{i 2}^{d} \leq \cdots \Gamma_{i T}^{d}$, em que $T=|\mathcal{T}|$ é o último período do horizonte de planejamento. Essa suposição implica que $\Gamma_{i t}^{d}$ é não decrescente com o período $t$, para todo $i \in \mathcal{I}$.

ii) $\Gamma_{i t}^{d}-\Gamma_{i, t-1}^{d} \leq 1, \forall i \in \mathcal{I}, t \in \mathcal{T}$. Essa suposição implica que o aumento em $\Gamma_{i t}^{d}$ é igual ou menor que o aumento nos períodos.

De acordo com as técnicas desenvolvidas em Bertsimas e Thiele (2006), deve-se maximizar o lado direito das restrições (4.12) e (4.13) sobre o conjunto de todas as possíveis realizações das demandas incertas. Para $i$ e $t$ dados, o problema auxiliar (4.14) deve ser resolvido:

$$
\begin{array}{ll}
\text { Maximizar } & \sum_{\tau=1}^{t} \hat{d}_{i \tau} z_{i \tau} \\
\text { Sujeito a: } & \sum_{\tau=1}^{t} z_{i \tau} \leq \Gamma_{i t}^{d}, \\
& 0 \leq z_{i \tau} \leq 1, \forall \tau \leq t .
\end{array}
$$

Como a filosofia da otimização robusta é baseada numa perspectiva de otimização em situações de pior caso, o problema auxiliar (4.14) resulta de mimimizar $\sum_{\tau=1}^{t} \hat{d}_{i \tau} z_{i \tau}$ na restrição (4.12) e maximizar $\sum_{\tau=1}^{t} \hat{d}_{i \tau} z_{i \tau}$ na restrição (4.13). Similarmente à Seção 4.2.1, pode-se determinar o equivalente robusto do problema (2.1)-(2.11) com demanda incerta $(C L C d)$ : 
Minimizar $\quad \psi^{d}=\sum_{i \in \mathcal{I}} \sum_{t \in \mathcal{T}}\left(c_{i t} X_{i t}+H_{i t}+s_{i t} Z_{i t}\right)+\sum_{j \in \mathcal{J}} \sum_{t \in \mathcal{T}} w_{j t} Y_{j t}+\sum_{t \in \mathcal{T}} o_{t} O_{t}$

Sujeito a: Restrições $(2.3),(2.5)-(2.8),(2.10),(2.11)$

$$
\begin{gathered}
H_{i t} \geq h_{i t}^{+}\left(\sum_{\tau=1}^{t}\left(X_{i \tau}-d_{i \tau}\right)+\lambda_{i t}^{d} \Gamma_{i t}^{d}+\sum_{\tau=1}^{t} \mu_{i \tau t}^{d}\right), i \in \mathcal{I}, t \in \mathcal{T} \\
H_{i t} \geq h_{i t}^{-}\left(-\sum_{\tau=1}^{t}\left(X_{i \tau}-d_{i \tau}\right)+\lambda_{i t}^{d} \Gamma_{i t}^{d}+\sum_{\tau=1}^{t} \mu_{i \tau t}^{d}\right), i \in \mathcal{I}, t \in \mathcal{T} \\
\sum_{\tau=1}^{t}\left(X_{i \tau}-d_{i \tau}\right)+\lambda_{i t}^{d} \Gamma_{i t}^{d}+\sum_{\tau=1}^{t} \mu_{i \tau t}^{d} \leq I_{i t}^{\max }, i \in \mathcal{I}, t \in \mathcal{T} \\
\lambda_{i t}^{d}+\mu_{i \tau t}^{d} \geq \hat{d}_{i \tau}, i \in \mathcal{I}, t \in \mathcal{T}, \forall \tau \leq t \\
\lambda_{i t}^{d}, \mu_{i \tau t}^{d} \geq 0, i \in \mathcal{I}, t \in \mathcal{T}, \forall \tau \leq t .
\end{gathered}
$$

A formulação (4.15) - (4.20) assegura que $H_{i t} \geq 0$, pois o lado direito das restrições (4.16) e (4.17) são sempre não negativos. No trabalho de Wei et al. (2010), os autores derivam limitantes probabilísticos de violação de restrições similares a (4.12) e (4.13). Considerando que $X_{i t}^{\star}$ seja a solução do equivalente robusto com demanda incerta, temse:

$$
\operatorname{Pr}\left[H_{i t}<h_{i t}^{+}\left(\sum_{\tau=1}^{t}\left(X_{i \tau}^{\star}-\tilde{d}_{i \tau}\right)\right)\right] \leq 1-\Phi\left(\frac{\Gamma_{i t}^{d}-1}{\sqrt{t}}\right)
$$

e

$$
\operatorname{Pr}\left[H_{i t}<h_{i t}^{-}\left(-\sum_{\tau=1}^{t}\left(X_{i \tau}^{\star}-\tilde{d}_{i \tau}\right)\right)\right] \leq 1-\Phi\left(\frac{\Gamma_{i t}^{d}-1}{\sqrt{t}}\right)
$$

em que $\Phi(\theta)$ é a função de distribuição acumulada de uma normal padrão, para todo $i \in \mathcal{I}, t \in \mathcal{T}$. 
Ressalta-se que outros tipos de conjuntos de incerteza podem ser construídos. Por exemplo, em vez de limitar a dispersão acumulada ao longo dos períodos do horizonte de planejamento, i.e., $\sum_{\tau=1}^{t}\left|z_{i \tau}\right| \leq \Gamma_{i t}^{d}, \forall i$, como apresentado, pode-se construir um budget de incerteza entre produtos, como sugerido no trabalho de Adida e Perakis (2010): $\sum_{i \in \mathcal{I}}\left|z_{i t}\right| \leq \Gamma_{t}^{d}, \forall t$. Esse modelo de incerteza considera que, em um determinado período $t$, é mais provável que nem todos os produtos tenham suas demandas no pior caso.

\subsubsection{Incerteza nos Custos e Demandas}

Considere que o modelo $(C L C d)$ também seja afetado pela incerteza dos custos, os quais são variáveis aleatórias de acordo com as suposições da Seção 4.2.1. Assume-se que não há correlação entre os custos unitários e as demandas. Observe que os custos unitários de estoque e atraso afetam diretamente as restrições de demanda do modelo $(C L C d)$, enquanto os outros custos podem ser diretamente transformados nos seus respectivos equivalentes robustos (veja Seção 4.2.1). Seja $\tilde{h}_{i t}^{+}=h_{i t}^{+}+\hat{h}_{i t}^{+} z_{i t}^{h+}$ para todo $z_{i t}^{h+} \in[0,1]$, então, nosso objetivo é tomar a realização de $z_{i t}^{h+}$ que maximize o lado direito da restrição (4.16). Nesse caso, é preciso resolver o problema auxiliar (4.23) para cada par $i \in \mathcal{I}$ e $t \in \mathcal{T}:$

$$
\begin{array}{ll}
\text { Maximizar } & \hat{h}_{i t}^{+} \mathcal{H}_{i t} z_{i t}^{h+} \\
\text { Sujeito a: } & z_{i t}^{h+} \leq \Gamma_{i t}^{h+}, \\
& 0 \leq z_{i t}^{h+} \leq 1
\end{array}
$$

de forma que o problema dual é

$$
\begin{array}{ll}
\text { Minimizar } & \lambda_{i t}^{h+} \Gamma_{i t}^{h+}+\mu_{i t}^{h+} \\
\text { Sujeito a: } & \lambda_{i t}^{h+}+\mu_{i t}^{h+} \geq \hat{h}_{i t}^{+} \mathcal{H}_{i t}, \\
& \lambda_{i t}^{h+} \geq, \mu_{i t}^{h+} \geq 0 .
\end{array}
$$

em que $\mathcal{H}_{i t}=\sum_{\tau=1}^{t}\left(X_{i \tau}-d_{i \tau}\right)+\lambda_{i t}^{d} \Gamma_{i t}^{d}+\sum_{\tau=1}^{t} \mu_{i \tau t}^{d}$.

Analogamente ao custo de atraso, e usando a informação dual em (4.17), obtém-se que o equivalente robusto de $C L C d$ com custos de estoque e atraso incertos é:

\footnotetext{
Minimizar $\quad \psi^{d}$

Sujeito a: Restrições (2.3), (2.5) - (2.8), (2.10), (2.11), (4.18) - (4.20)
} 


$$
\begin{gathered}
H_{i t} \geq h_{i t}^{+}\left(\sum_{\tau=1}^{t}\left(X_{i \tau}-d_{i \tau}\right)+\lambda_{i t}^{d} \Gamma_{i t}^{d}+\sum_{\tau=1}^{t} \mu_{i \tau t}^{d}\right)+\lambda_{i t}^{h+} \Gamma_{i t}^{h+}+\mu_{i t}^{h+}, i \in \mathcal{I}, t \in \mathcal{T} \\
\lambda_{i t}^{h+}+\mu_{i t}^{h+} \geq \hat{h}_{i t}^{+}\left(\sum_{\tau=1}^{t}\left(X_{i \tau}-d_{i \tau}\right)+\lambda_{i t}^{d} \Gamma_{i t}^{d}+\sum_{\tau=1}^{t} \mu_{i \tau t}^{d}\right), i \in \mathcal{I}, t \in \mathcal{T} \\
H_{i t} \geq h_{i t}^{-}\left(-\sum_{\tau=1}^{t}\left(X_{i \tau}-d_{i \tau}\right)+\lambda_{i t}^{d} \Gamma_{i t}^{d}+\sum_{\tau=1}^{t} \mu_{i \tau t}^{d}\right)+\lambda_{i t}^{h-} \Gamma_{i t}^{h-}+\mu_{i t}^{h-}, i \in \mathcal{I}, t \in \mathcal{T} \\
\lambda_{i t}^{h-}+\mu_{i t}^{h-} \geq \hat{h}_{i t}^{-}\left(\sum_{\tau=1}^{t}-\left(X_{i \tau}-d_{i \tau}\right)+\lambda_{i t}^{d} \Gamma_{i t}^{d}+\sum_{\tau=1}^{t} \mu_{i \tau t}^{d}\right), i \in \mathcal{I}, t \in \mathcal{T} \\
\lambda_{i t}^{h+}, \mu_{i t}^{h+}, \lambda_{i t}^{h-}, \mu_{i t}^{h-}, \geq 0, i \in \mathcal{I}, t \in \mathcal{T}
\end{gathered}
$$

A formulação (4.25)-(4.30) permite o tradeoff entre robustez e custo para $\Gamma_{i t}^{h+} \in$ $[0,1]$ e $\Gamma_{i t}^{h-} \in[0,1]$, i.e., assumindo que os budgets são valores inteiros, tem-se apenas duas situações possíveis: o caso nominal, com ambos $\Gamma_{i t}^{h+}=\Gamma_{i t}^{h-}=0$, e a situação de pior caso com ambos, $\Gamma_{i t}^{h+}=\Gamma_{i t}^{h-}=1$. Como os lados direito e esquerdo de (4.27) são iguais na solução ótima, e considerando $\Gamma_{i t}^{h+}=1$, pode-se substituir $\lambda_{i t}^{h+} \Gamma_{i t}^{h+}+\mu_{i t}^{h+}$ por $\hat{h}_{i t}^{+}\left(\sum_{\tau=1}^{t}\left(X_{i \tau}-d_{i \tau}\right)+\lambda_{i t}^{d} \Gamma_{i t}^{d}+\sum_{\tau=1}^{t} \mu_{i \tau t}^{d}\right)$ na inequação (4.26). Assim, a formulação (4.26)-(4.30) pode ser substituída pelas duas restrições a seguir:

$$
\begin{gathered}
H_{i t} \geq\left(h_{i t}^{+}+\hat{h}_{i t}^{+}\right)\left(\sum_{\tau=1}^{t}\left(X_{i \tau}-d_{i \tau}\right)+\lambda_{i t}^{d} \Gamma_{i t}^{d}+\sum_{\tau=1}^{t} \mu_{i \tau t}^{d}\right), i \in \mathcal{I}, t \in \mathcal{T} \\
H_{i t} \geq\left(h_{i t}^{-}+\hat{h}_{i t}^{-}\right)\left(\sum_{\tau=1}^{t}-\left(X_{i \tau}-d_{i \tau}\right)+\lambda_{i t}^{d} \Gamma_{i t}^{d}+\sum_{\tau=1}^{t} \mu_{i \tau t}^{d}\right), i \in \mathcal{I}, t \in \mathcal{T}
\end{gathered}
$$

Finalmente, o equivalente robusto com demandas e custos incertos $(C L C r)$ é expresso da seguinte forma: 


$$
\begin{array}{ll}
\text { Minimizar } & \psi^{d}+\sum_{(i, t) \in J^{c}} \mu_{i t}^{c}+\lambda^{c} \Gamma^{c}+\sum_{(i, t) \in J^{s}} \mu_{i t}^{s}+\lambda^{s} \Gamma^{s}+\sum_{(j, t) \in J^{w}} \mu_{j t}^{w}+\lambda^{w} \Gamma^{w}+\sum_{t \in J^{o}} \mu_{t}^{o}+\lambda^{o} \Gamma^{o} \\
\text { Sujeito a: } & \text { Restrições }(2.3),(2.5)-(2.8),(2.10),(2.11),(4.18)-(4.20),(4.31),(4.32) \\
& \mu_{i t}^{c}+\lambda^{c} \geq \hat{c}_{i t} X_{i t}, \forall(i, t) \in J^{c} \\
& \mu_{i t}^{s}+\lambda^{s} \geq \hat{s}_{i t} Z_{i t}, \forall(i, t) \in J^{s} \\
& \mu_{j t}^{w}+\lambda^{w} \geq \hat{w}_{j t} Y_{j t}, \forall(j, t) \in J^{w} \\
& \mu_{t}^{o}+\lambda^{o} \geq \hat{o}_{t} O_{t}, \forall t \in J^{o} \\
& \mu_{i t}^{c} \geq 0, \forall(i, t) \in J^{c} \\
& \mu_{i t}^{s} \geq 0, \forall(i, t) \in J^{s} \\
& \mu_{j t}^{w} \geq 0, \forall(j, t) \in J^{w} \\
& \mu_{t}^{o} \geq 0, \forall t \in J^{o} \\
& \lambda^{c}, \lambda^{s}, \lambda^{w}, \lambda^{o} \geq 0
\end{array}
$$

A Tabela 4.1 apresenta o número de restrições e variáveis dos modelos $C L C 1, C L C c$, $C L C d$ e $C L C r$, considerando: $\mathcal{L}=\{\tau \mid \tau \leq t, t \in \mathcal{T}\},|\mathcal{L}|=L$ e $U=\left|J^{c}\right|+\left|J^{h+}\right|+\left|J^{h-}\right|+$ $\left|J^{s}\right|+\left|J^{w}\right|+\left|J^{o}\right|$. Note que o número de variáveis binárias não se altera nas formulações robustas. Além disso, a quantidade de restrições e variáveis extras depende apenas do tamanho dos conjuntos de incerteza e, no caso de $L$, do número de períodos do horizonte de planejamento.

\begin{tabular}{llll}
\hline \multirow{2}{*}{ Modelo } & Restrições & \multicolumn{2}{c}{ Variáveis de Decisão } \\
\cline { 2 - 4 }$C L C 1$ & $2 I T+P T+T$ & Contínuas & Binárias \\
\hline$C L C c$ & $2 I T+P T+T+U$ & $3 I T+J T+T$ & $I T$ \\
$C L C d$ & $4 I T+P T+T+I T L$ & $3 I T+J T+T+I T L$ & $I T$ \\
$C L C r$ & $4 I T+P T+T+I T L+$ & $3 I T+J T+T+I T L+$ & $I T$ \\
& $\left|J^{c}\right|+\left|J^{s}\right|+\left|J^{w}\right|+\left|J^{o}\right|$ & $+\left|J^{c}\right|+\left|J^{s}\right|+\left|J^{w}\right|+\left|J^{o}\right|+4$ & \\
\hline
\end{tabular}

Tabela 4.1: Comparação entre os modelos $C L C 1, C L C c, C L C d$ e $C L C r$ em termos de número de restrições, número de variáveis contínuas e número de variáveis binárias.

\subsection{Resultados Computacionais}

Os experimentos computacionais têm o objetivo de analisar o desempenho dos modelos de otimização robusta apresentados em dois casos: $(i)$ a partir de exemplares baseados nos dados da empresa moveleira de pequeno porte e $(i i)$ considerando exemplares simulados de acordo com as características de empresas típicas do setor. Os modelos foram codificados 
no Sistema de Modelagem Algébrica GAMS (McCarl et al., 2010) e resolvido pelo software ILOG-Cplex 11.0 (ILOG, 2008), usando-se os parâmetros default do CPLEX 11.0. Os experimentos foram executados num notebook Core 2 Duo 4, 4.0 GB de memória RAM, $2.0 \mathrm{GHz}$, sob a plataforma Windows VISTA. Os dados utilizados são os mesmos descritos na Seção 2.5, considerando-se 3 produtos e 8 períodos do horizonte de planejamento. As exceções são explicitadas a seguir. O custo de preparação para a produção de um produto foi considerado 10 vezes o custo de produção, conforme Gramani et al. (2009). As demandas nominais e os tempos de produção dos três produtos são apresentados na Tabela 4.2.

\begin{tabular}{lccccccccc}
\hline Produto/Período & 1 & 2 & 3 & 4 & 5 & 6 & 7 & 8 & $v_{i}$ \\
\hline a5p & 34 & 169 & 110 & 60 & 58 & 45 & 70 & 172 & 11,34 \\
cmd & 13 & 100 & 200 & 116 & 199 & 153 & 26 & 128 & 10,32 \\
crd & 32 & 50 & 134 & 87 & 72 & 70 & 26 & 30 & 10,14 \\
\hline
\end{tabular}

Tabela 4.2: Demandas nominais $d_{i t}$ e tempos de produção $v_{i}$ (em minutos) do armário de 5 portas (a5p), da cômoda (cmd) e do criado-mudo (crd).

Simulação. Foram gerados um conjunto de exemplares baseados dos dados da Fábrica X. As dimensões da cada peça $p(p=1, \cdots, 49)$ foram mantidas para ser possível utilizar os mesmos padrões de corte $j(j=1, \cdots, 81)$, fornecidos pela empresa, em todos os problemas. Produtos adicionais foram criados usando as mesmas peças e gerando-se o parâmetro $r_{p i}$ a partir de uma distribuição uniforme no intervalo [0,5]. Outros parâmetros também foram gerados aleatoriamente a partir de uma distribuição uniforme, como se segue: $d_{i t}$ no intervalo $[0,200] ; I_{i t}^{\max }$ no intervalo $[120,250]$; todos os custos no intervalo $[a, b]$, em que $a$ e $b$ são os valores mínimos e máximos dos respectivos custos.

\subsubsection{Incerteza nos Custos}

Definiu-se $\gamma$ como o nível de variabilidade dos parâmetros incertos em relação aos respectivos valores nominais, de tal forma que $\hat{c}_{i t}=\gamma c_{i t}, \hat{h}_{i t}^{+}=\gamma h_{i t}^{+}$, e assim por diante para todos os outros custos. Nesses testes, foram adotados quatro valores para $\gamma: 5,10,20$ e $30 \%$.

Para analisar o efeito de cada custo individual no valor ótimo da função objetivo, o modelo $C L C c$ (4.10)-(4.11) foi testado de tal forma que apenas um custo foi variado por vez. No primeiro teste, por exemplo, $\Gamma^{c}$ variou entre 0 a $\left|J^{c}\right|=|\mathcal{I}||\mathcal{T}|=24$ (inclusive) com passo unitário, enquanto $\Gamma^{h+}=\Gamma^{h-}=\Gamma^{s}=\Gamma^{w}=\Gamma^{o}=0$, analogamente para os demais testes. Dessa forma, foram resolvidos, além do problema nominal, 728 exemplares 
(veja a segunda coluna da Tabela 4.3).

Tradeoff entre robustez e custo. A Tabela 4.3 resume o número de coeficientes sujeitos à incerteza $(|J|)$, o valor de $\Gamma$ para o qual a solução de pior caso (solução de Soyster) é alcançada e o respectivo aumento (ou deterioração) no valor da função objetivo, calculada pela expressão $\Delta=\left(z^{R}-z^{N}\right) / z^{N}$ (em \%), em que $z^{R}$ e $z^{N}$ são os valores ótimos dos modelos robustos e nominais, respectivamente. Note que as soluções de pior caso não são muito conservadoras, no sentido de que os aumentos nos valores ótimos das funções objetivos são menores do que a variabilidade do respectivo custo. Para todos os custos e níveis de variabilidade, o cenário de pior caso foi alcançado antes do pior caso teórico, i.e., $\Gamma<|J|$. O custo de produção ocasionou o maior aumento no valor da função objetivo, cerca de $20 \%$ quando o nível de variabilidade foi de $30 \%$. Por outro lado, o custo de estoque ocasiou a menor deterioração, menos de 0,5\% também no maior nível de variabilidade. Tais resultados parecem plausíveis, uma vez que o valor ótimo do modelo nominal (132597) é composto pelos seguintes custos parciais: custo de produção 87019 (65,6\%); custo de estoque 1789 (1,35\%); custo de preparação 32421 (24,5\%); custo de desperdício 5498 (4,14\%); e custo de hora-extra $5871(4,43)$.

As Figuras (4.1)-(4.5) ilustram o aumento no valor ótimo da solução robusta de acordo com $\Gamma$ para todos os tipos de custos e níveis de variabilidade. Como era esperado, os valores ótimos das funções objetivos aumentam monotonicamente com o aumento da robustez, i.e., de acordo com o aumento de $\Gamma$. Isso acontece porque, a cada unidade que o budget de incerteza aumenta, apenas o desvio mais desfavorável é incorporado à solução robusta, devido à parcela $\max \{\cdot\}$ em (4.6), fazendo com que o incremento ${ }^{1}$ no valor ótimo da função objetivo decresça também de acordo com $\Gamma$. Nas figuras, é possível confirmar o valor de $\Gamma$ a partir do qual o valor ótimo estabiliza-se, que corresponde ao cenário de pior caso. Além disso, observa-se que o aumento nos valores ótimos é bastante sensível ao nível de variabilidade, principalmente quando as incertezas referentes ao custo de produção são consideradas. Nos testes, o valor ótimo da função objetivo não aumenta com $\Gamma^{h-}$, pois $I_{i t}^{-}=0$ na otimalidade $(\forall i \in \mathcal{I}, t \in \mathcal{T})$.

Limitantes probabilísticos. As probabilidades aproximadas de violação das restrições, dadas pela expressão (4.4), são apresentadas nas figuras 4.1-4.5, e, em geral, decrescem de forma convexa até atingir valores próximos de zero. Note que os limitantes probabilísticos nas Figuras 4.1, 4.2 e 4.3 são iguais, pois o limitante (4.4) depende somente de $|J|$ e $\Gamma$. Nesses casos, a probabilidade de violação decresce e rapidamente tende a zero

\footnotetext{
${ }^{1} \mathrm{O} k$-ésimo incremento no valor ótimo da função objetivo (considerando apenas budgets inteiros) pode ser calculado da seguinte maneira: $\delta_{k}=z^{R}(\Gamma=k)-z^{R}(\Gamma=k-1)$, em que $z^{R}(\Gamma=k)$ é o valor ótimo da solução robusta quando $\Gamma=k$, para $k=1,2, \cdots, n$, com $n=|J|$. Assim, de acordo com a metodologia robusta utilizada nessa tese, tem-se que $\delta_{1} \geq \delta_{2} \geq \cdots \geq \delta_{n}$.
} 


\begin{tabular}{cccccccccc}
\hline Custo & $|J|$ & $\Gamma_{5 \%}$ & $\Delta(\%)$ & $\Gamma_{10 \%}$ & $\Delta(\%)$ & $\Gamma_{20 \%}$ & $\Delta(\%)$ & $\Gamma_{30 \%}$ & $\Delta(\%)$ \\
\hline$c_{i t}$ & 24 & 15 & 3,28 & 15 & 6,56 & 15 & 13,1 & 15 & 19,7 \\
$h_{i t}^{+}$ & 24 & 10 & 0,067 & 10 & 0,135 & 10 & 0,270 & 10 & 0,405 \\
$s_{i t}$ & 24 & 24 & 1,18 & 13 & 2,32 & 13 & 4,62 & 13 & 6,91 \\
$w_{j t}$ & 648 & 237 & 0,207 & 242 & 0,415 & 247 & 0,829 & 251 & 1,24 \\
$o_{t}$ & 8 & 6 & 0,221 & 6 & 0,443 & 6 & 0,885 & 6 & 1,32 \\
\hline
\end{tabular}

Tabela 4.3: Análise dos valores de $\Gamma$ (colunas 3, 5, 7 e 9) das soluções robustas e dos correspondentes aumentos $\Delta$ (em porcentagem) no valor da função objetivo (colunas 4, 6 , 8 e 10) para $\gamma=5,10,20$ and 30\%, em cada conjunto de coeficientes (primeira coluna). A coluna $|J|$ mostra o número total de coeficientes sujeitos à incerteza.

em torno de $\Gamma=15$.

Esse resultado confirma que o valor ótimo da função objetivo é marginalmente afetado conforme o nível de proteção aumenta, fato discutido no trabalho de Bertsimas e Sim (2004). Por exemplo, para assegurar uma probabilidade de violação das restrições menor do que $1 \%$, é suficiente escolher $\Gamma^{c}=13$, que proporciona uma deterioração na função objetivo de apenas 3.2\% (quando o nível de variabilidade é 5\%). Assim, garante-se um desempenho maior do que $99 \%$ de não violação das restrições sem aumentar drasticamente o budget de incerteza, assegurando que cerca de $54 \%$ dos coeficientes estão protegidos das incertezas. Na Figura 4.4, menos de 1\% de vioalação das restrições é alcançada com $\Gamma^{w}=61$, o que aumenta o valor ótimo (considerando a maior variabilidade) cerca de $1 \%$ e protege das incertezas cerca de 9,5\% dos coeficientes. Em contrapartida, a Figura 4.5 ilustra que é necessário ser bastante conservador para garantir menos de $1 \%$ de violação das restrições. Nesse caso, $\Gamma^{o}=8$, o que representa o pior caso ou a proteção total, dado pelo método de Soyster (1973). Porém, mesmo nessa situação, a função objetivo aumenta somente $1,3 \%$ quando $\gamma=30 \%$, e assegura-se que $100 \%$ dos coeficientes estão protegidos das incertezas. Esse resultado era esperado, conforme afirmado em Bertsimas e Sim (2004): para assegurar uma probabilidade pequena de violação das restrições no caso em que as mesmas apresentam poucos coeficientes incertos, é necessário garantir proteção total.

A Tabela 4.4 fornece as escolhas de $\Gamma$ para que as probabilidades de violação das restrições seja menor do que uma porcentagem denominada $\alpha$, com $\alpha=1,5,10,15,20$ e 25\%. A quantidade de coeficientes que estão protegidos das incertezas são representados por $\beta$ (em \%). Por exemplo, com $\alpha<1 \%$, tem-se que $\Gamma^{c}=13$, o que acarreta uma proteção dos coeficientes $\beta=13 /\left|J^{c}\right|=54 \%$. Esses resultados confirmam que, em alguns casos, é necessário assegurar proteção total quando o número de coeficientes é baixo: para garantir uma probabilidade menor do que $1 \%$ de violação da meta do decisor, deve-se escolher $\Gamma^{o}=8$, que protege $100 \%$ dos coefientes. Por outro lado, quando o número de coeficientes é grande, um budget de incerteza baixo pode ser suficiente para 
assegurar uma probabilidade de violação próxima de zero, como ilustrado na quarta linha da Tabela 4.4. Nesse caso, $\Gamma^{w}=61$ é suficiente para garantir que a violação seja menor do que 1\%, embora se proteja apenas 9,4\% dos coeficientes. Essa aparente contradição deve-se à propriedade acima destacada, que afirma que o desempenho do modelo robusto é marginalmente afetado pelo aumento no nível de proteção.

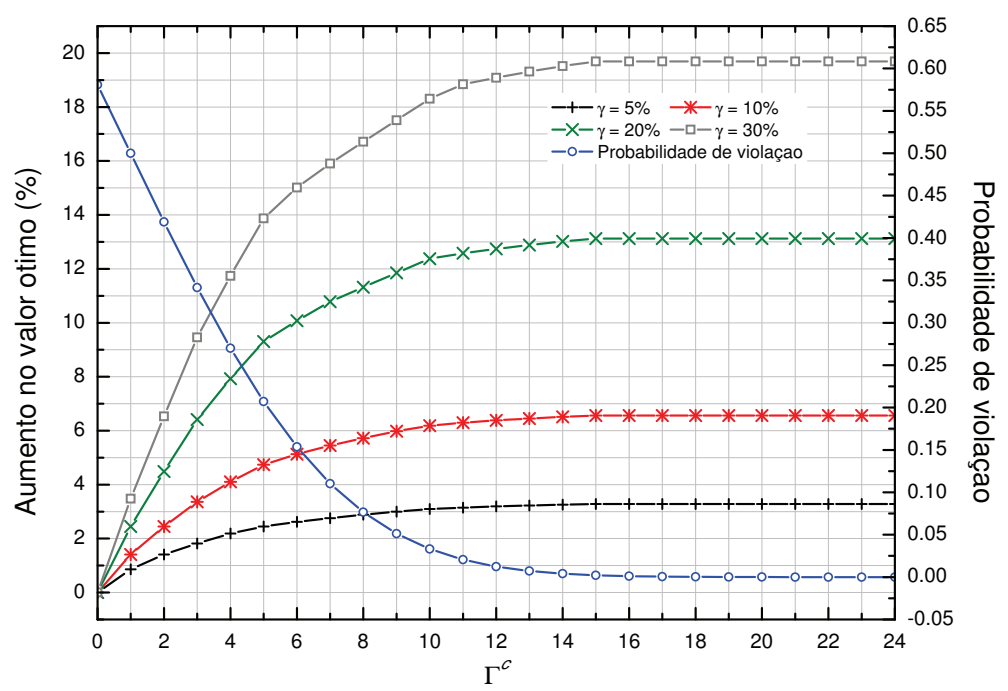

Figura 4.1: Aumento (em \%) no valor ótimo do modelo robusto com custos incertos e limitante probabilístico de violação da meta do decisor como função de $\Gamma^{c}$.

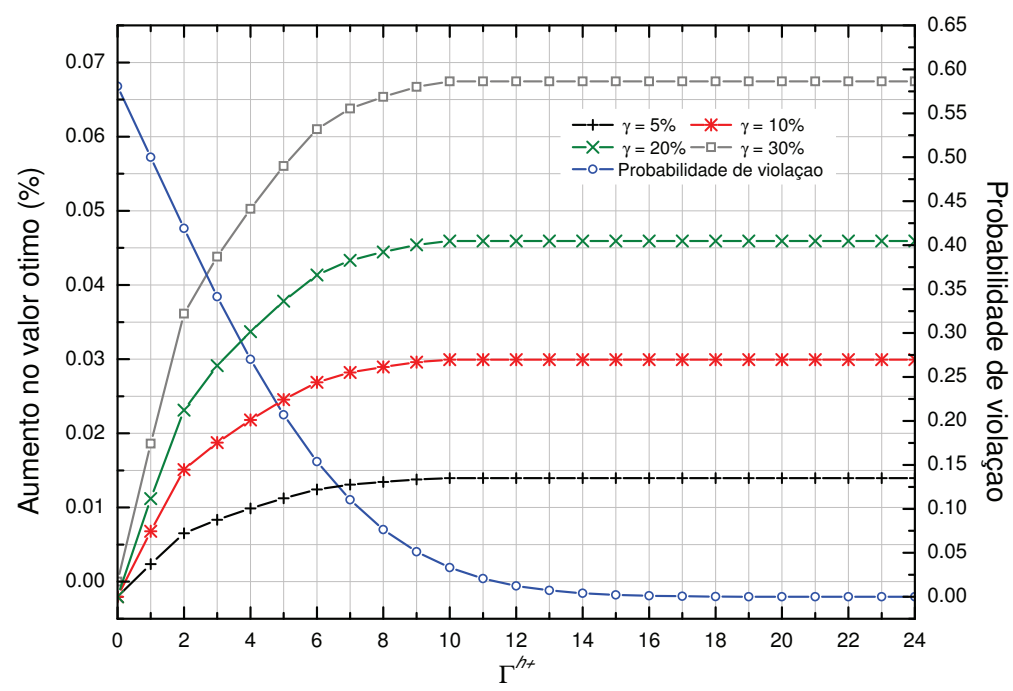

Figura 4.2: Aumento (em \%) no valor ótimo do modelo robusto com custos incertos e limitante probabilístico de violação da meta do decisor como função de $\Gamma^{h+}$. 


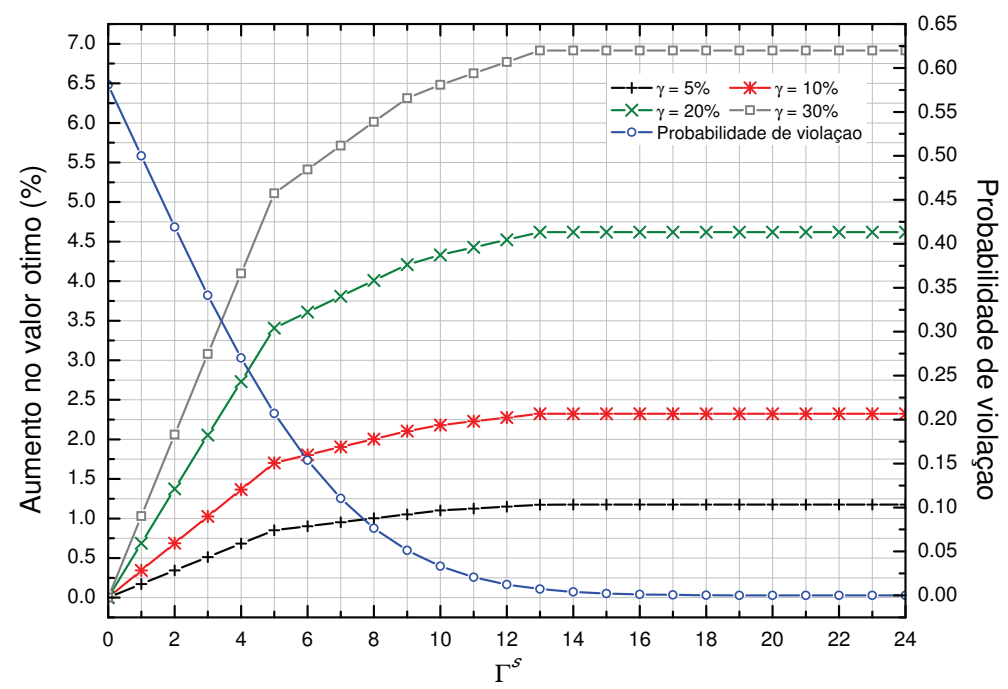

Figura 4.3: Aumento (em \%) no valor ótimo do modelo robusto com custos incertos e limitante probabilístico de violação da meta do decisor como função de $\Gamma^{s}$.

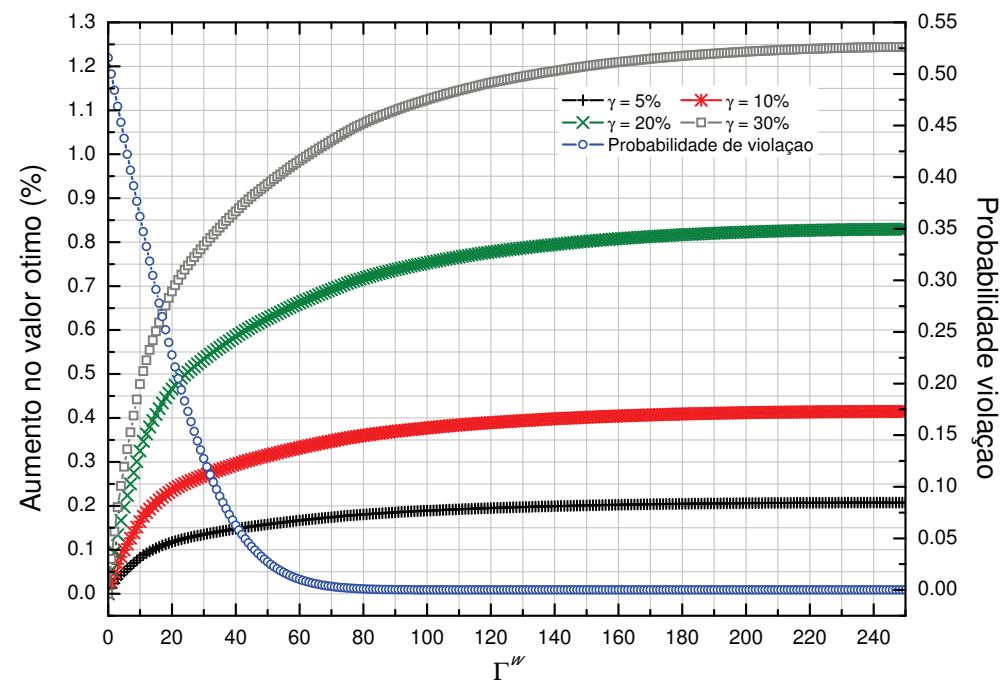

Figura 4.4: Aumento (em \%) no valor ótimo do modelo robusto com custos incertos e limitante probabilístico de violação da meta do decisor como função de $\Gamma^{w}$.

Mudanças estruturais na solução. Não foram observadas mudanças estruturais significativas nas soluções robustas em comparação à solução nominal. Para ilustrar essa afirmação, foram analisados os valores dos estoques totais acumulados $\left(\sum_{i, t} I_{i t}^{+}\right)$contra o nível de variabilidade e budget de incerteza $\Gamma^{c}$ quando apenas o custo de produção é afetado pelas incertezas (tal parâmetro é o que mais tem impacto no valor ótimo da função objetivo). Os pontos de máximo, mínimo, média, mediana e os quartis revelam que 


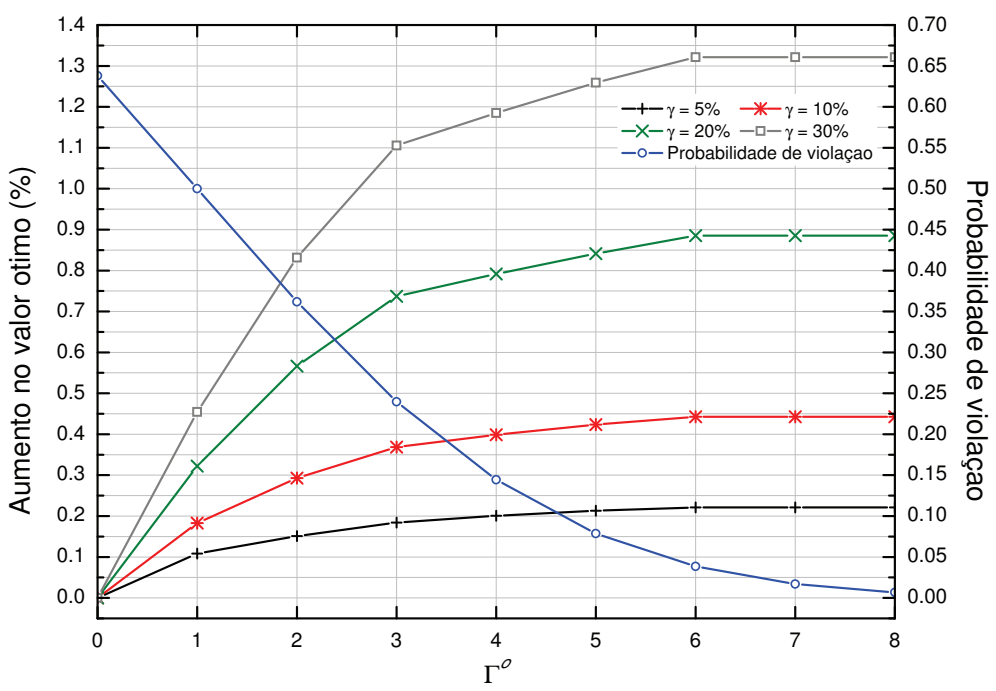

Figura 4.5: Tradeoff entre o custo total e $\Gamma^{o}$.

\begin{tabular}{ccccccccccccc}
\hline & $\alpha<25 \%$ & $\beta_{25 \%}$ & $\alpha<20 \%$ & $\beta_{20 \%}$ & $\alpha<15 \%$ & $\beta_{15 \%}$ & $\alpha<10 \%$ & $\beta_{10 \%}$ & $\alpha<5 \%$ & $\beta_{5 \%}$ & $\alpha<1 \%$ & $\beta_{1 \%}$ \\
\hline$\Gamma^{c}$ & 5 & 21 & 6 & 25 & 7 & 29 & 8 & 33 & 10 & 42 & 13 & 54 \\
$\Gamma^{h+}$ & 5 & 21 & 6 & 25 & 7 & 29 & 8 & 33 & 10 & 42 & 13 & 54 \\
$\Gamma^{s}$ & 5 & 21 & 6 & 25 & 7 & 29 & 8 & 33 & 10 & 42 & 13 & 54 \\
$\Gamma^{w}$ & 19 & 2,9 & 23 & 3,5 & 28 & 4,3 & 34 & 5,2 & 43 & 6,6 & 61 & 9,4 \\
$\Gamma^{o}$ & 3 & 38 & 4 & 50 & 4 & 50 & 5 & 63 & 5 & 63 & 8 & 100 \\
\hline
\end{tabular}

Tabela 4.4: Valores de $\Gamma$ necessários para assegurar uma probabilidade menor do que $\alpha \%$ de violação da meta do decisor e as correspondentes quantidades de coeficientes que estão protegidos da aleatoriedade $(\beta \%)$.

o estoque acumulado tende a apresentar relativamente maior dispersão conforme o nível de variabilidade aumenta, mas essa dispersão parece não ser significantemente diferente. Da análise, tem-se que mesmo com $\gamma=30 \%, 90 \%$ dos dados variam apenas entre 860 e 970, aproximadamente $11 \%$ de variação. A análise do comportamento do estoque acumulado com respeito a $\Gamma^{c}$ mostra que, aparentemente, há mais variações no estoque acumulado para valores de $\Gamma^{c}$ baixos e intermediários, enquanto que para valores mais conservadores, as variações parecem ser bem menores. Percepções similares a essas foram discutidas no trabalho de Maturana et al. (2007) num contexto de planejamento florestal. Sendo assim, pode-se conjecturar que a maior parte da deterioração no valor ótimo da função objetivo é consequência direta das variáveis duais auxiliares $\mu$ and $\lambda$.

Considerando todas as incertezas ao mesmo tempo. O modelo de otimização robusta $C L C c(4.10)$-(4.11) foi testado na situação em que todos os custos podem variar simultaneamente. Os budgets de incerteza foram escolhidos de tal forma que menos de $\alpha \%$ de violação das restrições é permitido, com $\alpha=1,5$ and 10\%. A Tabela 4.5 mostra os resultados referentes ao aumento no valor ótimo, calculado com base no valor do problema 
nominal. Como esperado, o valor ótimo aumenta mais quando todos os custos variam simultaneamente; entretanto, o aumento no valor da função objetivo é similar ao obtido pela soma dos incrementos de cada custo individual, dado um nível de variabilidade e um budget de incerteza. Por exemplo, considere $\Gamma^{c}=\Gamma^{h+}=\Gamma^{s}=13, \Gamma^{w}=61$ e $\Gamma^{o}=8$ (valores para os quais $\alpha=1 \%$ ), com $\gamma=30 \%$. Esses budgets, independentemente, resultam nos seguintes aumentos nos valores ótimos: 19, 0,41, 6,9, 0,99 e 1,3\%, respectivamente. Somando esses valores, obtém-se 28,9\%, que é, aproximadamente, o valor do aumento no valor ótimo quando todos os custos variam simultaneamente $(29,0 \%)$. Também foi confirmado que não há mudanças estruturais significativas nas soluções robustas, mesmo quando as incertezas afetam todos os parâmetros.

\begin{tabular}{cccccc}
\hline \multicolumn{5}{c}{ budget de Incerteza $\boldsymbol{\Gamma}=\left(\Gamma^{c}, \Gamma^{h+}, \Gamma^{s}, \Gamma^{w}, \Gamma^{o}\right)$} \\
\hline$<1 \%$ & $(13,13,13,61,8)$ & $<5 \%$ & $(10,10,10,43,5)$ & $<10 \%(8,8,8,34,5)$ \\
\hline$\gamma \%$ & Aumento (\%) & $\gamma \%$ & Aumento $(\%)$ & $\gamma \%$ & Aumento $(\%)$ \\
\hline 5 & 4,9 & 5 & 4,6 & 5 & 4,3 \\
10 & 9,7 & 10 & 9,2 & 10 & 8,6 \\
20 & 19 & 20 & 18 & 20 & 17 \\
30 & 29 & 30 & 27 & 30 & 25 \\
\hline
\end{tabular}

Tabela 4.5: Aumentos nos valores ótimos do problema nominal no caso em que todos os custos são considerados simultaneamente. A segunda linha da tabela mostra os budgets de incerteza que devem ser adotados para garantir menos de 1, 5 e $10 \%$ de violação da meta do decisor.

Tempos de execução. Todos os exemplares foram resolvidos até que a otimalidade fosse provada pelo CPLEX 11.0. Em média, os tempos de execução foram menores do que 0,5 segundo. Embora o teste com $\Gamma^{w}$ tenha requerido um pouco mais de tempo computacional, não foi observada nenhuma relação entre os tempos de execução e $\Gamma$ ou com o nível de variabilidade. Todavia, no caso em que todos os custos são considerados simultaneamente, os tempos de execução parecem aumentar de acordo com o aumento em ambos os parâmetros, nível de variabilidade e budget de incerteza. Nesses casos, todos os exemplares foram resolvidos em torno de 1 segundo. Tais resultados são plausíveis, considerando que todos os exemplares resolvidos têm apenas 24 variáveis binárias.

Simulação. Foram realizadas várias simulações com a finalidade de confirmar os resultados apresentados anteriormente, mas para outros conjuntos de dados. Porém, são relatados apenas os resultados provenientes da simulação em que todos os custos variam simultaneamente. Inicialmente, foram geradas 250 exemplares para cada nível de variabilidade $(\gamma=5,10,20$ e 30\%), considerando 3 produtos e 8 períodos. Cada exemplar foi resolvido 4 vezes para a obtenção do valor ótimo nominal e das soluções robustas para 3 escolhas da probabilidade de violação das restrições, $\alpha=1,5$ e $10 \%$ (veja os resultados anteriores do item 4), totalizando 1.000 exemplares diferentes e 4.000 
simulações. A Tabela 4.6 mostra os aumentos médios, máximos e mínimos (em \%) nos valores ótimos das funções objetivos em cada caso. Tais resultados confirmam que os valores ótimos das soluções robustas não são muito conservadores (não aumentam muito mais do que o nível de variabilidade considerado). Além disso, os resultados sugerem que os tempos de execução aumentam conforme ambos os parâmetros, nível de variabilidade e budgets de incerteza aumentam. Em média, os tempos de execução variaram no intervalo $[0,19 ; 16]$, em segundos. Resultados similares foram obtidos em exemplares maiores com mais produtos (6 e 10) e mais períodos (12 e 16).

\begin{tabular}{lrrrrrrrrrrrr}
\hline & \multicolumn{3}{c}{$\gamma=5 \%$} & \multicolumn{3}{c}{$\gamma=10 \%$} & \multicolumn{3}{c}{$\gamma=20 \%$} & \multicolumn{3}{c}{$\gamma=30 \%$} \\
\hline Aumento (\%) & $<10 \%$ & $<5 \%$ & $<1 \%$ & $<10 \%$ & $<5 \%$ & $<1 \%$ & $<10 \%$ & $<5 \%$ & $<1 \%$ & $<10 \%$ & $<5 \%$ & $<1 \%$ \\
\hline Médio & 3,6 & 4 & 4,6 & 8,1 & 8,7 & 9,4 & 14 & 16 & 18 & 21 & 23 & 27 \\
Máximo & 4,4 & 4,9 & 4,9 & 9,3 & 9,7 & 9,8 & 18 & 19 & 20 & 26 & 28 & 29 \\
Mínimo & 2,9 & 3,3 & 3,9 & 6,7 & 7,3 & 8,4 & 11 & 12 & 15 & 16 & 19 & 23 \\
\hline
\end{tabular}

Tabela 4.6: Aumento médio, máximo e mínimo nos valores ótimos dos problemas nominais de acordo com a simulação realizada com 1.000 exemplares. A primeira linha da tabela ilustra os níveis de variabilidade e a segunda linha indica a probabilidade máxima de violação da meta do decisor.

\subsubsection{Incerteza nas Demandas}

Analogamente aos testes anteriores, fixou-se $\hat{d}_{i t}=\gamma d_{i t}$, em que cada $d_{i t}$ é a demanda nominal e $\gamma=5,10,20$ e 30\% são os níveis de variabilidade. Os budgets de incerteza $\Gamma_{i t}^{d}$ foram considerados como funções lineares depedentes do tempo, idênticos para todos os produtos $i$, como proposto no trabalho de Adida e Perakis (2006): $\Gamma_{i t}^{d}=g t+b$, em que $g, b \geq 0$, e $g<1$ é necessário para evitar escolhas muito conservadoras para o budget de incerteza e, consequentemente, tornar as soluções robustas muito conservadoras também. A Tabela 4.7 ilustra 4 cenários possíveis para $\Gamma_{i t}^{d}$, assim como os budgets de incerteza acumulados como medidas de conservadorismo de cada cenário, dado por $\sum_{t \in \mathcal{T}} \Gamma_{i t}^{d}, i \in \mathcal{I}$. Note que $\Gamma_{i t}^{d} \geq t$ significa que o cenário de pior caso é obtido, i.e., $\tilde{d}_{i t}=d_{i t}+\hat{d}_{i t}$.

\begin{tabular}{lllll}
\hline & Cenário 1 & Cenário 2 & Cenário 3 & Cenário 4 \\
\hline$\Gamma_{i t}^{d}$ & $0.5+0.1 t$ & 1 & $0.5+0.5 t$ & $t$ \\
$\sum_{t \in \mathcal{T}} \Gamma_{i t}^{d}$ & 7.6 & 8 & 22 & 36 \\
\hline
\end{tabular}

Tabela 4.7: Cenários para os budgets de incerteza. A primeira linha da tabela mostra a equação dos budgets de incerteza como função linear do período do horizonte de planejamento; a segunda linha ilustra o budget acumulado ao final do período de planejamento.

Outra maneira de designar valores para $\Gamma_{i t}^{d}$ é apresentado no trabalho de Bertsimas e Thiele (2006), no qual os autores propõem um algoritmo para selecionar os budgets de incerteza em problemas de controle de estoque com custos estacionários. O algoritmo 
calcula o budget ótimo de incerteza pela resolução de um problema auxiliar de otimização, no qual os budgets são variáveis de decisão. Infelizmente, não é trivial estender o algoritmo para levar em consideração outras restrições e variáveis de decisão e aplicá-lo no presente problema. Além disso, em geral, as abordagens de Adida e Perakis (2006) e Bertsimas e Thiele (2006) geram budgets de incerteza próximos de $\sqrt{t+1}$ para cada período do horizonte de planejamento, o que justifica a utilização de um budget sub-ótimo. Outros trabalhos relacionados também utilizam budgets gerados aleatoriamente para cada período (Bienstock e Ozbay, 2008), ou simplesmente adotam-nos no intervalo [0,1] (Li e Ierapetritou, 2008).

Influência do nível de variabilidade e do budget de incerteza no valor ótimo da função objetivo. Como esperado, quando o nível de variabilidade aumenta, o valor ótimo da função objetivo também aumenta. Ao mesmo tempo, quando o budget de incerteza aumenta (torna-se mais conservador), os valores ótimos são mais deteriorados. Além disso, os valores ótimos são extremamente sensíveis às escolhas dos budgets e dos níveis de variabilidade. A Figura 4.6 (a, b e c) ilustra o aumento (em \%) no valor ótimo da função objetivo para diferentes níveis de variabilidade e budgets de incerteza, com base no valor ótimo da função objetivo do problema nominal igual a 132597. Observe na figura a) que para os dois primeiros budgets de incerteza menos conservadores, o aumento no valor ótimo pode ser considerado plausível, dado que nenhum ultrapassou o nível de variabilidade. Em b), tomando $\gamma=5$ e $10 \%$ para os dois budgets mais conservadores, nota-se que o aumento no valor ótimo já ultrapassa o nível de variabilidade. Em c), confirma-se que para níveis de variabilidade mais elevados, os dois últimos budgets causam um aumento demasiado no valor ótimo, que chega a $800 \%$ quando $\Gamma_{i t}=t$ e $\gamma=30 \%$.

Estudo do nível de serviço. Considerou-se o nível de serviço tipo II (ou taxa de atendimento da demanda) para analisar a fração da demanda atrasada ou perdida, como se segue: $\mathcal{B}=1-I^{-} / D$, em que o total de demanda atrasada é $I^{-}=\sum_{i, t} I_{i t}^{-}$, com $I_{i t}^{-}=d_{i t}-X_{i t}$, se $d_{i t}>X_{i t}$, e $I_{i t}^{-}=0$, caso contrário. A demanda total foi computada como $D=\sum_{i, t}\left(d_{i t}+\hat{d}_{i t}\right)$. A Figura 4.7 ilustra o nível de serviço para todo $\gamma$ e $\Gamma$. Não foi observado nenhuma relação geral entre o nível de serviço e os parâmetros $\gamma$ ou Г. Aparentemente, os melhores níveis de serviço dos cenários 1 e 2 foram obtidos para menores níveis de variabilidade. Nesses casos, incorreu-se em menos de $1 \%$ de demanda não atendida. O melhor desempenho relacionado ao nível de serviço foi observado quando $\gamma=5,10 \%$ e $\Gamma=1$, que forneceu, aproximadamente, $100 \%$ de demanda atendida sem atrasos. Nos cenários 3 e 4, o desempenho do nível de serviço foi similar; aparentemente, melhores níveis de serviço são alcançados quando o nível de variabilidade é menor. O pior desempenho do nível de serviço foi obtido quando $\Gamma=t$ e $\gamma=30 \%$, que produziu apenas $15 \%$ de demanda atendida sem atrasos. Em média, os dois cenários mais conservadores 
atendem apenas $78 \%$ da demanda sem atrasos.

Como comparação, foi resolvido o problema nominal usando a demanda de pior caso, i.e., substitui-se a demanda nominal $d_{i t}$ por $\left(d_{i t}+\hat{d}_{i t}\right)$ e o modelo $C L C$ foi resolvido. Inesperadamente, foram alcançados níveis de serviço superiores a $98 \%$ para todos os níveis de variabilidade. Nesse casos, pode-se afirmar que os problemas nominais de pior caso são preferíveis às versões robustas nos cenários 3 e 4, quando apenas os níveis de serviço são utilizados para determinar soluções boas e ruins. Em outras palavras, se os budgets de incerteza são muito conservadores, pode-se resolver o problema nominal de pior caso, que pode ser visto como uma aproximação do método de Soyster.

Esses resultados sugerem que as soluções robustas provenientes de escolhas muito conservadoras de $\Gamma$ podem apresentar valores ótimos muito deteriorados e níveis muito altos de demanda atrasada devido ao termo $\lambda_{i t}^{d} \Gamma_{i t}^{d}+\sum_{\tau=1}^{t} \mu_{i \tau t}^{d}$. De fato, conforme o budget de incerteza aumenta, o modelo está mais protegido contra a variação a demanda, i.e., mais desvios da demanda são incorporados pelo modelo pela utilização do termo robusto, o qual está diretamente multiplicado pelo respectivo custo (estoque ou atraso). Além disso, como o estoque é limitado superiormente, a segunda restrição (4.17) será mais ativada do que (4.16), o que acarretará mais demanda atrasada. Os resultados confirmam essa situação, como pode ser observado nas Figuras 4.8 e 4.9. Nos cenários mais conservadores 3 e 4, há uma visível diferença de comportamento entre os níveis de estoque e falta: enquanto a quantidade de produtos estocados reduz-se significativamente quando maiores variabilidades são consideradas, os atrasos aumentam drasticamente, o que compromete em demasia o nível de serviço. Em particular, quando $\Gamma=t$ e $\gamma=30 \%$, tem-se apenas 772 produtos em estoque (aproximadamente, 11\% menos estoque do que na solução nominal) e cerca de $85 \%$ da demanda é atrasada (cerca de $30 \%$ é totalmente perdida).

Limitantes probabilisticos. A Figura 4.10 ilustra as probabilidades de violação das restrições (4.12) e (4.13) com demanda incerta, de acordo com os limitantes probabilísticos (4.21) e (4.22), respectivamente, e para todos os budgets de incerteza considerados. Como esperado, $\Gamma$ 's mais conservadores apresentam menores probabilidades de violação das restrições. Observe que a probabilidade decresce de forma convexa e se aproxima de zero depois de 8 períodos no cenário mais conservador (nesse caso, a probabilidade de violação é 0,7\%). O cenário 3 alcança uma probabilidade de 10,8\% ao final do horizonte de planejamento, enquanto os cenários 1 e 2 atingem cerca de $50 \%$ de violação das restrições no último período. Note que o limitante mais apertado tem um bom desempenho (alta probabilidade de factibilidade do modelo) depois de 6 ou 7 períodos, enquanto o segundo limitante mais apertado necessita de 28 períodos para garantir menos de $1 \%$ de violação das restrições. O limitante gerado pelo cenário 1 tem um desempenho pobre, mesmo em situações nas quais o horizonte de planejamento é longo. Por exemplo, com 50 períodos, 
obtém-se cerca de $25 \%$ de chance de violação das restrições. Para garantir menos de $1 \%$ de violação nesse caso, o horizonte de planejamento deve ser de, aproximadamente, 547 períodos. O limitante probabilístico constante é o pior, uma vez que se mantém inalterado ao longo do horizonte de planejamento.

Mudanças estruturais na solução. Diferentemente dos testes envolvendo incerteza apenas nos custos, quando a demanda é incerta, as soluções robustas podem ser muito diferentes das soluções nominais. Além disso, os budgets afetam diretamente as soluções robustas, as quais podem ser significantemente diferentes de acordo com $\Gamma$, como já sugerido nos gráficos (veja as Figuras 4.8-4.9). As Figuras 4.11-4.14 ilustram os níveis acumulados da quantidade de produtos produzidos, quantidade de placas utilizadas, número de preparações e horas-extras incorridas ao final do horizonte de planejamento para todos os níveis de variabilidade e budgets considerados. Em todos os gráficos, as linhas contínuas indicam os respectivos valores nominais (i.e., as soluções ótimas do problema nominal), enquanto as linhas tracejadas e tracejadas-pontilhadas representam os níveis máximos e mínimos alcançados pelas soluções robustas, respectivamente. As variações entre os valores nominais, máximos e mínimos (em \%) também são enfatizadas nos gráficos.

Em geral, as soluções robustas estão concentradas acima dos valores nominais. Uma vez que os modelos de otimização robusta são baseados numa perspectiva de pior caso, as demandas sempre assumem valores no intervalo $\left[d_{i t}, d_{i t}+\hat{d}_{i t}\right]$. Então, há uma pressão para aumentar o nível de produção, o que geralmente aumenta também a quantidade de placas usadas. As horas-extras aparentemente aumentam quando altos níveis de produção são demandados, mas para uma dada capacidade limite, ambos os níveis de produção e horas-extras diminuem, ao passo que os atrasos crescem drasticamente - fato observado quando budgets de incerteza conservadores são adotados. Para ilustrar esse fenômeno, observe as soluções gráficas quando $\Gamma=t$ e $\gamma=30 \%$ (ilustradas por uma estrela em todos os gráficos). Nesse caso, o nível de produção e a quantidade de placas usadas coincidem com os menores valores encontrados, assim como o volume de estoque (veja a Figura 4.8), ao passo que o nível de serviço tem o pior desempenho (veja a Figura 4.9) e são necessárias poucas horas-extras na produção. Ainda, o número de preparações é $53 \%$ maior do que no problema nominal, refletindo uma política conservadora de evitar antecipar a produção de lotes de produção.

Tempos de execução. Todos os exemplares foram resolvidos em menos de 1 segundo. Em média, os exemplares demoraram 0,43 segundos para atingir a solução ótima. Não foi identificada nenhuma relação entre os tempos de execução e os parâmetros 


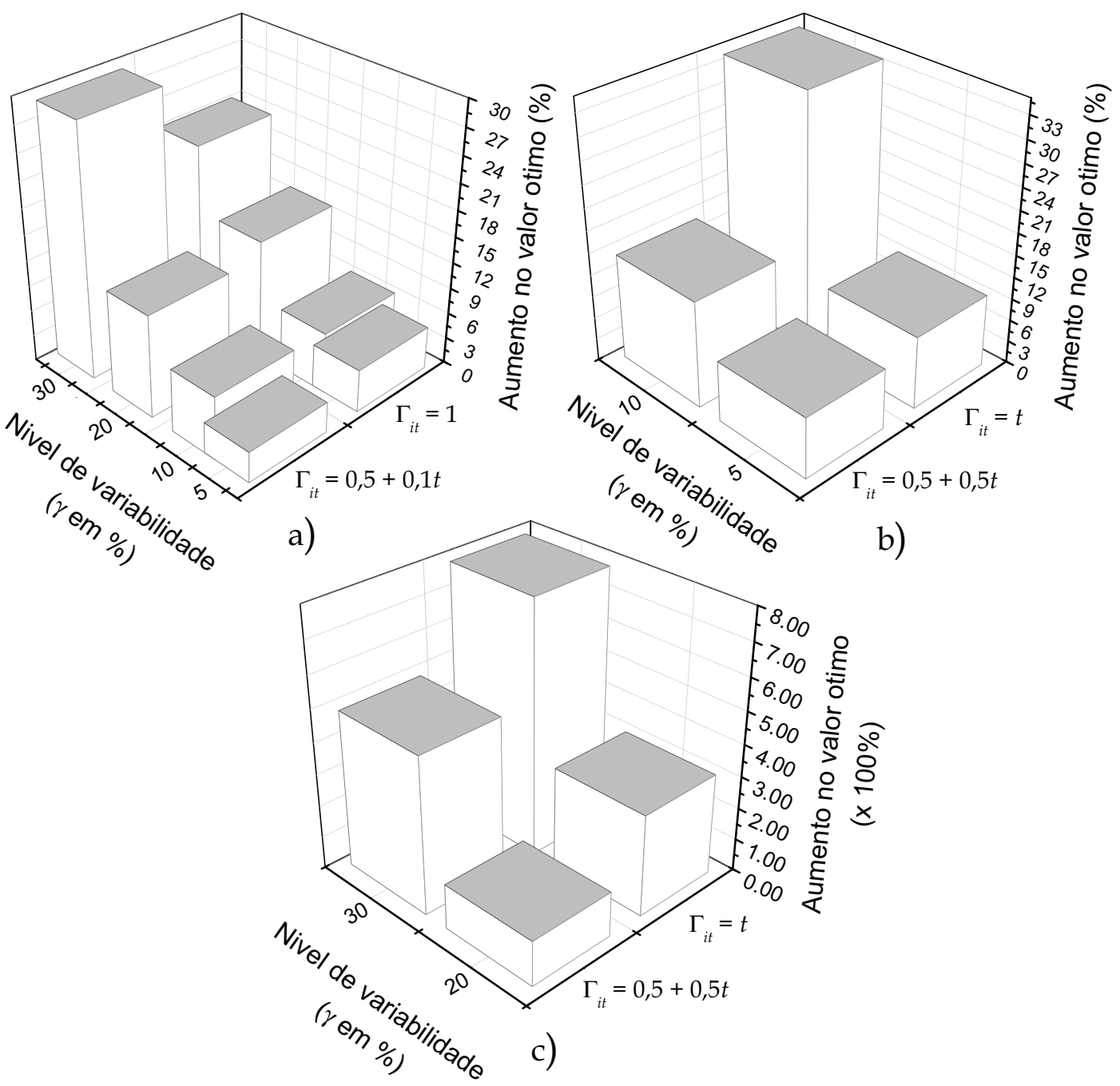

Figura 4.6: Aumento (em \%) no valor ótimo da função objetivo do problema com demanda incerta $C L C d$, considerando a) $\Gamma_{i t}=0,5+0,1 t$ e $\Gamma_{i t}=1$ para todos os níveis de variabilidade; b) $\Gamma_{i t}=0,5+0,5 t$ e $\Gamma_{i t}=t$ para $\gamma=5$ e $10 \%$; c) $\Gamma_{i t}=0,5+0,5 t$ e $\Gamma_{i t}=t$ para $\gamma=20$ e $30 \%$.

$\gamma$ ou $\Gamma$.

Simulação. A simulação foi realizada com o intuito de analisar o desempenho do modelo robusto com demanda incerta para diferentes níveis de variabilidade e budgets de incerteza. Além disso, foram propostas algumas variações do caso básico, as quais podem refletir características de outras empresas moveleiras. O caso básico foi denominado (P1), e está de acordo com as características dos exemplares já simulados. No segundo caso, (P2), os estoques não são mais limitados superiormente, i.e., as restrições $I_{i t}^{+} \geq I_{i t}^{\max }$ foram removidas, para todo $i, t$. No caso $(P 3)$, a capacidade extra foi aumentada para 44 horas por semana, o que resulta em dois turnos de trabalho adicionais por dia, ou pode representar a aquisição de novas máquinas e funcionários, por exemplo. Finalmente, no 


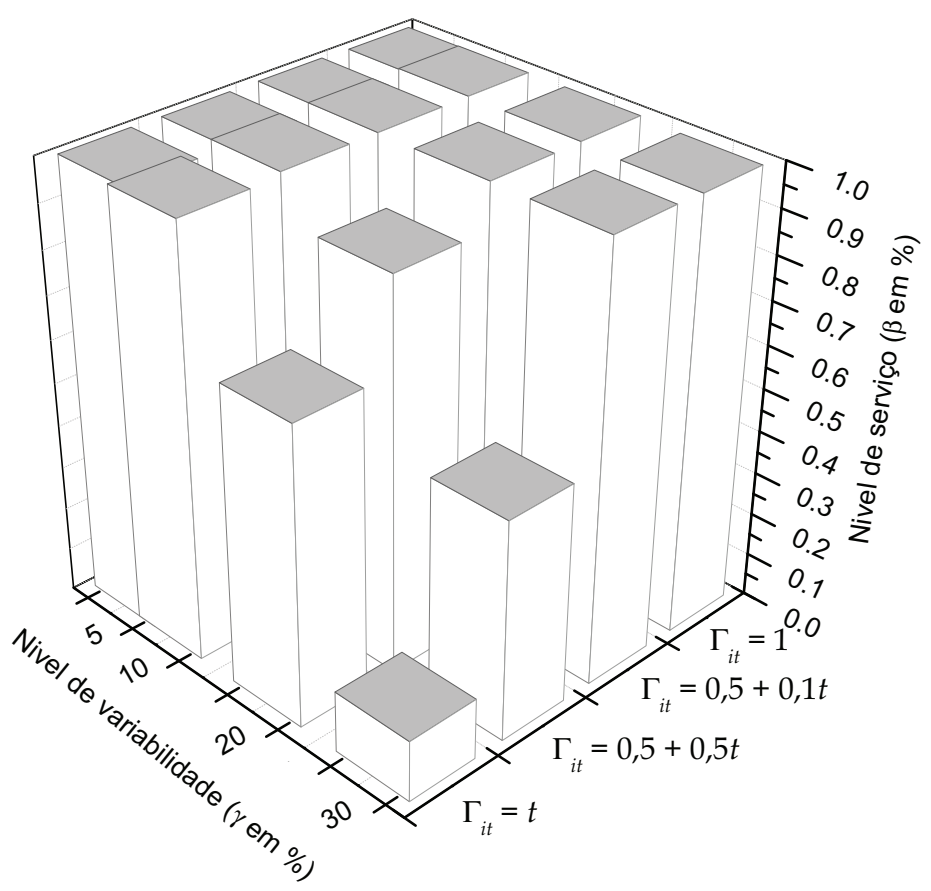

Figura 4.7: Nível de serviço obtido pelo problema robusto com demanda incerta $C L C d$, considerando vários níveis de variabilidade e budgets de incerteza.

caso $(P 4)$, horas-extras não são permitidas. Como resultado, 8.000 exemplares diferentes foram gerados e 40.000 simulações foram executadas. Medidas de desempenho. Duas medidas de desempenho foram consideradas para analisar quão boa ou ruim é a política robusta $(R O)$, comparada à abordagem de pior caso $(W C)$. A primeira medida quantifica o custo extra relativo de utilizar $W C$ em vez de considerar $R O$. Tal medida é dada por $\rho=\left(z^{W C}-z^{R O}\right) / z^{R O}$, em que $z^{W C}\left(z^{R O}\right)$ é o valor ótimo de acordo com a estratégia $W C$ $(R O)$. Se $\rho>0$, então a estratégia robusta é $\rho \%$ mais barata do que a estratégia de pior caso. A segunda medida é o nível de serviço previamente estudado. A Tabela 4.8 resume alguns resultados.

Em alguns casos, o teste Wilcoxon (Wilcoxon signed-rank test, com intervalos de confiança de 99\%) auxiliou na identificação de estratégias melhores ou piores. Para não incorrer em explanações muito extensas, são apresentados apenas os resultados mais gerais. Os resultados de $P 1$ mostram que a estratégia $W C$ tem um desempenho superior à estratégia $R O$ em termos de nível de serviço, mas em alguns casos é necessário incorrer num custo extra para implementá-la. Por exemplo, da Tabela 4.8, tem-se que, para $\gamma=5 \%, 92 \%$ da demanda é atendida sem atrasos pela estratégia $W C$; utilizando $\Gamma=0,5+0,1 t$ na política robusta, todavia, apenas $84 \%$ da demanda é atendida sem atrasos. Entretanto, o valor ótimo da estratégia de pior caso é 9,2\% mais dispendiosa. Nesse caso, existe um tradeoff entre ter um custo financeiro cerca de $9 \%$ maior com um 

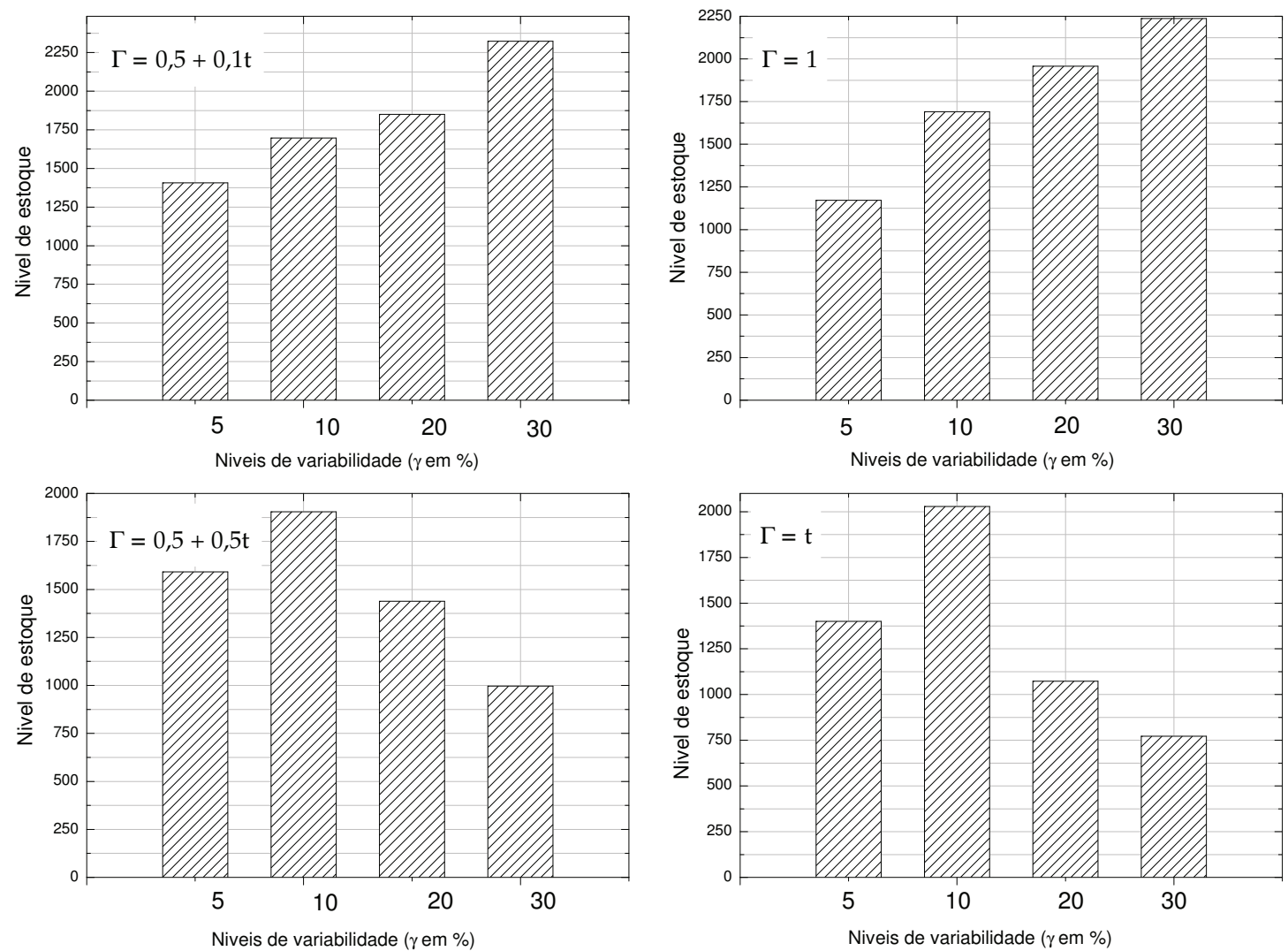

Figura 4.8: Níveis de estoque obtidos pelo problema $C L C d$ com demanda incerta, considerando vários níveis de variabilidade e budgets de incerteza.

nível de serviço $8 \%$ melhor, ou ter um nível de serviço levemente deteriorado, mas sem incorrer a custos adicionais para atingi-lo. Porém, há casos em que o custo extra requerido para alcançar melhores níveis de serviço pode ser inaceitável. Isso acontece, por exemplo, quando $\gamma=30 \%$ e a estratégia $W C$ atende $8 \%$ a mais de demanda sem atrasos, mas o custo dessa política é $120 \%$ maior do que o custo da estratégia robusta com $\Gamma=1$.

Em geral, a estratégia robusta com $\Gamma_{i t}^{d}=0,5+0,1 t$ ou 1 tem um desempenho superior ao da estratégia de pior caso, a política $R O \operatorname{com} \Gamma_{i t}^{d}=0,5+0,5 t$ tem um desempenho ruim para níveis de variabilidade elevados $(\gamma=20,30 \%)$, sendo superada pela estratégia $W C$. Finalmente, não se recomenda a adoção da estratégia robusta com $\Gamma_{i t}^{d}=t$, pois tanto o nível de serviço quanto os ótimos valores são piores do que a abordagem nominal de pior caso.

Os resultados de $P^{2}$ sugerem que a formulação robusta beneficia-se da remoção das restrições de estoque máximo permitido, enquanto que para a abordagem de pior caso, a eliminação das restrições é insignificante. Em particular, quando $\gamma=30 \%$, é notável que 

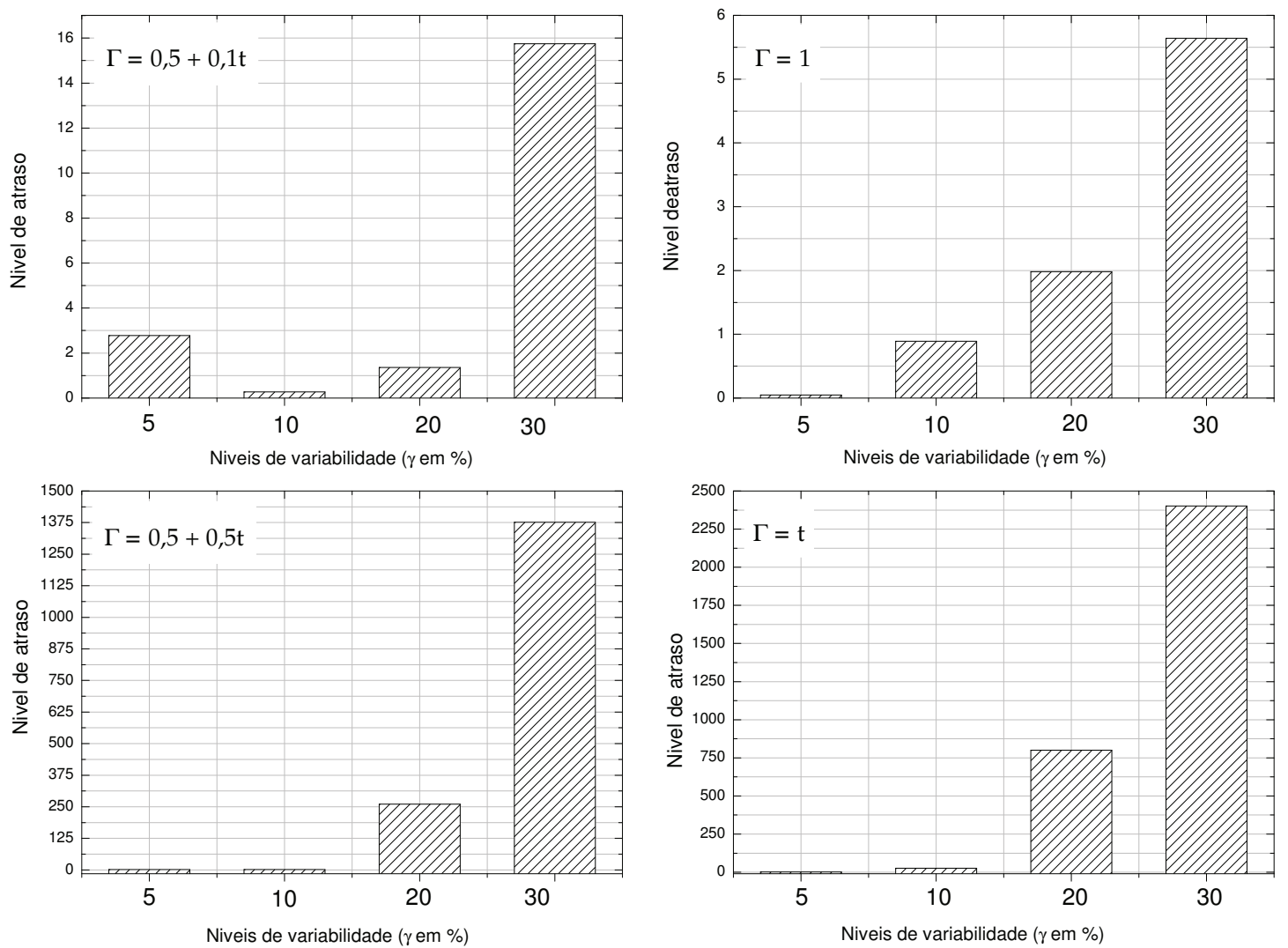

Figura 4.9: Níveis de atraso obtidos pelo problema $C L C d$ com demanda incerta, considerando vários níveis de variabilidade e budgets de incerteza.

o nível de serviço alcance uma melhora em torno de $18 \%$ (comparando os casos P2 e P1), enquanto o custo total incorrido piora $4,5 \%$ nos cenários 1 e 2, e melhora cerca de $46 \%$, em média, para $\Gamma$ 's mais conservadores. Nesse caso, se os cenários 1 e 2 forem adotados, a estratégia $R O$ tem um desempenho superior ao da política $W C$, tanto em nível de serviço quanto em custo total.

Comparando os casos P3 e P1, observa-se que é possível alcançar melhores níveis de serviço com a expansão da capacidade extra (P3), pois o nível de produção aumenta e menos atrasos são incorridos no atendimento da demanda. Entretanto, quando $\gamma=30 \%$ e budgets mais conservadores são adotados, os níveis de serviço não melhoram significativamente para compensar os altos custos da política robusta, e a estratégia de pior caso é mais recomendada.

Como já esperado, quando não é possível realizar horas-extras $(P 4)$, ambas as estratégias têm um desempenho inferior, pois o nível de serviço diminui consideravelmente. Nessa situação, a estratégia de pior caso é mais afetada do que a política robusta em 
relação ao nível de serviço. Além disso, embora os níveis de serviço não sejam significantemente diferentes (apenas no caso em que $\gamma=5 \%$ e o cenário 3 é adotado, $\mathcal{B}$ é estatísticamente melhor na estratégia $W C$ ), a política robusta é implementada a um custo mais baixo do que a política de pior caso.

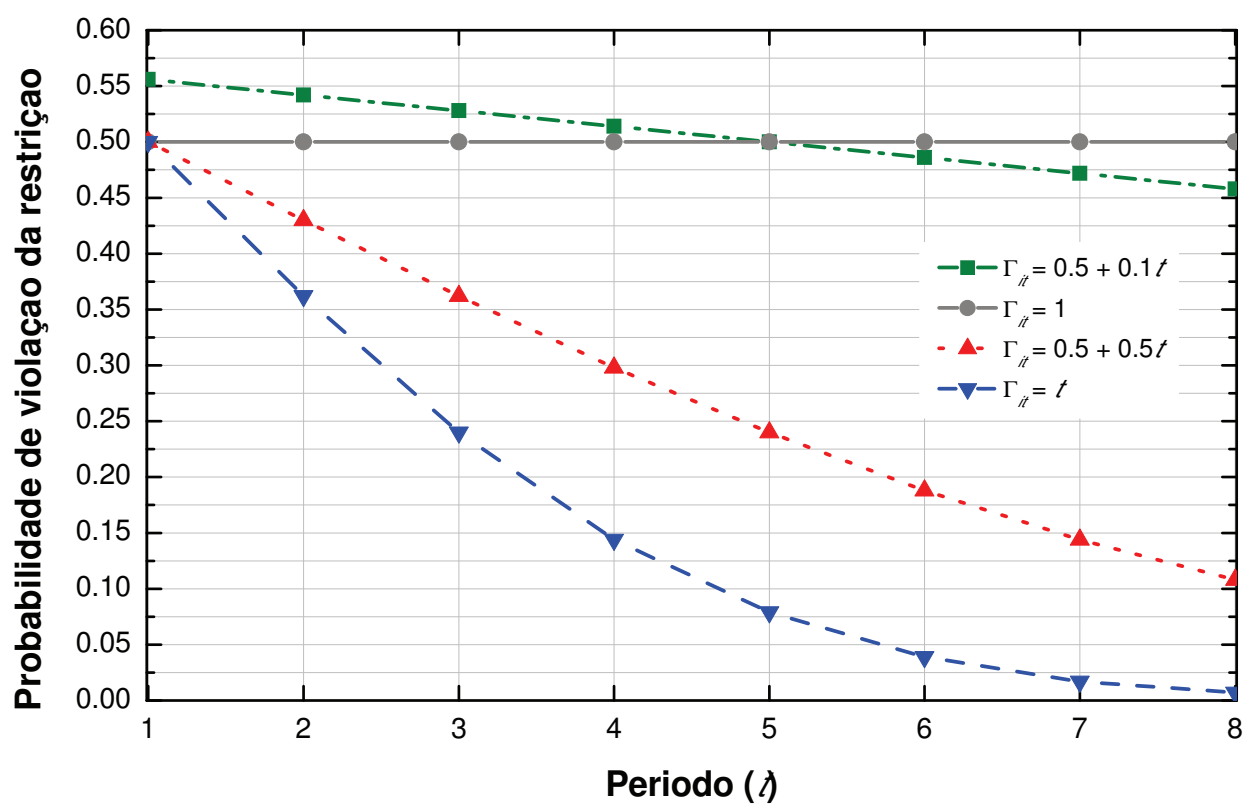

Figura 4.10: Probabilidade de violação das restrições de balanço de estoque.

Em muitos casos, a política robusta mostrou-se mais conservadora do que a estratégia de pior caso. De fato, quando $\Gamma_{i t}^{d}=t$, a restrição de demanda é "totalmente protegida", no sentido de que o balanceamento da demanda considera, além da demanda nominal $d_{i t} \mathrm{e}$ do desvio $\hat{d}_{i t}$ atual, todo o desvio dos períodos anteriores $\left(\hat{d}_{i t-1}, \hat{d}_{i t-2}, \cdots, \hat{d}_{i 1}\right)$, o que gera uma proteção excessiva e pessimista. Por outro lado, a estratégia de pior caso resolve um problema menos conservador, cuja demanda é igual a $d_{i t}+\hat{d}_{i t}$. Por essa razão, é crucial determinar valores plausíveis para os budgets de incerteza. 


\begin{tabular}{ccccccccccc}
\hline & \multicolumn{3}{c}{$\Gamma=0,5+0,1 t$} & \multicolumn{2}{c}{$\Gamma=1$} & \multicolumn{2}{c}{$\Gamma=0,5+0,5 t$} & \multicolumn{2}{c}{$\Gamma=t$} & \multicolumn{2}{c}{$W C$} \\
\hline & $\gamma$ & $\rho$ & $\mathcal{B}$ & $\rho$ & $\mathcal{B}$ & $\rho$ & $\mathcal{B}$ & $\rho$ & $\mathcal{B}$ & $\mathcal{B}$ \\
\hline P1 & 9,2 & 0,84 & 8,8 & 0,85 & 1,5 & 0,85 & $-1,7$ & 0,85 & 0,92 \\
P2 & $5 \%$ & 9,1 & 0,87 & 8,6 & 0,88 & 1,5 & 0,88 & $-1,9$ & 0,87 & 0,93 \\
P3 & & 2,8 & 1,00 & 3,0 & 1,00 & $-1,2$ & 1,00 & $-2,9$ & 1,00 & 1,00 \\
P4 & & 13 & 0,31 & 13 & 0,31 & 3,4 & 0,29 & $-0,1$ & 0,29 & 0,34 \\
\hline P1 & 25 & 0,80 & 24 & 0,81 & 4,4 & 0,79 & $-7,5$ & 0,77 & 0,86 \\
P2 & $10 \%$ & 26 & 0,76 & 25 & 0,78 & 4,9 & 0,76 & $-6,7$ & 0,74 & 0,84 \\
P3 & & 6,1 & 0,97 & 6,2 & 0,97 & $-3,2$ & 0,98 & -12 & 0,97 & 1,00 \\
P4 & 25 & 0,26 & 24 & 0,25 & 6,1 & 0,24 & $-0,44$ & 0,24 & 0,26 \\
\hline P1 & & 69 & 0,55 & 65 & 0,61 & -15 & 0,58 & -42 & 0,45 & 0,71 \\
P2 & $20 \%$ & 70 & 0,56 & 67 & 0,61 & -16 & 0,59 & -42 & 0,46 & 0,72 \\
P3 & 14 & 0,69 & 14 & 0,73 & -42 & 0,76 & -64 & 0,60 & 0,99 \\
P4 & & 48 & 0,14 & 48 & 0,15 & 7 & 0,13 & -6 & 0,13 & 0,14 \\
\hline P1 & 126 & 0,39 & 119 & 0,46 & -36 & 0,31 & -56 & 0,20 & 0,54 \\
P2 & $30 \%$ & 126 & 0,57 & 117 & 0,60 & 25 & 0,50 & $-1,7$ & 0,43 & 0,54 \\
P3 & 22 & 0,52 & 24 & 0,58 & -73 & 0,35 & -82 & 0,21 & 0,97 \\
P4 & 66 & 0,15 & 65 & 0,16 & 3,7 & 0,14 & -13 & 0,14 & 0,14 \\
\hline
\end{tabular}

Tabela 4.8: Resultados do modelo robusto $C L C d$ a partir de 40.000 simulações, nas quais foram testadas variações do problema padrão $(P 2-P 4)$ para diferentes budgets de incerteza $\Gamma$ e níveis de variabilidade $\gamma$. As colunas $\rho$ e $\mathcal{B}$ ilustram o custo relativo de utilizar a estratégia $W C$ em detrimento à abordagem $R O$ e o nível de serviço em cada caso, respectivamente. A última coluna mostra o nível de serviço obtido pela estratégia de pior caso $W C$.

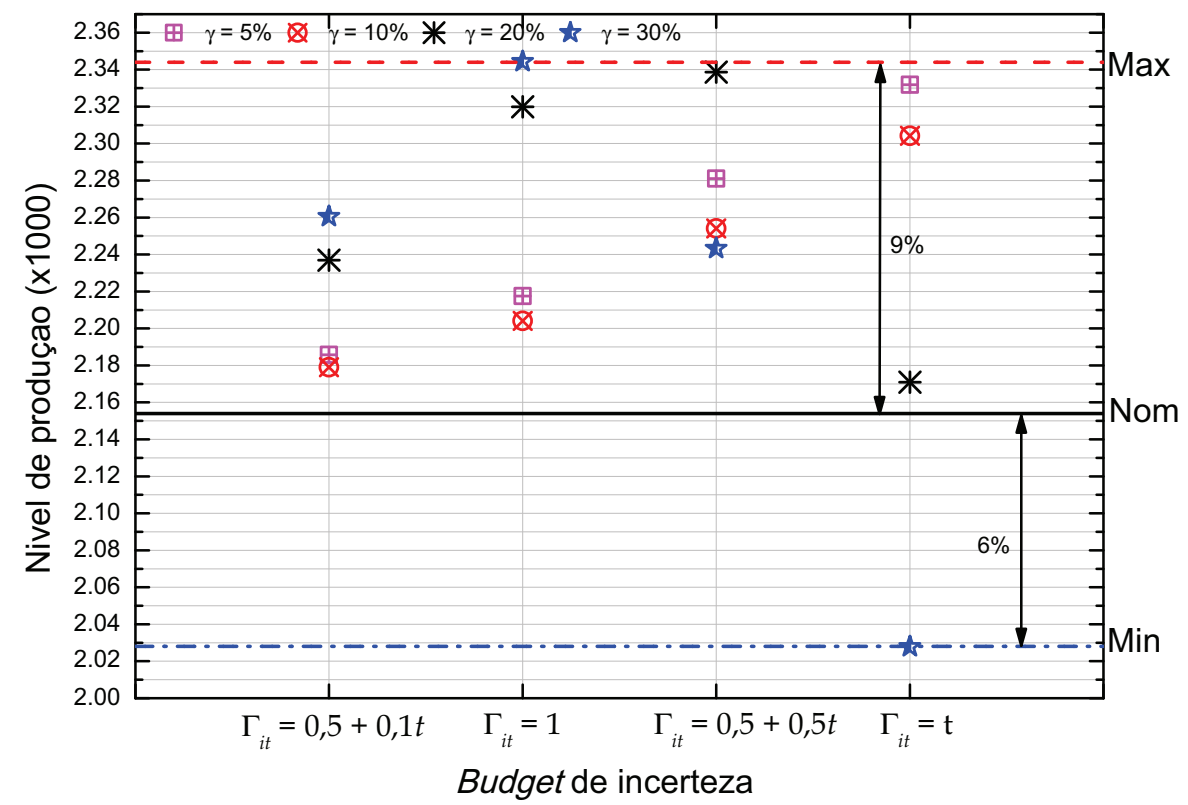

Figura 4.11: Nível de produção acumulado ao longo do horizonte de planejamento do problema robusto com demanda incerta $C L C d$, considerando vários níveis de variabilidade e budgets de incerteza, além dos valores nominal, máximo e mínimo. 


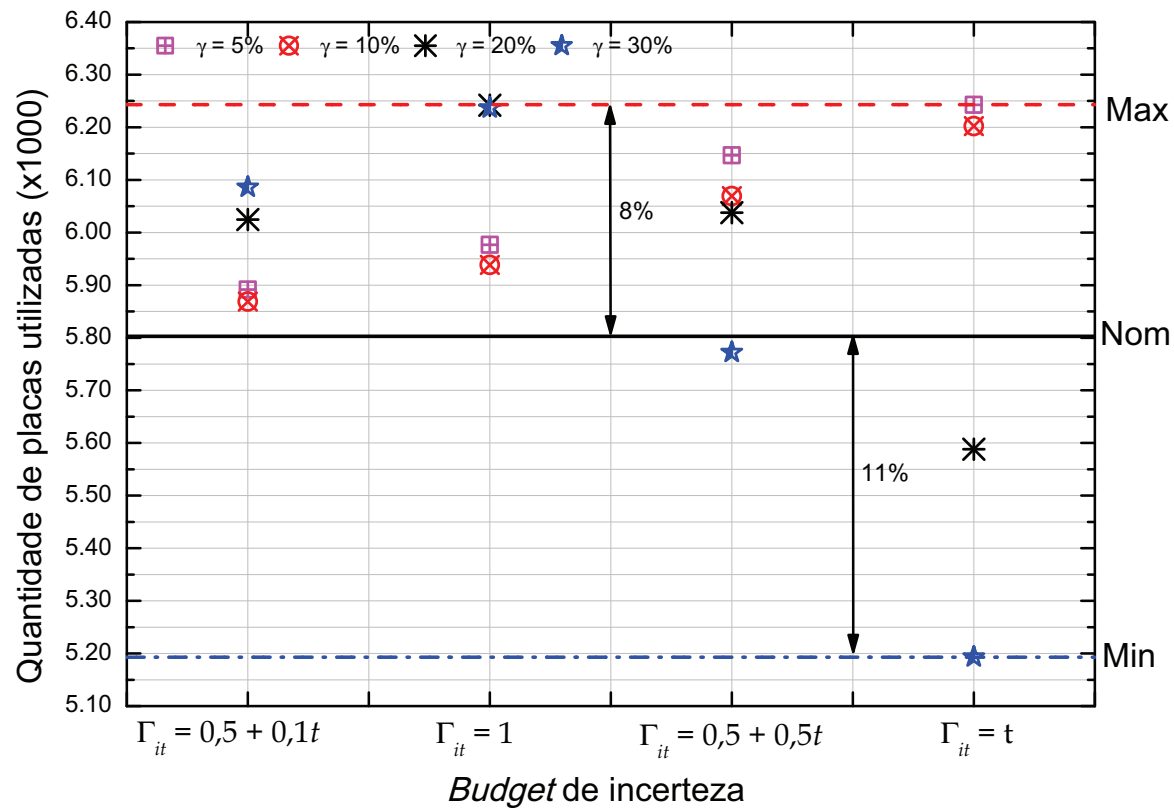

Figura 4.12: Quantidade de placas utilizadas ao longo do horizonte de planejamento do problema robusto com demanda incerta $C L C d$, considerando vários níveis de variabilidade e budgets de incerteza, além dos valores nominal, máximo e mínimo.

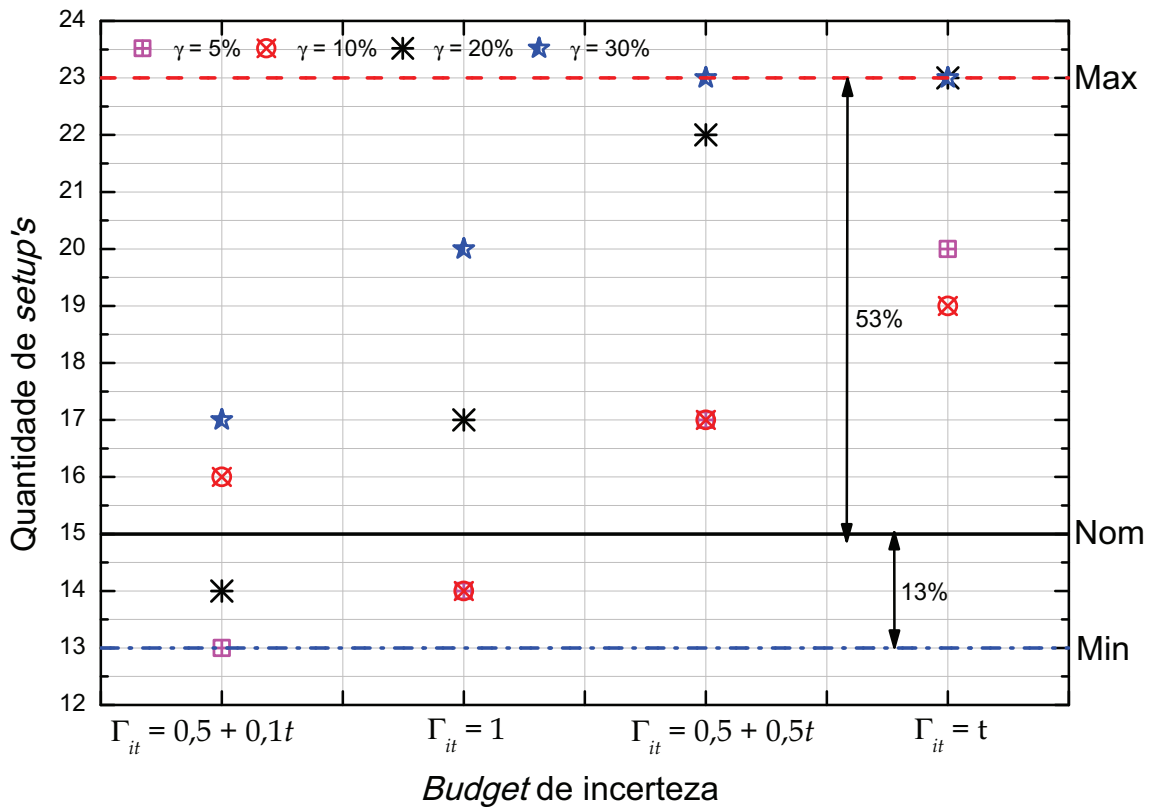

Figura 4.13: Quantidade de preparações de máquina necessárias ao longo do horizonte de planejamento do problema robusto com demanda incerta $C L C d$, considerando vários níveis de variabilidade e budgets de incerteza, além dos valores nominal, máximo e mínimo. 


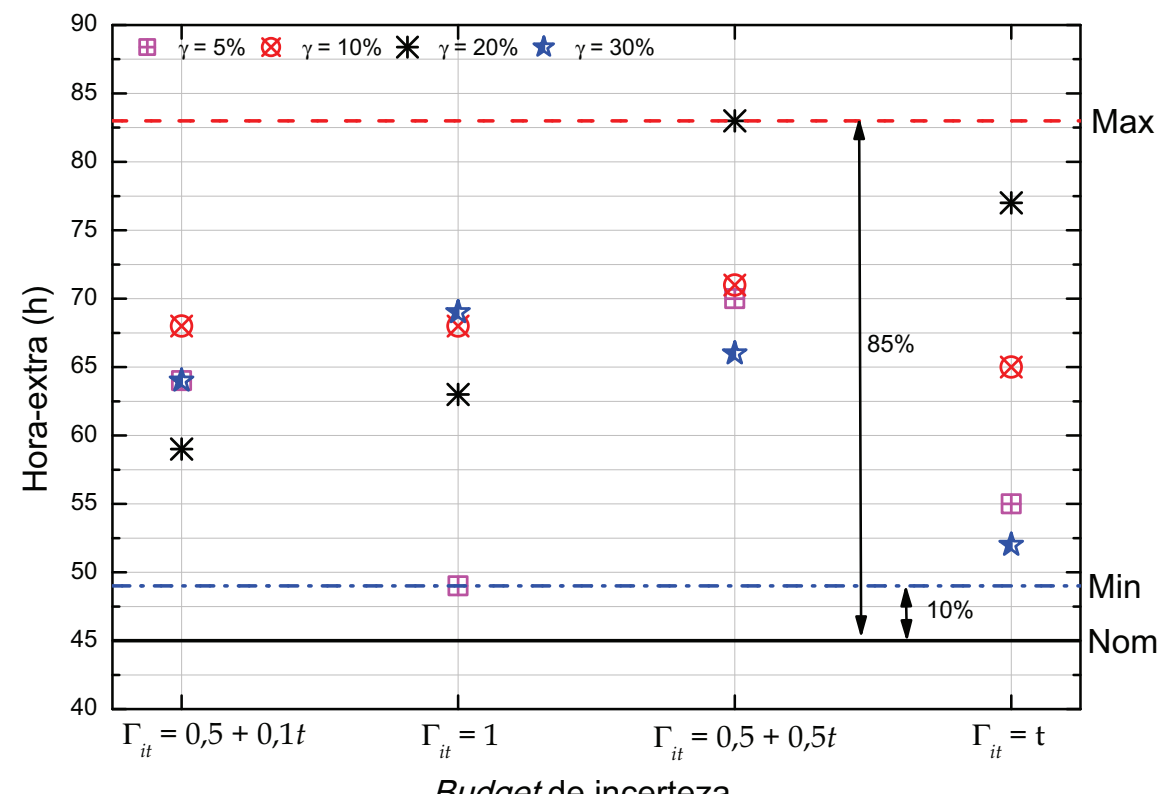

Figura 4.14: Horas-extras incorridas ao longo do horizonte de planejamento do problema robusto com demanda incerta $C L C d$, considerando vários níveis de variabilidade e budgets de incerteza, além dos valores nominal, máximo e mínimo.

\subsubsection{Incerteza nos custos e demandas}

Devido à similaridade com os testes anteriores, esses resultados são apresentados de maneira mais concisa. Os mesmos níveis de variabilidade foram considerados e os budgets de incerteza dos custos da função objetivo foram adotados de maneira que $\alpha \%=1 \%$, i.e., $\Gamma^{c}=13, \Gamma^{s}=13, \Gamma^{w}=61$ e $\Gamma^{o}=8$. Os budgets de incerteza das restrições de demanda foram assumidos apenas em dois cenários: $\Gamma_{i t}^{d}=0,5+0,1 t$ e $\Gamma_{i t}^{d}=t$, para todo $i \in \mathcal{I}, t \in \mathcal{T}$. Foram comparados os resultados dos modelos CLCc (4.10)-(4.11) (considerando todos os custos incertos ao mesmo tempo), $C L C d(4.15)-(4.20)$ e $C L D r$ (4.33) em termos de valores ótimos e estrutura das soluções. Como esperado, as soluções do modelo $C L C r$ são muito similares às soluções do modelo $C L C d$ e diferentes das soluções fornecidas pelo modelo $C L C c$. Além disso, os níveis de atraso aumentam quando a incerteza dos custos é incorporada ao modelo $C L C d$, o que ocasiona uma perda de nível de serviço significativa para budgets de incerteza mais conservadores. Por exemplo, quando $\gamma=30 \%$ e $\Gamma_{i t}^{d}=t$, o nível de serviço obtido pelo modelo $C L C d$ é, aproximadamente, $14 \%$; incorporando-se a incerteza dos custos, o nível de serviço vai a zero. Os níveis de estoque de $C L C d$ e $C L C r$ também são diferentes, mas não foi observada nenhuma tendência geral. Os valores ótimos do modelo $C L C r$ são piores do que os fornecidos pelo modelo $C L C d$ : 
aproximadamente 4, 9, 19 e $27 \%$ piores para $\gamma=5,10,20$ e 30\%, respectivamente.

Simulação. Para confirmar os resultados obtidos pelo modelo $C L C r, 1.000$ exemplares foram gerados aleatoriamente e resolvidos, considerando $\alpha=1 \%$ e para cada budgets de incerteza e nível de variabilidade. Os mesmos exemplares foram resolvidos ignorando-se os custos incertos, para fins de comparação. Como esperado, confirmou-se que os valores ótimos do modelo $C L C r$ são piores do que os do modelo $C L C d$, em média, 5, 9, 18 e 27\% para $\gamma=5,10,20$ e 30\%, respectivamente. Também não foi surpresa observar que os níveis de atraso pioram quando os custos incertos são incorporados ao modelo $C L C d$, principalmente nos cenários mais conservadores para o budgets de incerteza da demanda e para os níveis de variabilidade mais elevados. Não foram observadas outras tendências em relação ao nível de estoque e horas-extras, por exemplo. Entretanto, os tempos de execução aumentaram 1,5 vezes, em média. Embora não testados exaustivamente, alguns exemplares do modelo $C L C r$ com 26 produtos e 48 períodos foram gerados e resolvidos, considerando-se a capacidade regular cerca de 6 vezes maior (caso contrário, a solução seria infactível). Todos os exemplares foram resolvidos em menos de 1 hora, com certificado de otimalidade da solução. Nesses casos, note que o número de variáveis binárias é 1248, o que sugere a alta tratabilidade do modelo de otimização robusta.

\subsection{Modelos de Otimização Robusta versus Modelos Estocásticos Robustos}

Nessa seção, são comparados dois modelos robustos: $(i)$ o modelo de otimização robusta $C L C d$ (4.15)-(4.20); e (ii) uma versão estocástica robusta do tipo Média-Risco do modelo $C L C 1$. Por simplicidade, apenas a demanda é considerada um parâmetro incerto. Nas formulações estocásticas, o estoque $I_{i t s}^{+}$e o atraso $I_{i t s}^{-}$foram consideradas variáveis de decisão de segundo estágio, sendo ponderadas na função objetivo pela probabilidade $\pi_{s}$ associada a cada cenário. As outras variáveis de decisão foram designadas como primeiro estágio. A versão estocástica robusta do tipo média-risco do modelo $C L C 1$ é chamada, a partir desse ponto, de modelo MR1, e pode ser escrita da seguinte forma: 


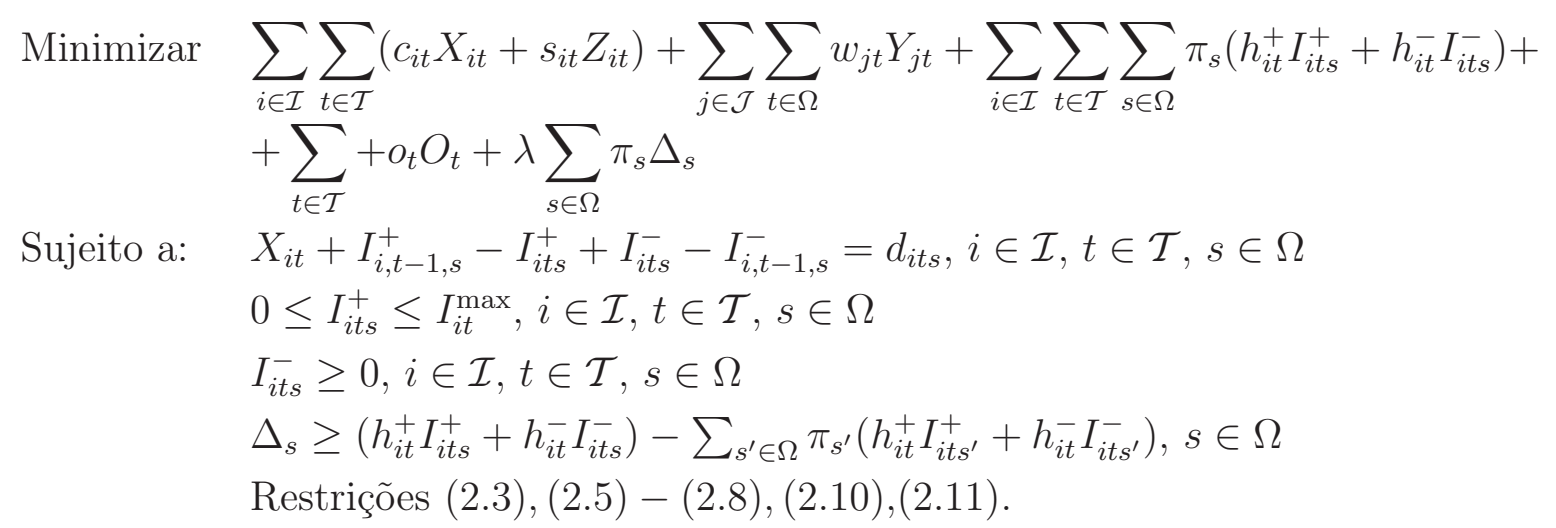

A função objetivo incorpora o termo de aversão ao risco para $\lambda>0$ e permite gerar soluções mais robustas aumentando-se o fator de risco $\lambda$. Para mais detalhes desse tipo de formulação, o leitor pode rever o Capítulo 3. Foram gerados aleatoriamente 100 cenários, segundo uma distribuição uniforme discreta entre $\left[0,70 d_{i t} ; 1,3 d_{i t}\right]^{2}$ e todos foram admitidos equiprováveis (mais detalhes podem ser obtidos no Teste B da Seção 3.3.2 do Capítulo 3).

Para o modelo $C L C d$, adotou-se $\Gamma_{i t}^{d}=g t, \operatorname{com} g=0,01$ até 1 . Dessa forma, vários budgets de incerteza foram testados, desde os menos conservadores até o mais conservador $\left(\Gamma_{i t}^{d}=t\right)$. Na comparação, considerou-se que o budget mais conservador implica na solução mais robusta. Assim, quando $\Gamma_{i t}^{d}=t$, o problema é totalmente robusto ou 100\%; quando $\Gamma_{i t}^{d}=0,5 t$, o problema é $50 \%$ robusto, e assim por diante. Para o modelo $M R 1$, a robustez do problema é representada pela porcentagem de decréscimo do desvio esperado $(\Delta)$ em relação ao desvio para $\lambda=0$ (problema estocástico tradicional). Quando o desvio atinge $30 \%$, por exemplo, diz-se que o problema é 30\% robusto. Os modelos são analisados de acordo com: (1) o aumento no valor ótimo da função objetivo; (2) o nível de serviço tipo II; e (3) o tempo de execução computacional. Nessa análise, adotou-se um exemplar com 3 produtos e 8 períodos, cujos parâmetros nominais são os mesmos utilizados nos experimentos computacionais desse capítulo.

Aumento no valor ótimo. As Figuras 4.15 e 4.16 ilustram o aumento no valor ótimo da função objetivo e a robustez dos modelos $M R 1$ e $C L C d$, de acordo com o aumento do fator de risco $(\lambda)$ e dos budgets de incerteza $(\Gamma)$, respectivamente. Da Figura 4.15, tem-se que o aumento no valor ótimo é mais acentuado até $\lambda=10$, decrescendo entre $(10,33]$ e atingindo o menor crescimento a partir de $\lambda=33$. Ao mesmo tempo, uma robustez elevada é atingida em $\lambda=10$; nesse caso, é possível afirmar que o modelo é $60 \%$ robusto. A partir desse ponto, a robustez aumenta lentamente numa transição de fases já evidenciada nos resultados computacionais do Capítulo 3. Para alcançar um

\footnotetext{
${ }^{2}$ Para considerar um nível de variabilidade $30 \%$ abaixo e acima da demanda nominal, como no caso robusto.
} 
modelo totalmente robusto, incorre-se num aumento do valor ótimo de $120 \%$. Por outro lado, na Figura 4.16, o aumento no valor ótimo é bastante lento até, aproximadamente, o budget $\Gamma=0,15 t$. Nesse ponto, atinge-se $15 \%$ de robustez a uma deterioração de $20 \%$ do valor ótimo. Os próximos budgets, entretanto, são bastante conservadores; por exemplo, para atingir uma robustez de $50 \%$, o valor ótimo aumenta $375 \%$. O aumento no valor ótimo segue de forma vertiginosa até $\Gamma=0,7 t$, a partir do qual é menos acentuado até $g=0,95$, voltando a acentuar-se no pior caso. Nesse cenário pessimista, $100 \%$ de robustez é alcançada por um aumento exorbitante de quase $800 \%$.

Dada essa análise, pode-se inferir que, em relação ao aumento no valor ótimo, o modelo $C L C d$ é competitivo com o modelo $M R 1$ apenas para budgets de incerteza pouco conservadores. Por exemplo, no modelo MR1, $11 \%$ de robustez é atingida a um custo $32 \%$ maior; no modelo $C L C d$, a mesma robustez resulta em um aumento do valor ótimo de apenas $11 \%$. Situação análoga pode ser verificada para alcançar uma robustez de $15 \%$. Para budgets de incerteza intermediários e conservadores, o modelo $C L C d$ é suplantado pelo modelo MR1, uma vez que MR1 consegue melhores valores de robustez com custos bem menores, i.e., possui melhores tradeoff's entre custo e robustez. Esses resultados confirmam os testes anteriores sobre o desempenho pobre do modelo de otimização robusta $C L C d$ com budgets pessimistas, ocasionado pela "super proteção" da restrição de atendimento da demanda (veja a simulação da Seção 4.3.2 desse capítulo).

Nivel de serviço. As Figuras 4.18 e 4.17 exibem o comportamento do nível de serviço à medida que a robustez aumenta, considerando: (a) apenas a demanda perdida (i.e., demanda atrasada no último período do horizonte de planejamento); e (b) a soma da demanda atrasada até o último período (composta pela demanda perdida em $T$ e a demanda atrasada em $\forall t, t \neq T$. Em relação ao nível de serviço, note que o modelo $C L C d$ tem vantagem sobre o modelo estocástico até, aproximadamente, $g=0,15$; nesses casos, o nível de serviço do modelo de otimização robusta é 100\%. Todavia, o modelo MR1 mantém ótimos níveis de serviço (maiores do que 93\%) para todos os valores de robustez, ao passo que o nível de serviço do modelo $C L C d$ deteriora-se razoavelmente quando a solução torna-se mais robusta. Analisando o nível de serviço referente ao total de demanda atrasada e perdida, a situação é ainda mais vantajosa para o modelo $M R 1$, que ainda mantém boas taxas de atendimento da demanda (cerca de 80\%) - em contrapartida ao modelo $C L C d$ - cujo nível de serviço cai drasticamente quando as demandas atrasadas são contabilizadas.

Tempo de execução. As Figuras 4.19 e 4.20 ilustram os tempos de execução do algoritmo branch-and-cut do CPLEX 11.0 para resolver até a prova de otimalidade os exemplares do modelo $M R 1$ e $C L C d$, respectivamente. Como já era de se esperar, o modelo MR1 é mais difícil de ser resolvido do que o modelo $C L C d$. Basicamente, tem-se 
duas razões que podem concorrer para aumentar a dificuldade do modelo $M R 1$ : o número de cenários e a parcela referente ao risco para $\lambda>0$ (para $\lambda=0$, tem-se o próprio modelo estocástico. De fato, a Tabela 4.9 mostra que o exemplar resolvido do modelo MR1 tem muito mais restrições e variáveis do que o modelo $C L C d$, o que compromete o seu tempo de execução. Além disso, o tempo de execução do modelo $M R 1$ parece aumentar, à medida que mais robustez é imposta ao modelo, o que não parece acontecer ao modelo $C L C d$. Na Figura 4.19, é possível observar que o tempo médio de resolução do modelo $M R 1$ foi 47 segundos, contra 0,36 segundos da versão $C L C d$. Considerando o exemplar resolvido, o modelo $C L C d$ é superior ao modelo $M R 1$, em termos de tempo de execução.

Assim, a partir dessa análise, é possível afirmar que o modelo $M R 1$ e o modelo $C L C d$ com budgets de incerteza pouco conservadores podem ser usados por tomadores de decisão aversos ao risco, pois ambos garantem a robustez do modelo a um custo relativamente baixo. Entretanto, se o nível de robustez desejado for muito elevado, budgets de incerteza mais conservadores precisam ser adotados, e o modelo $C L C d$ pode ser desvantajoso em relação ao modelo $M R 1$. Nesse caso, pode-se utilizar o modelo $M R 1 \mathrm{com}$ um fator de risco elevado.

Finalmente, cabe ressaltar que a comparação feita nessa seção é meramente ilustrativa. Ela tem como objetivo analisar as duas metodologias e ilustrar seus respectivos desempenhos, segundo três critérios básicos. Quais modelos ou técnicas são mais adequados em cada aplicação, é uma questão mais difícil de ser respondida, e depende do contexto da aplicação e do tomador de decisões. Mesmo a comparação apresentada aqui tem suas limitações, pois apenas um exemplar foi analisado, e considerando-se somente uma fonte de incerteza. Para recomendações mais gerais sobre quais metodologias são mais indicadas no tratamento do problema combinado $C L C 1$ sob incertezas, seria necessário realizar um planejamento de experimentos com diversos exemplares e com diferentes características, assim como considerar conjuntamente a presença de mais de uma fonte de incerteza.

\begin{tabular}{cccc}
\hline Modelo & Restrições & Variáveis lineares & Variáveis binárias \\
\hline CLCd & 688 & 896 & 24 \\
MR1 & 4516 & 6372 & 24 \\
\hline
\end{tabular}

Tabela 4.9: Número de variáveis de decisão e restrições de um exemplar dos modelos $C L C d$ e MR1.

\subsection{Considerações Finais}

Nesse capítulo, foram propostas formulações matemáticas baseadas em otimização robusta para o problema combinado de dimensionamento de lotes e corte de estoque $C L C 1$ 


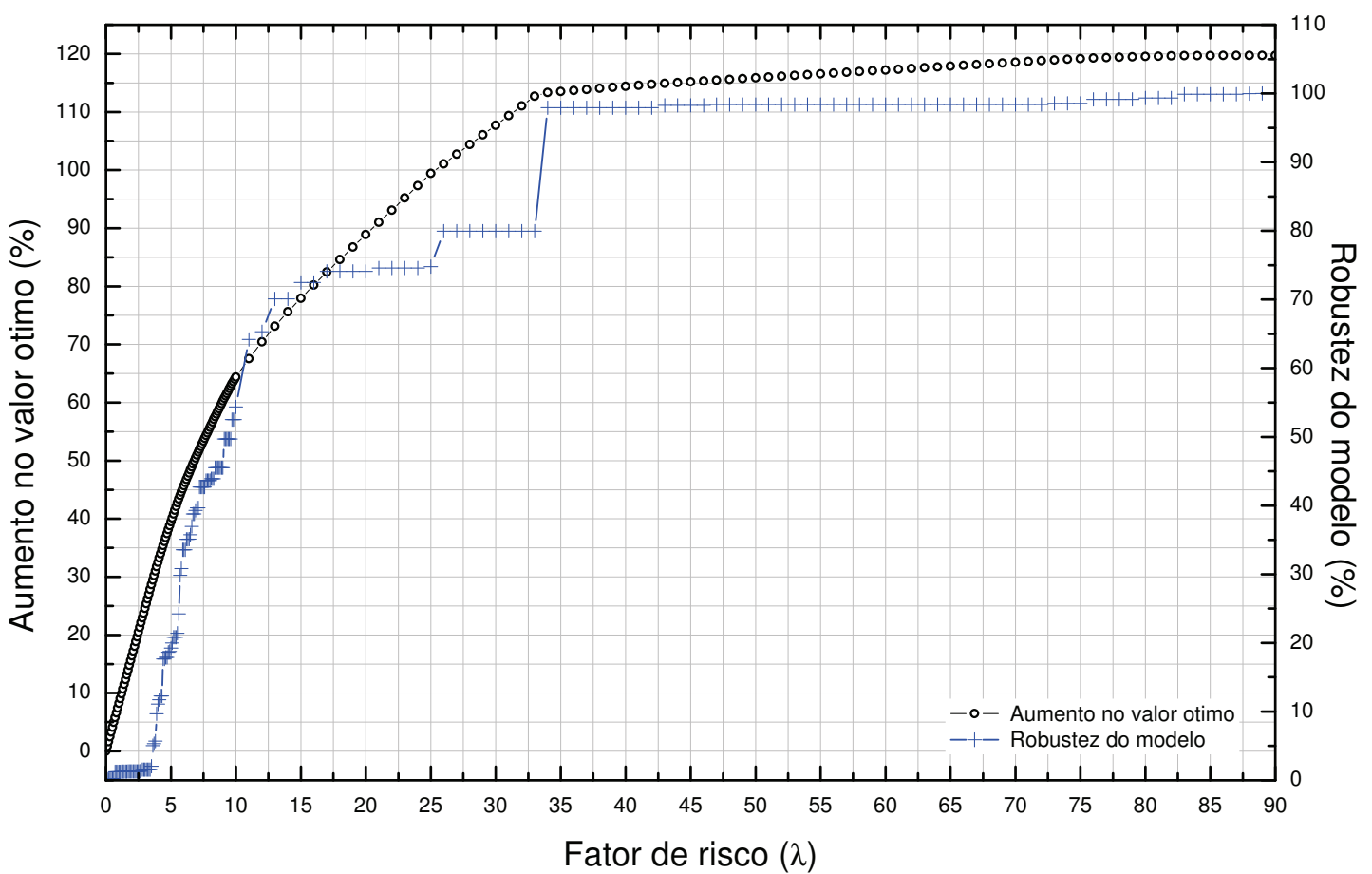

Figura 4.15: Aumento no valor ótimo da função objetivo e robustez do modelo MédiaRisco, considerando o fator de risco $(\lambda)$ entre 0 e 90.

em que custos e demandas são variáveis aleatórias pertencentes a um dado suporte. Foram exploradas técnicas conhecidas de otimização robusta e conjuntos de incerteza poliédricos mais simples, com a finalidade de preservar a tratabilidade computacional da abordagem robusta, uma vez que o problema nominal já é um problema de programação linear inteiramista NP-difícil. Um extenso conjunto de problemas-teste foi resolvido para analisar o desempenho das três formulações robustas propostas. Todos os exemplares foram resolvidos até a otimalidade em poucos segundos pelo software comercial CPLEX 11.0, devido ao relativamente baixo número de variáveis binárias envolvido nos exemplares resolvidos.

Quando a incerteza está apenas na função objetivo, os resultados computacionais confirmaram alguns insights já descritos em trabalhos da literatura, como: $(i)$ os valores ótimos são marginalmente afetados pelo crescimento do budgets de incerteza (Bertsimas e Sim, 2003, 2004); (ii) não há mudanças estruturais significativas nas soluções robustas, mesmo considerando-se todos os custos simultaneamente (Maturana et al., 2007). Em relação ao modelo com demanda incerta, confirmou-se que a seleção de um budget de incerteza representativo é crucial, pois uma escolha equivocada e/ou arbitrária pode resultar em soluções robustas extremante conservadores e com custos totais inaceitáveis. Entretanto, pode não ser uma tarefa simples selecionar budgets de incerteza representativos, mesmo para um especialista (gerente de produção, por exemplo), o que gera a 


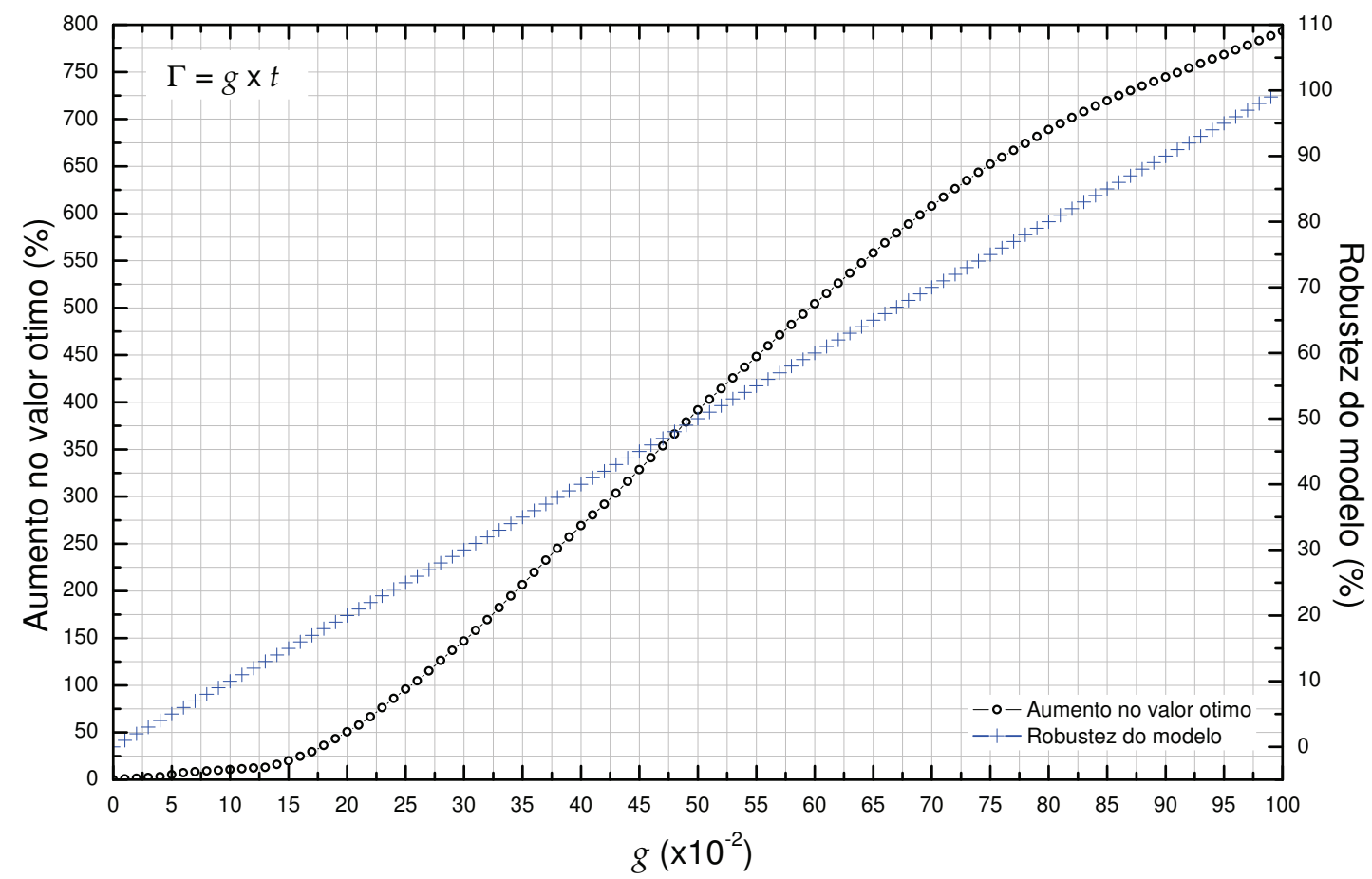

Figura 4.16: Aumento no valor ótimo e robustez do modelo de otimização robusta $C L C d$, considerando os budgets de incerteza $\Gamma_{i t}^{d}=g t$, com $g=0,01$ até 1 .

necessidade de resolver o problema várias vezes, considerando-se diferentes cenários para os budgets.

Nesse capítulo, foram consideradas duas medidas de desempenho para analisar as estratégias robustas $(R O)$ e de pior caso $(W C)$ : o nível de serviço e uma comparação relativa entre os valores ótimos de ambas as abordagens. Assim, há algumas situações importantes que devem ser analisadas: $(i)$ ambas as medidas de desempenho são superiores na estratégia $R O ;(i i)$ ambas as medidas de desempenho são superiores na estratégia $W C$; (iii) a estratégia $R O$ tem um desempenho inferior em termos de nível de serviço, mas o custo total é melhor. Note que é fácil escolher a melhor estratégia nos casos $(i)$ e (ii); basta utilizar a política cujas medidas de desempenho dominam as da outra estratégia. Entretanto, na situação (iii), não se tem uma estratégia totalmente dominada, o que dificulta a determinação da mais adequada. Nesse caso, deve-se analisar se a melhora no nível de serviço da estratégia $W C$ justifica o custo extra (à vezes, centenas de vezes mais elevado) para obtê-la. Em geral, baseado nos experimentos computacionais, recomenda-se adotar a estratégia de otimização robusta com budgets de incerteza menos conservadores, pois razoáveis níveis de serviço são obtidos a um custo total mais baixo.

Quando os parâmetros custos e demandas são considerados simultaneamente, as soluções robustas são similares às soluções do modelo em que apenas a demanda é incerta, 


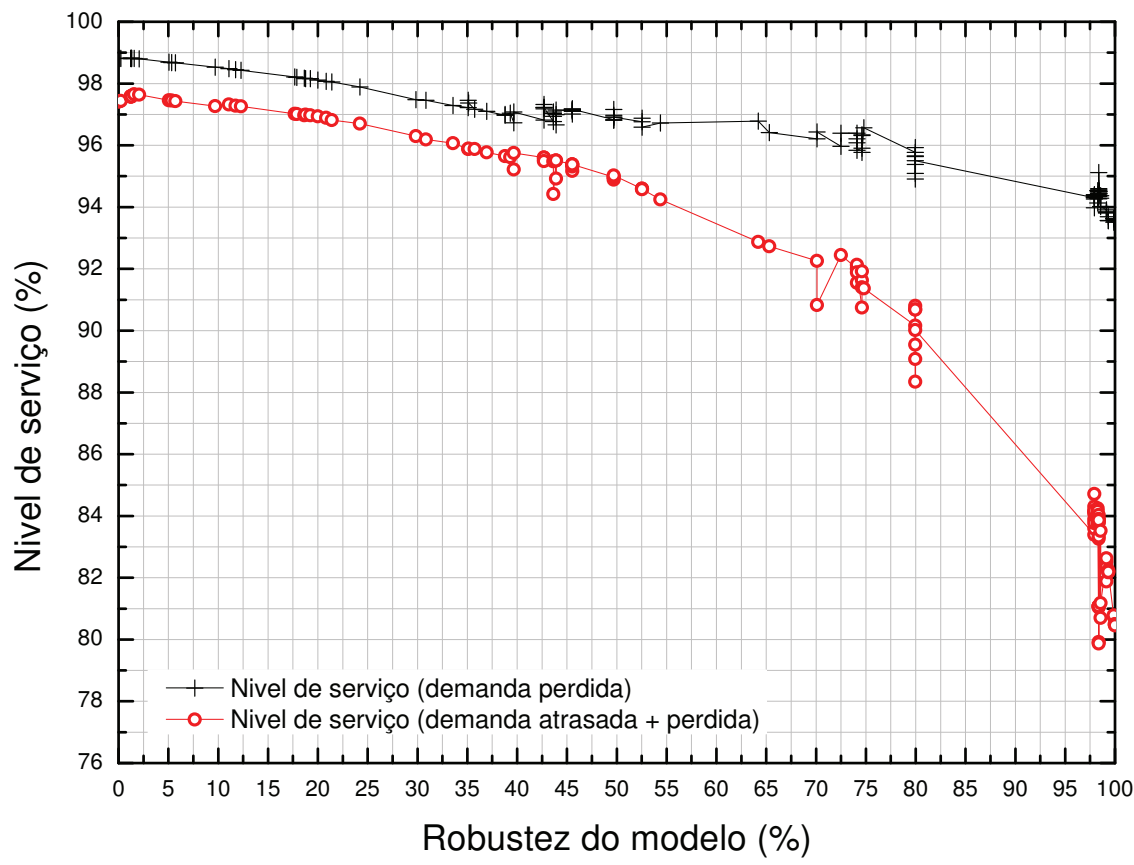

Figura 4.17: Nível de serviço do modelo $M R 1$ de acordo com o aumento da robustez.

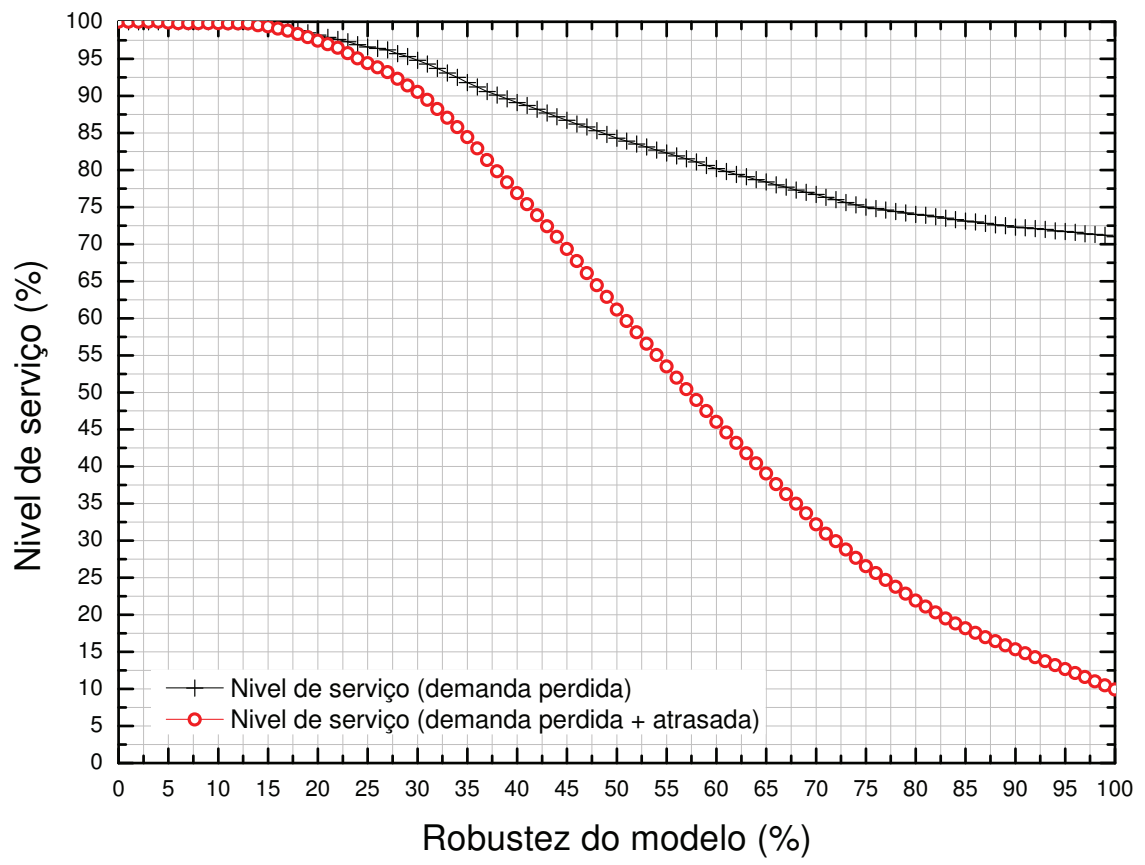

Figura 4.18: Nível de serviço do modelo de otimização robusta $C L C d$ de acordo com o aumento da robustez. 


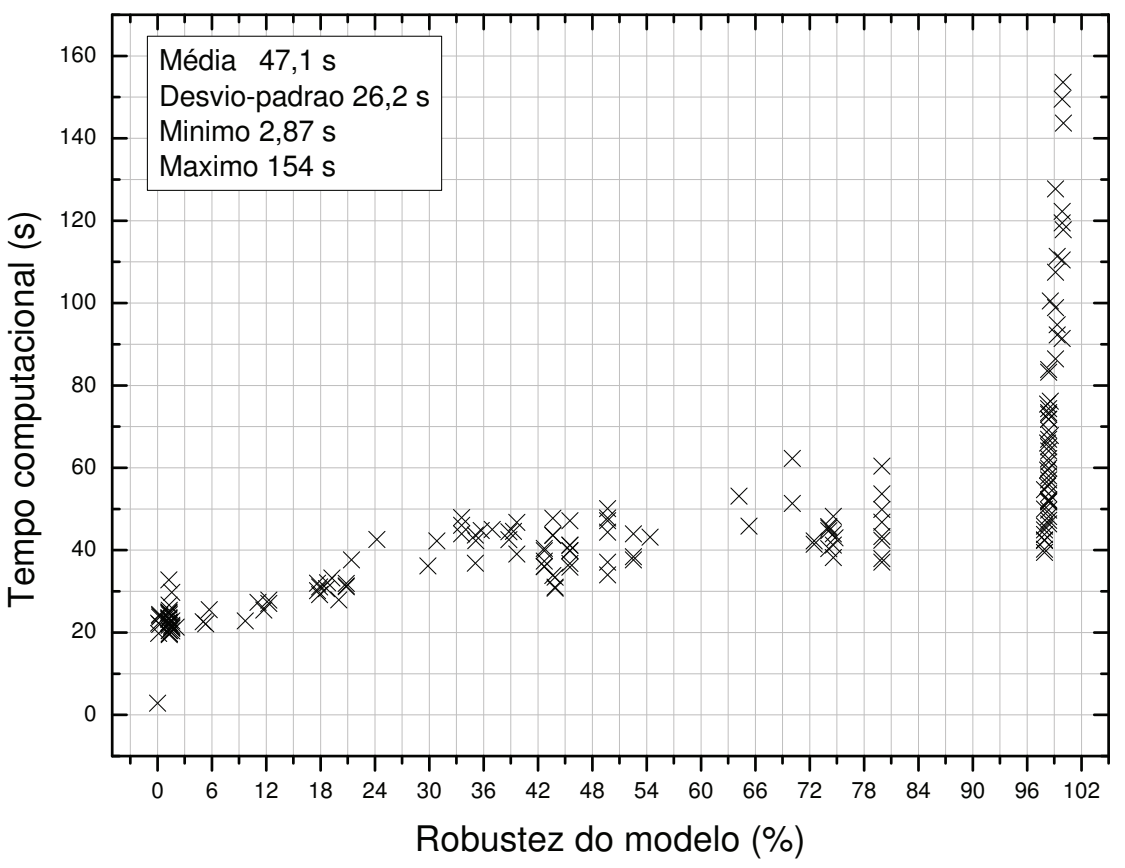

Figura 4.19: Tempo de execução computacional do modelo Média-Risco de acordo com o aumento da robustez.

mas os valores ótimos são mais deteriorados e os níveis de serviço tendem a diminuir para níveis de variabilidade mais elevados.

Ainda, o modelo de otimização robusta com demanda incerta $C L C d$ foi comparado a uma versão de programação estocástica robusta do tipo média-risco aplicada ao modelo $C L C 1$. Foram analisadas três importantes características: o aumento no valor ótimo da função objetivo, o nível de serviço e o tempo de execução computacional. Novamente, confirmou-se a importância de escolher budgtes de incerteza plausíveis, de modo a se obter um tradeoff aceitável entre custo e robustez. Verificou-se também que o modelo equivalente robusto é muito mais fácil de ser resolvido do que a versão estocástica robusta, o que é especialmente importante quando a versão determinística já apresenta dificuldade de resolução.

Convém ressaltar que a metodologia de otimização robusta deste capítulo poderia ter sido aplicada ao modelo $C L C 2$ de maneira similar ao que foi desenvolvido para o modelo CLC1. A dificuldade seria propor métodos de solução eficientes para resolver os modelos robustos na otimalidade e em tempos de execução aceitáveis na prática, principalmente se os exemplares dos modelos fossem de grande porte. Uma versão de otimização robusta com custos incertos do modelo CLC2 foi proposta no trabalho de Alem e Morabito (2008), no qual os autores confirmam vários insights obtidos na análise robusta do modelo $C L C 1 \mathrm{c}$. 


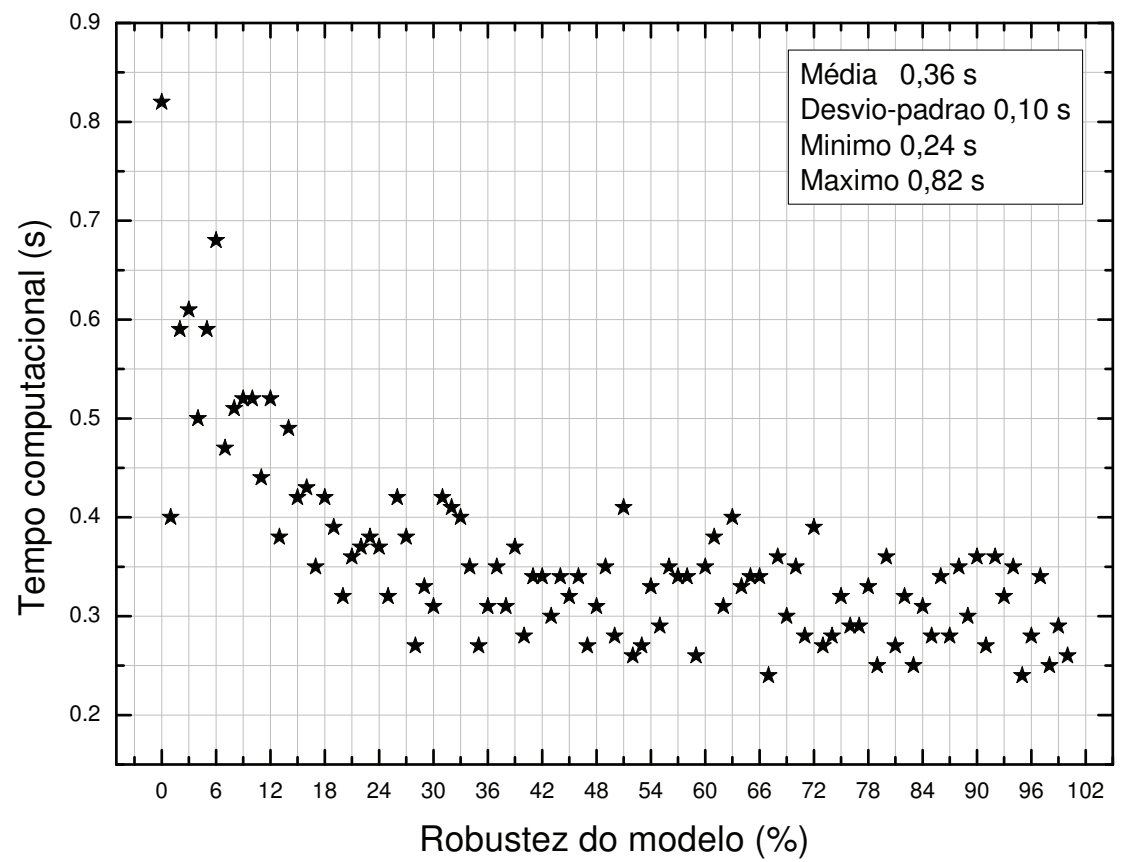

Figura 4.20: Tempo de execução computacional do modelo de otimização robusta $C L C d$ de acordo com o aumento da robustez.

Embora as reflexões feitas nesse capítulo refiram-se a um contexto particular de empresas moveleiras de pequeno porte, as mesmas podem ser úteis em outros contextos, especialmente quando decisões de corte de estoque e planejamento de produção e estocagem estão integradas. Ainda, há várias questões em aberto relativas a esse capítulo que devem ser melhor estudadas oportunamente; algumas delas encontram-se descritas na próxima seção.

\subsection{Pesquisas Futuras}

\subsubsection{Formulações Alternativas para o Modelo Nominal}

Em algumas situações, pode ser importante incorporar suposições e/ou restrições adicionais ao modelo nominal. Por exemplo: $(i)$ considerar tempos e/ou custos de preparação dependentes da sequência de produção; (ii) incluir restrições relacionadas a outros estágios de produção comumente encontrados em processos de manufatura similares (cortes secundários, furação, pintura, empacotamento, etc.); (iii) assegurar a integralidade das variáveis $Y_{j t}$ em situações de baixa demanda, por exemplo, e assim por diante. Em geral, quanto mais restrições são adicionadas ao modelo nominal, mais difícil será resolver 
exemplares de grande porte num tempo computacional plausível.

Para ilustrar isso, alguns exemplares das formulações robustas propostas nesse estudo foram resolvidas pelo método branch-and-cut do CPLEX $11.0 \mathrm{com}$ a imposição de integralidade sobre as variáveis de decisão $Y_{j t}$, considerando o conjunto padrão de dados de entrada. Como resultado, foram obtidas soluções com gaps de otimalidade apertados (em torno de 1\%) em poucos segundos, mas o algoritmo falha em encontrar e provar a otimalidade de uma solução mesmo após 1 hora de execução. Um tópico interessante de estudo é como o desempenho da metodologia de otimização robusta é afetado por essas soluções subótimas. Além disso, conforme o número de padrões de corte aumenta, os gaps de otimalidade aumentam e é necessário desenvolver métodos de solução mais elaborados, como algoritmos de geração de colunas, decomposição de Benders, branch-and-price, entre outros. O desenvolvimento de outros métodos exatos de solução para o problema é um tópico promissor de pesquisa futura.

\subsubsection{Restrições Agregadas}

Uma extensão natural desse estudo consiste em testar formulações alternativas para lidar com a questão de conservadorismo das restrições (4.26) e (4.28). Por exemplo, é possível agregar as restrições (4.26) em relação aos índices $i$ e $t$ :

$$
\sum_{i \in \mathcal{I}} \sum_{t \in \mathcal{T}} H_{i t} \geq \sum_{i \in \mathcal{I}} \sum_{t \in \mathcal{T}}\left[h_{i t}^{+}\left(\sum_{\tau=1}^{t}\left(X_{i \tau}-d_{i \tau}\right)+\lambda_{i t}^{d} \Gamma_{i t}^{d}+\sum_{\tau=1}^{t} \mu_{i \tau t}^{d}\right)+\mu_{i t}^{h+}\right]+\lambda^{h+} \Gamma^{h+}
$$

em que $\Gamma^{h+} \in\left[0,\left|J^{h+}\right|\right]$ evita formulações unicamente de pior caso. Entretanto, essa formulação pode gerar um plano de produção infactível, pois a mesma não assegura a satisfação das restrições de balanço de demanda para cada produto e período ao longo do horizonte de planejamento. Uma maneira de superar essa questão é gerar restrições adicionais que, juntamente com (4.35), poderiam manter a factibilidade da formulação original e ainda permitir o tradeoff entre robustez e custo, sem incorrer em situações apenas de pior caso. Restrições agregadoras foram usadas com sucesso na programação de colheita de uva para vinho (Bohle et al., 2009). A motivação dos autores foi evitar um único parâmetro incerto por restrição, que necessariamente resulta num budget de incerteza entre 0 e 1. 


\subsubsection{Adversarial Approach}

Outro tema interessante para pesquisa futura consiste em aplicar o método adversarial ao problema proposto nesse capítulo. Essa metodologia é baseada no método de planos de cortes, em que a cada iteração, apenas um subconjunto de incertezas é considerado no problema de otimização. Inicialmente, a abordagem adversarial foi proposta no trabalho de Bienstock e Ozbay (2008) para tratar problemas mais gerais de controle de estoque e problemas correlatos com demanda incerta. A motivação em utilizar tal método no problema apresentado nesse capítulo é desenvolver soluções menos conservadoras, especialmente quando diferentes fontes de incerteza afetam o problema nominal.

\subsubsection{Controle das Variáveis de Decisão}

Os decisores (gerentes de produção, por exemplo) podem selecionar o budget de incerteza mais apropriado de duas maneiras: $(i)$ de acordo com o limitante probabilístico de violação das restrições e $(i i)$ testando exaustivamente vários $\Gamma$ 's e escolhendo aquele que melhor se adapta ao seu particular interesse. Embora a opção (ii) não seja recomendada para problemas cujo tempo de execução é muito elevado, de um ponto de vista prático, é a opção mais interessante porque fornece um balanço de $\Gamma$ com outras decisões. Entretanto, como já observado na Seção 4.3.2, as soluções robustas mudam substancialmente com diferentes $\Gamma$ 's no caso de incerteza na demanda. Mais ainda, o decisor não tem muito controle sobre essas mudanças com a formulação $C L C d$.

Basedo nas questões destacadas, pode-se estender o modelo $C L C d$ de modo a agregar na mesma formulação diferentes budgets de incerteza, designando um índice $k \in \mathcal{K}=$ $\{1,2, \cdots, K\}$ para cada $\Gamma$, e um peso $\pi_{k}$ para o budget de incerteza $k$, de modo que $\pi_{k}>0$ e $\sum_{k} \pi_{k}=1$. Então, as variáveis de decisão podem ser agrupadas em estruturais e de controle, se puderem ser ajustadas ou não para cada cenário $k$, respectivamente. Além disso, é possível controlar as variáveis de decisão que dependem do cenário $k$, incluindo restrições de recurso, por exemplo: 


$$
\begin{array}{ll}
\text { Minimizar } & \bar{\psi}=\sum_{i \in \mathcal{I}} \sum_{t \in \mathcal{T}}\left(c_{i t} X_{i t}+s_{i t} Z_{i t}\right)+\sum_{i \in \mathcal{I}} \sum_{t \in \mathcal{T}} \sum_{k \in \mathcal{K}} \pi_{k} I_{i t k}+\sum_{j \in \mathcal{J}} \sum_{t \in \mathcal{T}} w_{j t} Y_{j t}+\sum_{t \in \mathcal{T}} o_{t} O_{t} \\
\text { Sujeito a: } \quad & I_{i t k} \geq h_{i t}^{+}\left(I_{i 0 k}^{+}+\sum_{\tau=1}^{t}\left(X_{i \tau}-\bar{d}_{i \tau}\right)+\lambda_{i t k}^{d} \Gamma_{i t k}^{d}+\sum_{\tau=1}^{t} \mu_{i \tau t k}^{d}\right), i \in \mathcal{I}, t \in \mathcal{T}, k \in \mathcal{K} \\
& I_{i t k} \geq h_{i t}^{-}\left(-I_{i 0 k}^{-}-\sum_{\tau=1}^{t}\left(X_{i \tau}-\bar{d}_{i \tau}\right)+\lambda_{i t k}^{d} \Gamma_{i t k}^{d}+\sum_{\tau=1}^{t} \mu_{i \tau t k}^{d}\right), i \in \mathcal{I}, t \in \mathcal{T}, k \in \mathcal{K} \\
& \sum_{\tau=1}^{t}\left(X_{i \tau}-\bar{d}_{i \tau}\right)+\lambda_{i t k}^{d} \Gamma_{i t k}^{d}+\sum_{\tau=1}^{t} \mu_{i \tau t k}^{d} \leq I_{i t}^{\text {max }}, i \in \mathcal{I}, t \in \mathcal{T}, k \in \mathcal{K} \\
& \lambda_{i t k}^{d}+\mu_{i \tau t k}^{d} \geq \hat{d}_{i \tau}, i \in \mathcal{I}, t \in \mathcal{T}, \forall \tau \leq t, k \in \mathcal{K} \\
& \lambda_{i t k}^{d} \geq 0, i \in \mathcal{I}, t \in \mathcal{T}, k \in \mathcal{K} \\
& \mu_{i \tau t k}^{d} \geq 0, i \in \mathcal{I}, t \in \mathcal{T}, \forall \tau \leq t, k \in \mathcal{K} .
\end{array}
$$

Note que na formulação (4.36), os níveis de produção, perda de material, preparação e hora-extra são independentes do budget de incerteza, mas é possível escrever outros modelos para que sejam dependentes. Além disso, pode-se assegurar que o desvio do custo de estoque/atraso para cada possível budget em relação ao valor esperado seja minimizado, incorporando-se o termo $\sum_{k \in \mathcal{K}} \pi_{k} \Delta_{k}$ na função objetivo, em que:

$$
\Delta_{k} \geq \sum_{i \in \mathcal{I}} \sum_{t \in \mathcal{T}} I_{i t k}-\sum_{i \in \mathcal{I}} \sum_{t \in \mathcal{T}} \sum_{k \in \mathcal{K}} I_{i t k^{\prime}}, k \in \mathcal{K}
$$

\subsubsection{Metodologia AARC}

Outra linha para pesquisa futura é a aplicação da metodologia AARC - affine adjustable robust counterpart (Ben-Tal et al., 2004) para lidar com a demanda incerta no problema $C L C$. Uma característica interessante dessa metodologia é que parte das variáveis de decisão podem ser determinadas depois da realização de um conjunto de variáveis aleatórias, similarmente às metodologias de programação estocástica de dois ou mais estágios, em que as variáveis de decisão estão categorizadas em wait-and-see ou here-and-now. Isso é particularmente promissor nesse contexto dinâmico e multiperíodo, uma vez que os níveis de estoque, atraso e hora-extra podem ser determinados depois que parte da demanda é realizada, enquanto os níveis de produção, frequência com que os padrões de corte são usados e preparação podem ser vistos como decisões de primeiro estágio. 


\section{Capítulo 5}

\section{Sumário e Contribuições}

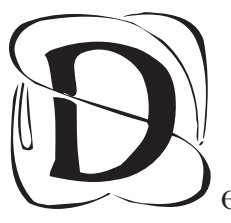

e maneira simplificada, o tema uno da presente Tese é a investigação de métodos de otimização para lidar com as incertezas em problemas específicos de planejamento da produção no contexto de fábricas de móveis de pequeno porte. A justificativa do tema torna-se desnecessária quando se admite a existência de fatores incertos em grande parte dos processos de manufatura e a improbabilidade de administrar esses fatores sem uma metodologia científica adequada. A motivação em estudar problemas combinados de dimensionamento de lotes e corte de estoque foi provocada por visitas técnicas a empresas moveleiras de pequeno porte típicas que enfrentam dificuldades de organizar o seu sistema produtivo e gerar bons planos de produção frente às incertezas.

Para alcançar êxito, foram estudados dois modelos de otimização que descrevem problemas combinados de dimensionamento de lotes e corte: o primeiro modelo - CLC1 - refere-se a uma simples extensão de um modelo conhecido da literatura; o segundo modelo - CLC2 - foi proposto nesta tese e descreve com mais detalhes restrições específicas do processo de produção de empresas moveleiras de pequeno porte. Ambos os problemas referem-se a problemas NP-difíceis. O modelo CLC2 foi analisado sob uma ótica determinística, de modo a prover seu desempenho em algumas situações específicas, utilizando-se o método branch-and-cut do CPLEX 11.0. Em seguida, analisou-se o desempenho de dois tipos de heurísticas relax-and-fix frente a seis classes de exemplares. A heurística relax-and-fix progressiva mostrou-se adequada para gerar limitantes superiores mais rapidamente do que a estratégia default do CPLEX 11.0. Entretanto, alguns exemplares obtiveram gaps elevados, sugerindo que pode valer a pena investigar versões mais eficientes ou métodos híbridos (heurísticas relax-and-fix inseridas em métodos branch-and-cut, por exemplo). 
O restante da tese é focado no desenvolvimento de modelos para os problemas combinados $C L C 1$ e $C L C 2$ sob incertezas. No Capítulo 3, foram desenvolvidos modelos de programação estocástica e programação estocástica robusta para o problema combinado CLC2, considerando demandas e tempos de preparação estocásticos. Outros parâmetros poderiam ter sido escolhidos e a análise seria similar. O modelo estocástico de dois estágios define uma matriz de recurso relativamente completa, fazendo com que seja sempre possível determinar um conjunto de variáveis de segundo estágio para quaisquer realizações das variáveis aleatórias. Os modelos Min-Max com arrependimento propostos consideram apenas os desvios mais desfavoráveis dos cenários e, ainda, não utilizam as informações das probabilidades dos diversos cenários. Os modelos estocásticos robustos do tipo média-risco consideram parcelas explícitas de aversão ao risco, enquanto os modelos com restrições de recurso adotam apenas restrições que visam estabilizar as decisões de segundo estágio. Ainda, foi mostrado que os modelos Média-Risco e com restrições de recurso são equivalentes. Os testes computacionais dos modelos estocásticos permitiram acessar o valor esperado de informação perfeita (EVPI) e o valor da solução estocástica $(V S S)$, para avaliar o impacto de utilizar os modelos estocásticos em detrimento a abordagens mais simples de valor esperado ou de aquisição de informação perfeita. Tamém foram propostas condições de suficiência para assegurar a factibilidade dos problemas $E E V$. Os testes com os modelos estocásticos robustos ilustraram o desempenho dos problemas à medida que a solução vai progressivamente se tornando robusta, muitas vezes às custas de deteriorações significativas nos valores ótimos das funções objetivos. Investigou-se também que o aumento do número de cenários no problema com recurso restrito pode tornar impraticável resolvê-lo sem métodos de solução eficientes. Ainda, vários insights e relações entre os modelos robustos foram apresentados e constituem-se contribuições no estudo e análise desses problemas. Baseado neste capítulo, está em fase de finalização o artigo "Risk-averse scenario-based models for furnishings production process", juntamente com o Prof. Reinaldo Morabito.

No Capítulo 4, foram desenvolvidos modelos de otimização robusta para o problema combinado de dimensionamento de lotes e corte de estoque $C L C 1$ na situação em que custos e demandas não são valores conhecidos com certeza. Similarmente ao Capítulo 3, outros parâmetros poderiam ter sido escolhidos e a análise seria semelhante. Diferentemente dos modelos baseados em programação estocástica (estocástica robusta), os modelos de otimização robusta consideram que os parâmetros incertos são variáveis aleatórias limitadas num suporte estabelecido a priori e otimizam o problema numa perspectiva de pior caso intervalar. Foram propostos três modelos robustos: $(i)$ com custos incertos; $(i i)$ com demandas incertas; e (iii) combinando os parâmetros custos e demandas incertos. Para determinar os modelos robustos equivalentes, foram utilizados conjuntos de incerteza poliédricos, que são relativamente conservadores, mas que não aumentam a complexidade 
do modelo. O desenvolvimento dos modelos robustos permitiu testar e analisar várias situações distintas e acessar os pontos fracos e fortes da metodologia, de forma independente para cada parâmetro incerto. Os resultados obtidos confirmaram algumas premissas já relacionadas em outros trabalhos da literatura e ainda indicaram que, em geral, não é preciso sacrificar muito a solução ótima para se obter uma solução robusta, quando apenas os custos variam. Comprovou-se também a importância de determinar budgets de incertezas representativos, de modo a evitar soluções muito conservadoras. Conclui-se também que o modelo que combina custos e demandas incertos não é tão conservador quando poderia ser, dada a situação de pior caso dos parâmetros. Ainda, o modelo de otimização robusta com demanda incerta $C L C d$ foi comparado a uma versão estocástica robusta do tipo média-risco do modelo $C L C 1$. Foram analisadas três importantes características: o aumento no valor ótimo da função objetivo, o nível de serviço e o tempo de execução computacional. Novamente, confirmou-se a importância de escolher budgtes de incerteza plausíveis, de modo a obter um tradeoff aceitável entre custo e robustez. Verificou-se também que o modelo equivalente robusto é muito mais fácil de ser resolvido do que a versão estocástica robusta, o que é especialmente importante quando a versão determinística já apresenta dificuldade de resolução. Este capítulo resultou no artigo "Production planning in furniture settings via robust optimization", juntamente com o Prof. Reinaldo Morabito (Alem e Morabito, 2011).

De forma geral, as duas metodologias empregadas nessa tese são valiosas para lidar com problemas de planejamento da produção sob incertezas. Cada uma apresenta diferenças marcantes em relação a maneira como a incerteza é representada, assim como suposições, simplificações e limitações próprias. O método mais adequado depende da aplicação específica e do tipo de dados que o decisor tem em mãos. Considerando a aplicação proposta nessa tese, é possível citar algumas vantagens e limitações de cada metodologia, que podem ser úteis também na escolha do método para tratar problemas similares e correlatos.

As principais vantagens dos modelos de programação estocástica (e programação estocástica robusta) identificadas nessa tese são:

i. Permitem modelar as variáveis aleatórias de forma bastante natural com a utilização de cenários, os quais podem ser gerados com diferentes estruturas e distribuições de probabilidade. Para o tomador de decisão, é importante ter a possibilidade de incorporar ou desconsiderar cenários com padrões totalmente distintos, uma vez que essa estratégia pode flexibilizar o plano de produção. Nessa tese, por exemplo, duas formas de geração de cenários foram utilizadas: a árvore de cenários e a simples enumeração de cenários equiprováveis. Porém, existem muitas outras formas, que podem originar cenários mais ou menos realistas. 
ii. A possibilidade de utilizar as variáveis de decisão de segundo estágio é interessante porque tais variáveis podem ser usadas para se proteger dos parâmetros estocásticos, ajustando e corrigindo decisões de primeiro estágio tomadas antes a realização das variáveis aleatórias. Além disso, é possível testar várias configurações para os conjuntos de variáveis de primeiro e segundo estágios.

iii O modelo Min-Max com arrependimento é bastante conservador, mas é uma alternativa interessante nas situações em que os cenários podem ser bem definidos, mas as respectivas probabilidades são difíceis de serem estimadas.

iv. O modelo de média-risco propicia uma análise multiobjetivo relativamente simples entre o custo da função objetivo e a robustez do modelo, uma vez que basta designar valores para o fator de risco $\lambda$ e analisar as soluções geradas. Dessa forma, os tomadores de decisão podem incorporar ao modelo a sua atitude em relação ao risco.

$v$. O modelo com recurso restrito é uma alternativa aos decisores com dificuldade para designar valores para $\lambda$. Nesse caso, basta decrementar uma tolerância inicial $\Delta_{\max }$ para gerar curvas de tradeoff entre o custo e a robustez do modelo.

vi. É possível inferir o ganho em se resolver os problemas estocásticos, em detrimento a utilizar abordagens de valor médio e de aquisição de informação perfeita. Assim, o tomador de decisão pode legitimar a sua escolha e ainda compará-la a estratégias mais comuns.

As principais limitações dos modelos de programação estocástica (e programação estocástica robusta) identificadas nessa tese são:

$i$ Como não existe uma fórmula geral para dividir as variáveis de primeiro e segundo estágios, cabe ao decisor escolher quais vão pertencer a um ou a outro grupo, o que pode provocar confusão e gerar modelos incoerentes. Por exemplo, no modelo $C L C 2$, definindo $Y_{j t}$ como primeiro estágio, automaticamente $Z_{j t}$ é primeiro estágio, pois não é possível cortar as placas e depois preparar as máquinas.

ii (a) Assumir uma distribuição de probabilidade para as variáveis aleatórias; (b) atribuir as probabilidades dos diferentes cenários; e (c) decidir sobre a estrutura da árvore de cenários e/ou a quantidade de cenários que devem ser considerados, são tarefas difíceis de serem realizadas, e requerem conhecimento profundo do problema a ser tratado e de técnicas especializadas de resolução. Por exemplo, caso fosse preciso construir uma árvore de cenários com restrições de antecipação, seria fundamental explorar formulações matemáticas mais convenientes para ser possível 
resolver o problema resultante. Se o decisor desejar utilizar 1000 cenários para aproximar a demanda estocástica do modelo $C L C$ 2, será necessário investigar métodos alternativos de solução deste modelo, por exemplo, baseado nas heurísticas relaxand-fix do Capítulo 2, que requerem menos esforço computacional que a estratégia default do CPLEX 11.0.

iii. Não é possível determinar, a priori, para qual valor de $\lambda$ o desvio $\Delta$ estabiliza-se, ou a a partir de qual tolerância $\Delta_{\max }$ não é mais possível assegurar robustez ao problema com restrição de recurso. Isso significa que o pior caso (100\% de robustez; caso mais conservador) só é conhecido depois de resolver os problemas robustos. Além disso, não se sabe o valor da tolerância inicial sem resolver o problema estocástico tradicional $(\lambda=0)$.

iv. Dependendo da escolha da estrutura da árvore de cenários e da quantidade de cenários necessários para representar as variáveis aleatórias, o modelo estocástico pode se tornar computacionalmente intratável. Por exemplo, no caso do modelo CLC2, não se obteria nenhuma solução factível utilizando a estratégia default do CPLEX 11.0 para o problema de recurso restrito com 400 cenários em 3600 segundos de execução do algoritmo no computador utilizado.

As principais vantagens dos modelos de otimização robusta identificadas nessa tese são:

i. Não é necessário inferir distribuições de probabilidade para modelar os parâmetros incertos, uma vez que os equivalentes robustos só requerem que as variáveis aleatórias sejam simétricas num intervalo pré-definido. Para o tomador de decisão, pode ser bastante natural inferir um limitante mínimo e máximo para a variação dos parâmetros incertos, baseados em dados históricos ou mesmo na sua experiência, em vez de determinar exatamente o valor da variável em cada cenário e a sua probabilidade de ocorrência.

ii. Caso uma descrição mais explícita dos parâmetros incertos esteja disponível, é possível incorporar as informações adicionais de forma relativamente simples, tanto na determinação do intervalo das variáveis aleatórias, quanto no nível de variabilidade do intervalo.

iii. Mesmo se os modelos determinísticos CLC1 ou CLC2 não assegurassem a factibilidade da solução para quaisquer conjuntos de dados de entrada, as respectivas versões de otimização robusta garantiriam a factibilidade do modelo em 100\% das vezes, a não ser que as variáveis aleatórias ultrapassassem os limites dos intervalos 
pré-estabelecidos. Nesse caso, ainda seria possível determinar a probabilidade de violação das restrições. Por outro lado, no caso da programação estocástica, é possível que algum cenário torne o problema infactível, a menos que se garanta, pelo menos, uma matriz de recurso relativamente completa. Isso pode ser facilmente verificado; basta impor $I_{i T}^{-}=0$, i.e., proibir atraso no último período $T$ do horizonte de planejamento. Provavelmente, o modelo de programação estocástica precise ser reescrito para penalizar as infactibilidades dos diferentes cenários, ao passo que o modelo de otimização robusta garante a factibilidade intervalar (desde que a versão nominal seja factível).

iv. É possível determinar facilmente a probabilidade de violação da meta do decisor, assim como das restrições que tenham parâmetros incertos. Para isso, basta ter em mãos o nível de violação $\left(\epsilon_{i}\right)$ e a cardinalidade do conjunto de incertezas, i.e., $\left|J_{i}\right|$.

v. O modelo de otimização robusta permite ao decisor incorporar a sua atitude em relação ao risco de forma muito simples, principalmente quando apenas a função objetivo é afetada pelas incertezas. Basta escolher um valor no intervalo $\left[0,\left|J_{i}\right|\right]$, considerando que os extremos 0 e $\left|J_{i}\right|$ representam decisões neutras e totalmente aversas ao risco, respectivamente. Assim, o decisor sabe exatamente qual é o pior caso teórico $\left(\Gamma=\left|J_{i}\right|\right)$, diferente do modelo de programação estocástica, que deve ser resolvido a priori para se saber o pior caso. Quando as demandas são incertas, não é mais natural determinar o budget de incerteza mais adequado, mas ainda é possível saber o pior caso teórico $(\Gamma=t)$, o que pode auxiliar o decisor a escolher budgets plausíveis.

vi. O modelo de otimização robusta é mais tratável computacionalmente, pois os equivalente robustos mantém a complexidade computacional do problema, diferentemente dos modelos estocásticos e estocásticos robustos. Porém, vale a ressalva de que conjuntos de incertezas não poliédricos (elipsoidais, por exemplo) podem tornar o equivalente robusto computacionalmente intratável.

As principais limitações dos modelos de otimização robusta identificadas nessa tese são:

i. O modelo de otimização robusta com poucos parâmetros incertos é, em geral, muito conservador, no sentido de que é preciso garantir quase o pior caso (modelo de Soyster) para assegurar uma pequena probabilidade de violação das restrições.

ii. É preciso converter restrições de igualdade em restrições de desigualdade para aplicar a técnica de otimização robusta; caso contrário, o equivalente robusto é trivialmente 
infactível. Por exemplo, a equação de balanceamento de estoque original do modelo $C L C 1$ teve que ser reescrita como duas restrições de desigualdade, uma envolvendo as variáveis de estoque, e a outra representando as variáveis de atraso, para permitir a aplicação da metodologia de otimização robusta.

iii. Algumas análises próprias da otimização robusta podem não fazer sentido se a solução ótima não é determinada. Por exemplo, as probabilidades de violação das restrições referem-se a uma situação na qual a solução ótima do problema robusto existe e pode ser determinada. Caso contrário, os limitantes probabilísticos podem ser inócuos. Analisar qual é o gap limite de aceitação de uma solução subótima, de tal forma que as análises robustas não sejam comprometidas, é um tema interessante para pesquisas futuras, mas ainda não se tem conhecimento de nada reportado na literatura.

iv. Não é simples determinar os equivalentes robustos quando várias fontes de incerteza afetam simultaneamente o problema. Nesse caso, é preciso interpretar as correlações entre os diversos parâmetros incertos, de modo que a versão robusta não seja muito conservadora.

v. A seleção dos budgets de incerteza no modelo de otimização robusta com demanda incerta não é trivial. De fato, no artigo pioneiro de Bertsimas e Thiele (2006), é proposto um procedimento para determinar os budgets ótimos. Entretanto, tal procedimento não pode ser aplicado em vários problemas práticos devido às suas suposições. A alternativa, então, é resolver vários exemplares com diferentes budgets, como foi feito nessa tese, o que demanda mais esforço computacional.

Convém ressaltar que a iniciativa de trabalhar com duas metodologias de otimização sob incertezas não é comum e é bastante trabalhosa, fazendo com que, inevitavelmente, o trabalho apresente limitações, como a ausência de métodos de solução eficientes para resolver exemplares mais complexos (determinísticos, estocásticos e robustos), e a falta de uma metodologia mais pragmática para a comparação entre as duas abordagens de otimização sob incertezas. Entretanto, acredita-se que as duas técnicas apresentadas nessa tese são valiosas para lidar com problemas de planejamento de produção sob incertezas, como, por exemplo, no caso de empresas moveleiras. Portanto, cabe ao decisor analisar as vantagens e limitações de cada metodologia no seu contexto específico, escolher uma delas ou trabalhar com ambas. Mesmo que os resultados aqui apresentados sejam referentes a uma aplicação particular na indústria de móveis, é possível estender o paradigma apresentado a outros problemas correlatos. 


\section{Apêndice A}

\section{Dados da Fábrica X}

\begin{tabular}{cccc}
\hline Padrão & Espessura $(\mathrm{mm})$ & Tempo (s) & Custo (u.m.) \\
\hline $1-0$ & 3 & 18,6 & 6,51 \\
$11-12$ & 9 & 62 & 12,85 \\
$13-20$ & 12 & 74,4 & 16,64 \\
$21-31$ & 15 & 93 & 19,82 \\
$21-31$ & 15 & 93 & 19,82 \\
$32-39$ & 20 & 124 & 26,88 \\
$40-42$ & 25 & 186 & 37,83 \\
$43-52$ & 3 & 18,6 & 6,51 \\
$53-56$ & 9 & 62 & 12,85 \\
$57-63$ & 12 & 74,4 & 16,64 \\
$64-69$ & 15 & 93 & 19,82 \\
$72-79$ & 20 & 124 & 26,88 \\
$80-81$ & 25 & 186 & 37,83 \\
\hline
\end{tabular}

Tabela A.1: Detalhamento dos padrões de corte utilizados: espessura, tempo de processamento e custo unitário. 


\begin{tabular}{|c|c|c|c|c|c|c|}
\hline & & Dados & & & $r_{p i}$ & \\
\hline Peça & $L(\mathrm{~mm})$ & $C(\mathrm{~mm})$ & $E(\mathrm{~mm})$ & $\mathrm{a} 5 \mathrm{p}$ & $\mathrm{cmd}$ & crd \\
\hline 1 & 565 & 2500 & 3 & 6 & 0 & 0 \\
\hline 2 & 453 & 647 & 3 & 4 & 6 & 0 \\
\hline 3 & 454 & 710 & 3 & 2 & 0 & 0 \\
\hline 4 & 454 & 454 & 3 & 2 & 0 & 0 \\
\hline 5 & 454 & 1080 & 3 & 5 & 0 & 0 \\
\hline 6 & 454 & 530 & 3 & 5 & 0 & 0 \\
\hline 7 & 500 & 1050 & 3 & 1 & 0 & 0 \\
\hline 8 & 215 & 483 & 3 & 2 & 0 & 0 \\
\hline 9 & 530 & 1062 & 3 & 0 & 2 & 0 \\
\hline 10 & 530 & 710 & 3 & 0 & 2 & 0 \\
\hline 11 & 377 & 388 & 3 & 0 & 0 & 3 \\
\hline 12 & 383 & 410 & 3 & 0 & 0 & 2 \\
\hline 13 & 213 & 445 & 3 & 0 & 0 & 4 \\
\hline 14 & 510 & 450 & 9 & 1 & 0 & 0 \\
\hline 15 & 50 & 630 & 9 & 0 & 0 & 3 \\
\hline 16 & 50 & 433 & 9 & 0 & 0 & 2 \\
\hline 17 & 50 & 295 & 9 & 0 & 0 & 2 \\
\hline 18 & 180 & 454 & 12 & 8 & 6 & 0 \\
\hline 19 & 180 & 635 & 12 & 4 & 3 & 0 \\
\hline 20 & 135 & 454 & 12 & 0 & 4 & 0 \\
\hline 21 & 50 & 635 & 12 & 0 & 1 & 0 \\
\hline 22 & 135 & 635 & 12 & 0 & 2 & 0 \\
\hline 23 & 65 & 440 & 12 & 0 & 2 & 0 \\
\hline 24 & 110 & 390 & 12 & 0 & 0 & 6 \\
\hline 25 & 110 & 370 & 12 & 0 & 0 & 3 \\
\hline 26 & 452 & 1049 & 15 & 5 & 0 & 0 \\
\hline 27 & 452 & 499 & 15 & 5 & 0 & 0 \\
\hline 28 & 429 & 452 & 15 & 2 & 0 & 0 \\
\hline 29 & 535 & 1050 & 15 & 2 & 0 & 0 \\
\hline 30 & 500 & 535 & 15 & 2 & 0 & 0 \\
\hline 31 & 430 & 535 & 15 & 2 & 0 & 0 \\
\hline 32 & 212 & 700 & 15 & 4 & 3 & 0 \\
\hline 33 & 75 & 700 & 15 & 0 & 1 & 0 \\
\hline 34 & 163 & 700 & 15 & 0 & 2 & 0 \\
\hline 35 & 440 & 600 & 15 & 0 & 0 & 2 \\
\hline 36 & 570 & 970 & 15 & 0 & 2 & 0 \\
\hline 37 & 132 & 450 & 15 & 0 & 0 & 3 \\
\hline 38 & 60 & 2500 & 20 & 12 & 0 & 0 \\
\hline 39 & 60 & 445 & 20 & 12 & 0 & 0 \\
\hline 40 & 40 & 445 & 20 & 26 & 0 & 0 \\
\hline 41 & 60 & 490 & 20 & 1 & 0 & 0 \\
\hline 42 & 60 & 500 & 20 & 3 & 0 & 0 \\
\hline 43 & 60 & 1050 & 20 & 5 & 0 & 0 \\
\hline 44 & 60 & 430 & 20 & 3 & 0 & 0 \\
\hline 45 & 60 & 440 & 20 & 4 & 0 & 0 \\
\hline 46 & 60 & 1060 & 20 & 2 & 0 & 0 \\
\hline 47 & 60 & 430 & 25 & 2 & 0 & 0 \\
\hline 48 & 60 & 500 & 25 & 4 & 0 & 0 \\
\hline 49 & 60 & 1050 & 25 & 4 & 0 & 0 \\
\hline
\end{tabular}

Tabela A.2: Detalhamento das 49 peças utilizadas na composição dos 3 produtos considerados: armário de 5 portas, cômoda e criado-mudo. As peças são caracterizadas pelo comprimento $C$, largura $(L)$ e espessura $(E)$. 


\begin{tabular}{c|cccccccc|c}
\hline Produto/Período & 1 & 2 & 3 & 4 & 5 & 6 & 7 & 8 & $I_{i t}^{\max }$ \\
\hline a5p & 121 & 192 & 104 & 138 & 95 & 56 & 54 & 75 & 120 \\
cmd & 171 & 182 & 190 & 73 & 54 & 12 & 106 & 61 & 250 \\
crd & 146 & 198 & 118 & 100 & 199 & 191 & 116 & 189 & 150 \\
\hline
\end{tabular}

Tabela A.3: Demandas nominais $\left(d_{i t}\right)$ e estoques máximos permitidos $\left(I_{i t}^{\max }\right)$ do exemplar 1 da Seção 2.5.2 do Capítulo 2.

\begin{tabular}{ccccccc}
\hline Período/Produto & a5p & cmd & crd & a5p-1 & cmd-1 & crd-1 \\
\hline 1 & 141 & 6 & 174 & 153 & 171 & 7 \\
2 & 125 & 142 & 70 & 179 & 75 & 161 \\
3 & 136 & 156 & 152 & 154 & 196 & 8 \\
4 & 141 & 93 & 155 & 143 & 4 & 99 \\
5 & 172 & 2 & 149 & 159 & 57 & 7 \\
6 & 132 & 176 & 164 & 35 & 108 & 49 \\
7 & 157 & 3 & 166 & 170 & 179 & 101 \\
8 & 107 & 168 & 48 & 128 & 104 & 49 \\
9 & 71 & 165 & 7 & 119 & 200 & 135 \\
10 & 105 & 141 & 29 & 175 & 155 & 12 \\
11 & 87 & 75 & 179 & 134 & 161 & 183 \\
12 & 179 & 165 & 153 & 73 & 15 & 18 \\
13 & 21 & 179 & 52 & 126 & 122 & 8 \\
14 & 65 & 65 & 22 & 108 & 24 & 60 \\
15 & 168 & 59 & 135 & 7 & 40 & 177 \\
16 & 156 & 41 & 134 & 23 & 13 & 102 \\
\hline \hline it & 120 & 250 & 150 & 125 & 206 & 131 \\
\hline \hline
\end{tabular}

Tabela A.4: Demandas nominais $\left(d_{i t}\right)$ e estoques máximos permitidos $\left(I_{i t}^{\max }\right)$ utilizadas nos exemplares 2, 3 e 4 da Seção 2.5.2 do Capítulo 2. 


\begin{tabular}{|c|c|c|c|c|c|c|c|c|c|c|c|c|c|c|c|}
\hline Peça/Padrão & 1 & 2 & 3 & 4 & 5 & 6 & 7 & 8 & 9 & 10 & 11 & 12 & 13 & 14 & 15 \\
\hline 1 & 3 & 0 & 0 & 0 & 0 & 0 & 0 & 0 & 0 & 0 & 0 & 0 & 0 & 0 & 0 \\
\hline 2 & 0 & 0 & 0 & 0 & 16 & 0 & 0 & 0 & 0 & 0 & 0 & 0 & 0 & 0 & 0 \\
\hline 3 & 0 & 0 & 0 & 0 & 0 & 6 & 12 & 0 & 0 & 0 & 0 & 0 & 0 & 0 & 0 \\
\hline 4 & 0 & 0 & 0 & 24 & 0 & 0 & 0 & 0 & 0 & 0 & 0 & 0 & 0 & 0 & 0 \\
\hline 5 & 0 & 8 & 0 & 0 & 0 & 0 & 0 & 0 & 0 & 0 & 0 & 0 & 0 & 0 & 0 \\
\hline 6 & 0 & 4 & 20 & 0 & 0 & 0 & 4 & 0 & 0 & 0 & 0 & 0 & 0 & 0 & 0 \\
\hline 7 & 0 & 0 & 0 & 0 & 0 & 5 & 0 & 0 & 0 & 0 & 0 & 0 & 0 & 0 & 0 \\
\hline 8 & 3 & 0 & 0 & 0 & 0 & 2 & 0 & 0 & 0 & 0 & 0 & 0 & 0 & 0 & 0 \\
\hline 9 & 0 & 0 & 0 & 0 & 0 & 0 & 0 & 5 & 0 & 0 & 0 & 0 & 0 & 0 & 0 \\
\hline 10 & 0 & 0 & 0 & 0 & 0 & 0 & 0 & 5 & 0 & 0 & 0 & 0 & 0 & 0 & 0 \\
\hline 11 & 0 & 0 & 0 & 0 & 0 & 0 & 0 & 0 & 14 & 0 & 0 & 0 & 0 & 0 & 0 \\
\hline 12 & 0 & 0 & 0 & 0 & 0 & 0 & 0 & 0 & 6 & 24 & 0 & 0 & 0 & 0 & 0 \\
\hline 13 & 0 & 0 & 0 & 0 & 0 & 0 & 0 & 0 & 18 & 9 & 0 & 0 & 0 & 0 & 0 \\
\hline 14 & 0 & 0 & 0 & 0 & 0 & 0 & 0 & 0 & 0 & 0 & 20 & 0 & 0 & 0 & 0 \\
\hline 15 & 0 & 0 & 0 & 0 & 0 & 0 & 0 & 0 & 0 & 0 & 3 & 74 & 0 & 0 & 0 \\
\hline 16 & 0 & 0 & 0 & 0 & 0 & 0 & 0 & 0 & 0 & 0 & 6 & 49 & 0 & 0 & 0 \\
\hline 17 & 0 & 0 & 0 & 0 & 0 & 0 & 0 & 0 & 0 & 0 & 3 & 74 & 0 & 0 & 0 \\
\hline 18 & 0 & 0 & 0 & 0 & 0 & 0 & 0 & 0 & 0 & 0 & 0 & 0 & 54 & 4 & 4 \\
\hline 19 & 0 & 0 & 0 & 0 & 0 & 0 & 0 & 0 & 0 & 0 & 0 & 0 & 0 & 36 & 4 \\
\hline 20 & 0 & 0 & 0 & 0 & 0 & 0 & 0 & 0 & 0 & 0 & 0 & 0 & 6 & 4 & 0 \\
\hline 21 & 0 & 0 & 0 & 0 & 0 & 0 & 0 & 0 & 0 & 0 & 0 & 0 & 0 & 0 & 120 \\
\hline 22 & 0 & 0 & 0 & 0 & 0 & 0 & 0 & 0 & 0 & 0 & 0 & 0 & 0 & 0 & 0 \\
\hline 23 & 0 & 0 & 0 & 0 & 0 & 0 & 0 & 0 & 0 & 0 & 0 & 0 & 0 & 0 & 0 \\
\hline 24 & 0 & 0 & 0 & 0 & 0 & 0 & 0 & 0 & 0 & 0 & 0 & 0 & 0 & 0 & 0 \\
\hline 25 & 0 & 0 & 0 & 0 & 0 & 0 & 0 & 0 & 0 & 0 & 0 & 0 & 0 & 0 & 0 \\
\hline 26 & 0 & 0 & 0 & 0 & 0 & 0 & 0 & 0 & 0 & 0 & 0 & 0 & 0 & 0 & 0 \\
\hline 27 & 0 & 0 & 0 & 0 & 0 & 0 & 0 & 0 & 0 & 0 & 0 & 0 & 0 & 0 & 0 \\
\hline 28 & 0 & 0 & 0 & 0 & 0 & 0 & 0 & 0 & 0 & 0 & 0 & 0 & 0 & 0 & 0 \\
\hline 29 & 0 & 0 & 0 & 0 & 0 & 0 & 0 & 0 & 0 & 0 & 0 & 0 & 0 & 0 & 0 \\
\hline 30 & 0 & 0 & 0 & 0 & 0 & 0 & 0 & 0 & 0 & 0 & 0 & 0 & 0 & 0 & 0 \\
\hline 31 & 0 & 0 & 0 & 0 & 0 & 0 & 0 & 0 & 0 & 0 & 0 & 0 & 0 & 0 & 0 \\
\hline 32 & 0 & 0 & 0 & 0 & 0 & 0 & 0 & 0 & 0 & 0 & 0 & 0 & 0 & 0 & 0 \\
\hline 33 & 0 & 0 & 0 & 0 & 0 & 0 & 0 & 0 & 0 & 0 & 0 & 0 & 0 & 0 & 0 \\
\hline 34 & 0 & 0 & 0 & 0 & 0 & 0 & 0 & 0 & 0 & 0 & 0 & 0 & 0 & 0 & 0 \\
\hline 35 & 0 & 0 & 0 & 0 & 0 & 0 & 0 & 0 & 0 & 0 & 0 & 0 & 0 & 0 & 0 \\
\hline 36 & 0 & 0 & 0 & 0 & 0 & 0 & 0 & 0 & 0 & 0 & 0 & 0 & 0 & 0 & 0 \\
\hline 37 & 0 & 0 & 0 & 0 & 0 & 0 & 0 & 0 & 0 & 0 & 0 & 0 & 0 & 0 & 0 \\
\hline 38 & 0 & 0 & 0 & 0 & 0 & 0 & 0 & 0 & 0 & 0 & 0 & 0 & 0 & 0 & 0 \\
\hline 39 & 0 & 0 & 0 & 0 & 0 & 0 & 0 & 0 & 0 & 0 & 0 & 0 & 0 & 0 & 0 \\
\hline 40 & 0 & 0 & 0 & 0 & 0 & 0 & 0 & 0 & 0 & 0 & 0 & 0 & 0 & 0 & 0 \\
\hline 41 & 0 & 0 & 0 & 0 & 0 & 0 & 0 & 0 & 0 & 0 & 0 & 0 & 0 & 0 & 0 \\
\hline 42 & 0 & 0 & 0 & 0 & 0 & 0 & 0 & 0 & 0 & 0 & 0 & 0 & 0 & 0 & 0 \\
\hline 43 & 0 & 0 & 0 & 0 & 0 & 0 & 0 & 0 & 0 & 0 & 0 & 0 & 0 & 0 & 0 \\
\hline 44 & 0 & 0 & 0 & 0 & 0 & 0 & 0 & 0 & 0 & 0 & 0 & 0 & 0 & 0 & 0 \\
\hline 45 & 0 & 0 & 0 & 0 & 0 & 0 & 0 & 0 & 0 & 0 & 0 & 0 & 0 & 0 & 0 \\
\hline 46 & 0 & 0 & 0 & 0 & 0 & 0 & 0 & 0 & 0 & 0 & 0 & 0 & 0 & 0 & 0 \\
\hline 47 & 0 & 0 & 0 & 0 & 0 & 0 & 0 & 0 & 0 & 0 & 0 & 0 & 0 & 0 & 0 \\
\hline 48 & 0 & 0 & 0 & 0 & 0 & 0 & 0 & 0 & 0 & 0 & 0 & 0 & 0 & 0 & 0 \\
\hline 49 & 0 & 0 & 0 & 0 & 0 & 0 & 0 & 0 & 0 & 0 & 0 & 0 & 0 & 0 & 0 \\
\hline
\end{tabular}

Tabela A.5: Padrões de corte mais frequentes disponibilizados pela Fábrica X (1-15). 


\begin{tabular}{|c|c|c|c|c|c|c|c|c|c|c|c|c|c|c|}
\hline Peça/Padrão & 16 & 17 & 18 & 19 & 20 & 21 & 22 & 23 & 24 & 25 & 26 & 27 & 28 & 29 \\
\hline 1 & 0 & 0 & 0 & 0 & 0 & 0 & 0 & 0 & 0 & 0 & 0 & 0 & 0 & 0 \\
\hline 2 & 0 & 0 & 0 & 0 & 0 & 0 & 0 & 0 & 0 & 0 & 0 & 0 & 0 & 0 \\
\hline 3 & 0 & 0 & 0 & 0 & 0 & 0 & 0 & 0 & 0 & 0 & 0 & 0 & 0 & 0 \\
\hline 4 & 0 & 0 & 0 & 0 & 0 & 0 & 0 & 0 & 0 & 0 & 0 & 0 & 0 & 0 \\
\hline 5 & 0 & 0 & 0 & 0 & 0 & 0 & 0 & 0 & 0 & 0 & 0 & 0 & 0 & 0 \\
\hline 6 & 0 & 0 & 0 & 0 & 0 & 0 & 0 & 0 & 0 & 0 & 0 & 0 & 0 & 0 \\
\hline 7 & 0 & 0 & 0 & 0 & 0 & 0 & 0 & 0 & 0 & 0 & 0 & 0 & 0 & 0 \\
\hline 8 & 0 & 0 & 0 & 0 & 0 & 0 & 0 & 0 & 0 & 0 & 0 & 0 & 0 & 0 \\
\hline 9 & 0 & 0 & 0 & 0 & 0 & 0 & 0 & 0 & 0 & 0 & 0 & 0 & 0 & 0 \\
\hline 10 & 0 & 0 & 0 & 0 & 0 & 0 & 0 & 0 & 0 & 0 & 0 & 0 & 0 & 0 \\
\hline 11 & 0 & 0 & 0 & 0 & 0 & 0 & 0 & 0 & 0 & 0 & 0 & 0 & 0 & 0 \\
\hline 12 & 0 & 0 & 0 & 0 & 0 & 0 & 0 & 0 & 0 & 0 & 0 & 0 & 0 & 0 \\
\hline 13 & 0 & 0 & 0 & 0 & 0 & 0 & 0 & 0 & 0 & 0 & 0 & 0 & 0 & 0 \\
\hline 14 & 0 & 0 & 0 & 0 & 0 & 0 & 0 & 0 & 0 & 0 & 0 & 0 & 0 & 0 \\
\hline 15 & 0 & 0 & 0 & 0 & 0 & 0 & 0 & 0 & 0 & 0 & 0 & 0 & 0 & 0 \\
\hline 16 & 0 & 0 & 0 & 0 & 0 & 0 & 0 & 0 & 0 & 0 & 0 & 0 & 0 & 0 \\
\hline 17 & 0 & 0 & 0 & 0 & 0 & 0 & 0 & 0 & 0 & 0 & 0 & 0 & 0 & 0 \\
\hline 18 & 4 & 8 & 0 & 0 & 0 & 0 & 0 & 0 & 0 & 0 & 0 & 0 & 0 & 0 \\
\hline 19 & 0 & 0 & 0 & 0 & 0 & 0 & 0 & 0 & 0 & 0 & 0 & 0 & 0 & 0 \\
\hline 20 & 0 & 4 & 78 & 0 & 0 & 0 & 0 & 0 & 0 & 0 & 0 & 0 & 0 & 0 \\
\hline 21 & 0 & 0 & 0 & 0 & 0 & 0 & 0 & 0 & 0 & 0 & 0 & 0 & 0 & 0 \\
\hline 22 & 52 & 0 & 0 & 0 & 0 & 0 & 0 & 0 & 0 & 0 & 0 & 0 & 0 & 0 \\
\hline 23 & 0 & 130 & 0 & 0 & 0 & 0 & 0 & 0 & 0 & 0 & 0 & 0 & 0 & 0 \\
\hline 24 & 0 & 0 & 0 & 96 & 4 & 0 & 0 & 0 & 0 & 0 & 0 & 0 & 0 & 0 \\
\hline 25 & 0 & 0 & 0 & 16 & 112 & 0 & 0 & 0 & 0 & 0 & 0 & 0 & 0 & 0 \\
\hline 26 & 0 & 0 & 0 & 0 & 0 & 8 & 0 & 0 & 0 & 0 & 0 & 0 & 0 & 0 \\
\hline 27 & 0 & 0 & 0 & 0 & 0 & 4 & 20 & 0 & 0 & 0 & 0 & 0 & 0 & 0 \\
\hline 28 & 0 & 0 & 0 & 0 & 0 & 0 & 0 & 0 & 0 & 24 & 0 & 0 & 0 & 0 \\
\hline 29 & 0 & 0 & 0 & 0 & 0 & 0 & 0 & 6 & 0 & 0 & 0 & 0 & 0 & 0 \\
\hline 30 & 0 & 0 & 0 & 0 & 0 & 0 & 0 & 3 & 6 & 0 & 0 & 0 & 0 & 0 \\
\hline 31 & 0 & 0 & 0 & 0 & 0 & 0 & 0 & 0 & 12 & 0 & 0 & 0 & 0 & 0 \\
\hline 32 & 0 & 0 & 0 & 0 & 0 & 0 & 2 & 3 & 3 & 0 & 30 & 8 & 2 & 28 \\
\hline 33 & 0 & 0 & 0 & 0 & 0 & 0 & 0 & 0 & 0 & 0 & 0 & 3 & 0 & 0 \\
\hline 34 & 0 & 0 & 0 & 0 & 0 & 0 & 0 & 0 & 0 & 0 & 0 & 0 & 38 & 4 \\
\hline 35 & 0 & 0 & 0 & 0 & 0 & 0 & 0 & 0 & 0 & 0 & 0 & 0 & 1 & 1 \\
\hline 36 & 0 & 0 & 0 & 0 & 0 & 0 & 0 & 0 & 0 & 0 & 0 & 6 & 0 & 0 \\
\hline 37 & 0 & 0 & 0 & 0 & 0 & 0 & 0 & 0 & 0 & 0 & 0 & 0 & 0 & 0 \\
\hline 38 & 0 & 0 & 0 & 0 & 0 & 0 & 0 & 0 & 0 & 0 & 0 & 0 & 0 & 0 \\
\hline 39 & 0 & 0 & 0 & 0 & 0 & 0 & 0 & 0 & 0 & 0 & 0 & 0 & 0 & 0 \\
\hline 40 & 0 & 0 & 0 & 0 & 0 & 0 & 0 & 0 & 0 & 0 & 0 & 0 & 0 & 0 \\
\hline 41 & 0 & 0 & 0 & 0 & 0 & 0 & 0 & 0 & 0 & 0 & 0 & 0 & 0 & 0 \\
\hline 42 & 0 & 0 & 0 & 0 & 0 & 0 & 0 & 0 & 0 & 0 & 0 & 0 & 0 & 0 \\
\hline 43 & 0 & 0 & 0 & 0 & 0 & 0 & 0 & 0 & 0 & 0 & 0 & 0 & 0 & 0 \\
\hline 44 & 0 & 0 & 0 & 0 & 0 & 0 & 0 & 0 & 0 & 0 & 0 & 0 & 0 & 0 \\
\hline 45 & 0 & 0 & 0 & 0 & 0 & 0 & 0 & 0 & 0 & 0 & 0 & 0 & 0 & 0 \\
\hline 46 & 0 & 0 & 0 & 0 & 0 & 0 & 0 & 0 & 0 & 0 & 0 & 0 & 0 & 0 \\
\hline 47 & 0 & 0 & 0 & 0 & 0 & 0 & 0 & 0 & 0 & 0 & 0 & 0 & 0 & 0 \\
\hline 48 & 0 & 0 & 0 & 0 & 0 & 0 & 0 & 0 & 0 & 0 & 0 & 0 & 0 & 0 \\
\hline 49 & 0 & 0 & 0 & 0 & 0 & 0 & 0 & 0 & 0 & 0 & 0 & 0 & 0 & 0 \\
\hline
\end{tabular}

Tabela A.6: Padrões de corte mais frequentes disponibilizados pela Fábrica X (16-30). 


\begin{tabular}{|c|c|c|c|c|c|c|c|c|c|c|c|c|c|}
\hline Peça/Padrão & 30 & 31 & 32 & 33 & 34 & 35 & 36 & 37 & 38 & 39 & 40 & 41 & 42 \\
\hline 1 & 0 & 0 & 0 & 0 & 0 & 0 & 0 & 0 & 0 & 0 & 0 & 0 & 0 \\
\hline 2 & 0 & 0 & 0 & 0 & 0 & 0 & 0 & 0 & 0 & 0 & 0 & 0 & 0 \\
\hline 3 & 0 & 0 & 0 & 0 & 0 & 0 & 0 & 0 & 0 & 0 & 0 & 0 & 0 \\
\hline 4 & 0 & 0 & 0 & 0 & 0 & 0 & 0 & 0 & 0 & 0 & 0 & 0 & 0 \\
\hline 5 & 0 & 0 & 0 & 0 & 0 & 0 & 0 & 0 & 0 & 0 & 0 & 0 & 0 \\
\hline 6 & 0 & 0 & 0 & 0 & 0 & 0 & 0 & 0 & 0 & 0 & 0 & 0 & 0 \\
\hline 7 & 0 & 0 & 0 & 0 & 0 & 0 & 0 & 0 & 0 & 0 & 0 & 0 & 0 \\
\hline 8 & 0 & 0 & 0 & 0 & 0 & 0 & 0 & 0 & 0 & 0 & 0 & 0 & 0 \\
\hline 9 & 0 & 0 & 0 & 0 & 0 & 0 & 0 & 0 & 0 & 0 & 0 & 0 & 0 \\
\hline 10 & 0 & 0 & 0 & 0 & 0 & 0 & 0 & 0 & 0 & 0 & 0 & 0 & 0 \\
\hline 11 & 0 & 0 & 0 & 0 & 0 & 0 & 0 & 0 & 0 & 0 & 0 & 0 & 0 \\
\hline 12 & 0 & 0 & 0 & 0 & 0 & 0 & 0 & 0 & 0 & 0 & 0 & 0 & 0 \\
\hline 13 & 0 & 0 & 0 & 0 & 0 & 0 & 0 & 0 & 0 & 0 & 0 & 0 & 0 \\
\hline 14 & 0 & 0 & 0 & 0 & 0 & 0 & 0 & 0 & 0 & 0 & 0 & 0 & 0 \\
\hline 15 & 0 & 0 & 0 & 0 & 0 & 0 & 0 & 0 & 0 & 0 & 0 & 0 & 0 \\
\hline 16 & 0 & 0 & 0 & 0 & 0 & 0 & 0 & 0 & 0 & 0 & 0 & 0 & 0 \\
\hline 17 & 0 & 0 & 0 & 0 & 0 & 0 & 0 & 0 & 0 & 0 & 0 & 0 & 0 \\
\hline 18 & 0 & 0 & 0 & 0 & 0 & 0 & 0 & 0 & 0 & 0 & 0 & 0 & 0 \\
\hline 19 & 0 & 0 & 0 & 0 & 0 & 0 & 0 & 0 & 0 & 0 & 0 & 0 & 0 \\
\hline 20 & 0 & 0 & 0 & 0 & 0 & 0 & 0 & 0 & 0 & 0 & 0 & 0 & 0 \\
\hline 21 & 0 & 0 & 0 & 0 & 0 & 0 & 0 & 0 & 0 & 0 & 0 & 0 & 0 \\
\hline 22 & 0 & 0 & 0 & 0 & 0 & 0 & 0 & 0 & 0 & 0 & 0 & 0 & 0 \\
\hline 23 & 0 & 0 & 0 & 0 & 0 & 0 & 0 & 0 & 0 & 0 & 0 & 0 & 0 \\
\hline 24 & 0 & 0 & 0 & 0 & 0 & 0 & 0 & 0 & 0 & 0 & 0 & 0 & 0 \\
\hline 25 & 0 & 0 & 0 & 0 & 0 & 0 & 0 & 0 & 0 & 0 & 0 & 0 & 0 \\
\hline 26 & 0 & 0 & 0 & 0 & 0 & 0 & 0 & 0 & 0 & 0 & 0 & 0 & 0 \\
\hline 27 & 0 & 0 & 0 & 0 & 0 & 0 & 0 & 0 & 0 & 0 & 0 & 0 & 0 \\
\hline 28 & 0 & 0 & 0 & 0 & 0 & 0 & 0 & 0 & 0 & 0 & 0 & 0 & 0 \\
\hline 29 & 0 & 0 & 0 & 0 & 0 & 0 & 0 & 0 & 0 & 0 & 0 & 0 & 0 \\
\hline 30 & 0 & 0 & 0 & 0 & 0 & 0 & 0 & 0 & 0 & 0 & 0 & 0 & 0 \\
\hline 31 & 0 & 0 & 0 & 0 & 0 & 0 & 0 & 0 & 0 & 0 & 0 & 0 & 0 \\
\hline 32 & 0 & 0 & 0 & 0 & 0 & 0 & 0 & 0 & 0 & 0 & 0 & 0 & 0 \\
\hline 33 & 0 & 0 & 0 & 0 & 0 & 0 & 0 & 0 & 0 & 0 & 0 & 0 & 0 \\
\hline 34 & 0 & 0 & 0 & 0 & 0 & 0 & 0 & 0 & 0 & 0 & 0 & 0 & 0 \\
\hline 35 & 18 & 0 & 0 & 0 & 0 & 0 & 0 & 0 & 0 & 0 & 0 & 0 & 0 \\
\hline 36 & 0 & 0 & 0 & 0 & 0 & 0 & 0 & 0 & 0 & 0 & 0 & 0 & 0 \\
\hline 37 & 0 & 80 & 0 & 0 & 0 & 0 & 0 & 0 & 0 & 0 & 0 & 0 & 0 \\
\hline 38 & 0 & 0 & 28 & 0 & 0 & 0 & 0 & 0 & 0 & 0 & 0 & 0 & 0 \\
\hline 39 & 0 & 0 & 12 & 0 & 0 & 1 & 64 & 4 & 0 & 0 & 0 & 0 & 0 \\
\hline 40 & 0 & 0 & 4 & 0 & 0 & 0 & 155 & 246 & 4 & 0 & 0 & 0 & 0 \\
\hline 41 & 0 & 0 & 0 & 2 & 2 & 16 & 0 & 0 & 0 & 0 & 0 & 0 & 0 \\
\hline 42 & 0 & 0 & 0 & 28 & 28 & 28 & 0 & 0 & 0 & 0 & 0 & 0 & 0 \\
\hline 43 & 0 & 0 & 0 & 56 & 56 & 49 & 0 & 0 & 0 & 0 & 0 & 0 & 0 \\
\hline 44 & 0 & 0 & 0 & 6 & 6 & 6 & 0 & 0 & 0 & 0 & 0 & 0 & 0 \\
\hline 45 & 0 & 0 & 0 & 0 & 0 & 0 & 0 & 0 & 46 & 172 & 0 & 0 & 0 \\
\hline 46 & 0 & 0 & 0 & 0 & 0 & 0 & 0 & 0 & 49 & 0 & 0 & 0 & 0 \\
\hline 47 & 0 & 0 & 0 & 0 & 0 & 0 & 0 & 0 & 0 & 0 & 6 & 8 & 176 \\
\hline 48 & 0 & 0 & 0 & 0 & 0 & 0 & 0 & 0 & 0 & 0 & 44 & 42 & 0 \\
\hline 49 & 0 & 0 & 0 & 0 & 0 & 0 & 0 & 0 & 0 & 0 & 49 & 49 & 0 \\
\hline
\end{tabular}

Tabela A.7: Padrões de corte mais frequentes disponibilizados pela Fábrica X (30-42). 


\begin{tabular}{|c|c|c|c|c|c|c|c|c|c|c|c|c|c|c|}
\hline Peça/Padrão & 43 & 44 & 45 & 46 & 47 & 48 & 49 & 50 & 51 & 52 & 53 & 54 & 55 & 56 \\
\hline 1 & 3 & 0 & 0 & 0 & 0 & 0 & 0 & 0 & 0 & 0 & 0 & 0 & 0 & 0 \\
\hline 2 & 0 & 0 & 0 & 0 & 0 & 0 & 0 & 0 & 0 & 0 & 0 & 0 & 0 & 0 \\
\hline 3 & 0 & 12 & 0 & 0 & 0 & 0 & 0 & 0 & 0 & 0 & 0 & 0 & 0 & 0 \\
\hline 4 & 0 & 0 & 0 & 0 & 0 & 0 & 0 & 0 & 0 & 0 & 0 & 0 & 0 & 0 \\
\hline 5 & 0 & 0 & 8 & 0 & 0 & 0 & 0 & 0 & 0 & 0 & 0 & 0 & 0 & 0 \\
\hline 6 & 0 & 0 & 0 & 0 & 0 & 0 & 0 & 0 & 0 & 0 & 0 & 0 & 0 & 0 \\
\hline 7 & 0 & 0 & 0 & 6 & 0 & 0 & 0 & 0 & 0 & 0 & 0 & 0 & 0 & 0 \\
\hline 8 & 0 & 0 & 0 & 0 & 40 & 0 & 0 & 0 & 0 & 0 & 0 & 0 & 0 & 0 \\
\hline 9 & 0 & 0 & 0 & 0 & 0 & 6 & 0 & 0 & 0 & 0 & 0 & 0 & 0 & 0 \\
\hline 10 & 0 & 0 & 0 & 0 & 0 & 0 & 10 & 0 & 0 & 0 & 0 & 0 & 0 & 0 \\
\hline 11 & 0 & 0 & 0 & 0 & 0 & 0 & 0 & 28 & 0 & 0 & 0 & 0 & 0 & 0 \\
\hline 12 & 0 & 0 & 0 & 0 & 0 & 0 & 0 & 0 & 28 & 0 & 0 & 0 & 0 & 0 \\
\hline 13 & 0 & 0 & 0 & 0 & 0 & 0 & 0 & 0 & 0 & 48 & 0 & 0 & 0 & 0 \\
\hline 14 & 0 & 0 & 0 & 0 & 0 & 0 & 0 & 0 & 0 & 0 & 20 & 0 & 0 & 0 \\
\hline 15 & 0 & 0 & 0 & 0 & 0 & 0 & 0 & 0 & 0 & 0 & 0 & 144 & 0 & 0 \\
\hline 16 & 0 & 0 & 0 & 0 & 0 & 0 & 0 & 0 & 0 & 0 & 0 & 0 & 220 & 0 \\
\hline 17 & 0 & 0 & 0 & 0 & 0 & 0 & 0 & 0 & 0 & 0 & 0 & 0 & 0 & 330 \\
\hline 18 & 0 & 0 & 0 & 0 & 0 & 0 & 0 & 0 & 0 & 0 & 0 & 0 & 0 & 0 \\
\hline 19 & 0 & 0 & 0 & 0 & 0 & 0 & 0 & 0 & 0 & 0 & 0 & 0 & 0 & 0 \\
\hline 20 & 0 & 0 & 0 & 0 & 0 & 0 & 0 & 0 & 0 & 0 & 0 & 0 & 0 & 0 \\
\hline 21 & 0 & 0 & 0 & 0 & 0 & 0 & 0 & 0 & 0 & 0 & 0 & 0 & 0 & 0 \\
\hline 22 & 0 & 0 & 0 & 0 & 0 & 0 & 0 & 0 & 0 & 0 & 0 & 0 & 0 & 0 \\
\hline 23 & 0 & 0 & 0 & 0 & 0 & 0 & 0 & 0 & 0 & 0 & 0 & 0 & 0 & 0 \\
\hline 24 & 0 & 0 & 0 & 0 & 0 & 0 & 0 & 0 & 0 & 0 & 0 & 0 & 0 & 0 \\
\hline 25 & 0 & 0 & 0 & 0 & 0 & 0 & 0 & 0 & 0 & 0 & 0 & 0 & 0 & 0 \\
\hline 26 & 0 & 0 & 0 & 0 & 0 & 0 & 0 & 0 & 0 & 0 & 0 & 0 & 0 & 0 \\
\hline 27 & 0 & 0 & 0 & 0 & 0 & 0 & 0 & 0 & 0 & 0 & 0 & 0 & 0 & 0 \\
\hline 28 & 0 & 0 & 0 & 0 & 0 & 0 & 0 & 0 & 0 & 0 & 0 & 0 & 0 & 0 \\
\hline 29 & 0 & 0 & 0 & 0 & 0 & 0 & 0 & 0 & 0 & 0 & 0 & 0 & 0 & 0 \\
\hline 30 & 0 & 0 & 0 & 0 & 0 & 0 & 0 & 0 & 0 & 0 & 0 & 0 & 0 & 0 \\
\hline 31 & 0 & 0 & 0 & 0 & 0 & 0 & 0 & 0 & 0 & 0 & 0 & 0 & 0 & 0 \\
\hline 32 & 0 & 0 & 0 & 0 & 0 & 0 & 0 & 0 & 0 & 0 & 0 & 0 & 0 & 0 \\
\hline 33 & 0 & 0 & 0 & 0 & 0 & 0 & 0 & 0 & 0 & 0 & 0 & 0 & 0 & 0 \\
\hline 34 & 0 & 0 & 0 & 0 & 0 & 0 & 0 & 0 & 0 & 0 & 0 & 0 & 0 & 0 \\
\hline 35 & 0 & 0 & 0 & 0 & 0 & 0 & 0 & 0 & 0 & 0 & 0 & 0 & 0 & 0 \\
\hline 36 & 0 & 0 & 0 & 0 & 0 & 0 & 0 & 0 & 0 & 0 & 0 & 0 & 0 & 0 \\
\hline 37 & 0 & 0 & 0 & 0 & 0 & 0 & 0 & 0 & 0 & 0 & 0 & 0 & 0 & 0 \\
\hline 38 & 0 & 0 & 0 & 0 & 0 & 0 & 0 & 0 & 0 & 0 & 0 & 0 & 0 & 0 \\
\hline 39 & 0 & 0 & 0 & 0 & 0 & 0 & 0 & 0 & 0 & 0 & 0 & 0 & 0 & 0 \\
\hline 40 & 0 & 0 & 0 & 0 & 0 & 0 & 0 & 0 & 0 & 0 & 0 & 0 & 0 & 0 \\
\hline 41 & 0 & 0 & 0 & 0 & 0 & 0 & 0 & 0 & 0 & 0 & 0 & 0 & 0 & 0 \\
\hline 42 & 0 & 0 & 0 & 0 & 0 & 0 & 0 & 0 & 0 & 0 & 0 & 0 & 0 & 0 \\
\hline 43 & 0 & 0 & 0 & 0 & 0 & 0 & 0 & 0 & 0 & 0 & 0 & 0 & 0 & 0 \\
\hline 44 & 0 & 0 & 0 & 0 & 0 & 0 & 0 & 0 & 0 & 0 & 0 & 0 & 0 & 0 \\
\hline 45 & 0 & 0 & 0 & 0 & 0 & 0 & 0 & 0 & 0 & 0 & 0 & 0 & 0 & 0 \\
\hline 46 & 0 & 0 & 0 & 0 & 0 & 0 & 0 & 0 & 0 & 0 & 0 & 0 & 0 & 0 \\
\hline 47 & 0 & 0 & 0 & 0 & 0 & 0 & 0 & 0 & 0 & 0 & 0 & 0 & 0 & 0 \\
\hline 48 & 0 & 0 & 0 & 0 & 0 & 0 & 0 & 0 & 0 & 0 & 0 & 0 & 0 & 0 \\
\hline 49 & 0 & 0 & 0 & 0 & 0 & 0 & 0 & 0 & 0 & 0 & 0 & 0 & 0 & 0 \\
\hline
\end{tabular}

Tabela A.8: Padrões de corte mais frequentes disponibilizados pela Fábrica X (43-56). 


\begin{tabular}{|c|c|c|c|c|c|c|c|c|c|c|c|c|c|c|}
\hline Peça/Padrão & 57 & 58 & 59 & 60 & 61 & 62 & 63 & 64 & 65 & 66 & 67 & 68 & 69 & 70 \\
\hline 1 & 0 & 0 & 0 & 0 & 0 & 0 & 0 & 0 & 0 & 0 & 0 & 0 & 0 & 0 \\
\hline 2 & 0 & 0 & 0 & 0 & 0 & 0 & 0 & 0 & 0 & 0 & 0 & 0 & 0 & 0 \\
\hline 3 & 0 & 0 & 0 & 0 & 0 & 0 & 0 & 0 & 0 & 0 & 0 & 0 & 0 & 0 \\
\hline 4 & 0 & 0 & 0 & 0 & 0 & 0 & 0 & 0 & 0 & 0 & 0 & 0 & 0 & 0 \\
\hline 5 & 0 & 0 & 0 & 0 & 0 & 0 & 0 & 0 & 0 & 0 & 0 & 0 & 0 & 0 \\
\hline 6 & 0 & 0 & 0 & 0 & 0 & 0 & 0 & 0 & 0 & 0 & 0 & 0 & 0 & 0 \\
\hline 7 & 0 & 0 & 0 & 0 & 0 & 0 & 0 & 0 & 0 & 0 & 0 & 0 & 0 & 0 \\
\hline 8 & 0 & 0 & 0 & 0 & 0 & 0 & 0 & 0 & 0 & 0 & 0 & 0 & 0 & 0 \\
\hline 9 & 0 & 0 & 0 & 0 & 0 & 0 & 0 & 0 & 0 & 0 & 0 & 0 & 0 & 0 \\
\hline 10 & 0 & 0 & 0 & 0 & 0 & 0 & 0 & 0 & 0 & 0 & 0 & 0 & 0 & 0 \\
\hline 11 & 0 & 0 & 0 & 0 & 0 & 0 & 0 & 0 & 0 & 0 & 0 & 0 & 0 & 0 \\
\hline 12 & 0 & 0 & 0 & 0 & 0 & 0 & 0 & 0 & 0 & 0 & 0 & 0 & 0 & 0 \\
\hline 13 & 0 & 0 & 0 & 0 & 0 & 0 & 0 & 0 & 0 & 0 & 0 & 0 & 0 & 0 \\
\hline 14 & 0 & 0 & 0 & 0 & 0 & 0 & 0 & 0 & 0 & 0 & 0 & 0 & 0 & 0 \\
\hline 15 & 0 & 0 & 0 & 0 & 0 & 0 & 0 & 0 & 0 & 0 & 0 & 0 & 0 & 0 \\
\hline 16 & 0 & 0 & 0 & 0 & 0 & 0 & 0 & 0 & 0 & 0 & 0 & 0 & 0 & 0 \\
\hline 17 & 0 & 0 & 0 & 0 & 0 & 0 & 0 & 0 & 0 & 0 & 0 & 0 & 0 & 0 \\
\hline 18 & 60 & 0 & 0 & 0 & 0 & 0 & 0 & 0 & 0 & 0 & 0 & 0 & 0 & 0 \\
\hline 19 & 0 & 40 & 0 & 0 & 0 & 0 & 0 & 0 & 0 & 0 & 0 & 0 & 0 & 0 \\
\hline 20 & 0 & 0 & 0 & 0 & 0 & 0 & 0 & 0 & 0 & 0 & 0 & 0 & 0 & 0 \\
\hline 21 & 0 & 0 & 144 & 0 & 0 & 0 & 0 & 0 & 0 & 0 & 0 & 0 & 0 & 0 \\
\hline 22 & 0 & 0 & 0 & 52 & 0 & 0 & 0 & 0 & 0 & 0 & 0 & 0 & 0 & 0 \\
\hline 23 & 0 & 0 & 0 & 0 & 168 & 0 & 0 & 0 & 0 & 0 & 0 & 0 & 0 & 0 \\
\hline 24 & 0 & 0 & 0 & 0 & 0 & 112 & 0 & 0 & 0 & 0 & 0 & 0 & 0 & 0 \\
\hline 25 & 0 & 0 & 0 & 0 & 0 & 0 & 112 & 0 & 0 & 0 & 0 & 0 & 0 & 0 \\
\hline 26 & 0 & 0 & 0 & 0 & 0 & 0 & 0 & 8 & 0 & 0 & 0 & 0 & 0 & 0 \\
\hline 27 & 0 & 0 & 0 & 0 & 0 & 0 & 0 & 0 & 20 & 0 & 0 & 0 & 0 & 0 \\
\hline 28 & 0 & 0 & 0 & 0 & 0 & 0 & 0 & 0 & 0 & 0 & 0 & 0 & 0 & 0 \\
\hline 29 & 0 & 0 & 0 & 0 & 0 & 0 & 0 & 0 & 0 & 6 & 0 & 0 & 0 & 0 \\
\hline 30 & 0 & 0 & 0 & 0 & 0 & 0 & 0 & 0 & 0 & 0 & 15 & 0 & 0 & 0 \\
\hline 31 & 0 & 0 & 0 & 0 & 0 & 0 & 0 & 0 & 0 & 0 & 0 & 0 & 0 & 0 \\
\hline 32 & 0 & 0 & 0 & 0 & 0 & 0 & 0 & 0 & 0 & 0 & 0 & 24 & 0 & 0 \\
\hline 33 & 0 & 0 & 0 & 0 & 0 & 0 & 0 & 0 & 0 & 0 & 0 & 0 & 72 & 0 \\
\hline 34 & 0 & 0 & 0 & 0 & 0 & 0 & 0 & 0 & 0 & 0 & 0 & 0 & 0 & 33 \\
\hline 35 & 0 & 0 & 0 & 0 & 0 & 0 & 0 & 0 & 0 & 0 & 0 & 0 & 0 & 0 \\
\hline 36 & 0 & 0 & 0 & 0 & 0 & 0 & 0 & 0 & 0 & 0 & 0 & 0 & 0 & 0 \\
\hline 37 & 0 & 0 & 0 & 0 & 0 & 0 & 0 & 0 & 0 & 0 & 0 & 0 & 0 & 0 \\
\hline 38 & 0 & 0 & 0 & 0 & 0 & 0 & 0 & 0 & 0 & 0 & 0 & 0 & 0 & 0 \\
\hline 39 & 0 & 0 & 0 & 0 & 0 & 0 & 0 & 0 & 0 & 0 & 0 & 0 & 0 & 0 \\
\hline 40 & 0 & 0 & 0 & 0 & 0 & 0 & 0 & 0 & 0 & 0 & 0 & 0 & 0 & 0 \\
\hline 41 & 0 & 0 & 0 & 0 & 0 & 0 & 0 & 0 & 0 & 0 & 0 & 0 & 0 & 0 \\
\hline 42 & 0 & 0 & 0 & 0 & 0 & 0 & 0 & 0 & 0 & 0 & 0 & 0 & 0 & 0 \\
\hline 43 & 0 & 0 & 0 & 0 & 0 & 0 & 0 & 0 & 0 & 0 & 0 & 0 & 0 & 0 \\
\hline 44 & 0 & 0 & 0 & 0 & 0 & 0 & 0 & 0 & 0 & 0 & 0 & 0 & 0 & 0 \\
\hline 45 & 0 & 0 & 0 & 0 & 0 & 0 & 0 & 0 & 0 & 0 & 0 & 0 & 0 & 0 \\
\hline 46 & 0 & 0 & 0 & 0 & 0 & 0 & 0 & 0 & 0 & 0 & 0 & 0 & 0 & 0 \\
\hline 47 & 0 & 0 & 0 & 0 & 0 & 0 & 0 & 0 & 0 & 0 & 0 & 0 & 0 & 0 \\
\hline 48 & 0 & 0 & 0 & 0 & 0 & 0 & 0 & 0 & 0 & 0 & 0 & 0 & 0 & 0 \\
\hline 49 & 0 & 0 & 0 & 0 & 0 & 0 & 0 & 0 & 0 & 0 & 0 & 0 & 0 & 0 \\
\hline
\end{tabular}

Tabela A.9: Padrões de corte mais frequentes disponibilizados pela Fábrica X (57-70). 


\begin{tabular}{|c|c|c|c|c|c|c|c|c|c|c|c|}
\hline Peça/Padrão & 71 & 72 & 73 & 74 & 75 & 76 & 77 & 78 & 79 & 80 & 81 \\
\hline 1 & 0 & 0 & 0 & 0 & 0 & 0 & 0 & 0 & 0 & 0 & 0 \\
\hline 2 & 0 & 0 & 0 & 0 & 0 & 0 & 0 & 0 & 0 & 0 & 0 \\
\hline 3 & 0 & 0 & 0 & 0 & 0 & 0 & 0 & 0 & 0 & 0 & 0 \\
\hline 4 & 0 & 0 & 0 & 0 & 0 & 0 & 0 & 0 & 0 & 0 & 0 \\
\hline 5 & 0 & 0 & 0 & 0 & 0 & 0 & 0 & 0 & 0 & 0 & 0 \\
\hline 6 & 0 & 0 & 0 & 0 & 0 & 0 & 0 & 0 & 0 & 0 & 0 \\
\hline 7 & 0 & 0 & 0 & 0 & 0 & 0 & 0 & 0 & 0 & 0 & 0 \\
\hline 8 & 0 & 0 & 0 & 0 & 0 & 0 & 0 & 0 & 0 & 0 & 0 \\
\hline 9 & 0 & 0 & 0 & 0 & 0 & 0 & 0 & 0 & 0 & 0 & 0 \\
\hline 10 & 0 & 0 & 0 & 0 & 0 & 0 & 0 & 0 & 0 & 0 & 0 \\
\hline 11 & 0 & 0 & 0 & 0 & 0 & 0 & 0 & 0 & 0 & 0 & 0 \\
\hline 12 & 0 & 0 & 0 & 0 & 0 & 0 & 0 & 0 & 0 & 0 & 0 \\
\hline 13 & 0 & 0 & 0 & 0 & 0 & 0 & 0 & 0 & 0 & 0 & 0 \\
\hline 14 & 0 & 0 & 0 & 0 & 0 & 0 & 0 & 0 & 0 & 0 & 0 \\
\hline 15 & 0 & 0 & 0 & 0 & 0 & 0 & 0 & 0 & 0 & 0 & 0 \\
\hline 16 & 0 & 0 & 0 & 0 & 0 & 0 & 0 & 0 & 0 & 0 & 0 \\
\hline 17 & 0 & 0 & 0 & 0 & 0 & 0 & 0 & 0 & 0 & 0 & 0 \\
\hline 18 & 0 & 0 & 0 & 0 & 0 & 0 & 0 & 0 & 0 & 0 & 0 \\
\hline 19 & 0 & 0 & 0 & 0 & 0 & 0 & 0 & 0 & 0 & 0 & 0 \\
\hline 20 & 0 & 0 & 0 & 0 & 0 & 0 & 0 & 0 & 0 & 0 & 0 \\
\hline 21 & 0 & 0 & 0 & 0 & 0 & 0 & 0 & 0 & 0 & 0 & 0 \\
\hline 22 & 0 & 0 & 0 & 0 & 0 & 0 & 0 & 0 & 0 & 0 & 0 \\
\hline 23 & 0 & 0 & 0 & 0 & 0 & 0 & 0 & 0 & 0 & 0 & 0 \\
\hline 24 & 0 & 0 & 0 & 0 & 0 & 0 & 0 & 0 & 0 & 0 & 0 \\
\hline 25 & 0 & 0 & 0 & 0 & 0 & 0 & 0 & 0 & 0 & 0 & 0 \\
\hline 26 & 0 & 0 & 0 & 0 & 0 & 0 & 0 & 0 & 0 & 0 & 0 \\
\hline 27 & 0 & 0 & 0 & 0 & 0 & 0 & 0 & 0 & 0 & 0 & 0 \\
\hline 28 & 0 & 0 & 0 & 0 & 0 & 0 & 0 & 0 & 0 & 0 & 0 \\
\hline 29 & 0 & 0 & 0 & 0 & 0 & 0 & 0 & 0 & 0 & 0 & 0 \\
\hline 30 & 0 & 0 & 0 & 0 & 0 & 0 & 0 & 0 & 0 & 0 & 0 \\
\hline 31 & 0 & 0 & 0 & 0 & 0 & 0 & 0 & 0 & 0 & 0 & 0 \\
\hline 32 & 0 & 0 & 0 & 0 & 0 & 0 & 0 & 0 & 0 & 0 & 0 \\
\hline 33 & 0 & 0 & 0 & 0 & 0 & 0 & 0 & 0 & 0 & 0 & 0 \\
\hline 34 & 0 & 0 & 0 & 0 & 0 & 0 & 0 & 0 & 0 & 0 & 0 \\
\hline 35 & 0 & 0 & 0 & 0 & 0 & 0 & 0 & 0 & 0 & 0 & 0 \\
\hline 36 & 6 & 0 & 0 & 0 & 0 & 0 & 0 & 0 & 0 & 0 & 0 \\
\hline 37 & 0 & 0 & 0 & 0 & 0 & 0 & 0 & 0 & 0 & 0 & 0 \\
\hline 38 & 0 & 30 & 0 & 0 & 0 & 0 & 0 & 0 & 0 & 0 & 0 \\
\hline 39 & 0 & 0 & 180 & 0 & 0 & 0 & 0 & 0 & 0 & 0 & 0 \\
\hline 40 & 0 & 0 & 0 & 272 & 0 & 0 & 0 & 0 & 0 & 0 & 0 \\
\hline 41 & 0 & 0 & 0 & 0 & 150 & 0 & 0 & 0 & 0 & 0 & 0 \\
\hline 42 & 0 & 0 & 0 & 0 & 0 & 150 & 0 & 0 & 0 & 0 & 0 \\
\hline 43 & 0 & 0 & 0 & 0 & 0 & 0 & 60 & 0 & 0 & 0 & 0 \\
\hline 44 & 0 & 0 & 0 & 0 & 0 & 0 & 0 & 180 & 0 & 0 & 0 \\
\hline 45 & 0 & 0 & 0 & 0 & 0 & 0 & 0 & 0 & 0 & 0 & 0 \\
\hline 46 & 0 & 0 & 0 & 0 & 0 & 0 & 0 & 0 & 60 & 0 & 0 \\
\hline 47 & 0 & 0 & 0 & 0 & 0 & 0 & 0 & 0 & 0 & 0 & 0 \\
\hline 48 & 0 & 0 & 0 & 0 & 0 & 0 & 0 & 0 & 0 & 150 & 0 \\
\hline 49 & 0 & 0 & 0 & 0 & 0 & 0 & 0 & 0 & 0 & 0 & 60 \\
\hline
\end{tabular}

Tabela A.10: Padrões de corte mais frequentes disponibilizados pela Fábrica X (70-81). 


\section{Apêndice B}

\section{Perfis de Desempenho}

A técnica conhecida por Perfis de Desempenho (Dolan e Moré, 2002) foi proposta inicialmente para a comparação de softwares científicos, mas na prática tem sido muito utilizada para comparar diferentes estratégias de solução em relação ao tempo de execução, gap e valor de função objetivo, como ilustrados nessa tese. O resumo a seguir é baseado no trabalho de Munari (2009) e explicita somente os principais conceitos da técnica. Para elaborar os gráficos ou perfis de desempenho, considere $S$ o conjunto de $n_{s}$ algoritmos ou métodos de solução a serem analisados e $P$ o conjunto de $n_{p}$ exemplares. Suponha que o objetivo dos métodos seja minimizar o valor da função objetivo dos exemplares. O desempenho do método $s \in S$ aplicado ao exemplar $p \in P$ é analisado pelo raio de desempenho, definido pela seguinte equação:

$$
r_{p s}=\frac{t_{p s}}{\min \left\{t_{p s} \mid s \in S\right\}}
$$

O valor $t_{p s}$ utilizado na comparação dos métodos representa o desempenho do método $s \in S$ aplicado ao exemplar $p \in P$. Quanto menor o $t_{p s}$, melhor é o desempenho do método considerado. Note que, de acordo com a equação (B.1), o melhor desempenho é atingido quando o raio $r_{p s}$ é igual a 1 , na situação em que o valor de $t_{p s}$ é mínimo. Se o método $s$ falhar na resolução do exemplar $p$, então $r_{p s}$ é definido como $r_{M}$, tal que

$$
r_{M} \geq r_{\bar{p} \bar{s}}, \forall \bar{p} \in P, \bar{s} \in S
$$

sendo que a escolha de $r_{M}$ não influencia na avaliação do desempenho, como mostrado em Dolan e Moré (2002).

Outra medida considerada na elaboração dos perfis de desempenho é o número de problemas para os quais o método $s$ apresentou um raio de desempenho igual ou melhor 
ao coeficiente $\tau$ dividido pelo número total de problemas do conjunto $S$, expressa pela equação:

$$
\rho_{s}(\tau)=\frac{1}{n_{p}}|S(\tau)|
$$

em que $S(\tau)=\left\{p \in P \mid r_{p s} \leq \tau\right\}$ e $|\cdot|$ representa a cardinalidade do conjunto. Note que $\rho_{s}(\tau)$ representa a probabilidade de um método $s$ ter um raio de desempenho dentro de um fator $\tau$. Nos gráficos, as curvas de desempenho são plotadas de acordo com os valores de $\tau$ e $\rho_{s}(\tau)$, referente aos eixos $x$ e $y$, respectivamente.

Em geral, utiliza-se a escala logarítmica na apresentação dos perfis de desempenho no gráfico, pois $r_{M}$ pode ser muito maior do que 1 , comprometendo a visualização da comparação. Nos gráficos apresentados nessa tese, é utilizado o seguinte mapeamento:

$$
\tau=\frac{1}{n_{p}}\left|\left\{p \in P: \log _{2}\left(r_{p s}\right) \leq \tau\right\}\right|
$$

Com isso, o fator $\tau$ varia no intervalo $\left[0, r_{M}\right), \operatorname{com} r_{M}=1+\max \left\{\log _{2}\left(r_{\bar{p} \bar{s}}\right)\right\}$. Com esse mapeamento, deve-se tomar cuidado na interpretação dos perfis de desempenho baseandose em $\tau$, devido à utilização da escala logarítmica.

$\mathrm{Na}$ análise dos perfis de desempenho, inicialmente, deve-se observar o valor associado a $\tau=1$, pois o valor $\rho_{s}(\tau=1)$ é a probabilidade de que o método $s$ seja melhor que os demais métodos. Além disso, é importante observar o valor $\rho_{s}\left(r_{M}\right)=1$ para analisar a fração de problemas $p \in P$ que o método $s$ não conseguiu resolver.

Os perfis de desempenho da presente tese foram criados com a utilização da planilha de cálculo perfis.xls, que foi introduzida no trabalho de Munari (2009) e disponibilizada no site do Laboratório de Otimização ${ }^{1}$, do Instituto de Ciências Matemáticas e de Computação - Universidade de São Paulo.

\footnotetext{
${ }^{1}$ http://www.otm.icmc.usp.br/aplicativos
} 


\section{Apêndice $\mathrm{C}$}

Tabelas Adicionais dos Resultados

Computacionais 


\begin{tabular}{|c|c|c|c|c|c|c|c|c|c|}
\hline \multirow[b]{2}{*}{ Exemplar } & \multirow[b]{2}{*}{ Custo } & \multicolumn{2}{|l|}{ MIP } & \multicolumn{3}{|c|}{ RFP } & \multicolumn{3}{|c|}{ RFR } \\
\hline & & $G A P$ & Tempo (s) & Custo & $G A P$ & Tempo (s) & Custo & $G A P$ & Tempo (s) \\
\hline 1 & 157433 & 0,0897 & 0,3700 & 157433 & 0,0897 & 1,130 & 157433 & 0,0897 & 0,0897 \\
\hline 2 & 123118 & 0,1549 & 0,3200 & 123118 & 0,1549 & 1,330 & 123118 & 0,1549 & 0,1549 \\
\hline 3 & 192245 & 0,2167 & 0,3300 & 192245 & 0,2167 & 1,200 & 192245 & 0,2167 & 0,2167 \\
\hline 4 & 173278 & 0,6182 & 0,4700 & 173316 & 0,6403 & 1,240 & 173316 & 0,6403 & 0,6403 \\
\hline 5 & 177639 & 0,2639 & 0,3100 & 177639 & 0,2639 & 1,160 & 177639 & 0,2639 & 0,2639 \\
\hline 6 & 175562 & 0,0000 & 0,3100 & 175562 & 0,0000 & 1,220 & 175562 & 0,0000 & 0,0000 \\
\hline 7 & 174573 & 0,1644 & 0,3700 & 174573 & 0,1644 & 1,290 & 174447 & 0,0924 & 0,0924 \\
\hline 8 & 169187 & 0,1292 & 0,3000 & 169187 & 0,1292 & 1,210 & 169187 & 0,1292 & 0,1292 \\
\hline 9 & 219122 & 0,7154 & 0,3200 & 219073 & 0,6927 & 1,400 & 218939 & 0,6314 & 0,6314 \\
\hline 10 & 181624 & 0,2262 & 0,3300 & 181624 & 0,2262 & 1,290 & 181624 & 0,2262 & 0,2262 \\
\hline Média & 174378 & 0,2579 & 0,3430 & 174377 & 0,2578 & 1,247 & 174351 & 0,2445 & 0,244 \\
\hline 11 & 347408 & 0,9592 & 7,180 & 347214 & 0,9028 & 3,080 & 348186 & 1,185 & 12,94 \\
\hline 12 & 329185 & 0,5252 & 4,430 & 330501 & 0,9269 & 1,580 & 330293 & 0,8634 & 9,410 \\
\hline 13 & 357570 & 0,6162 & 6,310 & 358626 & 0,9132 & 2,590 & 358619 & 0,9113 & 12,28 \\
\hline 14 & 381761 & 0,6361 & 4,680 & 383769 & 1,166 & 2,560 & 384480 & 1,353 & 11,36 \\
\hline 15 & 328689 & 0,6588 & 4,330 & 330544 & 1,227 & 1,630 & 329262 & 0,8341 & 10,90 \\
\hline 16 & 378272 & 0,6659 & 7,140 & 380338 & 1,216 & 2,460 & 379611 & 1,022 & 13,96 \\
\hline 17 & 372622 & 0,8711 & 5,360 & 373459 & 1,098 & 2,770 & 371874 & 0,6685 & 11,52 \\
\hline 18 & 317425 & 0,8964 & 4,770 & 318287 & 1,170 & 2,480 & 318653 & 1,287 & 11,52 \\
\hline 19 & 293368 & 0,9889 & 3,250 & 293947 & 1,188 & 1,770 & 294469 & 1,368 & 10,90 \\
\hline 20 & 379837 & 0,4882 & 4,570 & 382577 & 1,213 & 2,830 & 382866 & 1,289 & 13,03 \\
\hline Média & 348614 & 0,731 & 5,202 & 349926 & 1,102 & 2,375 & 349831 & 1,078 & 11,78 \\
\hline 21 & 405481 & 0,5129 & 0,5129 & 405279 & 0,4628 & 4,050 & 405279 & 0,4628 & 5,510 \\
\hline 22 & 354242 & 0,0604 & 0,0604 & 354291 & 0,0741 & 4,030 & 354291 & 0,0741 & 4,860 \\
\hline 23 & 268826 & 0,0130 & 0,0130 & 268826 & 0,0130 & 4,380 & 268826 & 0,0130 & 4,530 \\
\hline 24 & 376611 & 0,5147 & 0,5147 & 376375 & 0,4516 & 4,410 & 376375 & 0,4516 & 5,030 \\
\hline 25 & 312817 & 0,5183 & 0,5183 & 312788 & 0,5090 & 4,450 & 312788 & 0,5090 & 5,880 \\
\hline 26 & 309856 & 0,0000 & 0,0000 & 309856 & 0,0000 & 3,930 & 309856 & 0,0000 & 4,430 \\
\hline 27 & 328239 & 0,8272 & 0,8272 & 328240 & 0,8273 & 4,280 & 328239 & 0,8272 & 5,080 \\
\hline 28 & 324298 & 0,0668 & 0,0668 & 324298 & 0,0668 & 4,130 & 324298 & 0,0668 & 5,090 \\
\hline 29 & 348052 & 0,0372 & 0,0372 & 348052 & 0,0372 & 4,270 & 348052 & 0,0372 & 4,510 \\
\hline 30 & 330419 & 0,1163 & 0,1163 & 330435 & 0,1213 & 4,170 & 330435 & 0,1213 & 4,560 \\
\hline Média & 335884 & 0,2667 & 0,2667 & 335844 & 0,2563 & 4,210 & 335844 & 0,2563 & 4,948 \\
\hline
\end{tabular}

Tabela C.1: Custo total, gap de otimalidade e tempo de execução das estratégias MIP, RFP e RFR relativos aos exemplares $1-30$. 


\begin{tabular}{|c|c|c|c|c|c|c|c|c|c|}
\hline \multirow[b]{2}{*}{ Exemplar } & \multirow[b]{2}{*}{ Custo } & \multicolumn{2}{|l|}{ MIP } & \multicolumn{3}{|c|}{ RFP } & \multicolumn{3}{|c|}{ RFR } \\
\hline & & $G A P$ & Tempo (s) & Custo & $G A P$ & Tempo (s) & Custo & $G A P$ & Tempo (s) \\
\hline 31 & 686900 & 0,7194 & 47,99 & 691829 & 1,442 & 8,610 & 689181 & 1,054 & 37,77 \\
\hline 32 & 801339 & 0,7151 & 14,14 & 808117 & 1,567 & 8,980 & 803888 & 1,035 & 35,32 \\
\hline 33 & 587335 & 0,5942 & 12,25 & 589391 & 0,9463 & 6,030 & 589099 & 0,8963 & 30,18 \\
\hline 34 & 637801 & 0,5469 & 11,73 & 643295 & 1,413 & 9,240 & 639971 & 0,8891 & 28,17 \\
\hline 35 & 748277 & 0,8964 & 40,97 & 752277 & 1,436 & 7,570 & 748150 & 0,8792 & 27,94 \\
\hline 36 & 818709 & 0,7948 & 43,00 & 821070 & 1,085 & 6,840 & 820916 & 1,066 & 27,42 \\
\hline 37 & 696155 & 0,3955 & 50,47 & 704859 & 1,651 & 5,770 & 701347 & 1,144 & 34,43 \\
\hline 38 & 666841 & 0,2514 & 50,48 & 672613 & 1,119 & 6,730 & 671111 & 0,8932 & 32,49 \\
\hline 39 & 640510 & 0,3663 & 48,05 & 648992 & 1,695 & 5,920 & 646028 & 1,231 & 33,82 \\
\hline 40 & 648029 & 0,5210 & 54,46 & 652467 & 1,209 & 6,350 & 651844 & 1,113 & 31,69 \\
\hline Média & 693190 & 0,5801 & 37,35 & 698491 & 1,356 & 7,204 & 696153 & 1,020 & 31,92 \\
\hline 41 & 753039 & 2,334 & 4200 & 758076 & 3,018 & 11,70 & 758540 & 3,081 & 90,53 \\
\hline 42 & 869369 & 1,607 & 4200 & 878293 & 2,650 & 9,220 & 873752 & 2,120 & 88,15 \\
\hline 43 & 651853 & 2,136 & 4200 & 659445 & 3,326 & 11,75 & 657959 & 3,093 & 99,39 \\
\hline 44 & 703094 & 1,775 & 4200 & 708941 & 2,622 & 10,24 & 707885 & 2,469 & 80,13 \\
\hline 45 & 810612 & 1,582 & 4200 & 817517 & 2,447 & 7,950 & 815719 & 2,222 & 61,81 \\
\hline 46 & 882563 & 1,129 & 4200 & 891750 & 2,181 & 7,490 & 888788 & 1,842 & 71,89 \\
\hline 47 & 763771 & 2,712 & 4200 & 770924 & 3,674 & 14,49 & 767757 & 3,248 & 96,87 \\
\hline 48 & 732341 & 1,816 & 4200 & 741469 & 3,085 & 16,64 & 737439 & 2,525 & 102,0 \\
\hline 49 & 706025 & 1,963 & 4200 & 711482 & 2,751 & 19,55 & 710023 & 2,541 & 85,08 \\
\hline 50 & 712403 & 2,105 & 4200 & 717970 & 2,903 & 8,310 & 718976 & 3,047 & 93,83 \\
\hline Média & 758507 & 1,92 & 4200 & 765587 & 2,866 & 11,73 & 763684 & 2,619 & 86,97 \\
\hline 51 & 816950 & 4,896 & 4200 & 823007 & 5,673 & 20,06 & 818386 & 5,080 & 528,0 \\
\hline 52 & 2067654 & 116,5 & 4200 & 1699791 & 77,99 & 1272 & 1783996 & 86,81 & 3099 \\
\hline 53 & 687555 & 3,859 & 4200 & 692511 & 4,607 & 20,76 & 689847 & 4,205 & 1154 \\
\hline 54 & 750071 & 5,122 & 4200 & 750671 & 5,206 & 26,45 & 748852 & 4,951 & 1406 \\
\hline 55 & 939230 & 11,44 & 4200 & 932988 & 10,69 & 108,7 & 924092 & 9,639 & 2503 \\
\hline 56 & 3839522 & 185,5 & 4200 & 3872414 & 188,0 & 1183 & 3943279 & 193,2 & 2453 \\
\hline 57 & 825123 & 5,940 & 4200 & 817251 & 4,929 & 15,00 & 816676 & 4,855 & 1390 \\
\hline 58 & 791593 & 3,507 & 4200 & 801646 & 4,822 & 18,79 & 796216 & 4,112 & 293,7 \\
\hline 59 & 753534 & 4,481 & 4200 & 756567 & 4,902 & 14,79 & 754891 & 4,669 & 1197 \\
\hline 60 & 758072 & 4,925 & 4200 & 761519 & 5,402 & 12,66 & 760633 & 5,280 & 1444 \\
\hline Média & 1222931 & 34,62 & 4200 & 1190837 & 31,22 & 269,2 & 1203687 & 32,28 & 1547 \\
\hline
\end{tabular}

Tabela C.2: Custo total, gap de otimalidade e tempo de execução das estratégias MIP, RFP e RFR relativos aos exemplares $31-60$. 


\section{Referências Bibliográficas}

ABSi, N. Modélisation et résolution de problèmes de lot-sizing à capacité finie. Tese de Doutoramento, Universidade de Paris VI, Paris, 2005.

Absi, N.; Kedad-Sidhoum, S. Mip-based heuristics for multi-item capacitated lotsizing problem with setup times and shortage costs. RAIRO Operations Research, v. 41, p. 171-192, 2007.

AdIDA, E.; Joshi, P. A robust optimization approach to project scheduling and resource allocation. International Journal of Services Operations and Informatics, v. 4(2), p. 169-193, 2009.

AdidA, E.; Perakis, G. A robust optimization approach to dynamic pricing and inventory control with no backorders. Mathematical Programming Series B, v. 107, p. 97-129, 2006.

AdidA, E.; PerAkis, G. Dynamic pricing and inventory control: robust vs. stochastic uncertainty models - a computational study. Annals of Operations Research, v. 181(1), p. $125-157,2010$.

Aghassi, M.; Bertsimas, D. Robust game theory. Mathematical Programming., v. 107, n. 1, p. 231-273, 2006.

Aghezzaf, E.-H.; Sitompula, C.; NAjid, N. M. Models for robust tactical planning in multi-stage production systems with uncertain demands. Computers $\& 5$ Operations Research, v. 37(5), 2010.

Ahmed, S. Convexity and decomposition of mean-risk stochastic programs. Mathematical Programming Series A, v. 106, p. 433-446, 2006.

Ahmed, S.; SAhinidis, N. V. Robust process planning under uncertainty. Industrial E) Engineering Chemistry Research., v. 37(5), p. 1883-1892, 1998.

Alem, D. J.; Morabito, R. Otimização do problema integrado de programação da produção e corte de estoque com custos incertos em fábricas de móveis. Submetido., 2008.

Alem, D. J.; Morabito, R. Production planning in furniture settings via robust optimization. Computers \& Operations Research, aceito para publicação, 2011.

Aouam, T.; Rardin, R.; Abrache, J. Robust strategies for natural gas procurement. European Journal of Operational Research, v. 205, p. 151-158, 2010. 
AtAmtÜRK, A. Strong formulations of robust mixed 0-1 programming. Operations Research, v. 108, p. 235-250, 2006.

Bellman, R. Dynamic programming. Princeton University Press, 1957.

Bellman, R. E.; Zadeh, L. A. Decision making in fuzzy environment. Management Science, v. 17, p. 141-154, 1970.

Ben-Tal, A.; Golany, B.; Nemirovski, A.; ; Vial, J. Supplier-retailer flexible commitments contracts: a robust optimization approach. Manufacturing and Service Operations Management, v. 7(3), p. 248-271, 2005.

Ben-Tal, A.; Goryashko, A.; Guslitzer, E.; Nemirovski, A. Adjustable robust solutions of uncertain linear programs. Mathematical Programming Series A, v. 99, p. 351-376, 2004.

Ben-Tal, A.; Nemirovski, A. Robust convex optimization. Mathematics of Operations Research, v. 23, p. 769-805, 1998.

Ben-Tal, A.; Nemirovski, A. Robust solutions of uncertain linear programming. Operations Research Letters, v. 25, p. 1-13, 1999.

Ben-Tal, A.; Nemirovski, A. Robust solutions of linear programming problems contaminated with uncertain data. Mathematical Programming Series B, v. 88, p. 411424, 2000.

Benders, J. F. Partitioning procedures for solving mixed variable programming problems. Numerische Mathematik, v. 4, p. 238-252, 1962.

Beraldi, P.; Musmanno, R.; Triki, C.; Zenios, S. A. Limited recourse in twostage stochastic linear programs. Journal of Information and Optimization Science, v. 24(3), p. 445-465, 2003.

Bertrand, J. W. M.; Fransoo, J. C. Operations management research methodologies using quantitative modeling. International Journal of Operations \& Production Management, v. 22(2), p. 241-264, 2002.

Bertsimas, D.; Brown, D.; Caramanis, C. Theory and applications of robust optimization. SIAM Review, artigo aceito para publicação, 2010.

Bertsimas, D.; Pachamanova, D. Robust multiperiod portfolio management in the presence of transaction costs. Computers $\&$ Operations Research., v. 35(1), p. 3-17, 2008.

Bertsimas, D.; Pachamanova, D.; Sim, M. Robust linear optimization under general norms. Operations Research Letters, v. 32(6), p. 510-516, 2004.

Bertsimas, D.; Sim, M. Robust discrete optimization and network flows. Mathematical Programming, v. 98, p. 43-71, 2003.

Bertsimas, D.; Sim, M. The price of robustness. Operations Research, v. 52(1), p. 35-53, 2004. 
Bertsimas, D.; Sim, M. Tractable approximations to robust conic optimization problems. Math. Program., v. 107(1), p. 5-36, 2006.

Bertsimas, D.; Thiele, A. A robust optimization approach to inventory theory. Operations Research, v. 54(1), p. 150-168, 2006.

Beyer, H.-G.; Sendhoff, B. Robust optimization - a comprehensive survey. Computers Methods in Applied Mechanics Engineering., v. 196, p. 3190-3218, 2007.

BIEHL, S. V. Um problema de corte de peças integrado à programação da produção - uma abordagem por relaxação lagrangiana. Dissertação de Mestrado, Instituto de Ciências Matemáticas e de Computação - ICMC-USP, 2008.

Bienstock, D.; Ozbay, N. Computing robust basestock levels. Discrete Optimization, v. 5(2), p. 389-414, 2008.

Birge, J. R.; Louveaux, F. Introduction to stochastic programming. New York: Springer, $\mathrm{xx}+421$ p., 1997.

Bitran, G. R.; Yanasse, H. H. Computational complexity of the capacitated lot size problem. Management Science, v. 28, p. 1174-1186, 1982.

Bohle, C.; Maturana, S.; Vera, J. A robust optimization approach to wine grape harvesting scheduling. European Journal of Operational Research, v. 200(1), p. 245$252,2009$.

Buschkühl, L.; Sahling, F.; Helber, S.; Tempelmeier, H. Dynamic capacitated lot-sizing problems - a classification and review of solution approaches. OR Spectrum, v. 32(2), p. 231-261, 2010.

Camargo, R. S.; Miranda, G.; Luna, H. P. L. Benders decomposition for hub location problems with economies of scale. Transportation Science, v. 43(1), p. 86-97, 2009.

Carnieri, C.; Guillermo, A.; Gavinho, L. Solution procedures for cutting lumber into furniture parts. European Journal of Operational Research, v. 73, p. 495-501, 1994.

Cavali, R. Problema de corte e empacotamento na indústria de móveis: um estudo de caso. Dissertação de Mestrado, Ibilce-Unesp, 2004.

Charnes, A.; Cooper, W. Chance constrained programming. Management Science, v. 6(1), p. 73-79, 1959.

Chen, C.; ; Kwon, R. H. Robust portfolio selection for index tracking. Computers E Operations Research, doi:10.1016/j.cor.2010.08.019, 2011.

Chen, G.; Daskin, M. S.; Shen, Z.-J.; Uryasev, S. The $\alpha$-reliable mean-excess regret model for stochastic facility location modeling. Naval Research Logistics, v. 53, p. $617-626,2006$.

Chen, W.; Sim, M.; Sun, J.; TeO, C.-P. From cvar to uncertainty set: implications in joint chance constrained optimization. Operations Research, v. 58, p. 470-485, 2010. 
Chen, X.; Sim, M.; Sun, P. A robust optimization perspective on stochastic programming. Operations Research, v. 55(6), p. 1058-1070, 2007.

Chung, G.; Lansey, K.; Bayraksan, G. Reliable water supply system design under uncertainty. Environmental Modelling \& Software, p. 1-14, 2008.

Correia, M.; Oliveira, J.; Ferreira, J. Reel and sheet cutting at a paper mill. Computers $\&$ Operations Research, v. 31, p. 1223-1243, 2004.

Costa, A. M. A survey on benders decomposition applied to fixed-charge network design problems. Computers \& Operations Research, v. 32, p. 1429-1450, 2005.

DAntzig, G. Linear programming under uncertainty. Management Science, v. 1, p. 197-206, 1955.

DAntzig, G. Linear programming under uncertainty. Management Science, v. 50(12), p. 1764-1769, 2004.

Daskin, M.; Hesse, S.; ReVelle, C. $\alpha$-reliable p-minimax regret: a new model for strategic facility location modeling. Location Science, v. 5, p. 227-246, 1997.

Dolan, E. D.; Moré, J. J. Benchmarking optimization software with performance profiles. Mathematical Programming Series A, v. 91, p. 201-213, 2002.

Drexl, A.; Kimms, A. Lot sizing and scheduling - survey and extensions. European Journal of Operational Research, v. 99, p. 221-235, 1997.

Dupacová, J. Risk objectives in two-stage stochastic programming models. Kybernetika, v. 44(2), p. 227-242, 2008.

Dupacová, J.; Consigli, G.; Wallace, S. W. Scenarios for multistage stochastic programs. Annals of Operations Research, v. 100, p. 25-53, 2000.

El-Ghaoui, L.; LeBret, H. Robust solutions to least-square problems to uncertain data matrices. SIAM Journal on matrix analysis and applications, v. 18, p. 1035-1064, 1997.

El-Ghaoui, L.; Oustry, F.; Lebret, H. Robust solutions to uncertain semidefinite programs. SIAM Journal of Optimization, v. 9, p. 35-52, 1998.

Erdogan, E.; Iyengar, G. Ambiguous chance constrained problems and robust optimization. Operations Research, v. 107, p. 37-61, 2006.

FAbozzi, F. J.; HuAng, D.; Zhou, G. Robust portfolios: contributions from operations research and finance. Annals of Operations Research, v. 176(1), p. 191-220, 2010.

Ferreira, D.; Morabito, R.; Rangel, S. Solution approaches for the soft drink integrated production lot sizing and scheduling problem. European Journal of Operational Research, v. 196, p. 697-706, 2009.

Figueiredo, A. Análise de produtividade de padrões de corte na indústria de móveis. Dissertação de Mestrado, Ibilce-Unesp, 2006. 
Geng, N.; Jiang, Z.; Chen, F. Stochastic programming based capacity planning for semiconductor wafer fab with uncertain demand and capacity. European Journal of Operational Research, v. 198, p. 899-908, 2009.

Geoffrion, A. M. Generalized benders decomposition. Journal of Optimization Theory and Applications, v. 10, p. 237-260, 1972.

Geoffrion, A. M.; Graves, G. W. Multicommodity distribution system design by benders decomposition. Management Science, v. 20(5), p. 822-844, 1974.

Ghidini, C. T. L. S. Otimização de processos acoplados: programação da produção e corte de estoque. Tese de Doutoramento, Universidade de São Paulo, São Carlos, 2007.

Ghidini, C. T. L. S.; Alem, D.; Arenales, M. Solving a combined cutting stock and lot-sizing problem in small furniture industries. In: Proceedings of the 6th International Conference on Operational Research for Development (ICORD-VI), Fortaleza, Brazil, 2007.

Gilmore, P. C.; Gomory, R. E. A linear programming approach to the cutting-stock problem. Operations Research, v. 9, n. 6, p. 849-859, 1961.

Gilmore, P. C.; Gomory, R. E. A linear programming approach to the cutting stock problem: Part ii. Operations Research, v. 11, n. 1, p. 863-888, 1963.

Gilmore, P. C.; Gomory, R. E. Multistage cutting stock problems of two and more dimensions. Operations Research, v. 13(1), p. 94-120, 1965.

Gramani, M.; FrançA, P. The combined cutting stock and lot-sizing problem in industrial process. European Journal of Operational Research, v. 174, p. 509-521, 2006.

Gramani, M.; FrançA, P.; Arenales, M. A lagrangian relaxation approach to a coupled lot-sizing and cutting stock problem. International Journal of Production Economics, v. 119(2), p. 219-227, 2009.

HuANG, K. Multi-stage stochastic programming models in production planning. Tese de Doutoramento, School of Industrial and Systems Engineering - Georgia Institute of Technology, 2005.

ILOG Ilog cplex 11.0: user's manual and reference manuals. http://www.ilog.com/products/cplex/ (accessed June 2009), 2008.

Disponível em http://www.ilog.com/products/cplex/

Jans, R.; Degraeve, Z. Meta-heuristics for dynamic lot sizing: A review and comparison of solution approaches. European Journal of Operational Research, v. 177, p. $1855-1875,2007$.

Jans, R.; Degraeve, Z. Modeling industrial lot sizing problems: a review. International Journal of Production Research, v. 46(6), p. 1619-1643, 2008.

Jia, Z.; Ierapetritou, M. G. Short-term scheduling under uncertainty using milp sensitivity analysis. Industrial \& Engineering Chemistry Research, v. 43(14), p. 37823791, 2004. 
Kall, P.; Wallace, S. Stochastic programming. New York: Wiley, 1994.

Karimi, B.; Ghomi, S. F.; Wilson, J. A tabu search heuristic for solving the clsp with backlogging and set-up carry-over. Journal of the Operational Research Society, v. 57, p. 140-147, 2006.

Khor, C. S.; Elkamel, A.; Ponnambalamb, K.; Douglas, P. L. Two-stage stochastic programming with fixed recourse via scenario planning with economic and operational risk management for petroleum refinery planning under uncertainty. Chemical Engineering 86 Processing, v. 47, p. 1744-1764, 2008.

Konno, H.; Yamazaki, H. Mean-absolute deviation portfolio optimization model and its applications to tokyo stock market. Management Science, v. 37(5), p. 519-531, 1991.

LAGUnA, M. Applying robust optimisation to capacity expansion of one location in elecommunications with demand uncertainty. Management Science, v. 44(11), p. 101110, 1998.

LAI, K.; WAnG, M.; LiAng, L. A stochastic approach to professional services firms' revenue optimization. European Journal of Operational Research, v. 182, p. 971-982, 2007.

LAI, K.-K.; NG, W.-L. A stochastic approach to hotel revenue optimization. Computers \& Operations Research, v. 32, p. 1059-1072, 2005.

Leung, S.; Tsang, S.; NG, W.; Wu, Y. A robust optimization model for multisite production planning problem in an uncertain environment. European Journal of Operational Research, v. 181, p. 224-238, 2007.

Leung, S. C. H.; Wu, Y. A robust optimization model for stochastic aggregate production planning. Production Planning \& Control, v. 15, p. 502-514, 2004.

Li, Z.; Ierapetritou, M. G. Robust optimization for process scheduling under uncertainty. Industrial \&6 Engineering Chemistry Research, v. 47(12), p. 4148-4157, 2008.

MA, Z.; Kwon, R. H.; LEe, C.-G. A stochastic programming winner determination model for truckload procurement under shipment uncertainty. Transportation Research Part E, v. 46, p. 49-60, 2010.

Maes, J.; McClain, J. O.; van Wassenhove, L. N. Multilevel capacitated lotsizing complexity and lp-based heuristics. European Journal of Operational Research, v. 53, p. 131-148, 1991.

Magnanti, T. L.; Wong, R. T. Accelerating benders decomposition: algorithm enhancement and model selection criteria. Operations Research, v. 29, p. 464-484, 1981.

Markowitz, H. Portfolio selection: efficient diversification of investments. John Wiley \& Sons, 1959.

MARlA, L.; BARnhart, C. Robust optimization: lessons learned from aircraft routing. Transportation Science, submetido, 2009. 
Maturana, S.; Perez, F. O. A.; Vera, J. Robust optimization: a case in forest operations planning. USC ISE Working paper \#2007-03, 2007.

McCarl, B.; Meeraus, A.; EiJk, P.; Bussieck, M.; Dirkse, S.; Steacy, P. Mccarl gams user guide. http://www.gams.com/dd/docs/bigdocs/gams2002/mccarlgamsuserguide.pdf (acessado em Março de 2010), 2010.

Menon, S.; Schrage, L. Order allocation for stock cutting in the paper industry. Operations Research, v. 50, p. 324-332, 2002.

Morabito, R.; Arenales, M. N. Optimizing the cutting of stock plates in a furniture company. International Journal of Production Research, v. 38(12), p. 2725-2742, 2000.

Morabito, R.; Pureza, V. Modelagem e simulação. In: Miguel, P. A. C., ed. Metodologia de pesquisa em engenharia de produção e gestão de operações, cáp. 3, Rio de Janeiro: Elsevier, p. 165-194, 2010.

Mosquera, G. P. Contribuições para o problema de corte de estoque bidimensional na indústria moveleira. Dissertação de Mestrado, Ibilce-Unesp, 2007.

Mulvey, J.; Vanderbei, R.; Zenios, S. Robust optimization of large-scale systems. Operations Research, v. 43, p. 264-281, 1995.

Munari, P. Comparação de softwares cientificos utilizando perfis de desempenho: automatização dos cálculos pela planilha perfis.xls. Relatório Técnico 344, Universidade de São Paulo, 2009.

Disponível em http://www.icmc.usp.br/ biblio/BIBLIOTECA/rel_tec/RT_344. PDF

Munhoz, J. R. Otimização no planejamento agregado de produção em indústrias de processamento de suco concentrado congelado de laranja. Tese de Doutoramento, Universidade Federal de São Carlos, 2009.

Munhoz, J. R.; Morabito, R. Uma abordagem de otimização robusta no planejamento agregado de produção na indústria cítrica. Gestão e Produção, aceito para publicação., 2011.

Nonas, S.; Thorstenson, A. A combined cutting stock and lot sizing problem. European Journal of Operational Research, v. 120(2), p. 327-342, 2000.

Nonas, S. L.; Thorstenson, A. Solving a combined cutting-stock and lot-sizing problem with a column generating procedure. Computers $\&$ Operations Research, v. 35(10), p. 3371-3392, 2008.

OrdóÑez, F.; ZhaO, J. Robust capacity expansion of network flows. Networks, v. 50(2), p. 136-145, 2007.

PAIVA, R. P. O. Modelagem do planejamento agregado da produção em usinas cooperadas do setor sucroenergético utilizando programação matemática e otimização robusta. Tese de Doutoramento, Universidade Federal de São Carlos, 2009. 
Palma, C. D.; Nelson, J. D. A robust optimization approach protected harvest scheduling decisions against uncertainty. Canadian Journal of Forest Research, v. 39, p. 342-355, 2009.

PAn, F.; NAGI, R. Robust supply chain design under uncertain demand in agile manufacturing. Computers \& Operations Research, v. 37(4), p. 668-683, 2010.

Penuel, J.; Smith, J. C.; Y., Y. An integer decomposition algorithm for solving a two-stage facility location problem with second-stage activation costs. Naval Research Logistics, v. 57(5), p. 391-402, 2010.

Pochet, Y.; Wolsey, L. Production planing by mixed integer programing. Springer, New York, 2006.

Poltroniere, S.; Poldi, K.; Toledo, F.; Arenales, M. A coupling cutting stocklot sizing problem in the paper industry. Annals of Operations Research, v. 157(1), p. $91-104,2008$.

Rangel, S.; Figueiredo, A. G. O problema de corte de estoque em indústrias de móveis de pequeno e médio portes. Pesquisa Operacional, v. 28, p. 451-472, 2008.

Respício, A.; CAPtivo, M. Um dss para o problema de planejamento e sequenciamento da produção em indústrias de papel. In: DSI age-2002, international conference on decision making and decision support in the Internet age, University College Cork, Cork, Ireland, 2002.

RiIs, M.; Andersen, K. A. Multiperiod capacity expansion of a telecommunications connection with uncertain demand. Computers $\& 5$ Operations Research, v. 31, p. 14271436, 2004.

Ruszczynski, A. Decomposition methods. In: Ruszczynski, A.; Shapiro, A., eds. Handbooks in OR $\mathscr{6}$ MS, v. 10, cáp. 3, Elsevier Science B.V., p. 141-211, 2003.

Sadjadi, S.; Omrani, H. Data envelopment analysis with uncertain data: an application for iranian electricity distribution companies. Energy Policy, v. 36, p. 4247-4254, 2008.

Santos, M. O.; Massago, S.; Almada-Lobo, B. Infeasibility handling in genetic algorithm using nested domains for production planning. Computers \& Operations Research, v. 37(6), p. 1113-1122, 2010.

Dos Santos, S. M. P. G. Modelagem do problema integrado de dimensionamento do lotes e corte de estoque numa indústria moveleira. Dissertação de Mestrado, IbilceUnesp, 2008.

Shapiro, A.; Dentcheva, D.; ; Ruszczynski, A. Lectures on stochastic programming: modeling and theory. Philadelphia: SIAM, 2009.

Soyster, A. Convex programming with set-inclusive constraints and applications to inexact linear programming. Operations Research, v. 21, p. 1154-1157, 1973. 
SuH, M.-H.; ; LEE, T.-Y. Robust optimization method for the economic term in chemical process design and planning. Industrial 85 Engineering Chemistry Research, v. 40(25), p. 5950-5959, 2001.

Sungur, I.; Ordóñez, F.; Dessouky, M. A robust optimization approach for the capacitated vehicle routing problem with demand uncertainty. IIE Transactions, v. 40(5), p. 509-523, 2008.

TAkriti, S.; Ahmed, S. On robust optimization of two-stage systems. Mathematical Programming Series A, v. 99, p. 109-126, 2004.

Thiele, A. Robust stochastic programming with uncertain probabilities. IMA Journal of Management Mathematics, v. 19, p. 289-321, 2008.

Thomas, D.; Griffin, P. Coordinated supply chain management. European Journal of Operational Research, v. 94, p. 1-15, 1996.

Toledo, C. F. M.; FrançA, P. M.; Morabito, R.; Kimms, A. Multi-population genetic algorithm to solve the synchronized and integrated two-level lot sizing and scheduling problem. International Journal of Production Research, v. 47, p. 30973119, 2009.

Triki, C.; Violi, A. Dynamic pricing of electricity in retail markets. 4OR: A Quarterly Journal of Operations Research, v. 7(1), p. 21-36, 2007.

Ukkusuri, S. V.; Ramadurai, G.; Patil, G. A robust transportation signal control problem accounting for traffic dynamics. Computers $\&$ Operations Research, v. 37(5), p. 869-879, 2010.

Vladimirou, H.; Zenios, S. Stochastic linear programs with restricted recourse. European Journal of Operational Research, v. 101, p. 177-192, 1997.

WEI, C.; LI, Y.; CAI, X. Robust optimal policies of production and inventory with uncertain returns and demand. International Journal of Production Economics, doi:10.1016/j.ijpe.2009.11.008, 2010.

YAN, S.; TANG, C.-H. Inter-city bus scheduling under variable market share and uncertain market demands. Omega, v. 37, p. 178-192, 2009.

Yanasse, H. H.; Morabito, R. Linear models for one-group two-dimensional guillotine cutting problems. International Journal of Production Research, v. 44, p. 34713491, 2006.

Yanasse, H. H.; Morabito, R. A note on linear models for two-group and three-group two-dimensional guillotine cutting problems. International Journal of Production Research, v. 46, p. 6189-6206, 2008.

Yanasse, H. H.; Zinober, A. S. I.; Harris, R. G. Two-dimensional cutting stock with multiple stock sizes. Journal of Operational Research Society, v. 42(8), p. 673-683, 1991. 
YE, W.; ; ORDóÑEz, F. Robust optimization models for energy-limited wireless sensor networks under distance uncertainty. IEEE Transactions on Wireless Communications, v. 7(6), p. 2161-2169, 2008.

YU, C.; LI, H. A robust optimization model for stochastic logistic problems. International Journal of Production Economics, v. 64, p. 385-397, 2000.

Zanjani, M. K.; Ait-Kadi, D.; Nourelfath, M. Robust production planning in a manufacturing environment with random yield: A case in sawmill production planning. European Journal of Operational Research, v. 201(3), p. 882-891, 2009.

Zimmermann, H. Description and optimization of fuzzy systems. International Journal of General Systems, v. 2(4), p. 209-215, 1976. 